\title{
AMPLIFICADORES ÓPTICOS DE DUPLA PASSAGEM INCORPORANDO FIBRAS COMPENSADORAS DE DISPERSÃO
}

\author{
João Batista Rosolem
}

Orientador: Prof. Dr. Murilo Araujo Romero 


\section{AMPLIFICADORES ÓPTICOS DE DUPLA PASSAGEM INCORPORANDO FIBRAS COMPENSADORAS DE DISPERSÃO}

João Batista Rosolem

Tese apresentada à Escola de Engenharia de São Carlos da Universidade de São Paulo, como parte dos requisitos para obtenção do título de Doutor em Engenharia Elétrica.

Orientador:

Prof. Dr. Murilo Araujo Romero

São Carlos 


\section{AUTORIZO A REPRODUÇÃO E DIVULGAÇÃO TOTAL OU PARCIAL DESTE TRABALHO, POR QUALQUER MEIO CONVENCIONAL OU ELETRÔNICO, PARA FINS DE ESTUDO E PESQUISA, DESDE QUE CITADA A FONTE.}

Ficha catalográfica preparada pela Seção de Tratamento da Informação do Serviço de Biblioteca - EESC/USP

Tese (Doutorado) -- Escola de Engenharia de São Carlos Universidade de São Paulo, 2005.

Área: Engenharia Elétrica.

Orientador: Prof. Dr. Murilo Araujo Romero.

1. Amplificadores ópticos. 2. Fibra óptica. 3. Comunicação óptica. 4. Fotônica. 5. Opto-eletrônica. I. Título. 
À Fátima, ao João e à Ana.

Com amor e gratidão pela compreensão, carinho e apoio durante a realização deste trabalho. 


\section{AGRADECIMENTOS}

Ao Prof. Murilo Araujo Romero pela orientação, amizade, bom humor e pela confiança depositada durante a realização deste trabalho.

Aos meus pais, Valeriano e Terezina, por terem me permitido chegar até aqui, priorizando sempre minha formação.

Ao Prof. Amílcar Careli César pela amizade e estímulo.

À Alberto Paradisi, Rege Romeu Scarabucci e Sebastião Sahao Júnior por cederem horas e recursos do $\mathrm{CPqD}$ para realização deste doutorado.

Aos amigos e pesquisadores do CPqD, que contribuíram com este trabalho. Em especial, aos colegas: Antonio Amauri Juriollo, Roberto Arradi, Fábio Donatti Simões, Ronaldo Ferreira, Julio César Said, Antonio Coral, Maria Aparecida Dias Santos, Maria Fernanda M. B. de B. F. Oliveira e Mariza Rodrigues Horiuchi.

Ao amigo Julio César Rodrigues Fernandes de Oliveira, ao qual, foi confiado o legado de conhecimentos sobre EDFAs do CPqD.

À amiga Miriam Regina Xavier de Barros, pela colaboração na divulgação do tema desenvolvido.

Aos amigos Danilo César Dini, Sergio Celaschi, João Batista de Mello Ayres Neto e Horicléa Sampaio Monteiro, pioneiros no CPqD na tecnologia dos amplificadores ópticos a fibra dopada com érbio.

Ao Centro de Pesquisa e Desenvolvimento em Telecomunicações (CPqD) por todos os recursos oferecidos a este trabalho, que foi desenvolvido no âmbito dos projetos NASCO e GIGA.

À Universidade de São Paulo por todos os meus níveis de formação acadêmica. 


\section{RESUMO}

\section{ROSOLEM, J. B. Amplificadores Ópticos de Dupla Passagem Incorporando Fibras} Compensadoras de Dispersão. 2005. 129 f. Tese (Doutorado) - Escola de Engenharia de São Carlos, Universidade de São Paulo, 2005.

Amplificadores a fibra dopada com érbio de dupla passagem (DP-EDFA) contendo fibras compensadoras de dispersão (DCF) são estudados nesta tese. Os DP-EDFAs são uma alternativa para amplificadores de baixo custo e bom desempenho, sobretudo para utilização em redes metropolitanas. Devido a sua estrutura de dupla passagem, outras funções podem ser facilmente inseridas em seu circuito óptico, incrementando sua funcionalidade e reduzindo o custo envolvido. Considerando ainda que a compensação da dispersão é crítica para sistemas WDM de alta velocidade, um interessante tópico de investigação, que será bastante explorado nesta tese, refere-se a embutir uma fibra compensadora de dispersão dentro no circuito do DPEDFA. Estudos experimentais são conduzidos, mostrando as vantagens e os problemas associados a algumas topologias de circuitos de DP-EDFAs. Um circuito original de DPEDFA contendo DCF é proposto e caracterizado em termos de ganho e figura de ruído para diversas aplicações multicanal e multibanda dentro do espectro de transmissão da fibra óptica. Caracterizações sistêmicas em termos de taxa de erro de bit são também conduzidas.

Palavras-chave: amplificadores ópticos; fibra óptica; comunicação óptica; fotônica; optoeletrônica. 


\section{ABSTRACT}

\section{ROSOLEM, J. B. Double Pass Optical Amplifiers Embedding Dispersion Compensating}

Fibers. 2005. 129 f. Thesis (Doctoral) - Escola de Engenharia de São Carlos, Universidade de São Paulo, 2005.

Double pass erbium doped fiber amplifiers (DP-EDFA) with an embedded dispersion compensation fiber are studied in this work. DP-EDFA is a cost-effective alternative for optical amplifiers, yet preserving good optical performance, mainly for use in metropolitan networks. Due to its double pass circuit, others functions beyond amplification can be inserted within the amplification circuit, increasing its capabilities and decreasing the involved cost. Considering that dispersion compensation is very critical for high-speed DWDM systems operating with standard single mode fiber, a timely topic of investigation concerns the embedding of the high insertion loss DCFs (dispersion compensating fibers) into optical amplifier configurations. Experimental studies are conducted first showing the advantages and impairments associated with DP-EDFAs circuits using DCFs. Next, a DP-EDFA proposed in this work is characterized in terms of gain and noise figure for several applications in multichannel and multiband network topologies. Systemic characterization in terms of bit error rate is also conducted, evaluating the performance of the proposed DP-EDFA using DCF.

Keywords: optical amplifiers; optical fiber; optical communication; photonics; optoelectronics. 


\section{"The choices we make, not the chances we take, determine our destiny"}

Autor desconhecido 


\section{LISTA DE FIGURAS}

Fig.2.1 - Representação esquemática de várias redes WDM com EDFAs na planta de

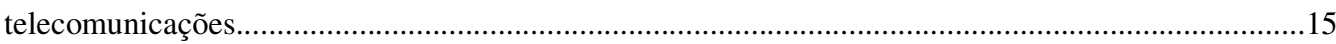

Fig.2.2 - (a) Configuração esquemática básica de um EDFA e (b) empacotamento de um amplificador real desenvolvido na Fundação CPqD.

Fig.2.3 - (a) Esquema de níveis de energia do átomo de érbio nas últimas camadas eletrônicas e (b) coeficientes de absorção e emissão de uma fibra dopada com érbio comercial. .18

Fig.2.4 - Configuração de bombeio bidirecional de um EDFA .19

Fig.2.5 - (a) Coeficiente de dispersão cromática para uma fibra DCF e para uma fibra de transmissão tipo convencional e (b) foto do empacotamento de uma fibra DCF [21].....

Fig.2.6 - Configuração de bombeio bidirecional de um EDFA usando DCF. .20

Fig.2.7 - Configuração básica de um DP-EDFA

Fig.2.8 - (a) Configuração do DP-EDFA usado em [36] e (b) potência de ASE das configurações de dupla passagem e passagem única [36]. .27

Fig.2.9 - (a) Ganho em função da potência de bombeio em $980 \mathrm{~nm}$ para os amplificadores DP-EDFA e convencional [36] e (b) Ganho em função da potência de entrada de sinal [36]

Fig.2.10 - (a) DP-EDFA com um estágio de ganho [37], (b) DP-EDFA com dois estágios de ganho [37], (c) ganho e figura de ruído em função da potência de entrada [37] e (d) ganho e figura de ruído em função da potência de bombeio [37]

Fig.2.11 - (a) Configuração do DP-EDFA de duas bandas proposta em [39] e (b) caracterização de ganho e figura de ruído para as duas bandas [39].

Fig.2.12 - Curva de ganho e figura de ruído em função da potência de bombeio para as configurações dos DPEDFAs com e sem fibra não bombeada e EDFA convencional com e sem fibra não bombeada [43]..32

Fig.2.13 - (a) Estruturas de EDFA convencional [55] e (b) DP-EDFA utilizadas para comparação das características de controle dinâmico de ganho [55] .33

Fig.2.14 - (a) Configuração de um EDFA de tripla passagem com filtro óptico embutido [57] e (b) configuração de um DP-EDFA com um conjunto mux-demux embutido [58] . .35

Fig.2.15 - Circuitos ópticos patenteados para DP-EDFAs contendo DCFs (a) referência [60], (b) referência [61] e

(c) referência [62] 
Fig.2.16 - Desempenho (a) Desempenho sistêmico dos sistemas uni e bidirecional em 2,5 Gb/s [75] e (b) gráfico de simulação numérica da penalidade em função do produto G.Rbs [75]...

Fig.3.1 - Arranjo experimental para determinar os níveis de intensidade dos retroespalhamentos Rayleigh e Brillouin gerado pelas DCFs.

Fig.3.2 - Resultados da avaliação de potência de saída e potência retroespalhada em função da potência de entrada, utilizando-se uma fibra DCF de 900 ps/nm em $1550 \mathrm{~nm}$. .44

Fig.3.3 - Configurações estudadas para DP-EDFAs com DCF embutida (a) usando acopladores combinadores de polarização (PBS) e espelhos de rotação de Faraday e (b) usando dois circuladores. .48

Fig.3.4 - (a) Diagrama da montagem experimental para avaliação da dependência com a polarização do DPEDFAs, (AM: atenuador monitor, FO: filtro óptico, OSA: analisador de espectro óptico) e (b) foto da montagem.

Fig.3.5 - Dependência do ganho com o ângulo de polarização para DP-EDFAs empregando circuladores ou dispositivos de polarização.

Fig.3.6 - Dependência da figura de ruído com o ângulo de polarização para DP-EDFAs empregando circuladores ou dispositivos de polarização.

Fig.3.7 - Desempenho sistêmico do sistema de transmissão e recepção sem DP-EDFAs....................................51

Fig.3.8 - Desempenho sistêmico dos DP-EDFAs testados. .53

Fig.3.9 - Curva da penalidade em função do produto RbsxG (coeficiente de retroespalhamento Rayleigh x Ganho) do amplificador de dupla passagem com circulador e rotacionador de Faraday....... .54

Fig.3.10 - Circuito do DP-EDFA avaliado e o arranjo experimental sistêmico para $10 \mathrm{~Gb} / \mathrm{s}$. 55

Fig.3.11 - Resultados da simulação de comprimento de fibra dopada versus ganho e figura de ruído de DP-EDFAs e SP-EDFAs contendo uma fibra DCF de 9 dB de atenuação, sinal em $1590 \mathrm{~nm}$, para $70 \mathrm{~mW}$ de potência de bombeio em $1480 \mathrm{~nm}$ . .56

Fig.3.12 - Ganho e figura de ruído para (a) DP-EDFA e (b) para SP-EDFA.....................................................57

Fig.3.13 - Gráficos da potência recebida versus a taxa de erro de bit (BER) na recepção, para (a) DP-EDFA e (b) SP-EDFA. . .59

Fig.4.1 - Resultados da simulação de ganho sob operação DWDM dos amplificadores (a) SP-EDFA e (b) DPEDFA. .64

Fig.4.2 - Ganho e figura de ruído do DP-EDFA para a banda L sob regime DWDM .65 
Fig.4.3 - BER em função da potência óptica recebida no pré-amplificador DP-EDFA para os canais de 1587,34 nm e $1604,50 \mathrm{~nm}$ em $10 \mathrm{Gbit} / \mathrm{s}$ .66

Fig.4.4 - Circuitos do DP-EDFA para amplificação nas bandas C e L (a) circuito paralelo e (b) circuito série......68

Fig.4.5 - Simulação dos níveis de ASE contrapropagante na saída do DP-EDFA sem o uso do filtro de ASE.......69

Fig.4.6 - Simulações de ganho e figura de ruído em função do comprimento de fibra dopada para DP-EDFA circuito paralelo (a) banda C e (b) banda L . .70

Fig.4.7 - Simulações de ganho e figura de ruído em função do comprimento de fibra dopada para DP-EDFA circuito série (a) banda $C$ para $\mathrm{L}_{2}=7 \mathrm{~m}$ e (b) DP-EDFA L para $\mathrm{L}_{1}=2,5 \mathrm{~m}$. . .71

Fig.4.8 - Caracterização de ganho e figura de ruído para o circuito DP-EDFA paralelo (a) banda C e (b) banda L .73

Fig.4.9 - Caracterização de ganho e figura de ruído para o circuito DP-EDFA série (a) banda C (b) banda L.......74

Fig.4.10 - Configuração do DP-EDFA/TDFA para as bandas S, C e L.........................................................77

Fig.4.11 - Perda e isolação dos multiplexadores usados no DP-EDFA/TDFA .77

Fig.4.12 - (a) Foto do sistema de 24 lasers cobrindo as três bandas e um analisador de espectro óptico, utilizado na caracterização do DP-EDFA/TDFA e (b) foto do empacotamento do DP-EDFA/TDFA com a fibra DCF .78

Fig.4.13 - Espectro de saída DWDM do DP-EDFA/TDFA para uma potência de entrada de -15 dBm. . .79

Fig.4.14 - Ganho e figura de ruído para o DP-EDF/TDFA com fibra DCF de $900 \mathrm{ps} / \mathrm{nm}$ e $\mathrm{P}_{\text {in }}$ de $-15,-20$ e -30 dBm, (a) Banda S, (b) Banda C e (c) Banda L . .80

Fig.4.15 - Ganho e figura de ruído para o DP-EDF/TDFA para $\mathrm{P}_{\text {in }}$ de $-20 \mathrm{dBm}$, sem DCF e com fibra DCF de 900 e -1600 ps/nm (a) Banda S, (b) Banda C e (c) Banda L . .82

Fig.4.16 - Ganho e figura de ruído para DP-EDF/TDFA e SP-EDFA, para $\mathrm{P}_{\text {in }}$ de -20 dBm, DCF -900 ps/nm (a)

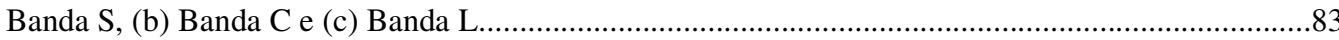

Fig.4.17 - Espectro de saída CWDM do DP-EDFA/TDFA com DCF para uma potência de entrada de -15 $\mathrm{dBm}$. .85

Fig.4.18 - Potência de saída e ganho em 1500,8 nm em função do comprimento de onda para vários valores da dimensão D mostrada na mesma figura. O valor do eixo maior da elipse é constante e vale 180 $\mathrm{mm}$. .88

Fig.4.19 - Ganho e figura de ruído em função da potência bombeio, para DP-EDFA e SP-EDFA com fibra dopada com érbio na banda $S$. 
Fig.4.20 - Circuito do DP-EDFA de três bandas para aplicações em sistemas CWDM...... .90

Fig.4.21- Simulação aproximada do ganho e da potência de bombeio residual do primeiro trecho de fibra L1 em função do comprimento de fibra dopada L1

Fig.4.22 - Espectro de saída CWDM do DP-EDFA com DCF para uma potência de entrada de -15 dBm...... .92

Fig.4.23 - Resultados da diferenças entre os parâmetros (a ganho) e (b) figura de ruído, para os amplificadores DPEDFA/TDFA e DP-EDFA. .93

Fig.4.24 - Rede CWDM em barramento mostrando apenas para o sentido estação-cliente . .95

Fig.4.25 - Simulações de comprimento máximo de redes CWDM em barramento para diversas situações .96

Fig.4.26 - (a) Sistema de transmissão e multiplexação dos conversores de comprimento de onda, (b) empacotamento para os 16 deriva-insere junto com trechos de fibra convencional que compõe a rede de CWDM de barramento e (c) DP-EDFA para as bandas S, C e L . .98

Fig.4.27 - Perda de inserção/remoção e perda média de passagem do sinal pelo deriva/insere e atenuação da fibra convencional dos tipos A\&B e C\&D obtida da referência [20]

Fig.4.28 - Taxa de erro de bit em função da potência recebida para três canais da grade CWDM amplificados pelo DP-EDFA com DCF 100

Fig.4.29 - Resumo das penalidades de todos os canais medidos para DP-EDFA com e sem DCF em $82 \mathrm{~km}$ e 122 km e SP-EDFA em $82 \mathrm{~km}$ sem DCF. 101

Fig.A.1 - Espectro de saída do amplificador mostrando a potência de saída somada a potência de ASE 114

Fig.A.2 - Eficiência de ganho do amplificador, definida através da curva de ganho em função da potência de bombeio.

Fig.A.3 - Potência de saída de vários canais WDM amplificados, ilustrando a variação de potência causada pela não planicidade de ganho do amplificador

Fig.A.4 - Curva de ganho em função da potência do sinal, na saída mostrando o ponto da potência de saturação

Fig.A.5 - Variação da potência de ASE com o comprimento de onda 118

Fig.B.1 - Tela do OASIX programado para simulação do DP-EDFA 121

Fig.B.2 - Resultados de saída do OASIX para o ganho do DP-EDFA usado na seção 3.3. O ganho é a perda de retorno com o sinal invertido 122

Fig.C.1 - Modelo de sistema de transmissão para modelo de orçamento de potência. 123 


\section{LISTA DE TABELAS}

Tab.2.1 - Resumo dos resultados obtidos nos experimentos em [27] e simulação em [28].................................25

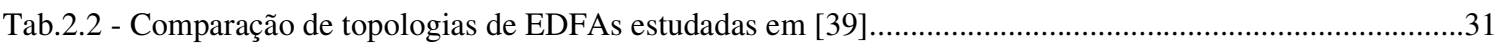

Tab.4.1 - Ganho e figura de ruído para o amplificador DP-EDFA/TDFA na grade CWDM..............................85

Tab.4.2 - Ganho e figura de ruído para o amplificador DP-EDFA na grade CWDM..........................................92

Tab. B.1 - Dados de fibras dopadas com érbio fornecidas pela OFS e utilizadas nesta Tese.............................120

Tab.C.1 - Faixas de comprimentos de fibra com DCFs projetados para compensar comprimentos típicos de fibra convencional [22]. 


\section{LISTA DE SIGLAS PRINCIPAIS}

ADD-DROP - Insere-remove.

AM - Atenuador monitor.

ASE - Emissão espontânea amplificada.

BER - Taxa de erro de bit.

BKB - Costa a costa.

CATV - Televisão a cabo.

CWDM - Multiplexação em comprimentos de onda com grande espaçamento.

DWDM - Multiplexação em comprimentos de onda denso.

DCF - Fibra compensadora de dispersão.

DP-EDFA - Amplificador a fibra dopada com érbio de dupla passagem.

DRA - Amplificador Raman distribuído.

EDFA - Amplificador a fibra dopada com érbio.

EDWA - Amplificador em guias de onda dopados.

FD - Faixa dinâmica do sistema.

FRM - Rotacionador de polarização Faraday.

FO - Filtro óptico.

FoM - Figura de mérito.

FWM - Mistura de quatro ondas.

FUNTTEL - Fundo nacional das telecomunicações.

GFF - Filtros aplainadores de ganho.

MPI - Interferência por múltiplas reflexões.

NASCO - Novos amplificadores para sistemas de comunicações ópticas.

OASIX - Simulador de amplificadores ópticos.

OSA - Analisador de espectro óptico.

PBS - Acoplador combinador de polarização.

PCE - Eficiência de conversão de potência.

PDG - Ganho dependente da polarização.

PMD - Dispersão do Modo de Polarização.

PRBS - Fonte de bits pseudo-aleatórios. 
SOA - Amplificador óptico semicondutor.

SP-EDFA - Amplificador a fibra dopada com érbio de passagem única.

SRS - Espalhamento Raman estimulado.

TDFA - Amplificador a fibra dopada com túlio.

UDWDM - Multiplexação em comprimentos de onda ultra denso.

WDM - Multiplexação em comprimentos de onda.

WDMA - Acesso por multiplexação em comprimentos de onda. 


\section{LISTA DOS SÍMBOLOS PRINCIPAIS}

G - ganho do amplificador.

NF - figura de ruído.

$R(\lambda)$ - perda do espelho refletor.

h - constante de Planck.

$v$ - frequiência óptica do sinal.

$\Delta v$ - largura de banda óptica.

Q - argumento da função taxa de erros.

n - número de amplificadores de linha bidirecionais;

$\mathrm{R}_{\mathrm{bs}}$ - coeficiente de retroespalhamento Rayleigh;

P - penalidade na recepção devido ao retroespalhamento Rayleigh;

$\mathrm{P}_{\mathrm{p}}(\mathrm{z})$ - potência de bombeio no comprimento de onda $\lambda_{\mathrm{p}}$,

$\mathrm{P}_{\mathrm{sk}}(\mathrm{z})$ - potência de sinal no comprimento de onda $\lambda_{\mathrm{sk}}$.

$P_{\text {in }}$ - Potência de entrada.

$P_{\text {asej }}(\mathrm{z})$ - potência de ASE de banda $\Delta v_{j}$ e frequência central $v_{\text {asej- }}$.

$\sigma_{a}\left(\lambda_{\mathrm{i}}\right)$ - seção de choque de absorção.

$\sigma_{\mathrm{e}}\left(\lambda_{\mathrm{i}}\right)$ - seção de choque de emissão estimulada.

$\Gamma_{\mathrm{s}}$ - fator de sobreposição entre a distribuição da dopagem de Érbio e o campo modal do sinal.

$\Gamma_{\mathrm{p}}$ - fator de sobreposição entre a distribuição da dopagem de érbio e o campo modal do bombeio.

$\alpha_{\mathrm{s}}$ - coeficiente de perda intrínseca no comprimento de onda do sinal.

$\alpha_{p}$ - coeficiente de perda intrínseca no comprimento de onda do bombeio.

$\mathrm{N}_{\mathrm{o}}$ - densidade da dopagem de érbio.

$\mathrm{N}_{2}$ - população no nível metaestável no estado de equilíbrio.

$A_{21}$ - taxa de emissão espontânea.

A - área efetiva da dopagem de érbio.

$\mathrm{P}_{\mathrm{T}}$ - potência óptica de saída do transmissor.

$P_{R}$ - sensibilidade do transmissor, medida em uma dada taxa de erros (normalmente $10^{-10}$ ).

$\mathrm{P}_{\mathrm{D}}$ - penalidade por dispersão, medida em uma dada taxa de erros (normalmente $10^{-10}$ ).

M - margem de segurança, em dB. 
$\mathrm{U}_{\mathrm{WDM}}$ - perdas em $\mathrm{dB}$, no pior caso, de todos elementos passivos associados com o equipamento WDM, incluindo efeitos de variação com a temperatura.

$1_{\mathrm{SM}}$ - comprimento total em km do cabo interno nos terminais de transmissão/recepção.

$\mathrm{U}_{\mathrm{SM}}$ - perda do cabo óptico interno da seção do terminal de transmissão, no final de sua vida útil, em $\mathrm{dB} / \mathrm{km}$.

$\mathrm{N}_{\mathrm{con}}$ - número de conexões ópticas.

$\mathrm{U}_{\text {con }}$ - pior caso de perda do conector óptico, em dB.

$1_{\mathrm{t}}$ - comprimento total do cabo em $\mathrm{km}$.

$\mathrm{U}_{\mathrm{c}}$ - perda do cabo no fim da vida útil, em dB/km, a $23^{\circ} \mathrm{C}$, no comprimento de onda central do transmissor.

$\mathrm{U}_{\mathrm{cT}}$ - aumento da perda devido ao efeito da temperatura no fim de vida útil do cabo, em $\mathrm{dB} / \mathrm{km}$, no pior caso, na faixa de temperatura de operação do cabo.

$\mathrm{U}_{\lambda}$ - maior aumento da perda do cabo em $\mathrm{dB} / \mathrm{km}$ em a $23^{\circ} \mathrm{C}$, acima de $\mathrm{U}_{\mathrm{c}}$, que ocorre na faixa de variação do comprimento de onda do transmissor.

$\mathrm{N}_{\mathrm{S}}$ - número de emendas no cabo no comprimento $\mathrm{l}_{\mathrm{t}}$.

$\mathrm{U}_{\mathrm{S}}$ - máxima perda de emenda admissível (dB/emenda) a $23^{\circ} \mathrm{C}$.

$\mathrm{U}_{\mathrm{ST}}$ - aumento da perda devido ao efeito da temperatura na perda da emenda no pior caso em $\mathrm{dB} / \mathrm{emenda}$.

$\mathrm{D}\left(\lambda_{\mathrm{t}}\right)$ - coeficiente de dispersão cromática no comprimento de onda $\lambda_{\mathrm{t}} \mathrm{em} \mathrm{ps/(nm.km).}$

1 - comprimento da fibra em $\mathrm{km}$.

$D_{\text {SRmax }}$ - dispersão máxima em ps/nm devido ao comprimento da fibra entre os pontos $\mathrm{S}$ e $\mathrm{R}$ que pode ser acomodada pelo receptor para uma taxa de $10^{-10}$.

$\mathrm{D}_{\max }$ - pior caso do módulo do valor do coeficiente de dispersão cromática em ps/(nm.km) na faixa espectral de operação do transmissor.

$l_{D}$ - comprimento limitado por dispersão em km.

B - taxa de transmissão em $\mathrm{Gb} / \mathrm{s}$.

$\Delta \lambda$ - largura espectral da fonte em nm medida a $20 \mathrm{~dB}$ abaixo do pico.

$\lambda_{\mathrm{c}}$ - comprimento de onda central em $\mu \mathrm{m}$.

$\lambda_{0}$ - comprimento de onda de corte da fibra em $\mu \mathrm{m}$.

$\varepsilon$ - fator de correção para cálculo de enlace limitado por dispersão ( $=0,306$ para uma penalidade por dispersão de 1 $\mathrm{dB}$ em $\left.10^{-10}\right)$.

$\Delta \mathrm{n}$ - diferença entre índices de refração. 


\section{SUMÁRIO}

\section{CAPÍTULO 1. INTRODUÇÃO} 1

1.1 Motivação deste trabalho .2

1.2 Uma breve história sobre os EDFAs no CPqD.....................................................

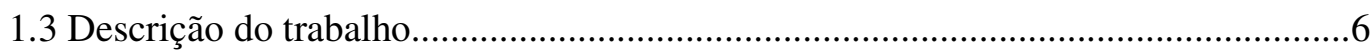

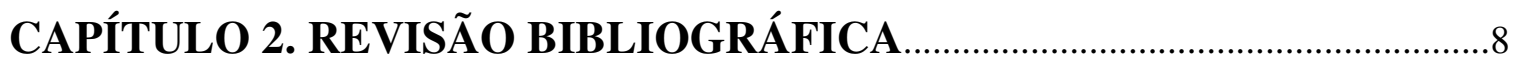

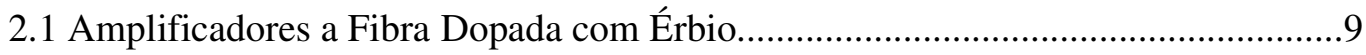

2.2 Amplificadores a Fibra Dopada com Érbio de Dupla Passagem..........................21

\section{CAPÍTULO 3. COMPARAÇÃO EXPERIMENTAL ENTRE DP-EDFAs}

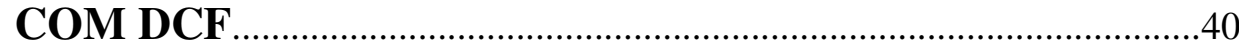

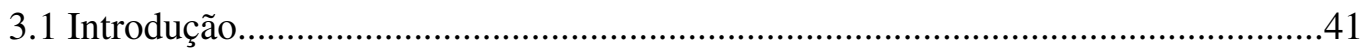

3.2 Comparação experimental de DP-EDFAs com DCF............................................43

3.3 Amplificador DP-EDFA com DCF monocanal para operação na Banda L............55

\section{CAPÍTULO 4. CIRCUITOS DE DP-EDFAs COM DCF PARA APLICAÇÕES EM SISTEMAS MULTICANAIS E

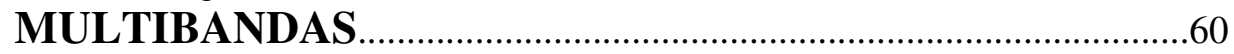

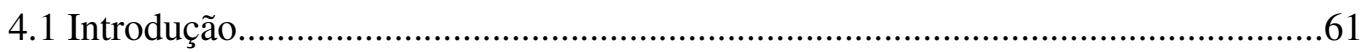

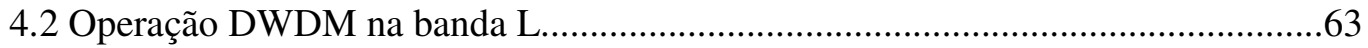

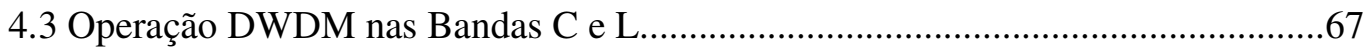

4.4 Operação DWDM nas Bandas S, C e L (DP-EDFA/TDFA)................................76

4.5 Operação CWDM nas Bandas S, C e L................................................................8

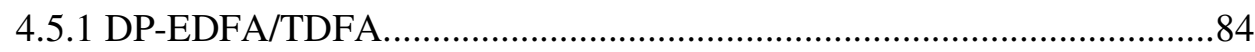

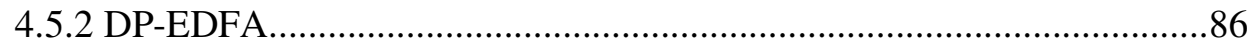

4.5.3 Caracterização sistêmica do DP-EDFA com DCF em redes CWDM de barramento. .95 
CAPÍTULO 5. CONCLUSÕES.

5.1 Contribuições originais desta Tese .103

5.2 Propostas para continuação deste trabalho 104 REFERÊNCIAS BIBLIOGRÁFICAS 105 APÊNDICE A. PARÂMETROS DE MÉRITO DE EDFAS 114 APÊNDICE B. AMBIENTE DE SIMULAÇÃO OASIX V3.1 119 APÊNDICE C. DIMENSIONAMENTO DE ENLACES ÓPTICOS CONSIDERANDO A DISPERSÃO. 123 APÊNDICE D. PUBLICAÇÕES DO AUTOR .128 


\section{CAPÍtULO 1}

\section{INTRODUÇÃO}

The interesting recent article on Bell Labs, Lucent Technologies (Physics Today, October 2001, page 26), omitted an important detail. Although the article lists some of Bell Labs' major achievements, including optical solitons, it does not mention erbium-doped fiber amplifiers (EDFAs). Despite their usefulness in improving our understanding of fiber nonlinearities and of new ways to exploit them, solitons have had only a limited impact on optical communications applications. EDFAs, however, have been key to enabling wavelengthdivision multiplexing technologies, broadband optical networks, and terabits-per-second terrestrial and undersea communications.

EDFAs were developed simultaneously at Southampton University and at Bell Labs, according to Herwig Kogelnik. His testimony is authoritative because he directed one of the two Bell Labs facilities in Crawford Hill, New Jersey, where the group of early EDFA investigators worked (1986-1990). The Crawford Hill investigations and demonstrations led to a rapid technology transfer to the Labs' submarine-link department in Holmdel, New Jersey, and to several other development sites thereafter. (Research on solitons also benefited greatly from the transfer!) That transfer was the culmination of 20 years of fiber-optic research at Bell Labs and probably represents one of the company's greatest success stories.

For my contribution to this early work, I received, jointly with the University of Southampton's David N. Payne, the 1998 Benjamin Franklin Medal in Engineering. Yet, for unexplained reasons, Bell Labs never claimed its contribution to the invention and early development of EDFAs, despite their tremendous impact on technology and business. Such an anomaly, or memory erasure, shows that historical accuracy, even in famed institutions, can become secondary to internal rivalries ("not started in my department") or marketing simplifications ("EDFAs have always been there"). True, practically all the early EDFA investigators have left the Labs, and the submarine group established its own company. But could this evolution justify censorship in Bell Labs' history? The Labs should be proud of having been on the forefront of another technology revolution, thanks to the vision and risk-taking stance of both investigators and managers of Crawford Hill.

Emmanuel Desurvire

Physics Today On Line - May 2002 http://www.physicstoday.org/pt/vol-55/iss-5/p13.html 


\subsection{Motivação deste trabalho}

A substituição de regeneradores eletrônicos por amplificadores ópticos em sistemas de comunicações ópticas, ocorrida na década de 90, possibilitou uma série de avanços nestes sistemas. Os amplificadores ópticos funcionam em uma larga faixa de comprimentos de onda de sinal, enquanto os regeneradores eletrônicos são equipamentos projetados para operar em apenas um comprimento de onda. Nos regeneradores eletrônicos, a recuperação do nível do sinal se faz através da recepção óptica, amplificação elétrica, extração de relógio, retemporização e retransmissão do sinal. Isso significa que os regeneradores eletrônicos funcionam em uma taxa de transmissão e em um formato de modulação específicos. Os amplificadores ópticos, por outro lado, são transparentes à taxa e ao formato de modulação do sinal. Esta transparência dos amplificadores ópticos possibilita a transmissão simultânea de diferentes serviços através da rede. A transparência possibilita também atualizações da rede sem necessidade de alteração do equipamento de amplificação. Devido a essas vantagens, o amplificador óptico tornou-se uma tecnologia de importância estratégica na implementação de redes DWDM, que permitiram um grande aumento da capacidade das fibras instaladas e uma maior flexibilidade na transmissão de informação em redes ópticas.

O amplificador óptico a fibra dopada com érbio é o sub-sistema mais usado para amplificação de sinais ópticos em sistemas de telecomunicações de longa distância. Porém, em redes metropolitanas, sobretudo redes que utilizam WDM de largo espaçamento espectral (CWDM), são necessários amplificadores que apresentem menor custo que os tradicionalmente usados. Os EDFAs de dupla passagem (DP-EDFA) são uma alternativa para amplificadores de baixo custo e bom desempenho. Devido a sua estrutura de dupla passagem, outras funções, além da amplificação óptica, podem ser inseridas em seu circuito óptico, aumentando, portanto, sua eficiência e reduzindo o custo envolvido. De fato, considerando 
ainda que a compensação da dispersão é crítica para sistemas WDM de alta capacidade, um interessante tópico de investigação, que será bastante explorado nesta tese, refere-se a embutir uma fibra compensadora de dispersão (DCF) dentro no circuito do DP-EDFA. O DP-EDFA é, portanto, o tema central desta tese, que foca o estudo e as aplicações conjugadas de DPEDFAs com fibras compensadoras de dispersão (DCF). 


\subsection{Uma breve história sobre os EDFAs no CPqD}

A participação deste autor junto ao grupo de fibras ópticas do $\mathrm{CPqD}$ teve início em 1987, ainda como estudante de mestrado provindo da EESC-USP para ali no CPqD realizar as atividades experimentais da dissertação. Foi no primeiro semestre de 1988 que ouvimos falar pela primeira vez em amplificadores ópticos a fibra, quando o meu então orientador Sergio Celaschi fixou, no mural do prédio em que realizava pesquisas, um gráfico de ganho de um amplificador a fibra dopada com érbio (EDFA), obtido de um artigo da Universidade de Southampton que ficou histórico pelo seu pioneirismo. A euforia daquele momento foi canalizada para uma pesquisa exploratória com a participação de pesquisadores daquele grupo, entre eles Danilo C. Dini, Sergio Celaschi, João Batista de M. Ayres, Horicléa S. Monteiro e Antonio Amauri Juriollo. Em 1990, durante a Copa do Mundo de futebol na Itália, Horicléa S. Monteiro esteve no CSELT, em Turim, onde conseguiu algumas gramas do sal cloreto de érbio, que foi a substância básica para obtenção da primeira fibra dopada com érbio experimental. A obtenção de resultados relevantes viabilizou a oficialização do projeto em 1991, para o desenvolvimento da fibra dopada com érbio, projeto no qual este autor iniciou sua participação no final de 1992. Em 1993 obtivemos o primeiro protótipo de um EDFA, combinando não somente a fibra dopada com érbio, mas também outros elementos desenvolvidos no $\mathrm{CPqD}$, tais como o laser de bombeio e o multiplexador de bombeio. $\mathrm{O}$ protótipo foi apresentado pela primeira vez em 1993 no famoso Seminário de Rede Externa do Sistema Telebrás, em Brasília. A Telesp foi a primeira empresa a se interessar pelo equipamento, o que levou a realização de um teste de campo entre Campinas e São Paulo em 1994. Com o sucesso do teste, em 1995 foi desenvolvido o primeiro EDFA com características industriais, que foi transferido para duas empresas brasileiras: AGC Optosystems e ABC Xtal. Nesta primeira metade da década de 90, o mercado brasileiro de 
telecomunicações era pouco propenso ao uso desta tecnologia, porém, em outros países mais desenvolvidos, tais como nos EUA e Japão, os sistemas submarinos já começavam a usar EDFAs e os primeiros sistemas WDM (Wavelength Division Multiplexing) começavam a ser explorados devido às vantagens do uso de EDFAs nestes sistemas. Em 1996 instalamos para a TELERJ um enlace óptico bidirecional pioneiro com EDFAs ligando a cidade do Rio de Janeiro e a fábrica da Volkswagen em Resende, na extensão de $180 \mathrm{~km}$. A fábrica (e o enlace) foram inauguradas pelo então presidente Fernando Henrique Cardoso, dois dias após o trágico acidente da TAM em Congonhas. De 1995 a 2001 percorremos dezenas de vezes as operadoras de telecomunicações brasileiras treinando engenheiros e técnicos na tecnologia EDFA e sistemas WDM. Em 2002, no projeto NASCO, financiado pelo FUNTTEL, reiniciamos novos desenvolvimentos com amplificadores ópticos que estavam paralisadas desde a privatização do Sistema Telebrás, ocorrida em 1998. Uma série de novos circuitos de amplificadores ópticos, desenvolvidos nesta época, foram transferidos para a empresa brasileira PADTEC. Atualmente estes amplificadores são exportados para vários países. Foi também em 2002 que iniciamos nossas pesquisas com os amplificadores a fibra dopada com érbio de dupla passagem, que é o tema desta tese. O início da pesquisa com este tipo de amplificador coincidiu com a busca no panorama internacional por amplificadores de baixo custo, característica esta proporcionada pelos amplificadores de dupla passagem. A partir de 2004 as pesquisas com este tipo amplificador no CPqD continuaram, agora dentro do âmbito do Projeto GIGA, onde o mesmo agora está sendo desenvolvido como uma solução para uso em redes CWDM metropolitanas. 


\subsection{Descrição do trabalho}

Uma revisão bibliográfica, apresentada no capítulo 2, procurará abordar inicialmente aspectos relativos aos EDFAs e sua contextualização histórica no âmbito das comunicações ópticas. Em seguida desenvolvemos uma revisão bibliográfica específica sobre DP-EDFAs. Apresentamos os avanços de suas configurações de circuito óptico desde o início da década de 90 até a atualidade, discutindo suas principais figuras de mérito e, sempre que possível, comparando com os EDFAs convencionais.

No Capítulo 3 apresentamos uma série de estudos experimentais envolvendo DPEDFAs que incorporam fibras DCF. Inicialmente caracterizamos uma fibra DCF em função dos níveis de retroespalhamentos Rayleigh e Brillouin gerados pela mesma e cuja influência negativa em um sistema de comunicações ópticas é significativa. Em seguida caracterizamos três tipos de circuitos ópticos para DP-EDFAs contendo fibra DCF embutida. Buscou-se realizar neste estudo uma avaliação experimental detalhada de duas configurações de DPEDFAs contendo DCF embutida disponíveis na literatura, primordialmente sob a forma de patente e ainda sem comprovação prática. Neste estudo experimental foi também avaliada uma nova configuração de DP-EDFA contendo DCF embutida, por nós proposta. Os resultados a serem descritos mostram que as duas primeiras propostas patenteadas apresentam sérios problemas de funcionamento prático, o que não ocorre com a nossa implementação. Finalmente apresentamos uma aplicação monocanal na banda L de um DP-EDFAs com DCF embutida, validando o circuito implementado.

Em seguida, no Capítulo 4, desenvolvemos diversas aplicações do DP-EDFA proposto, em sistemas multicanais e multibandas. Serão detalhados neste capítulo aplicações DWDM na banda L, DWDM nas bandas C e L, DWDM nas bandas S e C e L e aplicações CWDM nas bandas $\mathrm{S}$ e $\mathrm{C}$ e $\mathrm{L}$. 
O Capítulo 5 apresenta as conclusões desta tese de doutorado e suas contribuições científicas.

Em seguida são apresentadas as referências utilizadas e quatro anexos que discutem temas complementares a esta tese. O Anexo A descreve as definições dos principais parâmetros de mérito dos EDFAs. O Anexo B descreve a ferramenta computacional OASIX, que foi utilizada como suporte para o desenvolvimento dos DP-EDFAs. O Anexo C descreve uma metodologia para cálculo de enlaces ópticos devido a limitações por atenuação e dispersão cromática. O Apêndice D lista os trabalhos relativos ao tema da tese publicados pelo autor durante o doutorado. 
CAPÍtulO 2 REVISÃO BIBLIOGRÁFICA 


\subsection{Amplificadores a Fibra Dopada com Érbio}

Como já conhecido, existem vantagens no uso de fibras ópticas na transmissão de sinais em curta e longa distância. Ainda que a transmissão pela fibra seja vantajosa em vários aspectos em relação aos outros meios, tais como rádio, satélite, cabo coaxial ou par trançado, alguns efeitos físicos também limitam, em algum nível, a transmissão de sinais por fibra óptica. Dois efeitos merecem ser antecipadamente citados para melhor compreensão da operação dos amplificadores ópticos. O primeiro efeito está relacionado com a atenuação que o sinal óptico sofre ao percorrer a fibra óptica. Este efeito deve-se principalmente ao fenômeno conhecido como espalhamento Rayleigh, o qual apresenta dependência com o comprimento de onda do sinal transmitido na fibra. A menor atenuação na fibra de sílica ocorre na região do espectro óptico em torno de $1550 \mathrm{~nm}$. Devido a este motivo a transmissão por fibra óptica em longas distâncias ocorre principalmente em torno desta região, ou, como é chamada no meio técnico, terceira janela espectral. Valores de atenuação nesta janela são da ordem de $0,25 \mathrm{~dB} / \mathrm{km}$ ou menos, o que significa que após $100 \mathrm{~km}$ a potência do sinal é atenuada da ordem de $25 \mathrm{~dB}$, ou, em unidades lineares, 316 vezes. Ademais, o equipamento de recepção óptico tem limites de recepção bastante estreitos, tipicamente entre -25 a -35 dBm de potência recebida, enquanto os sinais ópticos são transmitidos com níveis de potência pouco acima de $0 \mathrm{dBm}$. Considerando margens de operação e perdas em conectores e em emendas de fibras, após 100 km o sinal já se encontra nos limites da sensibilidade do receptor. Porém, dado que distâncias maiores do que estas são na prática encontradas na ligação de sistemas de longa distância, torna-se necessário o uso de elementos que recuperem o nível de sinal. No Apêndice C discutiremos com mais detalhes o cálculo de orçamento de potência dos sistemas ópticos.

Um outro efeito que limita a transmissão de sinais ao longo da fibra é a dispersão cromática. Neste caso os sinais digitais sofrem degradação pelo alargamento do pulso ao 
longo do enlace. Este efeito é causado pela dependência da velocidade da luz no meio óptico, em relação ao índice de refração da fibra. Dado que o índice de refração da fibra tem dependência com o comprimento de onda, então, não só o comprimento de onda do sinal transmitido, mas, também, sua largura espectral tem influência direta neste efeito. Para sinais transmitidos em fibras convencionais por lasers DFB modulados diretamente em 2,5 Gb/s na região de $1550 \mathrm{~nm}$ a distância transmitida é inferior a $70 \mathrm{~km}$, para que não se acumulem altas penalidades devido à dispersão cromática. No Apêndice $\mathrm{C}$ analisaremos com mais detalhes os cálculos das limitações dos sistemas ópticos devido a dispersão cromática.

Além destes, outros efeitos, tais como a dispersão do modo de polarização (PMD) e efeitos não-lineares, podem degenerar a qualidade do sinal transmitido. Porém, nos ateremos, por hora, aos efeitos de atenuação e dispersão, já comentados anteriormente.

Até o fim da década de 80, o equipamento utilizado para recompor a qualidade do sinal óptico degradado pelo efeito de atenuação e dispersão cromática era o regenerador eletrônico. Nos regeneradores eletrônicos, a recuperação do nível do sinal se faz através da recepção optoeletrônica, amplificação elétrica, retemporização e retransmissão eletroóptica do sinal. Os regeneradores eletrônicos detectam uma portadora óptica por vez, numa taxa de transmissão e formato de modulação específicos.

A substituição de regeneradores eletrônicos por amplificadores ópticos durante a década de 90, possibilitou uma série de avanços nos sistemas de comunicações ópticas. Os amplificadores ópticos, em sua região espectral de funcionamento, podem amplificar até centenas de portadoras ópticas simultaneamente, em qualquer taxa de transmissão e formato de modulação. Devido a essa vantagem sobre os regeneradores eletrônicos, o amplificador óptico tornou-se uma tecnologia de importância estratégica na implementação de sistemas WDM. Os sistemas WDM, por sua vez, possibilitaram um grande aumento da capacidade de transmissão das redes ópticas, capacidade esta que migrou do nível de gigabit por segundo no 
início da década de 90 para o nível de terabit por segundo na atualidade. Deve ser ressaltado, todavia, que regeneradores ainda são utilizados em sistemas WDM terrestres amplificados, aparecendo em intervalos de aproximadamente $600 \mathrm{~km}$, com os amplificadores espaçados de $80 \mathrm{~km}$.

Existem atualmente disponíveis vários tipos de amplificadores ópticos. Podemos citar os amplificadores a fibra dopada ou guias dopados, os amplificadores a semicondutor, os amplificadores Raman e os amplificadores paramétricos.

Os amplificadores a semicondutor (SOA) [1] são similares, em construção, a lasers semicondutores convencionais. Eles consistem de um material que forma a região ativa, envolvida por duas camadas (uma superior e outra inferior) de semicondutores de diferente composição. As camadas semicondutoras que envolvem a região ativa são projetadas para que a luz seja guiada pelo dispositivo. Isto é conseguido através da diferença no índice de refração em relação à camada ativa, de modo semelhante ao que ocorre entre o núcleo e a casca da fibra óptica. Uma corrente elétrica passa através do dispositivo e serve para excitar elétrons na região ativa. Quando fótons atravessam a região ativa os elétrons transferem parte de sua energia na forma de fótons adicionais no comprimento de onda destes fótons incidentes. Portanto, o sinal óptico experimenta ganho ao atravessar o dispositivo. Ambas as faces do SOA são projetadas para uma refletividade muito baixa, de maneira que não ocorram reflexões indesejadas dentro do semicondutor. Esta é a principal diferença com relação aos lasers que têm faces com alta refletividade, para que o efeito "laser" ocorra.

O amplificador Raman [2] usa propriedades intrínsecas das fibras de sílica para obter amplificação de sinal. Isto significa que as próprias fibras de transmissão podem ser usadas como um meio de amplificação, e, portanto, a atenuação dos sinais transmitidos através da fibra pode ser compensada pelas próprias fibras. Um amplificador trabalhando com base neste princípio é comumente chamado de amplificador Raman distribuído (DRA - Distributed 
Raman Amplifier). A propriedade física que viabiliza o DRA é o espalhamento Raman estimulado (SRS - Stimulated Raman Scattering). O SRS é um processo inelástico no qual a energia é transferida para o meio e uma onda de Stokes de baixa freqüência é criada. Esta onda de baixa freqüência pode se propagar nas duas direções: copropagante e contrapropagante à direção de propagação do sinal. O SRS ocorre quando uma potência de bombeio suficientemente alta é lançada na fibra, simultaneamente a um sinal de maior comprimento de onda, a ser amplificado. O ganho Raman depende fortemente da potência de bombeio e da diferença de freqüência entre o sinal e o bombeio. A amplificação ocorre quando um fóton de bombeio transfere sua energia para estimular a emissão de um novo fóton no comprimento de onda do sinal, com a energia residual dissipada na forma de fônons.

Amplificadores paramétricos a fibra óptica são baseados no efeito não-linear conhecido como mistura de quatro ondas (FWM) [3]. Mistura de quatro ondas é o efeito pelo qual três ondas eletromagnéticas com freqüências $\omega_{1}, \omega_{2}$ e $\omega_{3}$ interagem e geram uma nova onda em $\omega_{4}=\omega_{1} \pm \omega_{2} \mp \omega_{3}$. Este efeito acontece em fibras ópticas e pode ser muito significativo se há casamento de fase entre as ondas envolvidas. Para que o efeito seja efetivo, uma portadora óptica $\omega_{1}$ (portadora de bombeio) carregando alta potência deve estar espectralmente localizada muito próxima do zero de dispersão da fibra, de modo a transferir energia para uma portadora com menor potência (portadora de sinal), localizada próxima de $\omega_{1}$

A estrutura de amplificação de interesse desta dissertação é o amplificador óptico a fibra dopada. Existem vários tipos de amplificadores a fibra dopada [4], sendo que o mais conhecido é o amplificador a fibra de sílica dopada com érbio (EDFA), que é o sub-sistema mais usado para amplificação de sinais ópticos em sistemas de telecomunicações. Outros amplificadores a fibra dopada, também conhecidos, são os de fibra de fluoreto dopada com túlio (TDFA), os de fibra de fluoreto dopada com praseodímio, e ainda os de fibra de telureto 
dopada com túlio ou érbio [4]. Os amplificadores ópticos podem também ser construídos por meio de dopagem em guias ópticos. O amplificador em guia dopado com érbio (EDWA) é um dispositivo semelhante ao EDFA, porém a amplificação ocorre em um guia óptico, construído a partir de uma matriz de vidro dopado com érbio.

Apesar das investigações sobre amplificadores a fibra terem sido realizados desde a década de 60, a primeira configuração prática de EDFAs foi apresentada ao mundo na segunda metade da década de 80 , feito este creditado ao grupo liderado por David Payne da Universidade de Southampton (U.K.) [5]. De 1985 a 1990 avanços extraordinários ocorreram. Grande parte destes avanços pode ser atribuídos ao grupo liderado por Emmanuel Desurvire, então no Bell Labs (USA) [6].

Um dos primeiros desafios foi a disponibilização de lasers de bombeio para excitação da fibra dopada com érbio, pois os lasers existentes nesta época não eram práticos para uso em sistemas de telecomunicações. Outro importante desafio foi o desenvolvimento de um modelo teórico que permitisse a otimização da fibra dopada com érbio para o correto funcionamento dos EDFAs. Já em 1991 foi apresentada uma modelagem detalhada do funcionamento dos EDFAs por Giles e Desurvire [7], que, até hoje, vem sendo largamente utilizada. Contribuição bastante significativa tem sido também dada por pesquisadores brasileiros ao desenvolvimento desta tecnologia (como exemplo veja as referências [8-11]). Em 1994 o CPqD, pertencente na época ao Sistema Telebrás, realizou, em conjunto com a Telesp, a primeira demonstração em campo desta técnica utilizando tecnologia nacional [9].

Desde o início da década de 90, os EDFAs têm sido usados em uma grande variedade de aplicações, sobretudo em sistemas de longa distância. Apesar de desenvolvidos para a substituição de regeneradores submarinos, os EDFAs passaram a ser utilizados também em sistemas terrestres, não somente como amplificadores de linha, como era o caso em sistemas submarinos, mas também como amplificadores de potência (junto ao transmissor) e como pré- 
amplificadores (junto ao receptor). São usados também em sistemas ópticos sem repetição, nos quais grandes distâncias são vencidas graças ao uso de bombeio remoto. Outra aplicação importante ocorre em sistemas de distribuição de TV (CATV) onde é utilizado para a compensação das perdas ópticas de distribuição. Porém, o maior impacto provocado pelo advento do amplificador refere-se à implantação de sistemas DWDM em longas distâncias, que aumentou de forma extraordinária a capacidade de transmissão $(\mathrm{Gb} / \mathrm{s} . \mathrm{km})$ das redes existentes, enquanto sistemas CWDM são muito usados em redes metropolitanas de acesso. A Figura 2.1 mostra uma representação generalizada do uso de WDM na planta de telecomunicações, compreendendo o uso de DWDM e CWDM. Na atualidade, sistemas comerciais podem ser adquiridos em até dezenas de canais para operação entre 1530 a 1564 nm (banda C) e entre 1570 a 1610 nm (banda L). De [12 - 20] são listadas algumas referências para normas de padronização de sistemas WDM e amplificadores ópticos.

Os EDFAs apresentam um circuito óptico interno, composto, na sua configuração mais básica (Figura 2.2(a)), por um laser de bombeio, cuja função é fornecer energia óptica para que ocorra amplificação óptica em um certo comprimento de fibra dopada com érbio, acopladores multiplexadores de bombeio e sinal, que promovem a inserção simultânea das potências do sinal e do bombeio na fibra dopada, e isoladores, que permitem o funcionamento estável do amplificador, eliminando reflexões ópticas dos conectores e retroespalhamentos de luz provenientes da fibra do enlace. São factíveis diversas configurações de circuitos ópticos para EDFAs, cada uma apresentando vantagens e desvantagens específicas [11]. No circuito mostrado na Figura 2.2(a), o sinal a ser amplificado e o bombeio se propagam pela fibra dopada na mesma direção, o que dá o nome de bombeio copropagante à esta configuração. A Figura 2.2(b) mostra o empacotamento de um amplificador real desenvolvido na Fundação CPqD. 


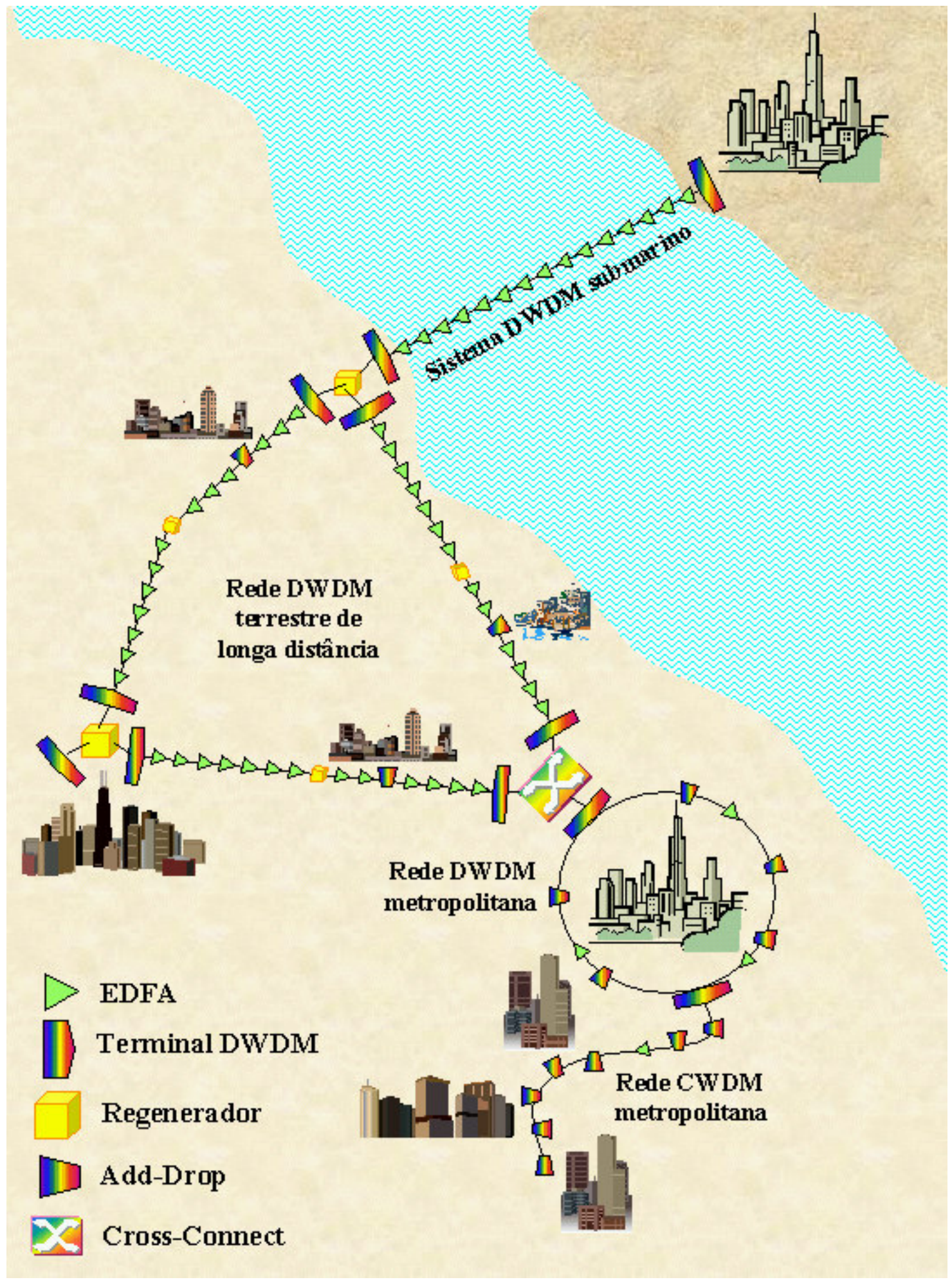

Fig. 2.1 - Representação esquemática de várias redes WDM com EDFAs na planta de telecomunicações. Os EDFAs são utilizados em sistemas submarinos, sistemas terrestres de longa distância e em redes metropolitanas. Propostas para redes de acesso do tipo CWDM usando EDFAs são feitas nesta tese. 


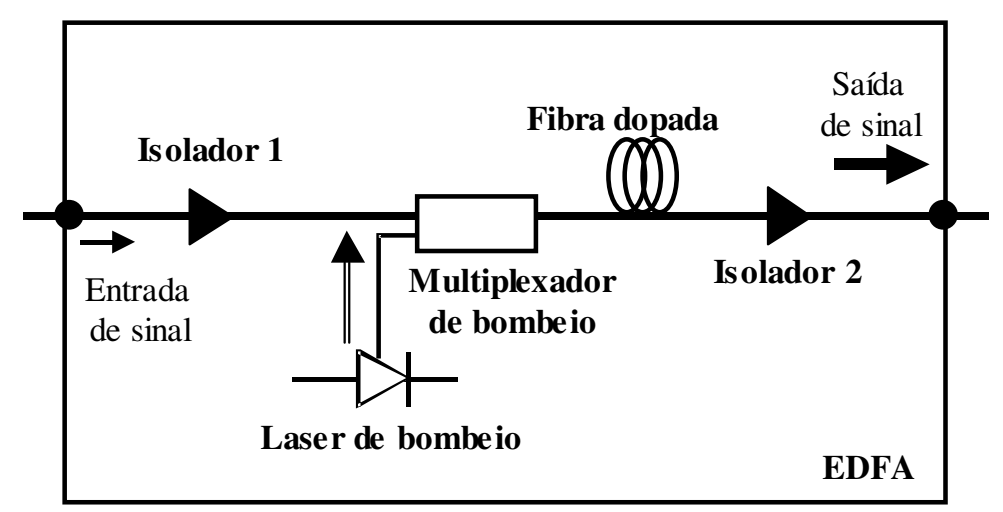

(a)

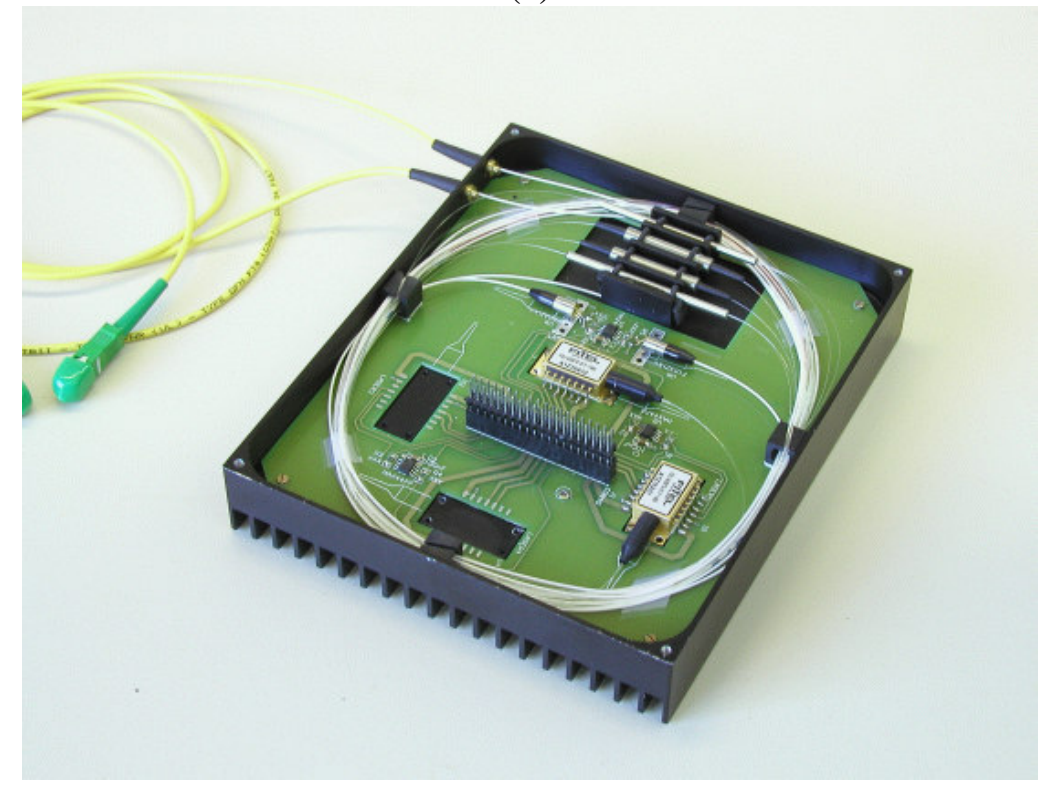

(b)

Fig. 2.2 - (a) Configuração esquemática básica de um EDFA e (b) empacotamento de um amplificador real desenvolvido na Fundação CPqD.

O érbio presente na fibra dopada do EDFA é um elemento da família terras raras da tabela periódica. Na Figura 2.3(a), ilustramos o esquema dos níveis de energia do átomo de érbio para as últimas camadas eletrônicas. Para que o processo de amplificação ocorra, elétrons do nível fundamental devem absorver a energia de bombeio e atingir níveis eletrônicos de maior energia. Tendo permanecido nestes níveis por um tempo característico, os elétrons decaem para o nível fundamental emitindo fótons com comprimento de onda dentro da região espectral de amplificação. No diagrama da Figura 2.3(a) são representadas as transições que produzem absorção em cada um dos dois comprimentos de onda mais usados para o bombeio dos amplificadores de Érbio: 980 e $1480 \mathrm{~nm}$. Outros comprimentos de onda 
possíveis seriam 810 e $659 \mathrm{~nm}$. A emissão ocorre numa faixa larga de comprimentos de onda em torno de $1550 \mathrm{~nm}$. O nível $\mathrm{N}_{1}\left({ }^{4} \mathrm{I}_{15 / 2}\right)$ é o nível fundamental enquanto o nível $\mathrm{N}_{2}\left({ }^{4} \mathrm{I}_{13 / 2}\right)$ é o nível metaestável. As transições do nível $\mathrm{N}_{2}$ para $\mathrm{N}_{1}$ são as que efetivamente produzem ganho no amplificador, pois o ganho do amplificador depende do tempo de permanência do elétron neste nível (tempo de vida), da ordem de $10 \mathrm{~ms}$. Os tempos de vida do elétron nos outros níveis são da ordem de microssegundos, o que não resulta em ganho. O sistema de amplificação com bombeio em $1480 \mathrm{~nm}$ é conhecido como sistema de dois níveis, pois os elétrons são excitados diretamente para o nível metaestável. O sistema de amplificação com bombeio em $980 \mathrm{~nm}$ é denominado de três níveis, pois os elétrons são excitados inicialmente para o nível $\mathrm{N}_{3}\left({ }^{4} \mathrm{I}_{11 / 2}\right)$, onde permanecem por poucos microssegundos antes de decaírem para o nível metaestável. A Figura 2.3(b) mostra um gráfico do comportamento espectral da absorção (atenuação) e emissão (ganho) de uma fibra dopada comercial, na região entre 1450 e $1650 \mathrm{~nm}$.

Existem dois processos que levam à emissão na região de $1550 \mathrm{~nm}$ : emissão estimulada e emissão espontânea. Na presença de sinal, ambos os processos de emissão acontecem simultaneamente no amplificador. A passagem de sinal óptico pelo meio dopado com érbio, e já previamente excitado com bombeio, estimula a transição dos elétrons para níveis de energia menor, levando à emissão de luz coerente no comprimento de onda original, isto é, amplificando o sinal. Esta é a chamada emissão estimulada, que produz o ganho do amplificador. Entretanto, parte dos elétrons decai espontaneamente para níveis de menor energia, gerando fótons com comprimento de onda, direção de propagação e polarização diferentes do sinal. A emissão espontânea gerada no amplificador se propaga ao longo da fibra e é também amplificada, gerando ruído na saída do amplificador. Este ruído é chamado de emissão espontânea amplificada ou ASE (Amplified Spontaneous Emission). 
Para obter os parâmetros básicos de desempenho do EDFA, que são o ganho e a figura de ruído, cujas definições são dadas no Apêndice A, torna-se necessária a resolução de equações relacionando a propagação das ondas eletromagnéticas do sinal, do bombeio e da ASE ao longo da fibra dopada. Estas equações dependem de vários parâmetros da fibra dopada, tais como seção de choque de absorção do bombeio e do sinal, seção de choque de emissão de bombeio e de sinal, fator de sobreposição entre os campos modais do sinal e do bombeio, e distribuição radial da dopagem de érbio, concentração de íons de érbio na fibra, dentre outros. Estas equações são complexas e, em geral, resolvidas através de ferramenta computacional. Atualmente, para o desenvolvimento e projeto de novos amplificadores, estão disponíveis programas comerciais que já incorporam estas equações, bastando ao projetista inserir os parâmetros específicos da fibra dopada, fornecidos pelo fabricante da mesma. Um dos programas mais conhecidos para este propósito é o OASIX, que foi desenvolvido pela Lucent utilizando a modelagem teórica descrita em [7]. Este software será utilizado posteriormente no suporte ao desenvolvimento experimental descrito nesta tese. Maiores detalhes sobre sua utilização, bem como as equações de propagação do sinal, do bombeio e da ASE podem ser encontrados no Apêndice B.

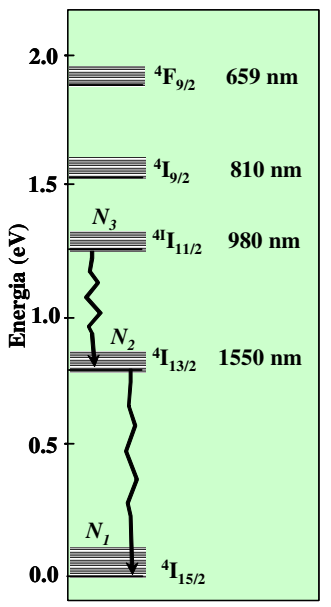

(a)

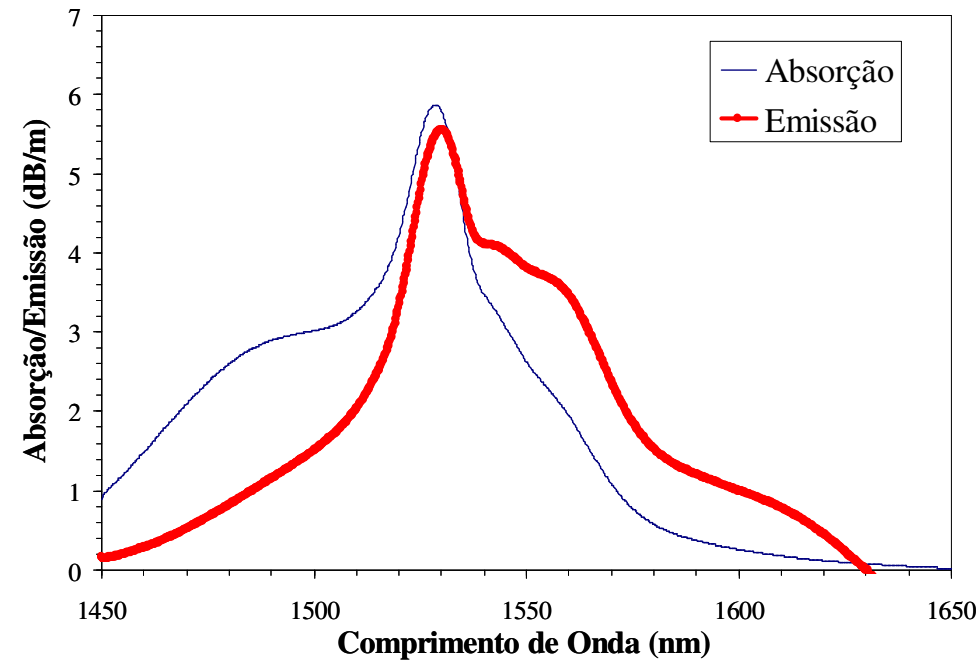

(b)

Fig. 2.3 - (a) Esquema de níveis de energia do átomo de érbio nas últimas camadas eletrônicas e (b) comportamento espectral típico da absorção (atenuação) e emissão (ganho) de uma fibra dopada comercial. 
A Figura 2.2(a) ilustra o que chamamos de configuração básica de um EDFA. Para construir EDFAs com maior ganho ou maior potência de saída uma opção de circuito óptico muito utilizada é o circuito conhecido como de bombeio bidirecional, ilustrado na Figura 2.4. Basicamente, neste novo circuito, adicionam-se, na saída do circuito mostrado na Figura 2.2(a), mais um multiplexador de bombeio e mais um laser de bombeio, arranjados na configuração conhecida como bombeio contrapropagante.

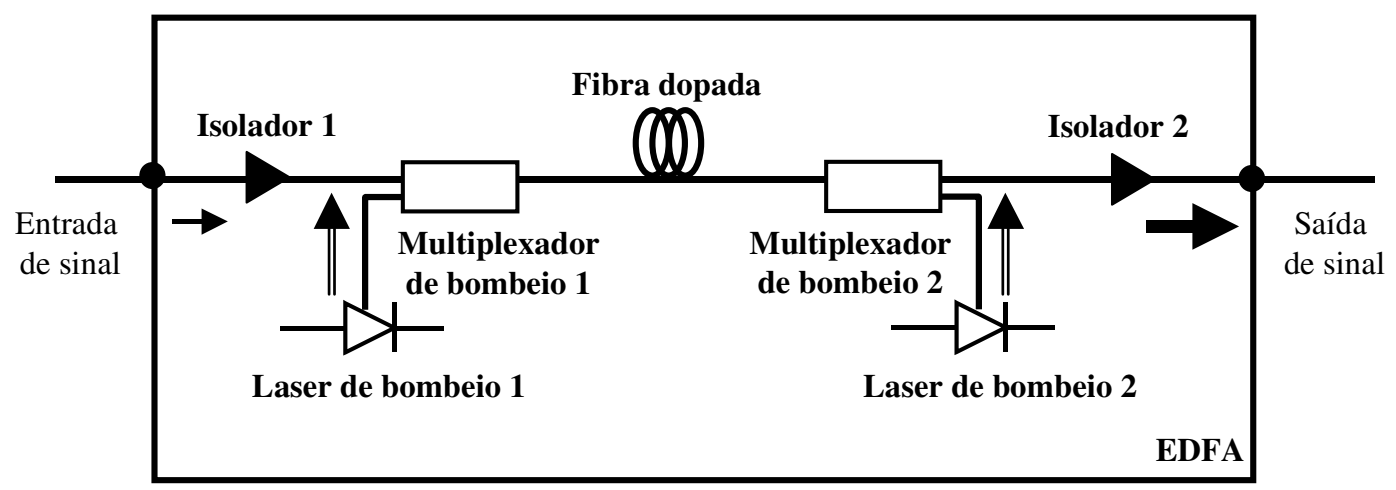

Fig. 2.4 - Configuração de bombeio bidirecional de um EDFA.

Porém, o amplificador óptico somente eleva o nível de sinal, não atuando na correção do efeito de dispersão cromática. Uma tecnologia passiva para correção da dispersão, que é freqüentemente associada aos amplificadores ópticos, é a tecnologia das fibras compensadoras de dispersão (DCFs). As DCFs são fibras especiais que apresentam um valor negativo e elevado do coeficiente de dispersão cromática (Figura 2.5(a)), em contraste com as fibras convencionais, que apresentam este coeficiente positivo para comprimentos de onda superiores a $1300 \mathrm{~nm}$. Por meio do uso de alguns quilômetros de DCFs, é possível compensar a dispersão cromática de enlaces típicos. Estas fibras são em geral enroladas em um carretel de pequenas dimensões (Figura 2.5 (b)) [21] e embutidas dentro de caixas modulares, instaladas dentro do próprio bastidor do equipamento de transmissão. Possuem valores de atenuação superiores aos das fibras usadas nos enlaces $(\approx 0,5 \mathrm{~dB} / \mathrm{km})$. Valores típicos de perda de inserção dos módulos estão entre 5 a $10 \mathrm{~dB}$. Devido a esta alta perda é comum a utilização de DCFs entre estágios de amplificadores [22 - 24], conforme mostra a Figura 2.6. 
Desta forma o conjunto amplificador e DCF passa a executar uma função semelhante a um regenerador 2R (amplificação e reformatação). No Apêndice C detalharemos os procedimentos de projeto para escolha de uma fibra DCF para compensação de dispersão, bem como outros aspectos relacionados ao orçamento de potência e aos limites devidos a dispersão cromática em um sistema de comunicações ópticas.

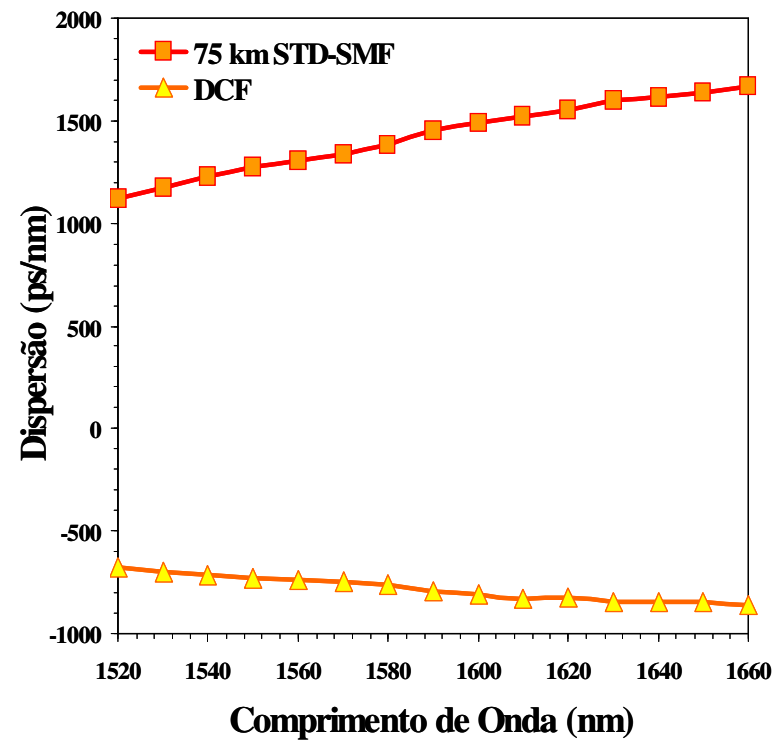

(a)

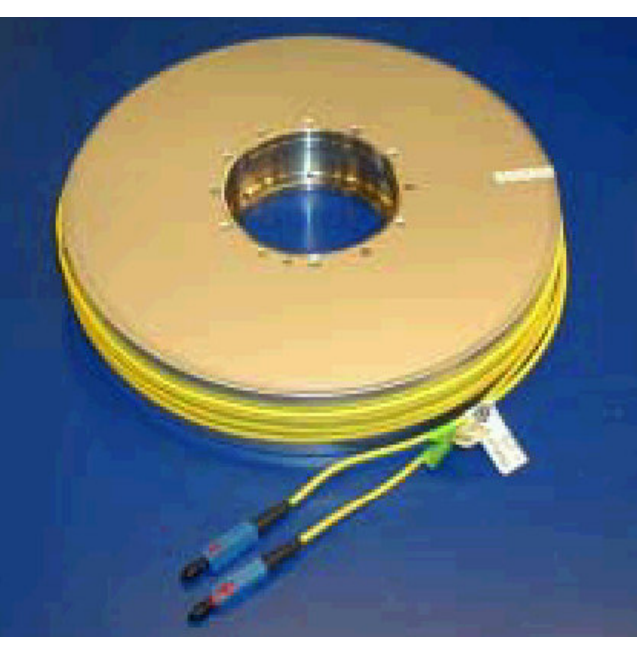

(b)

Fig.2.5 - (a) Coeficiente de dispersão cromática para uma fibra DCF e para uma fibra de transmissão tipo convencional e (b) foto do empacotamento de uma fibra DCF [21].

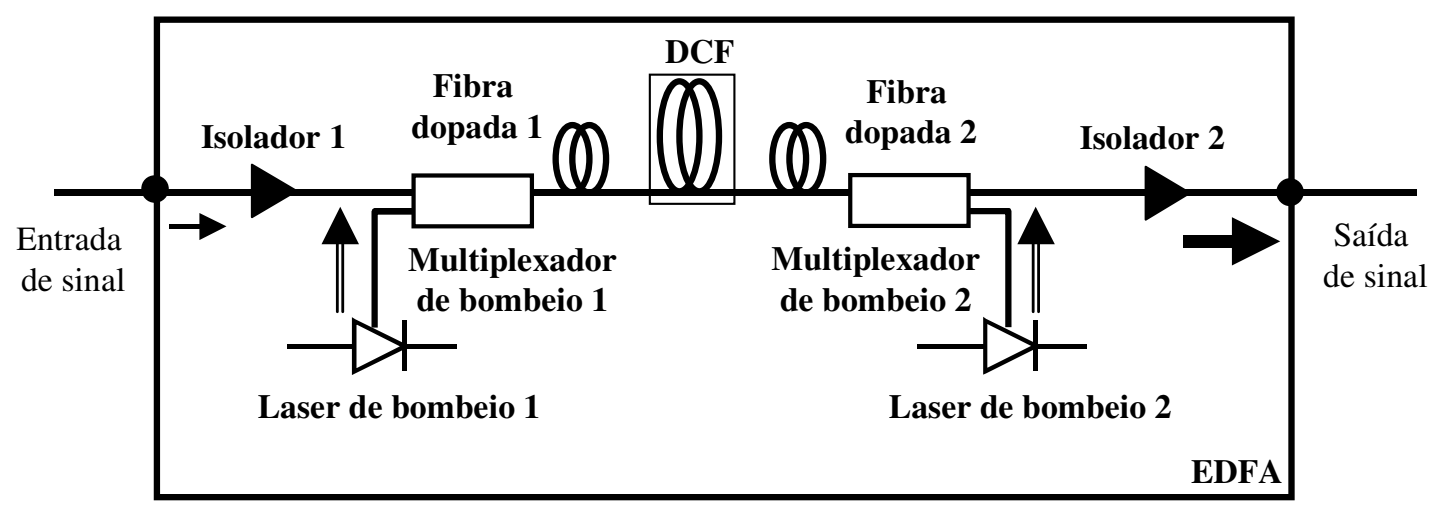

Fig. 2.6 - Configuração de bombeio bidirecional de um EDFA usando DCF. 


\subsection{Amplificadores a Fibra Dopada com Érbio de Dupla Passagem}

A engenharia de telecomunicações tem-se aproveitado da natureza bidirecional dos meios de propagação para implementar dispositivos que maximizem a capacidade de transmissão. Maximizar a capacidade de transmissão de um meio significa reduzir custos, mantendo, ainda assim, níveis de operação adequados. Um exemplo de aplicação deste conceito em comunicações ópticas é o uso de transmissão bidirecional em uma única fibra [25], tema este que foi objeto da dissertação de mestrado do autor. Neste caso, pode-se utilizar uma única fibra óptica para transmitir e receber sinais, mesmo que as frequiências ópticas destes sinais sejam as mesmas. Esta técnica tem sido utilizada para aumentar a capacidade de cabos ópticos já instalados quando os mesmos encontram-se com todas as suas fibras utilizadas. O uso de transmissão bidirecional, neste caso por aumentar a capacidade do cabo já instalado, evita a instalação de um novo cabo.

Um outro exemplo de aplicação, que é o objeto desta tese, é o de maximizar o potencial de um meio que produz ganho de sinal (amplificação) através da dupla passagem (passagem bidirecional) de um sinal através deste meio. Em comunicações ópticas esta implementação física é conhecida como amplificador óptico de dupla passagem (DP), também denominado de amplificador óptico reflexivo.

Amplificadores de dupla passagem tem sido propostos para melhorar o ganho de EDFAs. Se comparados aos EDFAs convencionais de única passagem (SP-EDFA) discutidos anteriormente, as configurações de dupla passagem melhoram a equalização espectral do ganho porque trabalham no regime de saturação do amplificador. EDFAs de dupla passagem (DP-EDFA) se assemelham, em uma primeira aproximação, à configuração de única passagem do tipo bombeio bidirecional, usando, porém, um menor número de componentes, o que reduz seu custo e o torna mais atraente. DP-EDFAs tem também atraído atenção em anos 
recentes pois eles requerem menor comprimento de fibra dopada para aplicações na banda $\mathrm{L}$, fornecendo amplificação óptica eficiente nesta região do espectro.

Em redes metropolitanas, sobretudo nas redes CWDM, são necessários amplificadores que apresentem menor custo que os tradicionalmente usados. Os EDFAs de dupla passagem são uma alternativa para disponibilizar amplificadores de baixo custo e desempenho adequado. Devido a sua estrutura de dupla passagem, tanto a função amplificação como outras funções inseridas em seu circuito óptico podem apresentar maior eficiência, reduzindo o custo. De fato, considerando que a compensação da dispersão é crítica para sistemas DWDM de alta velocidade, um interessante tópico de investigação, que será posteriormente descrito, refere-se a embutir uma fibra DCF dentro da topologia do EDFA de dupla passagem.

A Figura 2.7 mostra o circuito de um DP-EDFA. O sinal, após passar por um circulador, é amplificado pela fibra dopada com érbio, numa configuração de bombeio copropagante, por exemplo. Em seguida o sinal é refletido por um espelho ou refletor, colocado ao final da fibra dopada, retornando até a entrada, onde, através do mesmo circulador óptico, é removido do circuito do amplificador. Nesta nova configuração, o circulador óptico, além de permitir a conexão bidirecional de entrada e saída com baixa perda, age também como isolador para as portas de entrada e saída. Este tipo de amplificador pode produzir mais do que o dobro de ganho que o amplificador de circuito básico, mostrado na Figura 2.2(a), utilizando componentes similares. Em valores atuais o custo aproximado dos componentes para a montagem de um amplificador de bombeio bidirecional, como o mostrado na Figura 2.4, seria de US\$ 2.000,00, contra um custo aproximado de US\$1.000,00 para um DP-EDFA como mostrado na Figura 2.7. 


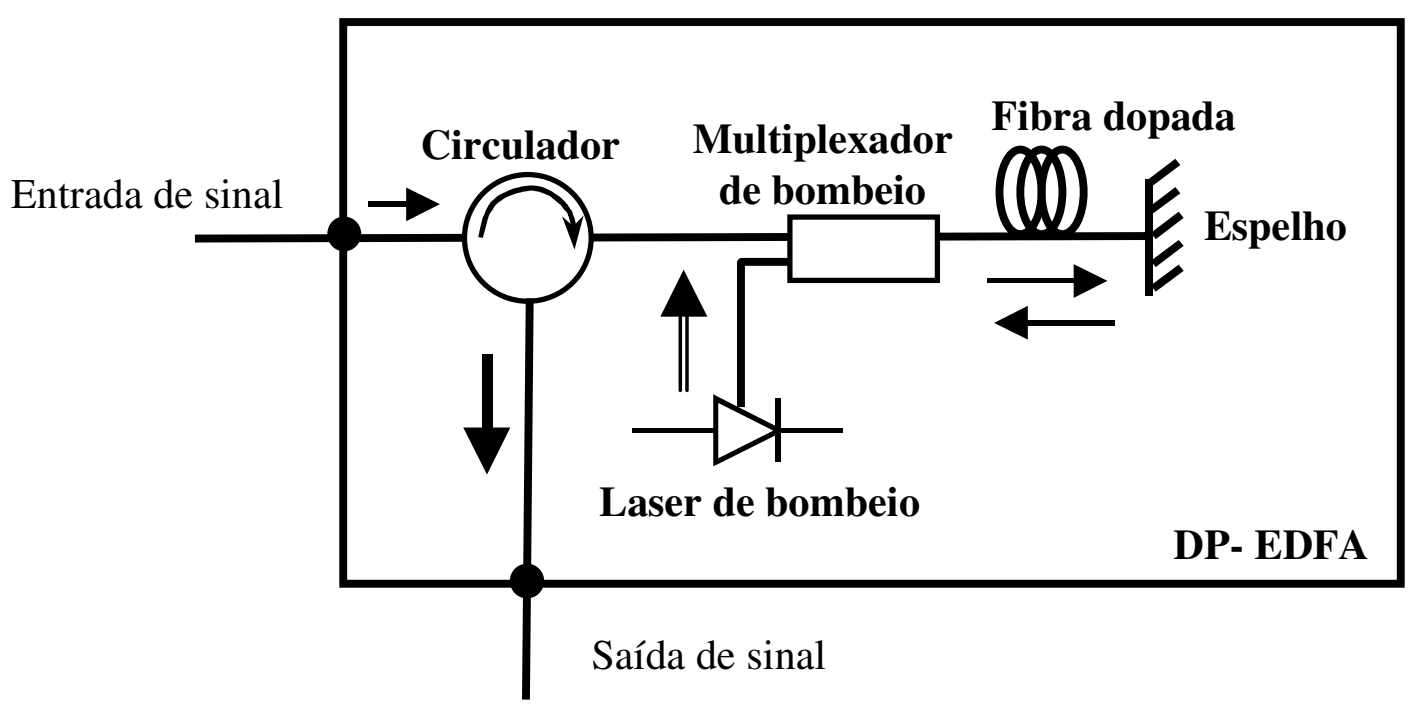

Fig. 2.7 - Configuração básica de um DP-EDFA.

Trabalhos prévios sobre amplificadores ópticos semicondutores de dupla passagem já haviam sido realizados [26] quando a primeira citação sobre amplificadores de dupla passagem a fibra dopada com érbio (DP-EDFA) foi registrada por S. Nishi al. em 1990 [27]. No estudo conduzido em [27] um DP-EDFA é caracterizado em termos de ganho líquido e coeficiente de ganho. Em [27] é também analisada a influência do espelho de sinal e bombeio, bem como a inserção de um filtro óptico logo antes do espelho, com o objetivo de remoção de parte da emissão espontânea amplificada (ASE) do DP-EDFA. Finalmente, são comparados os desempenhos da configuração de dupla passagem mostrada na Figura 2.7 em contraste com a topologia tradicional mostrada na Figura 2.2(a), removendo-se o espelho e trocando o circulador por um isolador. Apresentamos na Tabela 2.1 um resumo dos resultados do trabalho desenvolvido em [27].

Em 1991, um trabalho de simulação realizado por Lauridsen et al. [28] produziu resultados semelhantes aos obtidos em [27], analisando também a figura de ruído. Os resultados de [28] são também apresentados na Tabela 1.

Os dados adicionais para as experiências relatadas em [27] são: perda de inserção do isolador igual a $1,5 \mathrm{~dB}$, comprimento de onda de sinal igual $1552 \mathrm{~nm}$, comprimento de onda 
de bombeio de $1480 \mathrm{~nm}$, potência de bombeio igual a $18 \mathrm{~mW}$, dopagem de érbio igual a 25 ppm, comprimento de fibra dopada igual a $50 \mathrm{~m}$, potência de entrada igual a $-30 \mathrm{dBm}$, largura do filtro igual a $3 \mathrm{~nm}$, e perda de inserção do filtro igual a 1,5 dB e perda de inserção do espelho igual a $1,2 \mathrm{~dB}$.

Os dados adicionais para as simulações relatadas em [28] são: perda de inserção do isolador igual a $1,2 \mathrm{~dB}$, comprimento de onda de sinal igual $1530 \mathrm{~nm}$, comprimento de onda de bombeio de $980 \mathrm{~nm}$, potência de bombeio igual a 4,1 $\mathrm{mW}$, concentração de érbio na fibra dopada igual a $2.10^{24} \mathrm{~m}^{-3}$, potência de entrada igual $-30 \mathrm{dBm}$, largura do filtro igual a $3 \mathrm{~nm}$, perda de inserção do filtro igual a 1,5 dB e coeficiente de reflexão do espelho igual a $99 \%$.

Uma análise dos resultados mostrados na Tabela 2.1 fornece importantes indicativos sobre esta tecnologia. Pode-se concluir que os DP-EDFAs usados naquelas investigações possuíam aproximadamente o dobro do coeficiente de ganho que os EDFAs convencionais. Esta característica mostra que estes amplificadores aproveitam melhor a potência de bombeio do que os amplificadores convencionais. A análise mostra também que espelhos que refletem tanto o sinal como o bombeio proporcionam melhor ganho aos DP-EDFAs. Finalmente, podese concluir que a figura de ruído dos DP-EDFAs é mais elevada do que observado nos amplificadores convencionais. Este valor mais elevado deve-se, conforme será visto mais adiante, ao alto valor da potência de ASE contrapropagante, que é o mecanismo de ruído dominante nos DP-EDFAs. O valor da potência de ASE copropagante, que predomina nos EDFAs convencionais, têm valor inferior ao da potência de ASE contrapropagante. Finalmente podemos comentar, observando a Tabela 1, que filtros inseridos na cavidade de ganho para redução da ASE dos DP-EDFAs, permitem uma redução da figura de ruído. O ganho, porém, fica restrito à uma dada faixa espectral, além de ser reduzido devido a atenuação suplementar inserida. 
Tab. 2.1 - Resumo dos resultados obtidos nos experimentos em [27] e simulação em [28].

\begin{tabular}{|c|c|c|c|c|}
\hline Ref & Configuração & Ganho $(\mathrm{dB})$ & $\begin{array}{c}\text { Coeficiente de } \\
\text { Ganho }(\mathrm{dB} / \mathrm{mW})\end{array}$ & $\begin{array}{c}\text { Figura de } \\
\text { Ruído }(\mathrm{dB})\end{array}$ \\
\hline$[27]$ & Copropagante convencional & $\approx 3$ & 0,4 & - \\
\hline$[27]$ & Dupla passagem & $\approx 19$ & 1,1 & - \\
\hline$[27]$ & $\begin{array}{c}\text { Dupla passagem com } \\
\text { filtragem de ASE e bombeio }\end{array}$ & $\approx 10$ & 0,9 & - \\
\hline$[28]$ & Copropagante convencional & 18 & 4,8 & 4,3 \\
\hline$[28]$ & Dupla passagem & 28 & 8,5 & 6,0 \\
\hline$[28]$ & $\begin{array}{c}\text { Dupla passagem com } \\
\text { filtragem de ASE e reflexão } \\
\text { de bombeio }\end{array}$ & 33 & 8,9 & 5,6 \\
\hline
\end{tabular}

Ainda em 1992 Duling III et al. [29] propuseram um DP-EDFA utilizando um espelho de rotação de Faraday (FRM) em lugar do espelho convencional e um combinador de polarização (PBS) no lugar do circulador, com o objetivo de obter um amplificador de polarização única. A introdução do FRM rotaciona em 45 graus a polarização do sinal nele incidente com 45 graus adicionais no retorno enquanto o PBS permite somente a saída da polarização que esteja alinhada com seu eixo de entrada e saída.

Em 1994 C. R. Giles [30] propõe uma configuração de DP-EDFA usando um FRM e um circulador na entrada do amplificador com o objetivo de reduzir a variação do ganho dos EDFAs com a polarização (PDG), como resultado do fenômeno de polarization hole burning. Em [30] os valores da variação do ganho com a polarização são da ordem de $0,3 \mathrm{~dB}$ para DPEDFAs sem a presença do FRM e tornam-se praticamente nulos como o uso de FRM. Uma detalhada análise teórica das propriedades de DP-EDFAs usando FRM é feita posteriormente, em 1996, por S. Yamashita et al. [31].

Outros trabalhos propondo configurações mais complexas de DP-EDFAs foram apresentados ainda em 1994 por J. Y. Zeng et al. [32], em 1995 por J. M. P. Delavaux et al. [33] e em 1998 por F. Hakimini et al. [34]. Em [32] é proposto um acoplador estrela de 64 portas com um DP-EDFA para cada oito portas. A aplicação visada se refere a redes WDMA (Wavelength Division Multiplexing Access). Em [33] é proposto um DP-EDFA com 
múltiplos estágios baseado no uso de circulador de quatro portas e FRMs. Neste trabalho são feitas as primeiras avaliações sistêmicas do amplificador em um sistema de $10 \mathrm{~Gb} / \mathrm{s}$, mostrando excelente desempenho em termos de taxa de erro de bit. Em [34] é proposto um DP-EDFA usando um combinador de polarização (substituindo o circulador óptico) em conjunto com FRM. O circuito proposto de dois estágios constituiu-se em um amplificador de elevada potência de saída (acima de $1 \mathrm{~W}$ ) para sistemas WDM.

Trabalhos posteriores e relativamente recentes, realizados por B. Heens et al. [35], K. F. Chang et al. [36] e J. T. Ahn et al. [37], semelhantes aos trabalhos [27] e [28] mencionados anteriormente, investigam as vantagens e desvantagens do uso de DP-EDFAs, propondo novas topologias para redução da figura de ruído. Em [35] estudos são dedicados à operação de DP-EDFAs como amplificadores de potência e pré-amplificadores. O espelho utilizado é constituído de um acoplador óptico de razão de acoplamento variável. Os resultados indicam um maior ganho para o DP-EDFA comparado com o EDFA convencional. Porém, o DPEDFA apresenta maior figura de ruído. Os amplificadores foram estudados com bombeio em 980 e 1480 nm. Em [36] resultados são apresentados em conjunto com um modelo teórico para a descrição do funcionamento de DP-EDFAs. Foi utilizado no DP-EDFA um circulador óptico com as saídas conectadas de tal forma a constituir um espelho, conforme mostra a Figura 2.8(a). A Figura 2.8(b) mostra curvas de potência de ASE em função do comprimento de onda para o amplificador DP-EDFA e para um amplificador convencional, que é obtida desconectando-se as portas 1 e 3 do circulador \# 2 e adotando a porta 3 como saída. Pode-se observar que a potência de ASE da configuração DP-EDFA é consideravelmente maior do que a configuração convencional de passagem única. 


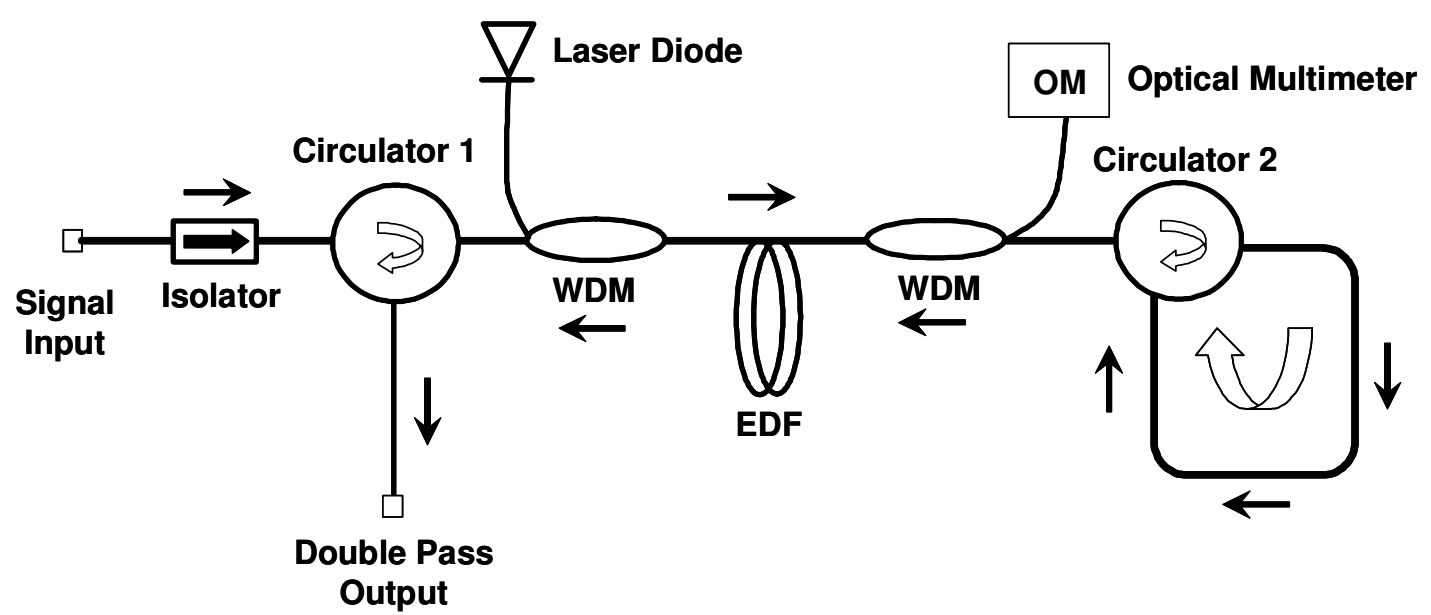

(a)

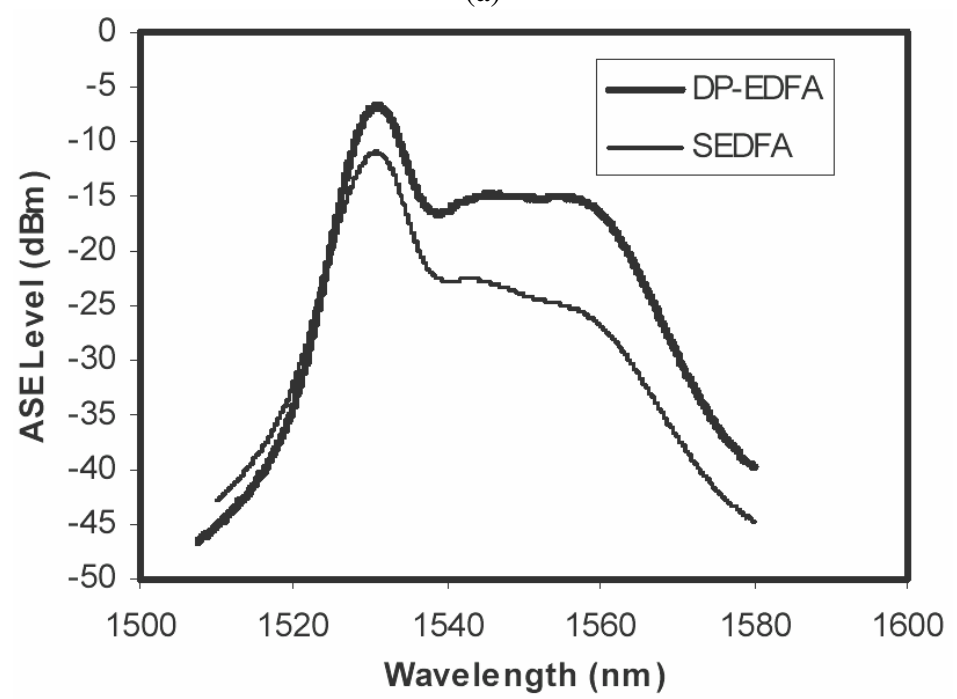

(b)

Fig. 2.8 - (a) Configuração do DP-EDFA usado em [36] e (b) potência de ASE das configurações de dupla passagem e passagem única [36].

Na Figura 2.9(a) mostramos os resultados para o ganho em função da potência de bombeio em $980 \mathrm{~nm}$, onde se pode observar que o ganho do DP-EDFA é cerca de 6 a $7 \mathrm{~dB}$ superior ao da configuração convencional, enquanto a figura de ruído é cerca de 1,4 dB maior. Observando agora a Figura 2.9(b), vemos que o ganho da configuração DP-EDFA se iguala ao ganho da configuração convencional para valores de potência de entrada em torno da potência de saturação do EDFA convencional, fato este já observado em [35]. A figura de ruído é também mais elevada para altas potências de entrada, o que mostra que a configuração 
DP-EDFA apresenta desvantagens tanto quanto ao ganho como quanto à figura de ruído, quando opera nesta faixa de valores.

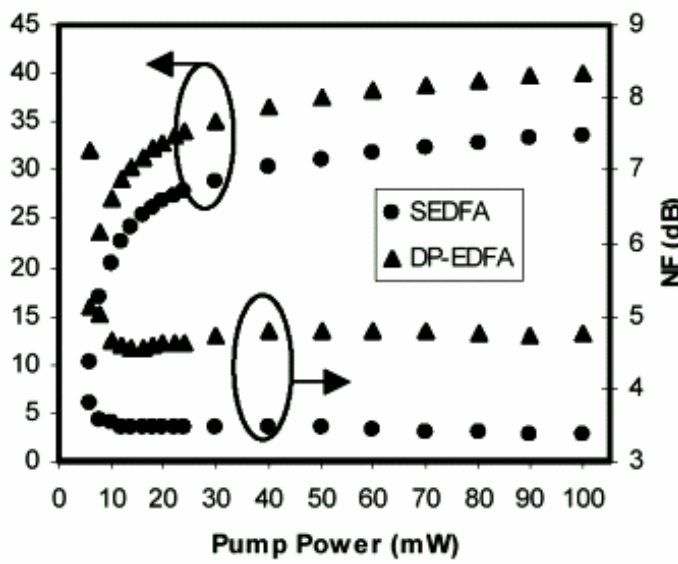

(a)

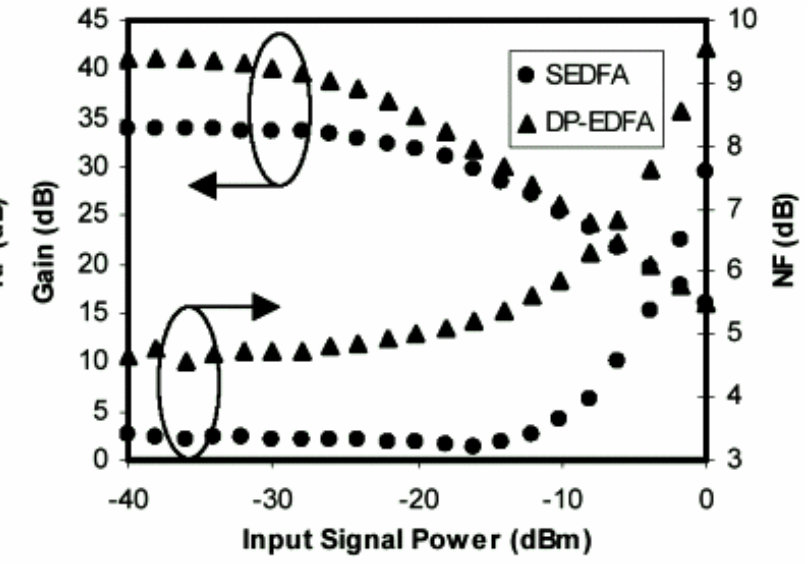

(b)

Fig. 2.9 - (a) Ganho em função da potência de bombeio em $980 \mathrm{~nm}$ para os amplificadores DP-EDFA e convencional [36] e (b) Ganho em função da potência de entrada de sinal [36].

Em [37] é proposta uma nova configuração de DP-EDFA com o objetivo de reduzir sua figura de ruído. O circuito mostrado na Figura 2.10(b) consiste de uma configuração tradicional de dupla passagem como aquela mostrada na Figura 2.7, acrescida de um estágio inicial de configuração convencional copropagante. O objetivo do primeiro estágio é fornecer uma primeira amplificação de baixo ruído. Este sinal é posteriormente amplificado por um segundo estágio de dupla passagem e de alto ganho. O circulador inserido entre os dois estágios previne o aumento de figura de ruído. O segundo estágio é bombeado com o resíduo de bombeio do primeiro estágio, que utiliza um laser de bombeio em $1480 \mathrm{~nm}$. As Figuras 10(c) e 10(d) ilustram os resultados de ganho e figura de ruído para as configurações analisadas em [37], que foram as configurações DP-EDFA com um estágio de ganho (Figura 2.10(a)) e com dois estágios de ganho (Figura 2.10(b)) e as configurações de EDFAs convencionais com um e dois estágios de ganho. Nestes dois últimos casos o FRM foi substituído por um isolador, na saída do qual mediu-se a potência de saída. Pode ser observado que um DP-EDFA que possua um primeiro estágio de amplificação convencional, tem a figura de ruído reduzida em $2 \mathrm{~dB}$ ao custo de uma pequena compressão no ganho. 


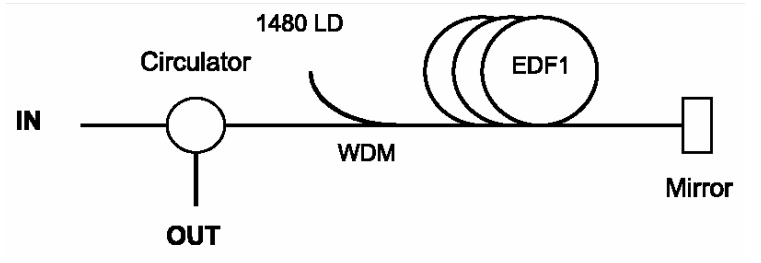

(a)

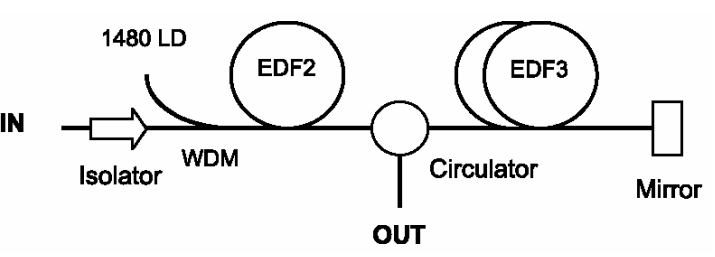

(b)

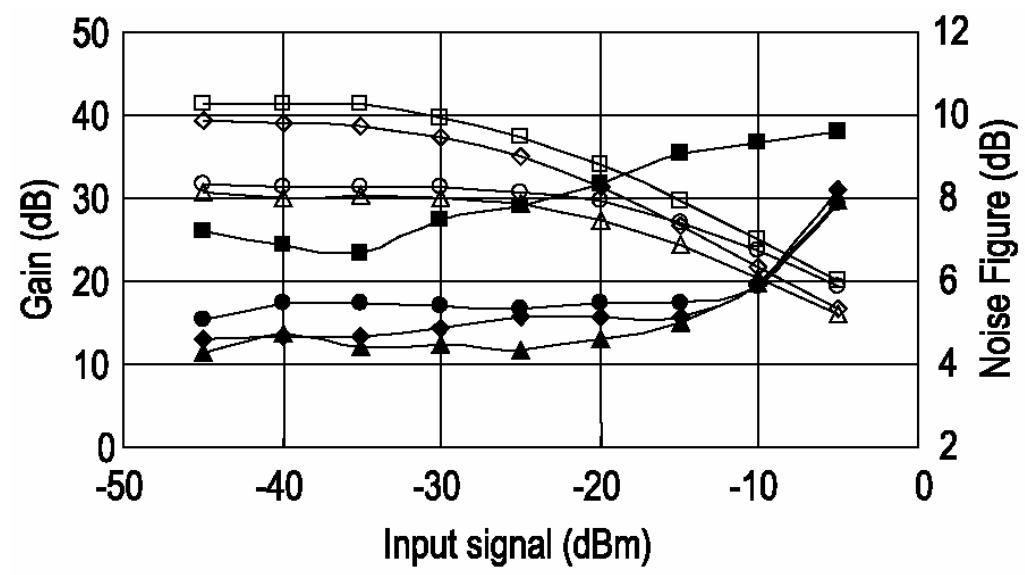

(c)

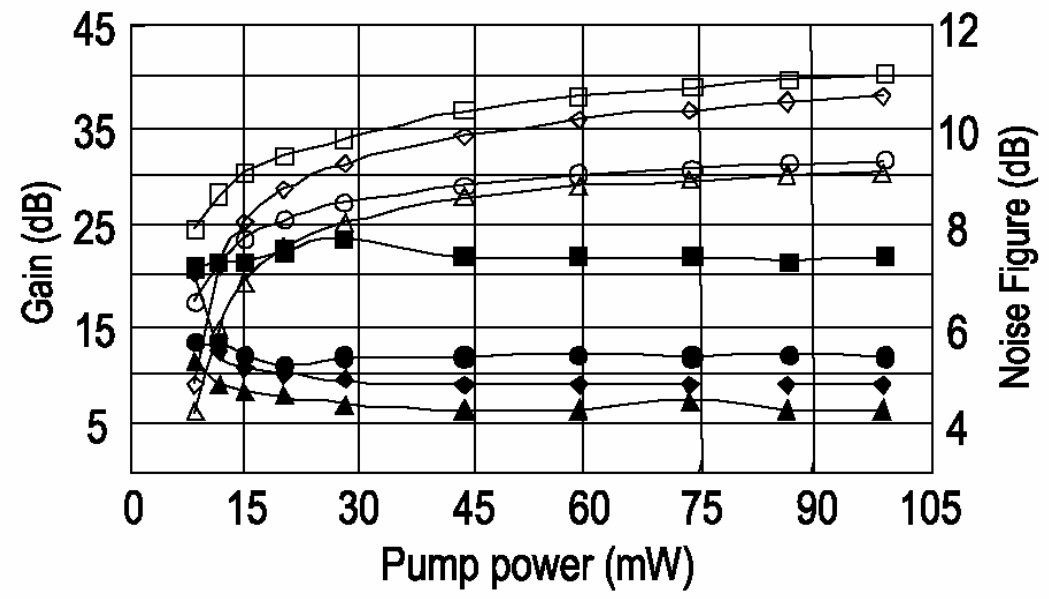

(d)

Fig. 2.10 - (a) DP-EDFA com um estágio de ganho [37], (b) DP-EDFA com dois estágios de ganho [37], (c) ganho e figura de ruído em função da potência de entrada [37] e (d) ganho e figura de ruído em função da potência de bombeio [37]. Quadrado vazado: ganho DP-EDFA de um estágio, losango vazado: ganho DP-EDFA de dois estágios, círculo vazado: ganho EDFA de um estágio, triângulo vazado: ganho EDFA de dois estágios.

Símbolos cheios: figura de ruído.

Uma outra abordagem de interesse para os DP-EDFAs é sua aplicação como amplificadores para a banda L (1570 a $1610 \mathrm{~nm})$. Nesta faixa de freqüências os EDFAs convencionais apresentam baixa eficiência de ganho devido ao fato desta região estar espectralmente distante do pico de emissão do íon de érbio, em 1530 nm, sendo necessários 
extensos comprimentos de fibra dopada para prover níveis de ganho aceitáveis. DP-EDFAs tem sido usados para melhorar o desempenho dos EDFAs nesta região. Vários trabalhos tem sido publicados nos últimos anos, entre eles: S. T. Hwang et al. [38-39], Q. Mao et al. [40], S. W. Harun et al. [41-45], J.T. Ahn et al. [46], H. Meng et al. [47] e L. L. Yi et al. [48]. Grande parte destes trabalhos enfoca a redução do comprimento de fibra dopada quando do uso de DP-EDFAs. Em [39], um DP-EDFA cobrindo as bandas C e L é proposto. A Figura 2.11(a) mostra a configuração implementada, que consiste de um primeiro estágio de EDFA convencional para amplificação das duas bandas, seguido de um DP-EDFA somente para a banda L. A Figura 2.11(b) mostra a caracterização de ganho e figura de ruído para as duas bandas. Neste trabalho são também avaliadas as seguintes configurações de amplificadores: EDFA convencional, no qual o primeiro estágio é comum às duas bandas e o segundo somente para a banda L, e amplificação paralela de bandas. A configuração de bombeio bidirecional é utilizada para a banda L na configuração paralela. Uma comparação destas configurações é mostrada na Tabela 2.2. Podemos concluir que a configuração proposta de DP-EDFA gera o mesmo nível de ganho para um menor nível de bombeio e menor comprimento de fibra dopada utilizada, possuindo também maior eficiência de conversão de potência (PCE), definida como o quociente entre a potência de saída saturada de um EDFA pela potência de bombeio utilizada. 


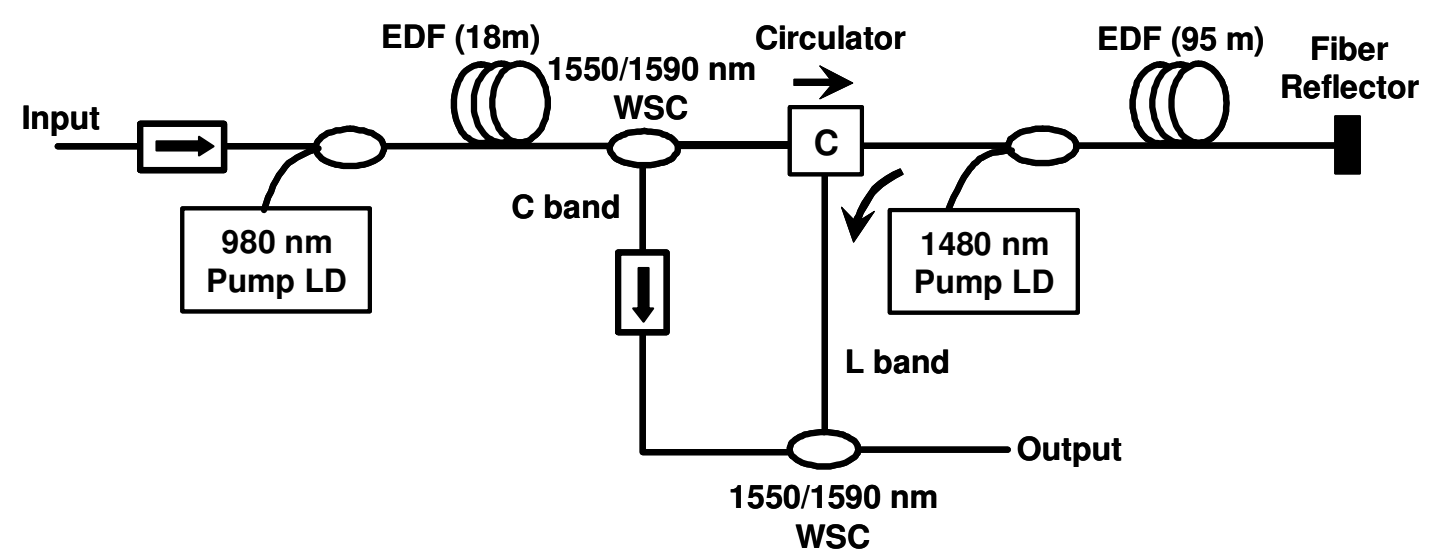

(a)

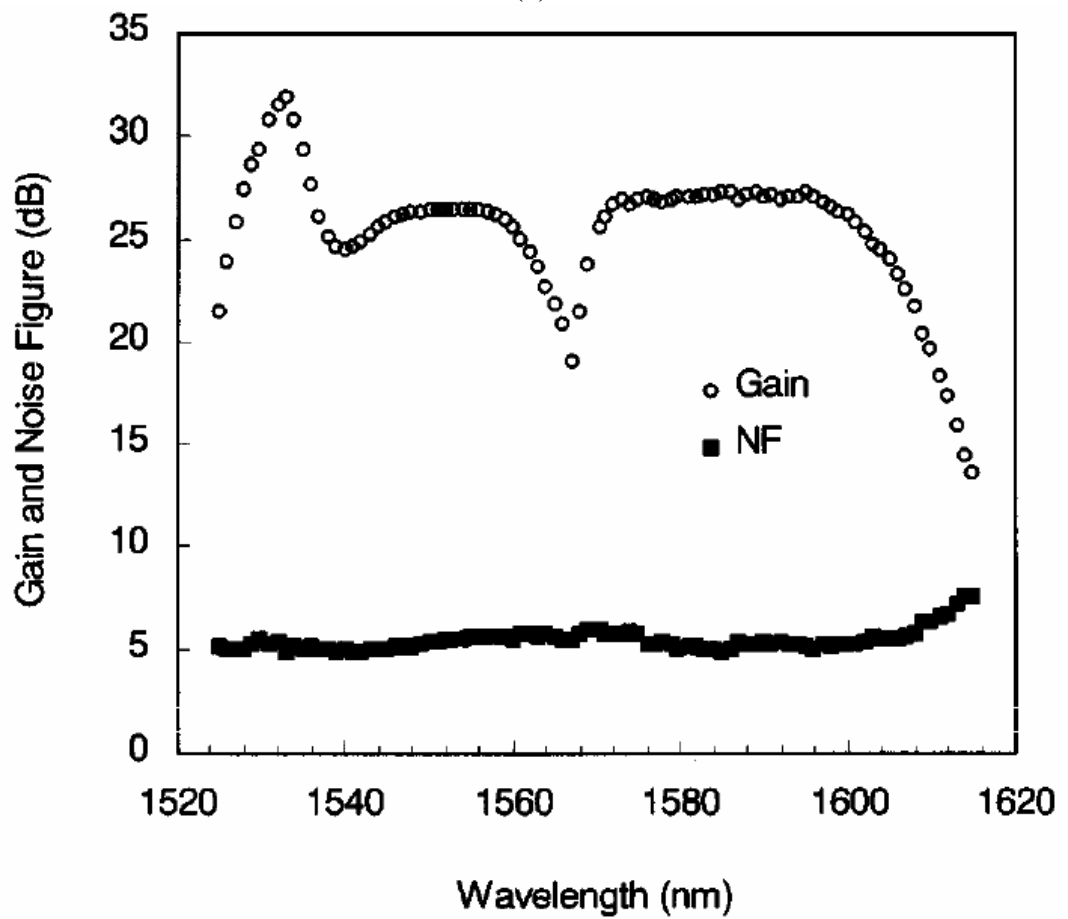

(b)

Fig. 2.11 - (a) Configuração do DP-EDFA de duas bandas proposta em [39] e (b) caracterização de ganho e figura de ruído para as duas bandas [39].

Tab. 2.2 - Comparação de topologias de EDFAs estudadas em [39].

\begin{tabular}{|c|c|c|c|}
\hline Estrutura & Potência de bombeio (mW) & Comprimento da EDF (m) & PCE (\%) \\
\hline Paralela & 324 & 207 & 9,2 \\
\hline Passagem única & 196 & 196 & 15,1 \\
\hline Dupla passagem & 153 & 113 & 20,5 \\
\hline
\end{tabular}

Outro enfoque dado nestes trabalhos consiste no reaproveitamento da alta potência de ASE contrapropagante para bombear a própria fibra dopada, gerando ganho adicional na 
banda L. Esta técnica é abordada em [40, 42, 43, 46]. Em [43], um amplificador DP-EDFA de dois estágios, sendo, porém, o primeiro estágio constituído de um trecho de fibra dopada sem bombeamento, é caracterizado em termos de ganho e figura de ruído. Como pode ser observado na Figura 2.12, ocorre um aumento no ganho do DP-EDFA, em relação àquele empregando fibra bombeada, da ordem de $1,5 \mathrm{~dB}$, com um custo na figura de ruído da ordem de 1,2 dB. A configuração de EDFA convencional é também analisada nestes trabalhos. Como já esperado, o ganho da configuração convencional é menor que aquele da configuração DP-EDFA, porém com figura de ruído também menor.

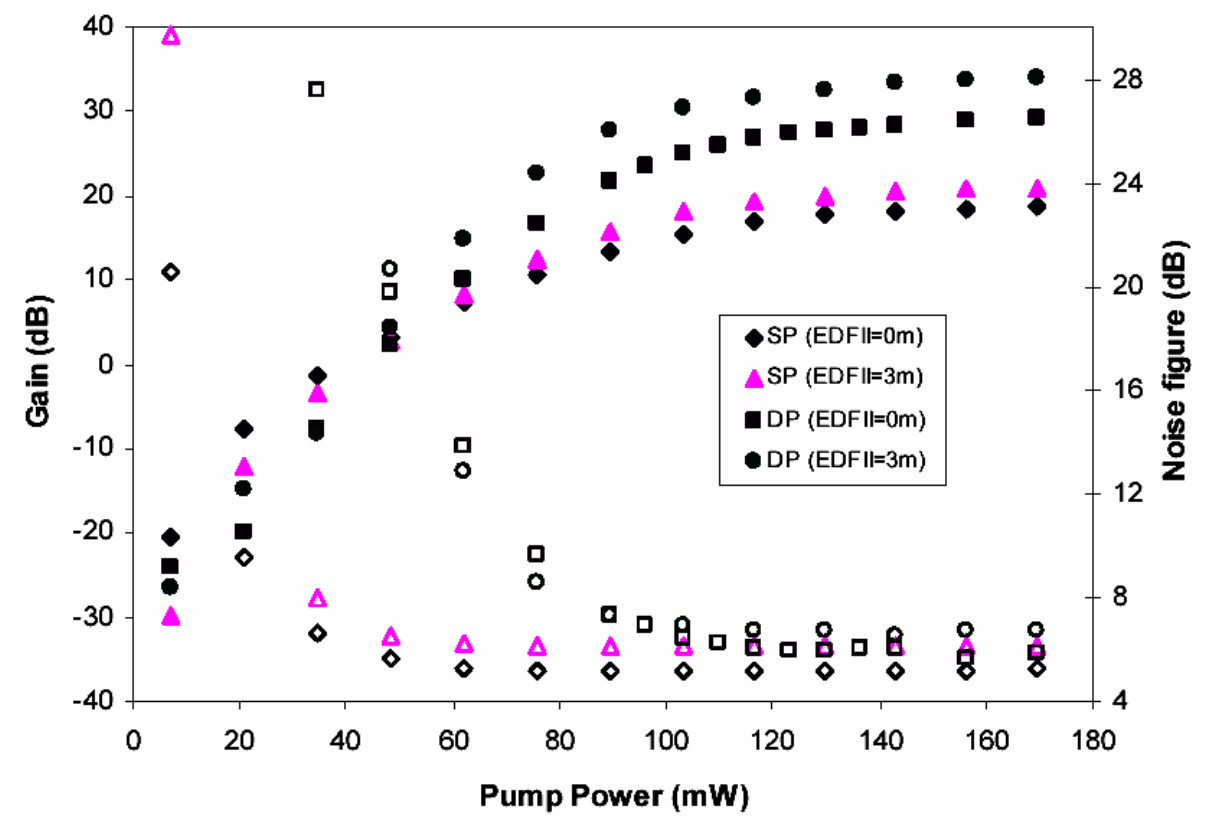

Fig.2.12 - Curva de ganho e figura de ruído em função da potência de bombeio para as configurações dos DP-

EDFAs com e sem fibra não bombeada e EDFA convencional com e sem fibra não bombeada [43].

DP-EDFAs têm sido também estudados para uso na banda S (1450 - 1510 nm). Para esta banda de transmissão o amplificador mais utilizado é baseado em fibras de vidros fluoretos dopados com túlio (TDFA). Esta tecnologia apresenta baixa eficiência de conversão de potência e o uso da dupla passagem aumenta esta eficiência. Alguns dos trabalhos realizados utilizando a estrutura de dupla passagem em TDFAs foram de Aozasa et al. [49-50] e Bastos Filho et al. [51]. De acordo com [50] o uso da dupla passagem permite uma elevação 
da eficiência de conversão de potência de 30 para $52 \%$, quando comparado a um TDFA convencional, utilizando potência de bombeio da ordem de $260 \mathrm{~mW}$.

Alguns estudos têm sido feitos em relação ao controle de ganho de DP-EDFAs. Entre estes estudos citamos: J. Nilsson [52-53], Inoue, K. [54] e Xia, Bing et al. [55]. Em [55], novamente, a estrutura EDFA convencional (Figura 2.13(a)) é comparada com a estrutura DPEDFA (Figura 2.13(b)), agora em termos de controle automático do ganho na banda L. Mostra-se que o amplificador DP-EDFA, em relação ao EDFA convencional, possui maior eficiência de conversão de potência, como já visto anteriormente, e potência crítica, definida como a mais alta potência de entrada total que ainda permite uma variação da potência saída controlada inferior a $0,5 \mathrm{~dB}$. No entanto, o DP-EDFA possui maior figura de ruído e maior variação dinâmica do ganho em comparação com o EDFA convencional.

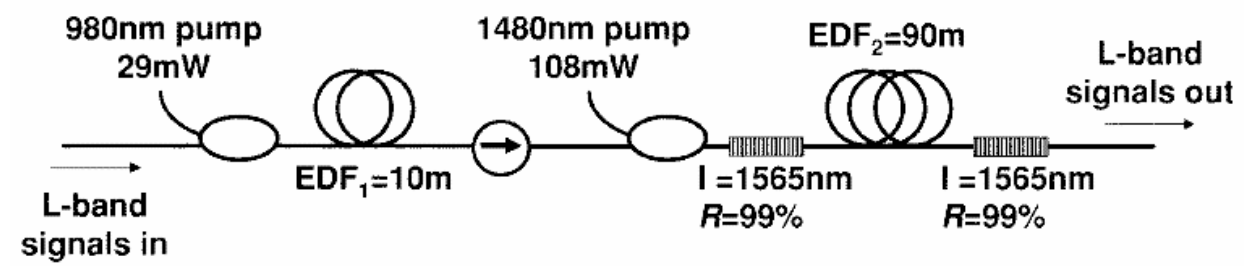

(a)

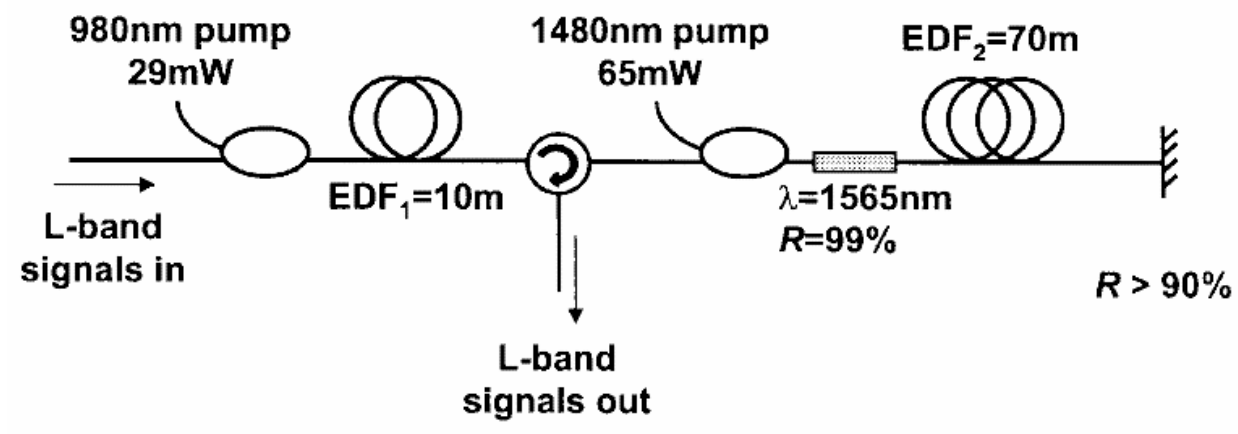

(b)

Fig. 2.13 - (a) Estruturas de EDFA convencional [55] e (b) DP-EDFA utilizadas para comparação das características de controle dinâmico de ganho [55].

Um importante aspecto a ser também discutido concerne a modelagem teórica dos DPEDFAs. Poucos trabalhos têm abordado este tema, entre eles podemos citar as referências [11, 36, 40, 47]. Nestes trabalhos, o ganho e figura de ruído são modelados a partir de estudos 
prévios realizados por Giles et al. [7] e por Mao et al. em [56]. No modelo desenvolvido em [56], para estudar os parâmetros de desempenho de amplificadores ópticos bidirecionais, uma importante conclusão é que, para uma dada potência de bombeio, considerando dois sinais no mesmo comprimento de onda propagando-se pela fibra em sentidos opostos, o ganho experimentado para estes dois sinais será o mesmo. Partindo desta conclusão, Mao et al., em [40], analisam os amplificadores de dupla passagem e mostram que o ganho total de um amplificador de dupla passagem pode ser dado por:

$G_{D P-E D F A}=R(\lambda) * G^{2}(\lambda)$

onde $R(\lambda)$ representa a perda do espelho refletor e $G(\lambda)$ é o ganho do EDFA de passagem única (SP-EDFA). Expressões para o cálculo do ganho de passagem única podem ser obtidas de [7].

A expressão (1) é, no entanto, bastante limitada para prever o funcionamento de um DP-EDFA mediante a variação de parâmetros, tais como, potência de entrada, potência de bombeio e comprimento de fibra dopada.

A inserção de componentes adicionais em circuitos ópticos de DP-EDFAs tem permitido grandes avanços nestes amplificadores. Na referência [57], M. A. Mahdi et al. apresentam um amplificador de tripla-passagem (Figura 2.14(a)) com filtro óptico embutido. Neste experimento, graças à utilização do filtro e à tripla passagem do sinal pelo amplificador, um alto valor de ganho (da ordem de $51 \mathrm{~dB}$ ) em $1550 \mathrm{~nm}$ foi obtido. O uso do filtro, no entanto, condiciona o uso deste tipo de amplificador a sistemas monocanais. Já na referência [58], B. Bouzid apresenta um DP-EDFA que utiliza um conjunto demultiplexadormultiplexador óptico embutido em sua estrutura, conforme mostra a Figura 2.14(b), para uso em sistemas DWDM. Graças ao uso destes elementos filtrantes, tanto o ganho como a figura de ruído do amplificador de dupla passagem puderam ser melhorados. 


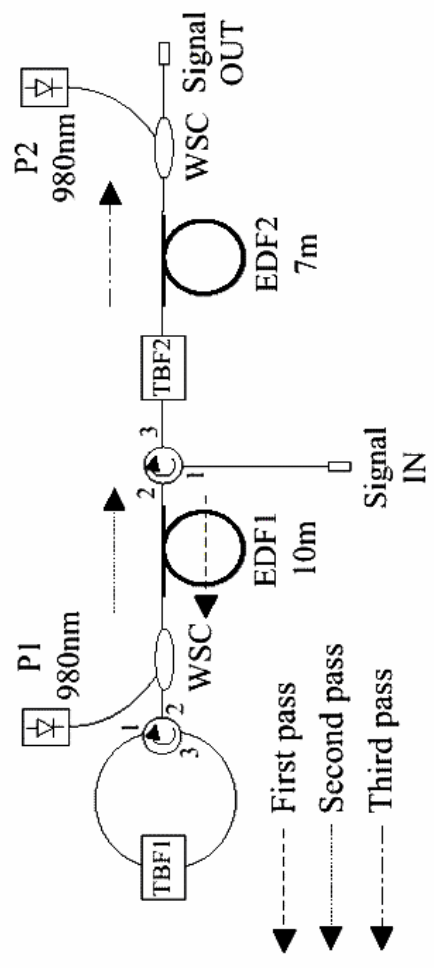

(a)

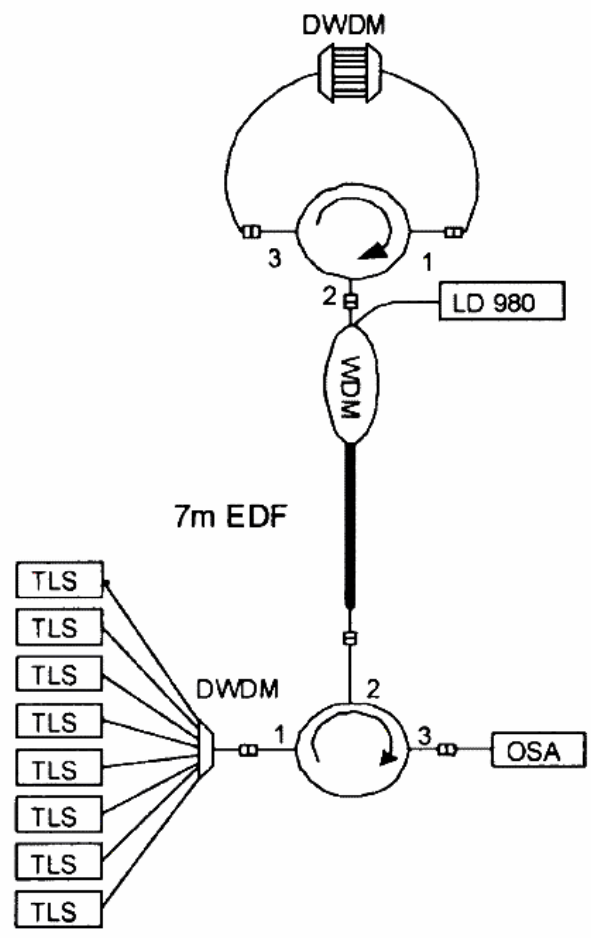

(b)

Fig.2.14 - (a) Configuração de um EDFA de tripla passagem com filtro óptico embutido [57] e (b) configuração de um DP-EDFA com um conjunto mux-demux embutido [58].

Analisaremos agora uma configuração interessante, baseada no uso de fibras compensadoras de dispersão (DCF) inseridas no circuito de ganho dos DP-EDFAs. Este tópico tem grande relevância dado que a dispersão é extremamente crítica em sistemas DWDM de alta taxa de transmissão. O DP-EDFA ideal seria aquele que, ao mesmo tempo, proporcionasse dupla passagem tanto na fibra dopada quanto na fibra compensadora de dispersão para proporcionar simultaneamente os efeitos de duplicação, tanto do ganho quanto da compensação da dispersão. Como veremos ao longo desta exposição, uma série de efeitos ópticos sistemicamente danosos impedem a montagem deste DP-EDFA ideal.

Poucos trabalhos relativos a esta aplicação têm sido publicados. A primeira investigação se deve a J. M. Delavaux et al. [59]. Neste estudo, uma DCF com passagem dupla de sinal pela mesma é inserida entre o primeiro e o segundo estágio de um EDFA convencional. Apesar do objeto de estudo em [59] não ser um amplificador de dupla 
passagem, resultados sistêmicos interessantes foram obtidos. Um sistema monocanal operando em $10 \mathrm{~Gb} / \mathrm{s}$ em uma distância de $122 \mathrm{~km}$ em fibra STD pôde ser estabelecido. Posteriormente, uma série de patentes foram requeridas contemplando o DP-EDFA com DCF. Estas patentes são de H. Onaka et al. [60], L. B. E. J. Moeller [61] e T. Ito [62]. Na proposta de [60], a DCF é inserida no DP-EDFA entre o FRM e a fibra dopada com érbio e um circulador é o dispositivo que permite a entrada e saída de sinal (Figura 2.15(a)). Na proposta de [61], o DP-EDFA é usado em uma estrutura que permite que o sinal passe quatro vezes pela DCF antes que atinja a saída de um circulador (Figura 2.15(b)). Estas múltiplas passagens ocorrem devido ao uso de um multiplexador de polarização associado a dois FRMs colocados em pontos estratégicos do circuito óptico. Em [62], o circulador de entrada é substituído por um multiplexador de polarização e a DCF colocada entre o multiplexador e o DP-EDFA ou entre o DP-EDFA e o FRM (Figura 2.15(c)).

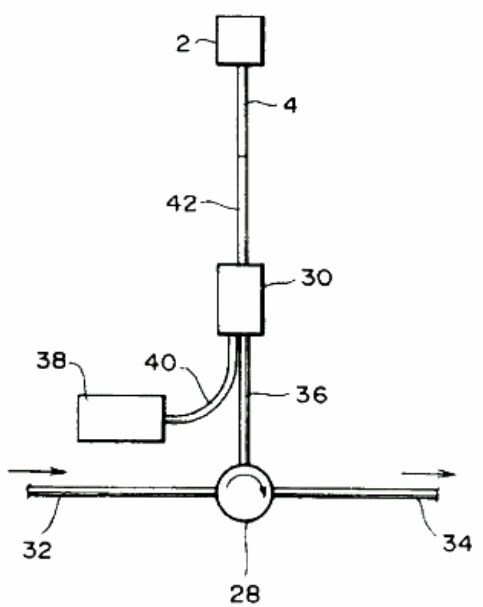

(a)

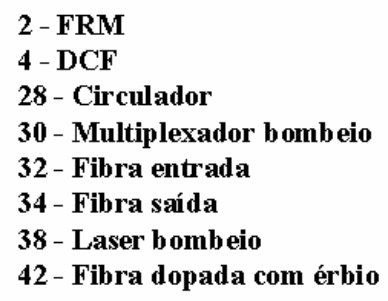

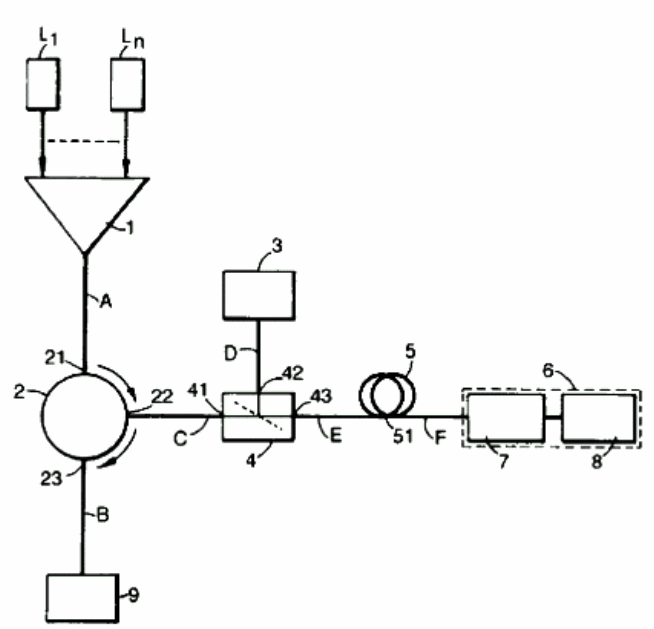

(b)

1 - Multiplexador DWDM

2 - Circulador

3 - FRM 2

4 - Multiplexador polarização

5 - DCF

6 - FRM 1

9 - Receptor

L1 - Ln - Lasers

$A$ - B - Enlaces de fibra

A - B - C - D - E - F - posições para EDFA

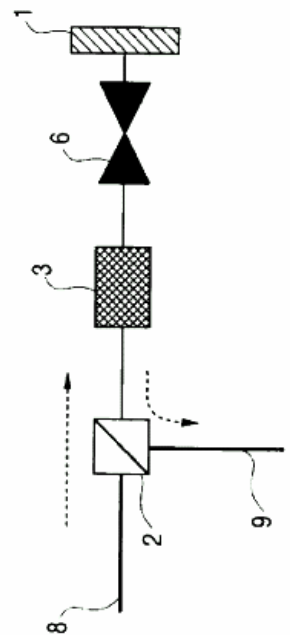

(c)
1 - FRM

2 - Multiplexador de Polarização

3 - DCF

6 - EDFA

8 - Fibra de entrada

9 - Fibra de saída

Fig. 2.15 - Circuitos ópticos patenteados para DP-EDFAs contendo DCFs (a) referência [60], (b) referência [61] e (c) referência [62]. 
O uso das configurações mostradas nas Figuras 2.15(b) e 2.15(c) permite, na saída do amplificador, a isolação do sinal amplificado em relação ao restroespalhamento Rayleigh gerado na própria DCF. No circuito apresentado na Figura 2.15(c), para que exista uma alta isolação entre sinal e retroespalhamentos na saída do amplificador, deve-se garantir um adequado controle da polarização de entrada do mesmo. Este controle é necessário, dado que a fibra usada na porta de entrada do multiplexador de polarização é do tipo polarização mantida. Estas fibras possuem um eixo preferencial de polarização e, portanto, necessitam que o sinal de entrada tenha a sua polarização alinhada com este eixo. Porém, as propriedades de polarização dos sinais ópticos transmitidos pela fibra, flutuam com o tempo, conforme demonstram os estudos realizados em [63-70], de forma que este requisito torna-se muito difícil de ser implementado na prática, principalmente em amplificadores de linha. Este controle poderia ser feito por controladores de polarização manuais ou automaticamente, através de sistema mais complexo que faz uso de realimentação de sinal. Todavia, tal mecanismo pode inviabilizar o uso deste tipo de amplificador em situações práticas, dado que aumenta o custo e a complexidade dos sistemas ópticos.

Além do retroespalhamento Rayleigh, outro sinal retroespalhado que pode ser gerado na DCF é causado pelo efeito Brillouin. O espalhamento Brillouin ocorre em decorrência da interação entre a luz e ondas acústicas na sílica, causando uma conversão de parte do sinal óptico para freqüências menores, bem como a inversão do sentido de propagação da luz. A radiação gerada no espalhamento Brillouin está deslocada da ordem de 0,08 nm em relação ao comprimento de onda injetado na fibra. A presença do espalhamento Brillouin tem várias consequiências para os sistemas de comunicações ópticas, sendo que a principal delas é a redução da potência transmitida. Como a luz espalhada é contrapropagante ao sinal injetado na fibra, o espalhamento Brillouin impõe dificuldades para a implementação de transmissão bidirecional. No caso da DCF, o limiar de potência para o aparecimento do efeito Brillouin é 
menor do que em fibras usadas em enlaces, pois a área do núcleo das DCF é menor que das fibras de transmissão. O uso de DCFs no circuito de EDFAs de qualquer espécie exige um estudo criterioso para impedir que o efeito seja gerado e amplificado.

Outro efeito danoso que pode ser produzido nas estruturas mostradas na Figura 2.15 é o chamado MPI (Multipath Interference). O MPI é uma fonte de ruído que tem origem nas inúmeras reflexões de sinal, ASE e retroespalhamento, que podem ocorrer em uma cavidade com e sem ganho.

Todos estes efeitos tem sido pouco investigados para DP-EDFAs, embora alguns estudos já tinham sido publicados para sistemas com EDFAs convencionais, feitos por M. J. Yadlowsky et al. [71], J. Bromage [72] e Winzer P. J. et al. [73], assim como em sistemas com EDFAs bidirecionais por M. Sumida et al. [74] e J. Ko et al. [75] bem como para sistemas com amplificadores Raman de dupla passagem com DCF embutida por R. Sugizaki et al. [76] e M. Tang et al. [77-78]. Os efeitos discutidos acima e estudados nestas referências são bastante similares àqueles que ocorrem com os DP-EDFAs de DCF embutida. A Figura 2.16 mostra os efeitos do retroespalhamento Rayleigh no receptor de um sistema bidirecional. Pode ser observado que um patamar de erros em taxas razoavelmente altas. Uma expressão para cálculo da penalidade (em $\mathrm{dB})$ em um receptor óptico devido ao retroespalhamento Rayleigh obtida em [75], é dada pela expressão (2). A penalidade é definida como a diferença entre a sensibilidade original do sistema em uma dada taxa de erros e a nova sensibilidade obtida com o efeito Rayleigh presente.

$$
P=-5 \log \left(1-4 Q^{2}\left(\left(1+\frac{(n+1)}{2} R_{b s} \cdot G+\frac{(n+1)(2 n+1)}{6} R_{b s}{ }^{2} \cdot G^{2}\right) \frac{h v B}{P_{i n}}+\frac{n(n+1)}{2} R_{b s}{ }^{2} \cdot G^{2}\right)\right)
$$

onde:

Q : argumento da função taxa de erros;

$\mathrm{n}$ : número de amplificadores de linha bidirecionais; 
$\mathrm{R}_{\mathrm{bs}}$ : coeficiente de retroespalhamento Rayleigh;

G : ganho linear do amplificador;

h : constante de Plank;

$v$ : freqüência óptica do sinal;

B : taxa de transmissão;

$\mathrm{P}_{\text {in }}$ : Potência de entrada no amplificador.

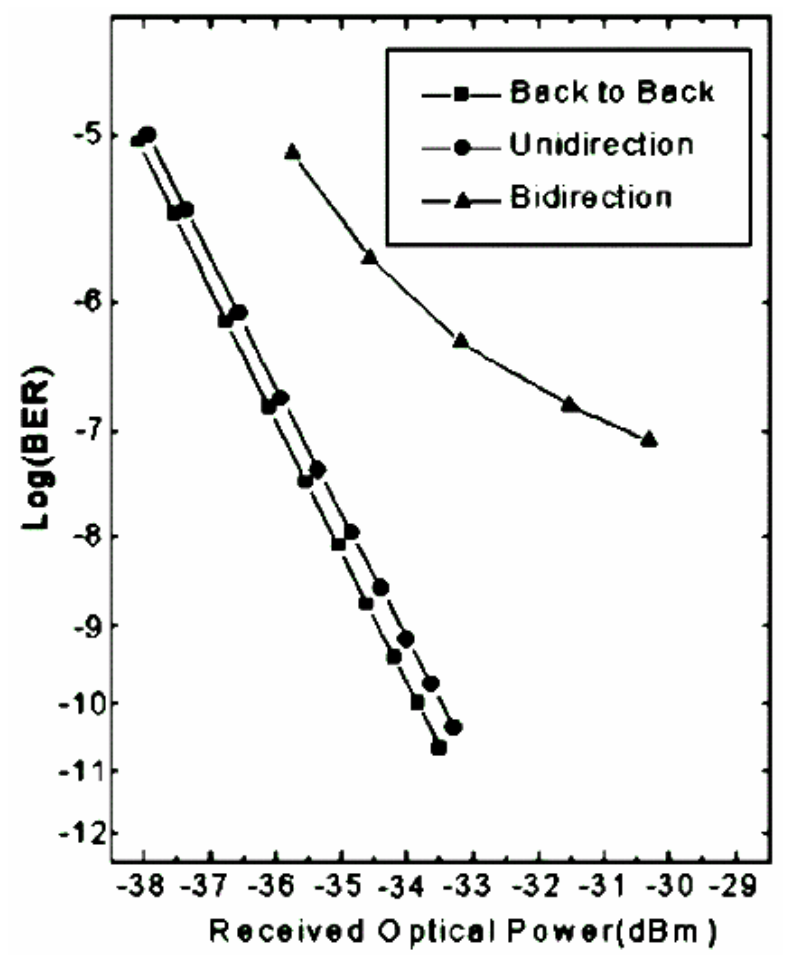

Fig. 2.16 - Desempenho sistêmico dos sistemas uni e bidirecional em 2,5 Gb/s [75].

No Capítulo 3 apresentaremos uma série de experimentos realizados para avaliar o desempenho dos DP-EDFAs contendo DCFs esquematizados na Figura 2.15, considerando os parâmetros de mérito: ganho, figura de ruído e dependência com a polarização. $O$ desempenho sistêmico destes amplificadores será também avaliado. Não há registro na literatura de alguma avaliação semelhante. Será também proposto um novo circuito de amplificação de dupla passagem contendo a fibra DCF, que tem como objetivo a eliminação das deficiências dos circuitos apresentados na Figura 2.15. 
CAPÍtULO 3

\section{COMPARAÇÃO EXPERIMENTAL ENTRE DP-EDFAs}

COM DCF 


\subsection{Introdução}

No capítulo anterior realizamos uma revisão bibliográfica sobre DP-EDFAs, culminando com trabalhos onde é proposta a implementação de DP-EDFAs com fibras DCFs embutidas na estrutura do amplificador. Até hoje nenhum estudo experimental foi feito na literatura avaliando o desempenho desta associação. Desta forma, descreveremos, na seção 3.2, uma série de experimentos que foram realizados para analisar o desempenho dos DPEDFAs contendo DCFs.

Uma primeira abordagem, feita na Seção 3.2, será caracterizar uma fibra DCF quanto aos níveis gerados de retroespalhamentos Rayleigh e Brillouin. Esta caracterização visa determinar o coeficiente de retroespalhamento Rayleigh, bem como o limiar de aparecimento do efeito Brilloin na fibra DCF em função da potência de entrada.

Em seguida, vamos examinar o comportamento funcional de três diferentes circuitos ópticos de DP-EDFAs com DCF embutida. Os três tipos de circuito óptico são:

1. DP-EDFA com DCF embutida, usando um combinador de polarização na entrada/saída e um rotacionador de Faraday para reflexão do sinal. Este circuito é proposto na referência [62].

2. DP-EDFA com DCF embutida usando um circulador na entrada/saída e um circulador para reflexão do sinal. Este circuito é proposto originalmente por este autor.

3. DP-EDFA com DCF embutida usando um circulador na entrada/saída e um rotacionador de Faraday para reflexão do sinal. Este circuito é proposto nas referências [60, 61].

Os DP-EDFAS com DCF embutida serão caracterizados quanto ao ganho, figura de ruído e sensibilidade à polarização, bem como através da avaliação sistêmica pela taxa de erro de bit (BER). Um importante fator a ser avaliado nestas caracterizações é a análise do 
retroespalhamento Rayleigh proveniente das DCFs, que é amplificado pelo estágio de amplificação. Os resultados desta investigação experimental enfatizam particularmente a eficiência de cada uma das topologias propostas acima para a eliminação desta fonte de ruído.

Finalmente, na Seção 3.3, validamos experimentalmente uma primeira aplicação de um DP-EDFA com DCF embutida usando o circuito por nós proposto. Iniciaremos com aplicações na banda L, onde os DP-EDFA são muito atraentes, pois permitem reduzir o comprimento de fibra dopada utilizada. Nesta seção apresentamos os resultados de ganho e figura de ruído dos DP-EDFAs e dos SP-EDFAs (amplificadores convencionais de passagem única) com DCF embutida em sistemas monocanais para operação entre 1570 a $1610 \mathrm{~nm}$. Resultados sistêmicos de taxa de erro de bit (BER) em 10Gb/s serão apresentados, comparando DP-EDFAs com SP-EDFAs. 


\subsection{Comparação experimental de DP-EDFAs com DCF}

Antes que os DP-EDFAs sejam avaliados, é necessária uma caracterização dos níveis de retroespalhamentos Rayleigh e Brillouin, gerados pelas DCFs. A intensidade do efeito Brillouin depende do nível de potência de entrada na DCF bem como de outros fatores tais como a largura espectral da fonte de óptica, tensões mecânicas na fibra, área do núcleo da fibra, etc... Enquanto que o efeito Rayleigh não pode ser eliminado, o efeito Brillouin apresenta um limiar de potência a partir do qual surge e seu retroespalhamento aumenta com grande intensidade.

Para determinar os níveis de intensidade dos retroespalhamentos Rayleigh e Brillouin gerado pelas DCFs utilizamos o arranjo experimental mostrado na Figura 3.1.

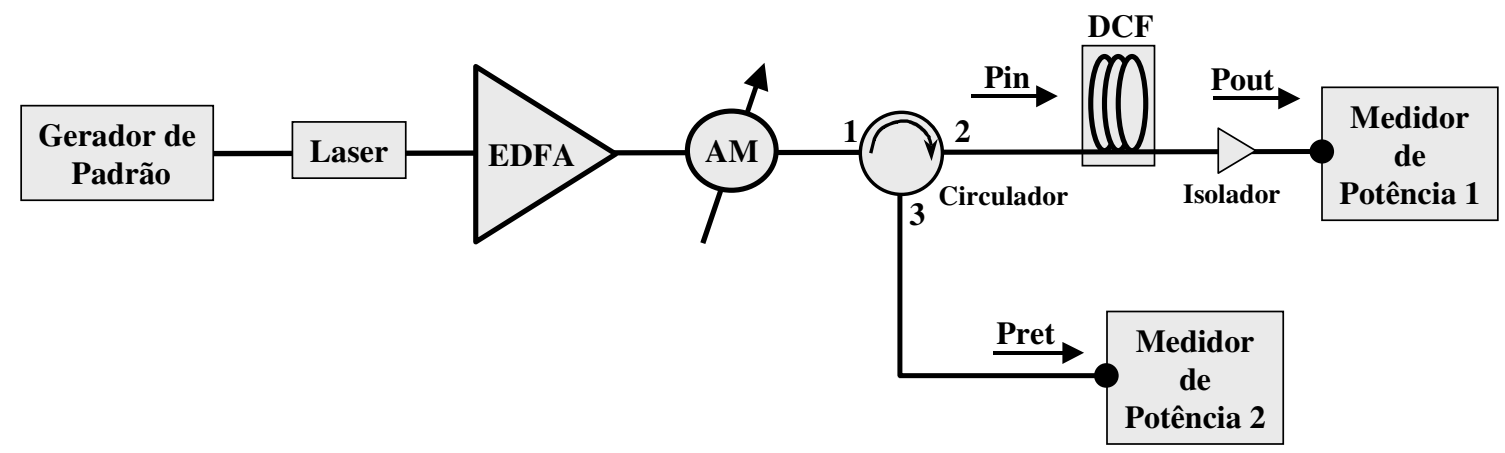

Fig. 3.1 - Arranjo experimental para determinar os níveis de intensidade dos retroespalhamentos Rayleigh e Brillouin gerado pelas DCFs.

Basicamente o arranjo experimental é formado por um laser DFB no comprimento de onda de $1558 \mathrm{~nm}$, opcionalmente modulado por um gerador de padrão em $2.5 \mathrm{~Gb} / \mathrm{s}$. O sinal do laser é amplificado por um EDFA convencional. O nível de potência de entrada na fibra DCF é determinado e monitorado pelo atenuador monitor de potência (AM). A potência de saída da fibra DCF é monitorada no medidor de potência \#1 e a potência retroespalhada no medidor de potência \#2. O circulador é utilizado para permitir a conexão do sinal de entrada e a remoção do sinal retroespalhado com baixas perdas. O isolador na saída da fibra DCF 
impede o retorno de reflexões de Fresnel para o medidor de potência \#2. Todos os valores de potência foram calibrados com relação às perdas introduzidas pelos circulador e isolador. A Figura 3.2 mostra os resultados da avaliação de potência de saída e potência retroespalhada, em função da potência de entrada $\left(\mathrm{P}_{\text {in }}\right)$, utilizando-se uma fibra DCF de -900 ps/nm em 1550 nm com perda de 6,0 dB. Estes níveis de potência foram medidos com e sem a presença de sinal de entrada modulado em 2,5 Gb/s. Quando o laser de sinal não é modulado (é o caso, por exemplo, de sistemas com modulação externa) a largura de linha espectral do laser é estreita $(<0,005 \mathrm{~nm})$ propiciando um baixo limiar de aparecimento do efeito Brillouin, enquanto que, para o laser DFB modulado diretamente, a largura de linha do laser se alarga o suficiente (> 0,05 $\mathrm{nm}$ ) para elevar o limiar de aparecimento do efeito Brillouin [79].

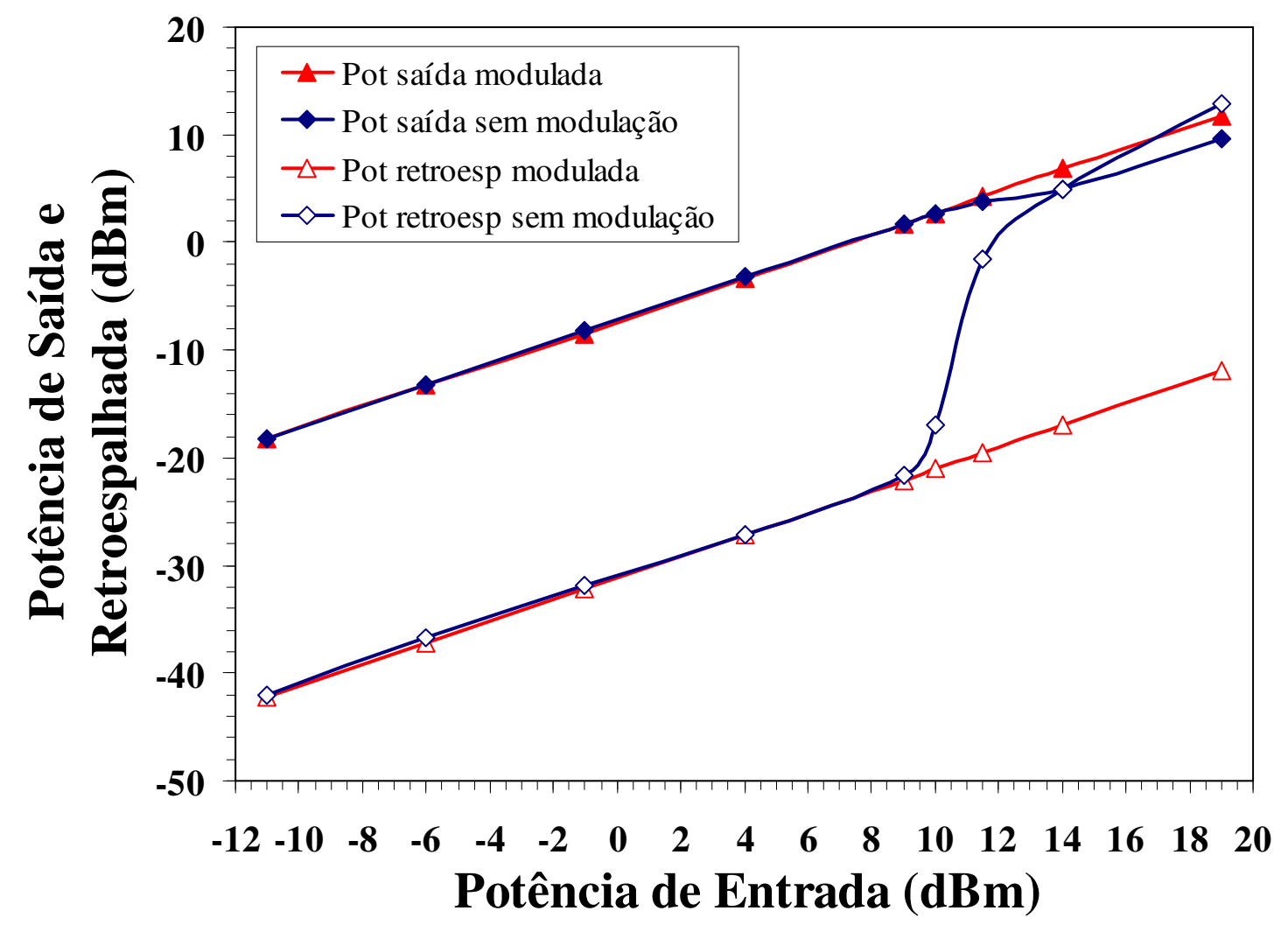

Fig. 3.2 - Resultados da avaliação de potência de saída e potência retroespalhada em função da potência de entrada, utilizando-se uma fibra DCF de -900 ps/nm em $1550 \mathrm{~nm}$.

Observando a curva do retroespalhamento na Figura 3.2 podemos verificar que o limiar do efeito Brillouin é $9 \mathrm{dBm}$ para sinal não modulado e maior que $20 \mathrm{dBm}$ para sinal 
modulado. A título de comparação, o valor deste limiar para fibras convencionais, apresentado em [79], é de $13 \mathrm{dBm}$. Podemos observar também, na porção linear da curva de retroespalhamento (potências inferiores a $9 \mathrm{dBm}$ ), que o nível de potência retroespalhamento Rayleigh é 30,7 dB inferior a potência de entrada na DCF. Este é o valor do coeficiente de retroespalhamento Rayleigh $\left(\mathrm{R}_{\mathrm{bs}}\right)$ desta fibra DCF, que é definido pelo quociente entre a potência retroespalhada e a potência incidente na fibra. Também, para efeito de comparação, o valor deste coeficiente para fibras convencionais, apresentado em [75] é de $31 \mathrm{~dB}$. O retroespalhamento Rayleigh, uma vez inserido numa cavidade de ganho, aumentará de intensidade, reduzindo a relação sinal/ruído do sinal transmitido. O mesmo ocorrerá em relação ao retroespalhamento Brilloin, desde que o limiar de aparecimento do mesmo seja atingido. Porém, a degradação da relação sinal/ruído devido ao efeito Brillouin é muito mais severa [79]. Posteriormente, ainda neste capítulo, detalharemos a influência destes valores no desempenho sistêmico de DP-EDFAs contendo DCFs.

Iremos agora analisar as topologias propostas para DP-EDFAs usando fibras DCF. A primeira topologia de DP-EDFA a ser analisada é composta por combinador de polarização (PBS), multiplexador de bombeio, fibra dopada e rotacionador de polarização de Faraday (FRM), conforme mostra a Figura 3.3(a). O princípio de funcionamento deste circuito é a ação conjugada do combinador de polarização com o rotacionador de Faraday. O sinal de entrada deve ter sua polarização alinhada com a fibra de entrada, a qual emprega uma fibra de polarização mantida, para que o mesmo não seja fortemente atenuado pelo combinador de polarização. Uma vez percorrida a fibra dopada e a fibra DCF o sinal tem a fase da polarização rotacionada em 90 graus após a passagem pelo espelho do rotacionador de Faraday. Esta rotação não é experimentada pelo retroespalhamento Rayleigh que retroespalha ao longo da fibra DCF e retorna para a saída passando pela fibra dopada. Semelhante ao comportamento da entrada, na saída do combinador de polarização, o sinal de retorno deve ter 
sua polarização alinhada com o mesmo, porém agora com 90 graus de defasagem em relação a polarização da entrada. Como somente o sinal sofre esta rotação no FRM, somente ele retornará a saída do amplificador. O retroespalhamento Rayleigh portanto, é removido pelo combinador de polarização.

A eficiência deste processo de remoção está vinculada não somente ao valor de isolação de polarização do combinador, mas também ao estado de polarização das fibras instaladas que, em enlaces reais se alteram com o tempo [63-70], tornando esta configuração muito difícil de ser implementada na prática. Deve-se notar também que um retroespalhamento Rayleigh de segunda ordem é também gerado dentro da DCF nesta configuração. Este retroespalhamento Rayleigh de segunda ordem é gerado após a passagem do sinal pelo FRM, quando o mesmo volta para a fibra DCF. O retroespalhamento de segunda ordem após atingir e ser refletido pelo FRM, se direciona a saída e tem sua potência somada à potência do primeiro retroespalhamento. No entanto sua intensidade é inferior a do primeiro, devido às perdas sofridas pela primeira passagem do sinal pela fibra DCF. O retroespalhamento de segunda ordem deve ser somado ao valor do retroespalhamento Rayleigh $\left(\mathrm{R}_{\mathrm{bs}}\right)$ medido e mostrado na Figura 3.2. A Figura 3.3(a) indica o sentido de fluxo do sinal e dos retroespalhamentos Rayleigh de primeira e segunda ordem neste circuito de DPEDFA.

Para implementar um DP-EDFA com DCF embutida sem requerer sistemas complexos de controle de polarização, com vistas à supressão de espalhamento Rayleigh, propomos o arranjo mostrado na Figura 3.3(b). Especificamente, o circulador \#1 é usado na entrada do amplificador para acoplar luz na entrada e saída do mesmo. No circuito de amplificação um esquema de bombeio do tipo copropagante é utilizado. O circulador \#2 é então colocado após a fibra dopada com érbio, para conectar a DCF de tal forma que o sinal passa apenas uma vez por esta fibra. Como conseqüência, o sinal retroespalhado é removido 
do circuito de amplificação, uma vez que o circulador bloqueia o retorno deste sinal. Pelo mesmo motivo, os circuladores contribuem também para diminuir o ruído de interferência causado por múltiplas reflexões no circuito do amplificador [80]. A Figura 3.3(b) indica também o sentido de fluxo do sinal e do retroespalhamento Rayleigh neste DP-EDFA.

Para avaliar o desempenho das duas configurações mostradas nas Figuras 3.3(a) e (b) em função da polarização do sinal óptico de entrada, o arranjo da Figura 3.4(a) foi usado (foto da montagem na Figura 3.4(b)). Um laser DFB de 1556 nm é modulado diretamente por uma sequiência binária pseudo-aleatória de $2^{23}-1$ bits fornecida por um gerador de padrão em 2.5 Gb/s. O sinal do laser atravessa então um controlador de polarização antes de atingir o amplificador de dupla passagem sob teste. Neste controlador, a polarização de entrada é alterada em uma faixa de 180 graus para dois níveis de potência de entrada: $-10 \mathrm{dBm}$ e -20 dBm. Ambos os amplificadores utilizaram a configuração de bombeio copropagante para uma potência de bombeio de $70 \mathrm{~mW}$ em $1480 \mathrm{~nm}$. Uma amostra do sinal amplificado é monitorada por um analisador de espectro óptico e o restante atravessa 50 ou $100 \mathrm{~km}$ de fibra convencional antes de ser detectado por um pré-amplificador, seguido de um receptor óptico usando fotodetector Pin. Após o amplificador, é usado um filtro óptico de 0,5 nm de largura espectral e um atenuador óptico, com o intuito de prevenir a saturação do receptor. A fibra DCF tem um coeficiente de compensação de -900 ps/nm e 6 dB de perda de inserção em 1550 $\mathrm{nm}$, capaz de compensar a dispersão introduzida pelos $50 \mathrm{~km}$ de fibra convencional em passagem única ou $100 \mathrm{~km}$ de fibra convencional em dupla passagem. Foram também feitas medições adicionais de dependência de polarização nos mesmos amplificadores, porém, desta vez, sem a DCF embutida. Neste caso, esta fibra foi substituída por um atenuador de $6 \mathrm{~dB}$, correspondente à atenuação introduzida pela DCF. O objetivo é evidenciar os efeitos causados especificamente pela DCF. Vale comentar que a escolha do comprimento de onda de 
operação do laser na banda $C$ deve-se unicamente ao fato de ser esta a faixa de operação espectral do controlador de polarização.

(a)

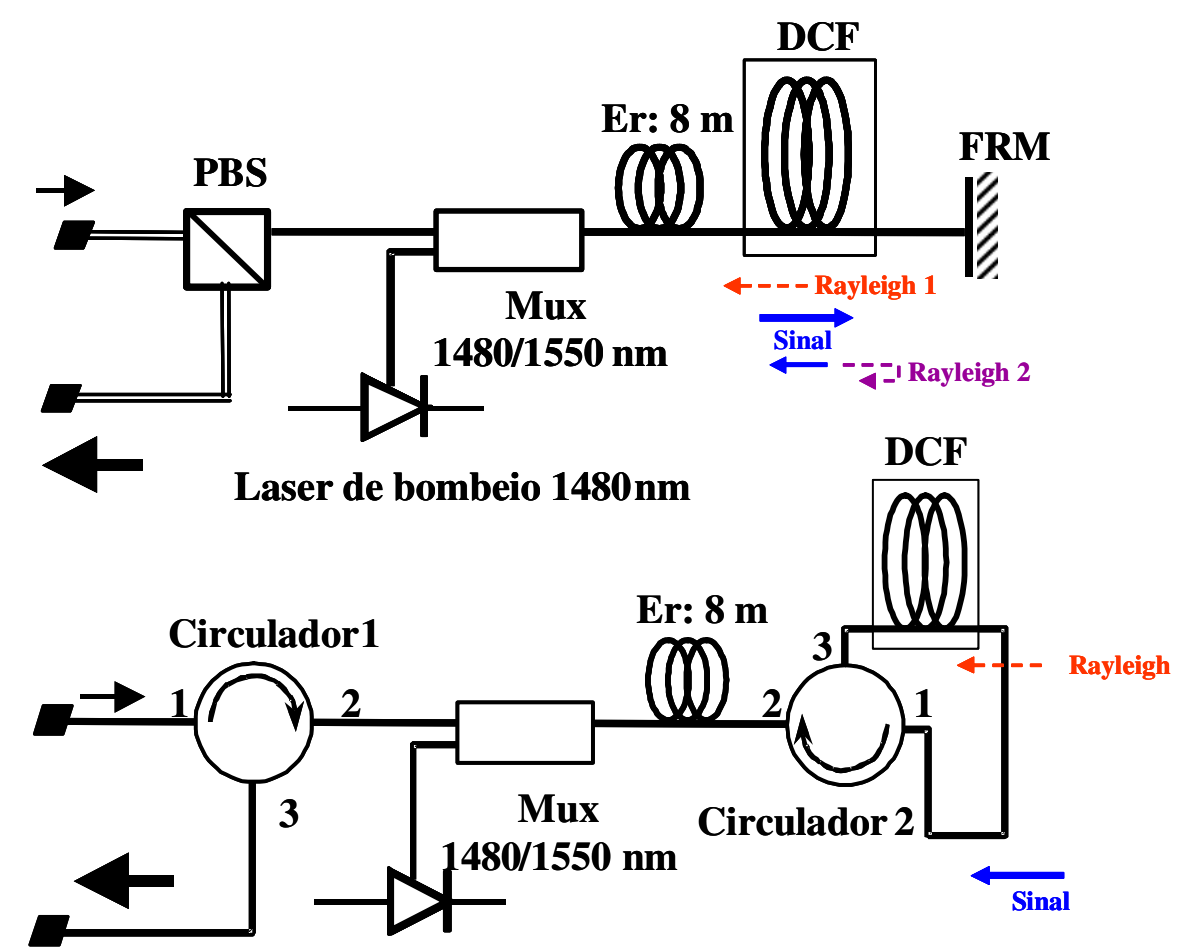

Laser de bombeio $1480 \mathrm{~nm}$

Fig. 3.3 - Configurações estudadas para DP-EDFAs com DCF embutida (a) usando acopladores combinadores de polarização (PBS) e espelhos de rotação de Faraday e (b) usando dois circuladores com perda inferior a $1 \mathrm{~dB}$.

Na Figura 3.5 são mostrados os resultados relativos ao ganho dos DP-EDFAs como função do ângulo de polarização relativo, para valores de potência de entrada de -10 e -20 dBm, com e sem a presença da DCF. Na Figura 3.6 mostramos os resultados relativos à figura de ruído. No caso do DP-EDFA baseado em dispositivos de polarização pode ser observado que tanto o ganho como a figura de ruído são extremamente sensíveis à polarização. Neste caso a variação de ganho foi superior a $18 \mathrm{~dB}$ e a $11 \mathrm{~dB}$, respectivamente, com e sem DCF, enquanto a variação da figura de ruído excedeu a 16 dB sobre 180 graus de variação da polarização de entrada. Por outro lado, para o EDFA baseado em circuladores observamos que a variação de ganho sobre 180 graus de variação da polarização de entrada é significativamente reduzida. A maior variação foi de 2,5 dB com DCF e 1,2 dB sem DCF. A 
máxima variação da figura de ruído foi de $2,5 \mathrm{~dB}$ com DCF e 1,3 dB sem DCF. Os DPEDFAs com componentes de polarização, mesmo na ausência da DCF, foram afetados pela variação da polarização, dado que este efeito se correlaciona com o alinhamento da polarização das fibras no combinador de polarização. Diversos trabalhos relatados anteriormente mostram o alto grau de variação da polarização do sinal que percorre a fibra. A título de exemplo, em [66] foram medidos aproximadamente 50 graus de variação da polarização em 50 horas de observação de cabos instalados.

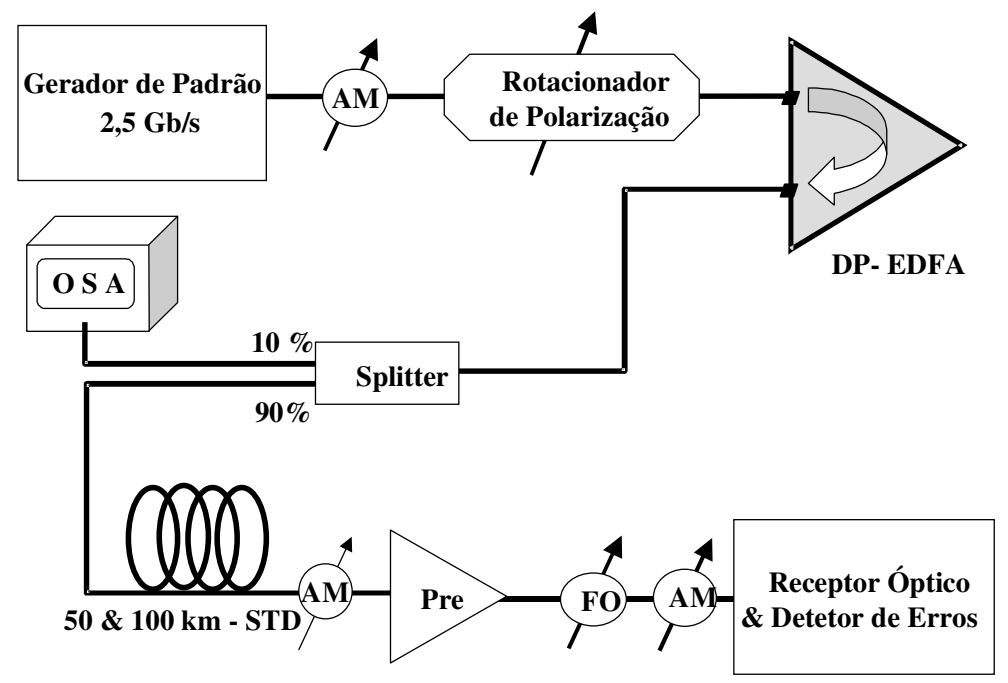

(a)

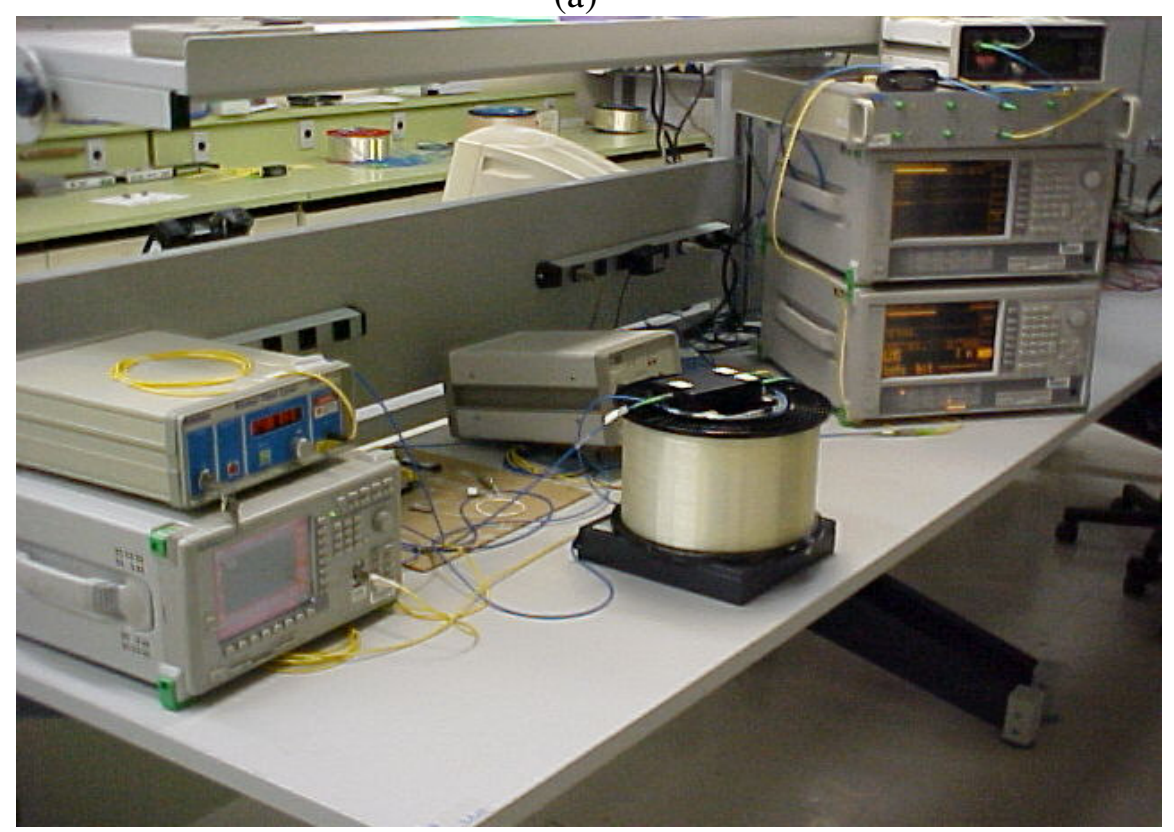

(b)

Fig. 3.4 - (a) Diagrama da montagem experimental para avaliação da dependência com a polarização do DPEDFAs, (AM: atenuador monitor, FO: filtro óptico, OSA: analisador de espectro óptico) e (b) foto da montagem. 


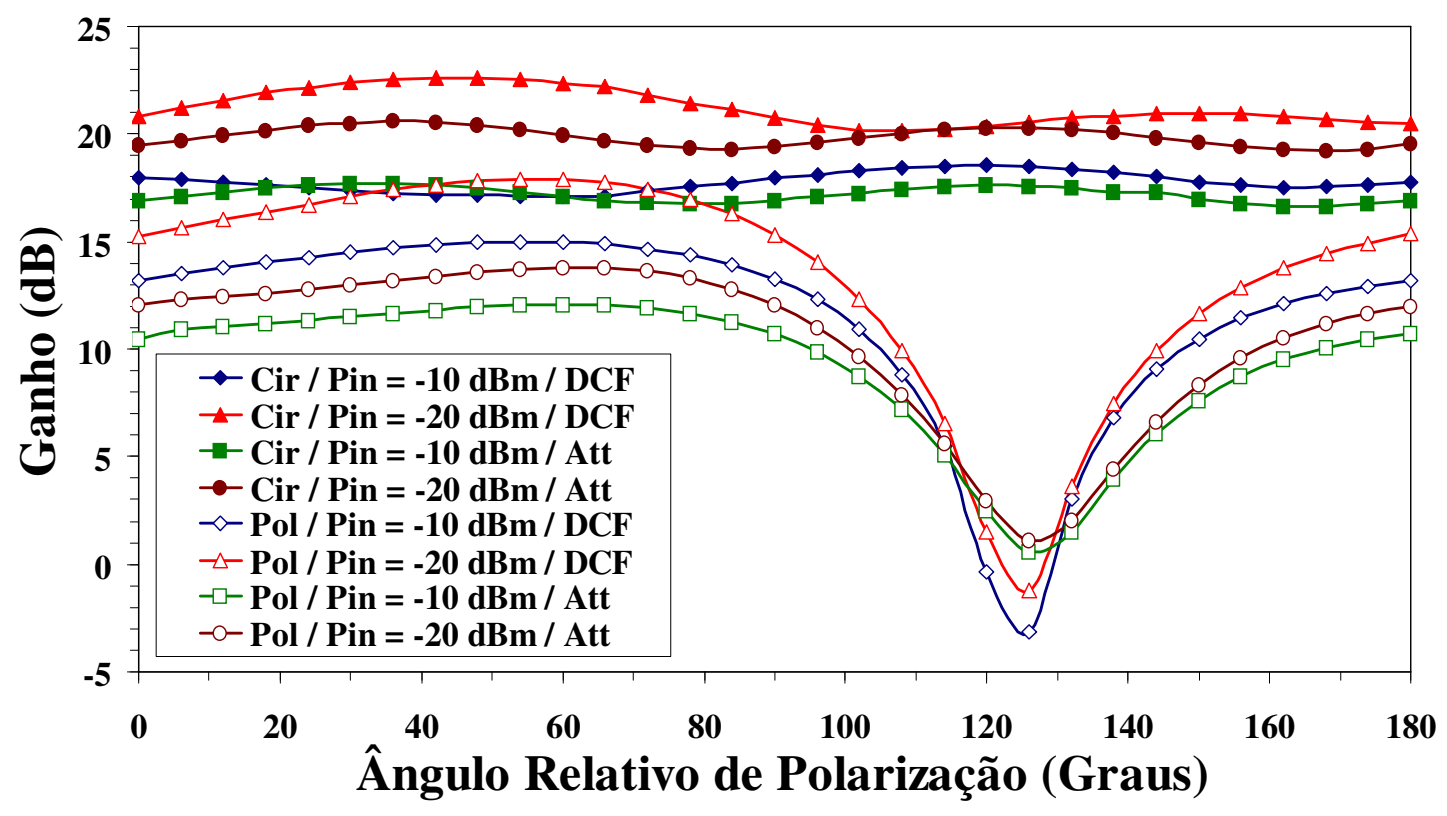

Fig. 3.5 - Dependência do ganho com o ângulo de polarização para DP-EDFAs empregando circuladores ou dispositivos de polarização.

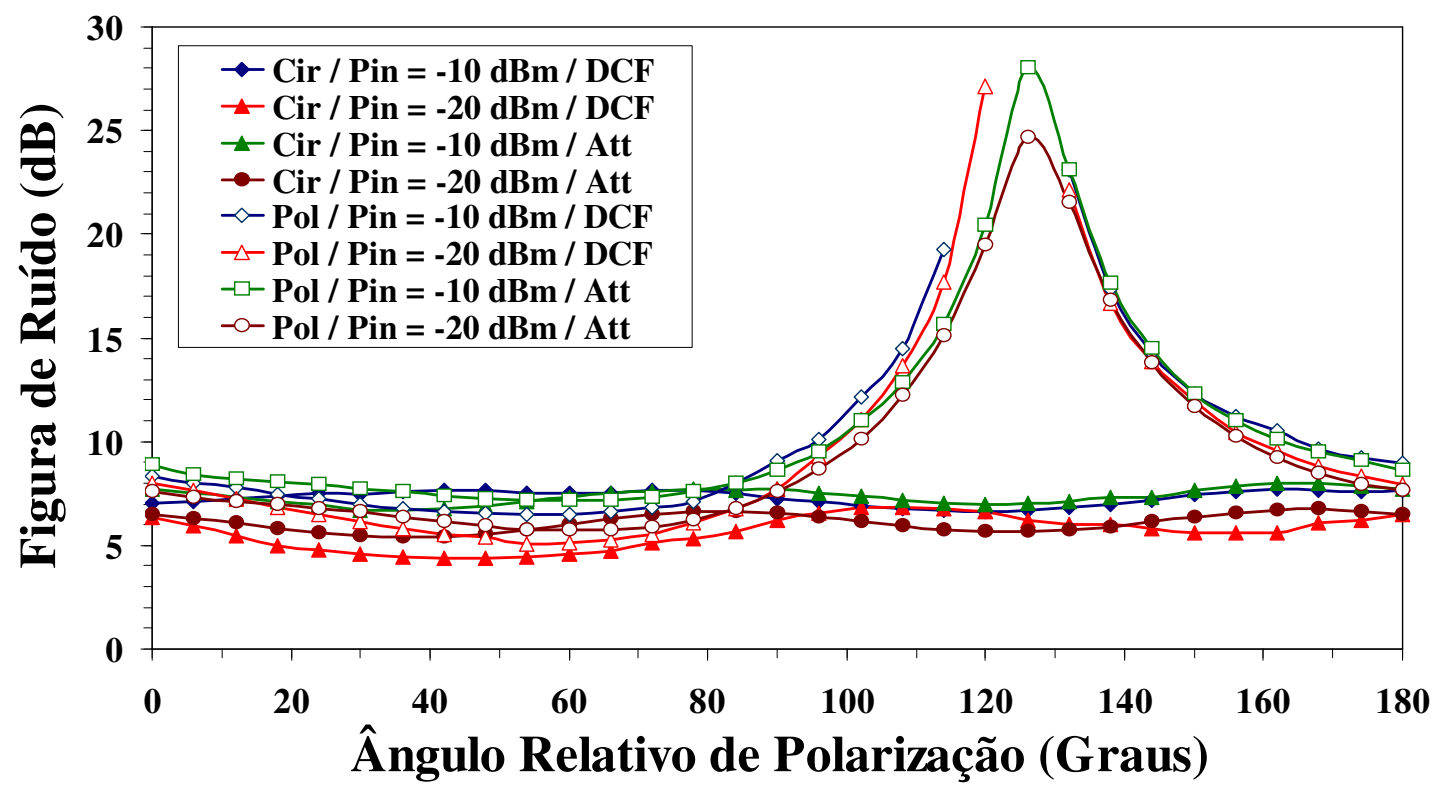

Fig. 3.6 - Dependência da figura de ruído com o ângulo de polarização para DP-EDFAs empregando circuladores ou dispositivos de polarização.

Em seguida conduzimos medidas de taxa de erro de bit (BER) como função da potência recebida no pré-amplificador do receptor. As seguintes caracterizações foram feitas, na seqüência: sistema sem fibra e sem DP-EDFAs (conhecido como BKB - back-to-back), sistema com $50 \mathrm{~km}$ e $100 \mathrm{~km}$ de fibra convencional, sistema com $50 \mathrm{~km}$ de fibra convencional 
e uma fibra DCF de $-900 \mathrm{ps} / \mathrm{nm}$ e sistema com $100 \mathrm{~km}$ de fibra convencional e uma fibra DCF de -1600 ps/nm. Os resultados desta caracterização são mostrados na Figura 3.7. Pode se observar claramente o efeito de compensação da dispersão cromática efetuada pelas DCFs, que reduzem significativamente a penalidade, comparativamente aos sistemas com fibras convencionais.

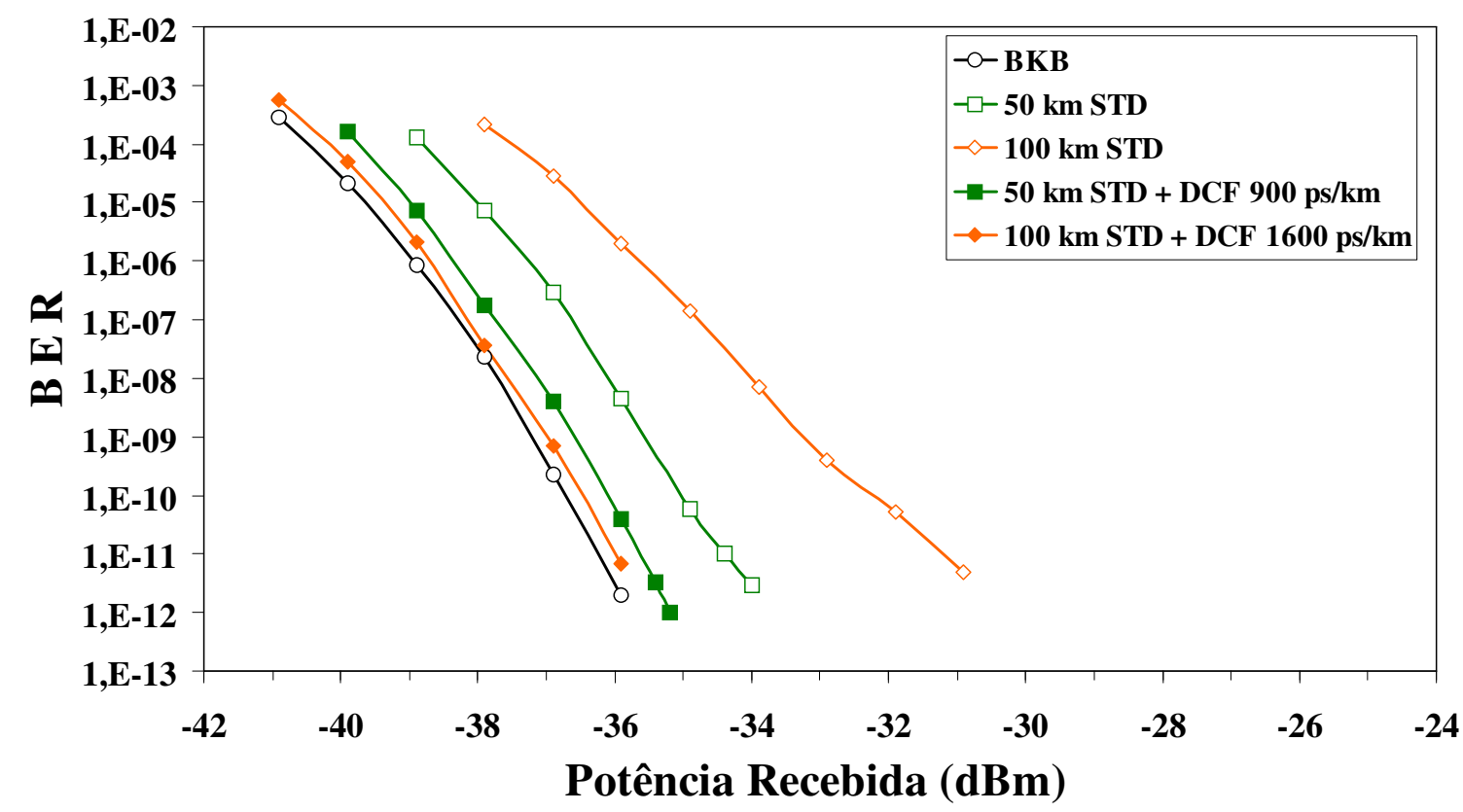

Fig. 3.7 - Desempenho sistêmico do sistema de transmissão e recepção sem DP-EDFAs.

Em seguida, introduzimos no sistema de transmissão os DP-EDFAs, conforme Figura 3.4. Para avaliar e ilustrar os efeitos do retroespalhamento Rayleigh, foi também testada, além das configurações ilustradas nas Figuras 3.3(a) e 3.3(b), uma terceira configuração, já mencionada no início deste capítulo, na qual é mantido o FRM mas o PBS é substituído por um circulador na entrada do amplificador. A caracterização destas configurações em termos de BER foi feita na melhor condição de ganho relativo à polarização, usando potência de entrada de $-20 \mathrm{dBm}$ e potência de bombeio de $70 \mathrm{~mW}$. Para entendimento dos efeitos da ASE e do retroespalhamento Rayleigh no receptor óptico, a caracterização sistêmica foi feita de duas formas diferentes. A primeira usando uma DCF de $-900 \mathrm{ps} / \mathrm{nm}$ seguida de um trecho de 
fibra de comprimento adequado para compensação total da dispersão e a segunda usando um atenuador de $6 \mathrm{~dB}$ no lugar da DCF.

Como pode ser observado na Figura 3.8, todos os DP-EDFAs testados com o atenuador de $6 \mathrm{~dB}$, que substitui a DCF, mostram penalidade da ordem de $3 \mathrm{~dB}$ para uma BER igual a $10^{-10}$, relativa à configuração sistêmica sem fibra e sem DP-EDFA ("back-toback"). Esta penalidade é devida a ASE dos DP-EDFAs, que, conforme já visto anteriormente, apresentam figura de ruído superior aos EDFAs convencionais. Quando a DCF é introduzida não ocorre variação do desempenho em taxa de erro para o DP-EDFA com dois circuladores, indicando que o retroespalhamento foi adequadamente suprimido. Entretanto, o DP-EDFA que faz uso de PBS e FRM apresenta uma penalidade da ordem de 6 dB relativa à configuração "back-to-back”. Esta penalidade é atribuída à isolação não ideal do PBS e ao retroespalhamento Rayleigh de segunda ordem criado pela segunda passagem do sinal na fibra DCF, que permite que uma fração de retroespalhamento esteja presente na saída do amplificador. Na terceira configuração, escolhida para melhor ilustrar os efeitos do retroespalhamento Rayleigh, como o circulador substitui o PBS, nenhum bloqueio é feito ao retroespalhamento Rayleigh, que, como pode ser visto, deteriora totalmente o desempenho sistêmico, com uma penalidade entre 10 a $16 \mathrm{~dB}$ para taxas de erros entre $10^{-11}$ e $10^{-12}$. Este desempenho é similar ao de amplificadores bidirecionais [75], conforme mostra a Figura 2.16.

Em resumo, mostramos que a configuração de DP-EDFA usando o conjunto de acoplador combinador de polarização e espelho de rotação de Faraday mostrou ser mais dependente em relação a polarização do sinal de entrada em termos de ganho e figura de ruído. Esta configuração não funcionará adequadamente em sistemas práticos a menos que seja adotado um esquema automático de controle de polarização. Além disso, esta configuração não apresentará níveis de BER adequados a uma boa operação do sistema quando a DCF estiver incorporada. A terceira opção usando, um circulador de entrada em um 
espelho de rotação de Faraday mostrou o pior desempenho de todas as configurações avaliadas, uma vez que nenhuma isolação entre sinal e restroespalhamento está presente. Em contraste, o EDFA de dupla passagem baseado em circuladores mostrou-se pouco dependente da polarização de entrada, dependência esta em sua maior parte causada pelo uso de circuladores não ideais.

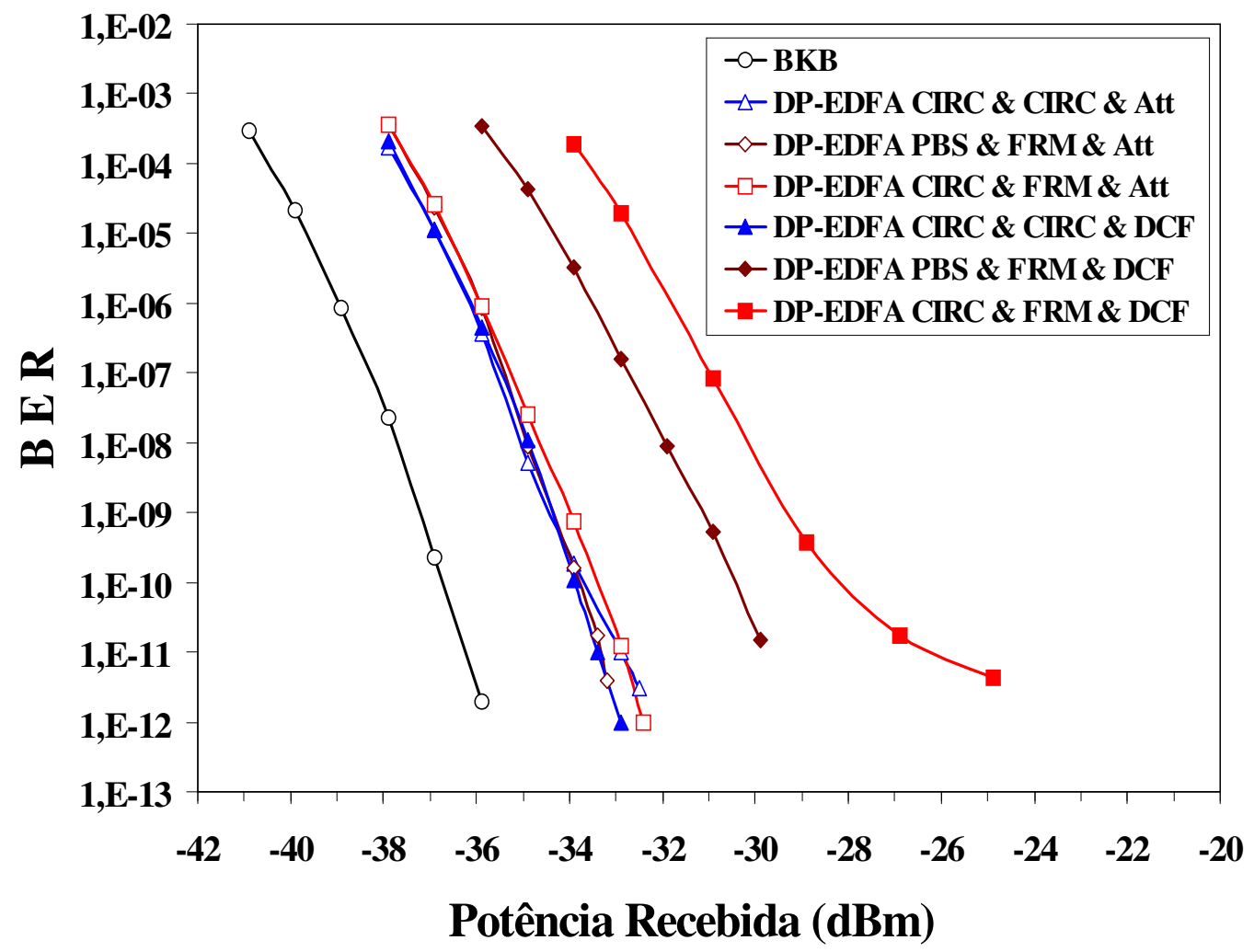

Fig. 3.8 - Desempenho sistêmico dos DP-EDFAs testados.

Vamos verificar agora a adequação dos resultados experimentais, obtidos para o amplificador com circulador e rotacionador de Faraday, utilizando a expressão (2), definida no capitulo 2, para penalidade em um receptor óptico devido ao efeito do retroespalhamento Rayleigh. A Figura 3.9 apresenta uma curva da penalidade em função do produto $\mathrm{R}_{\mathrm{bs}} \mathrm{xG}$ (coeficiente de retroespalhamento Rayleigh x Ganho) do amplificador de dupla passagem com circulador e rotacionador de Faraday.

Para obter este gráfico utilizamos os seguintes valores para os parâmetros da expressão (2): $\mathrm{Q}=7\left(\mathrm{BER}=10^{-12}\right) ; \mathrm{n}=1 ; \mathrm{R}_{\mathrm{bs}}=0,00107(-29,7 \mathrm{~dB}) ; \mathrm{h}=6,626176.10^{-34} ; \mathrm{v}=$ 
192,66 THz; $\mathrm{B}=2,5 \mathrm{~Gb} / \mathrm{s} ; \mathrm{P}_{\text {in }}=-20 \mathrm{dBm}$. Ao valor do coeficiente de retroespalhamento Rayleigh de primeira ordem da fibra DCF de -900 ps/nm obtido anteriormente $\left(R_{b s}=-30,7\right.$ $\mathrm{dB}$ ), foi adicionado o de segunda ordem, que tem valor $6 \mathrm{~dB}$ menor, devido a perda intrínseca da DCF. Podemos observar claramente que, mantendo o valor de $\mathrm{R}_{\mathrm{bs}}$ constante e variando o valor de ganho na faixa entre 15 a $20 \mathrm{~dB}$, existe um valor de ganho máximo a partir do qual a penalidade aumenta acentuadamente, degradando a qualidade do sinal. A Figura 3.9 aponta também a região de operação do amplificador de dupla passagem com circulador e rotacionador de Faraday utilizado no experimento mostrado na Figura 3.8. Pode ser observado que este amplificador opera em uma região de grande degradação do sinal. Para fugir desta região, uma alternativa seria operar com ganhos reduzidos, porém esta alternativa não é satisfatória para a maioria das aplicações em sistemas ópticos. Quanto ao retroespalhamento Brillouin, podemos afirmar que o seu limiar não é atingido devido ao uso de modulação direta, modulação esta que necessitaria de ganhos consideravelmente altos para que o limiar em questão fosse atingido.

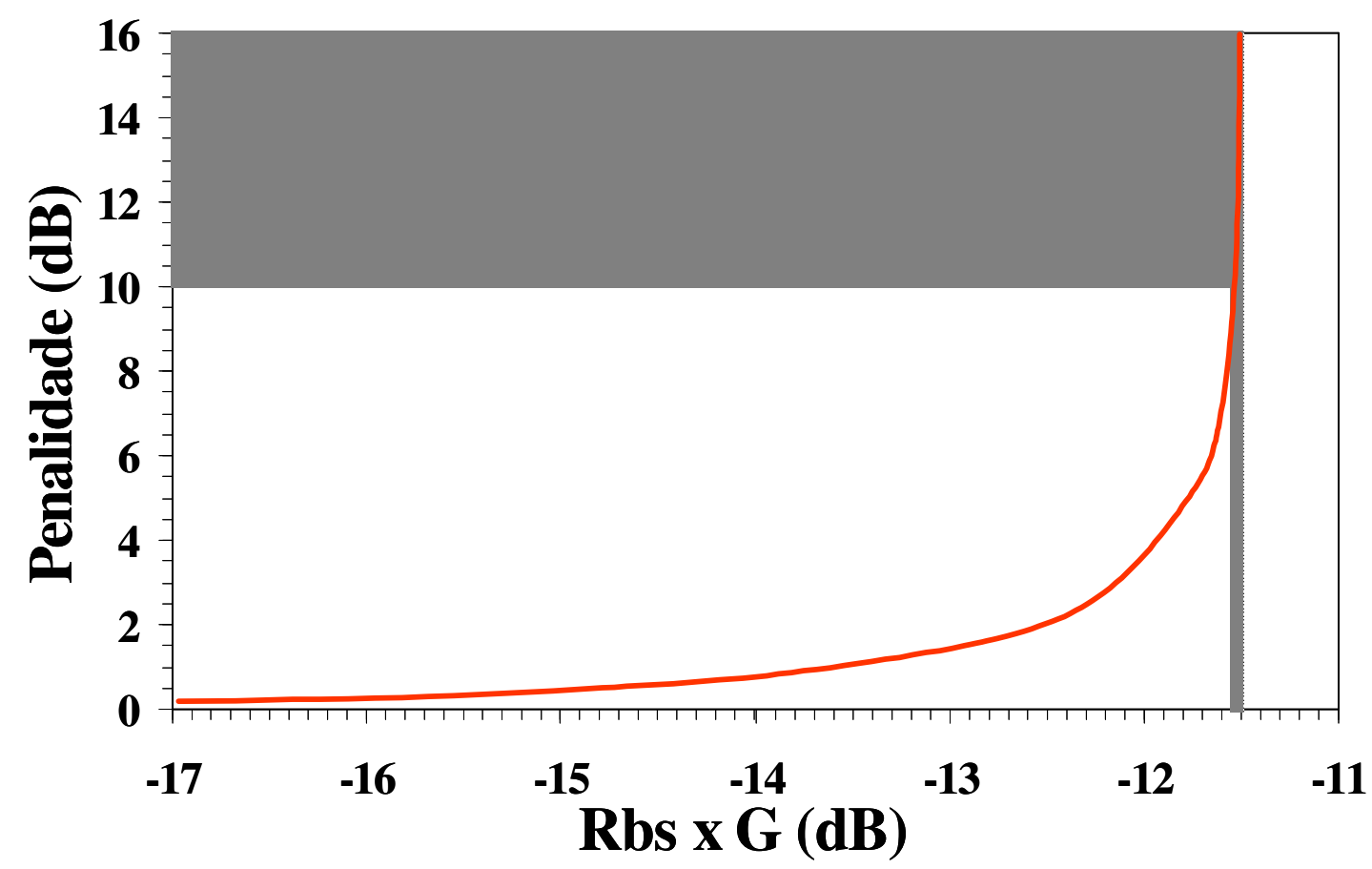

Fig. 3.9 - Curva da penalidade em função do produto $\mathrm{R}_{\mathrm{bs}} \mathrm{xG}$ (coeficiente de retroespalhamento Rayleigh $\mathrm{x}$ Ganho) do amplificador de dupla passagem com circulador e rotacionador de Faraday. 


\subsection{Operação monocanal do DP-EDFA com DCF na banda L}

Em seguida, realizamos uma caracterização sistêmica preliminar com o amplificador proposto. A Figura 3.10 mostra o arranjo experimental, além do circuito do DP-EDFA, utilizados para as medidas de desempenho em um sistema monocanal na banda L. A fibra dopada com érbio foi bombeada por um laser semicondutor de $1480 \mathrm{~nm}$ com uma potência de $70 \mathrm{~mW}$. A fibra utilizada, com 60 metros de comprimento, tem pico de absorção em $1530 \mathrm{~nm}$ entre 5 a $7 \mathrm{~dB}$ e é, na realidade, otimizada para operação na banda C. Extensos comprimentos de fibra são necessários para operação na banda L. A utilização da dupla passagem pela fibra dopada reduz este comprimento, como pode ser observado na comparação mostrada na Figura 3.10. Estas curvas representam simulações para o comprimento de fibra dopada versus ganho e figura de ruído, realizadas utilizando o software OASIX versão 3.1 (ver mais detalhes no Apêndice B). A estrutura do amplificador DP-EDFA é semelhante aquela já mostrada na Figura 3.3(b) da seção anterior. Foi utilizado um módulo de fibra DCF de 1490 ps/nm em 1490 nm, com 9 dB de perda de inserção. Pode-se observar claramente na Figura 3.11 que o DP-EDFA apresenta ganho superior ao SP-EDFA. Porém, como já esperado, a figura de ruído é também superior.

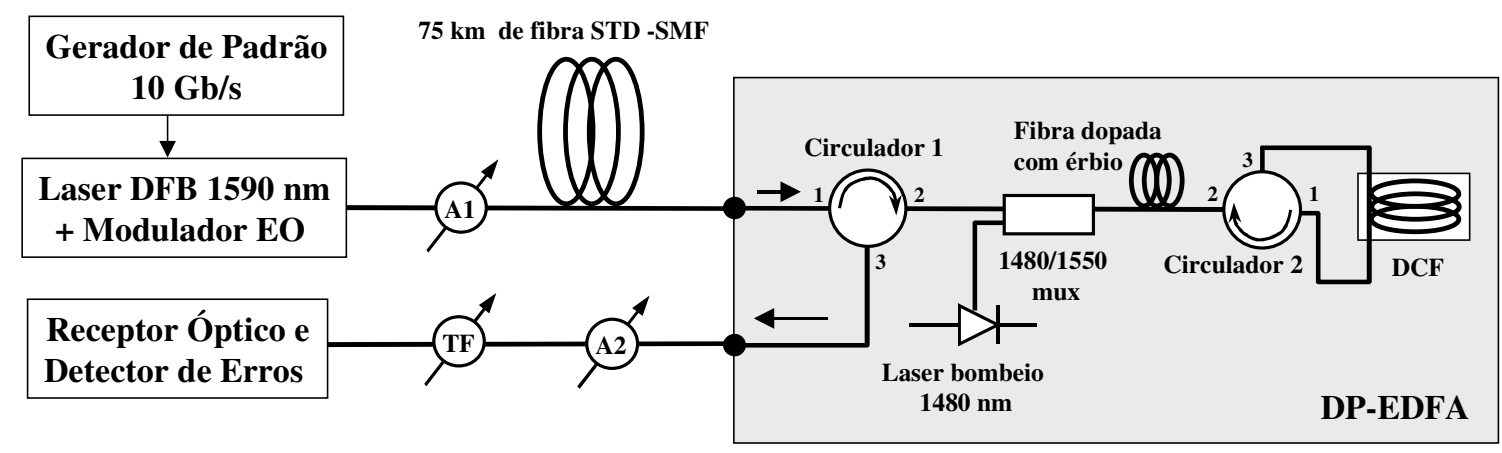

Fig. 3.10 - Circuito do DP-EDFA avaliado e o arranjo experimental sistêmico para $10 \mathrm{~Gb} / \mathrm{s}$.

Antes de realizar a caracterização sistêmica, o amplificador foi avaliado em termos de ganho e figura de ruído na faixa espectral de 1545 a $1615 \mathrm{~nm}$ usando um laser sintonizável e 
um analisador de espectro óptico. Tanto o DP-EDFA contendo o módulo de fibra DCF como o amplificador de passagem única (SP-EDFA) foram caracterizados. Para obtenção do SPEDFA a conexão da fibra DCF com a porta \# 1 do circulador \#2 é aberta, sendo medida neste extremo da DCF a potência de saída.

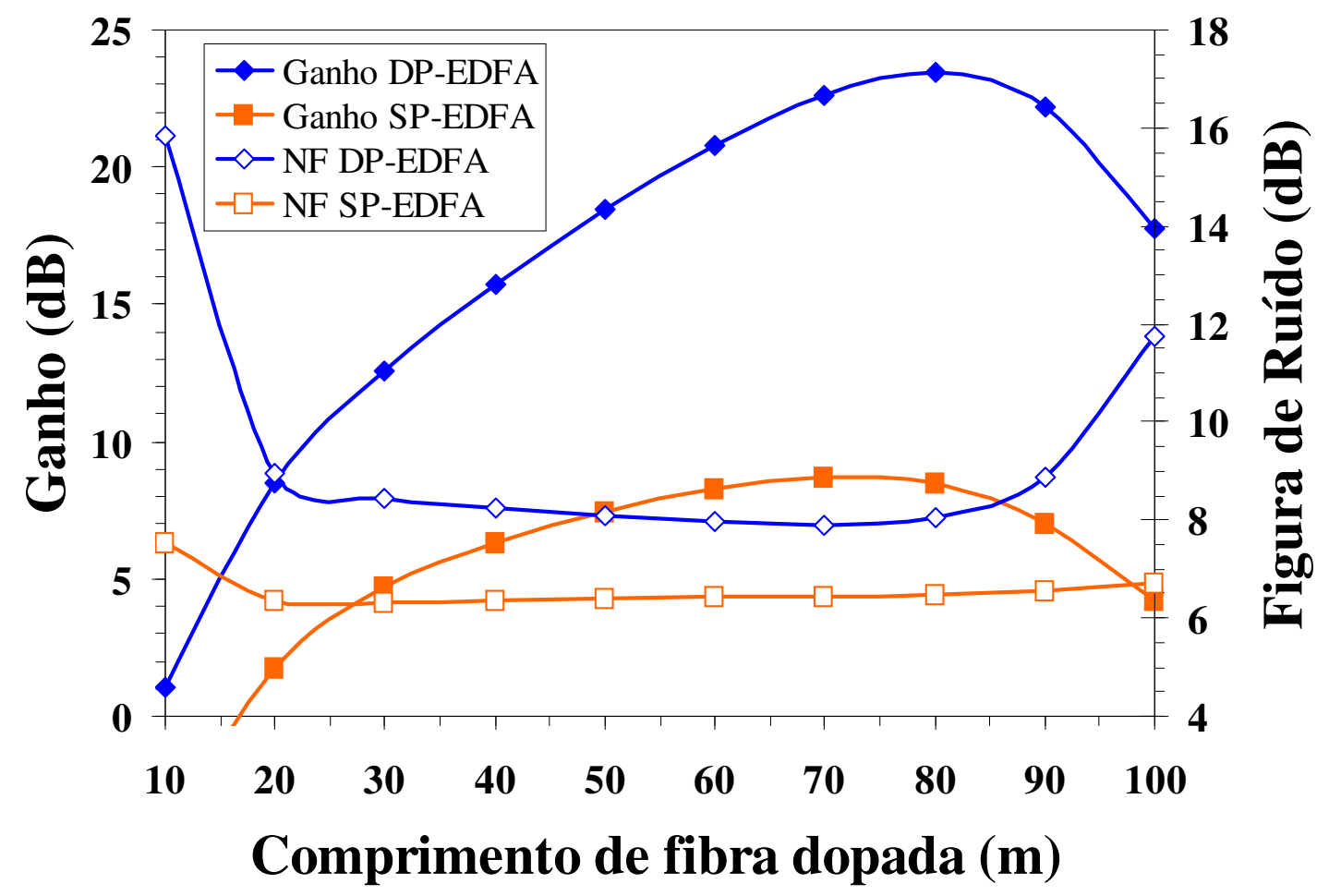

Fig.3.11 - Resultados da simulação de comprimento de fibra dopada versus ganho e figura de ruído do DPEDFAs e SP-EDFAs contendo uma fibra DCF de $9 \mathrm{~dB}$ de atenuação, sinal em $1590 \mathrm{~nm}$, para $70 \mathrm{~mW}$ de potência de bombeio em $1480 \mathrm{~nm}$.

Os amplificadores foram caracterizados em termos de ganho e figura de ruído em função do comprimento de onda, na faixa do espectro de 1545 a $1610 \mathrm{~nm}$, usando um laser sintonizável e um analisador de espectro, nas potências de entrada de -30, -20 e -10 dBm. Os resultados são mostrados nas Figuras 3.12(a) para DP-EDFA e na Figura 3.12(b) para SPEDFA. Podemos observar que, apesar da alta atenuação causada pela DCF, o ganho do DPEDFA é alto, enquanto que, para o SP-EDFA, que não compensa perda de inserção da DCF, o ganho é baixo. Em $1590 \mathrm{~nm}$ o valor do ganho para o DP-EDFA é de $22 \mathrm{~dB}$ para $-30 \mathrm{dBm}$ e $-20 \mathrm{~dB}$ de potência de entrada e $20 \mathrm{~dB}$ para $-10 \mathrm{dBm}$ de potência de entrada. A maior figura 
de ruído observada na configuração DP-EDFA é associada à natureza do processo de amplificação de dupla passagem, já descrita no Capítulo 2. Os valores de ganho do SP-EDFA estão em torno de $8,9 \mathrm{~dB}$ para -30 e $-20 \mathrm{dBm}$ de potência de entrada e 7,8 dB para $-10 \mathrm{dBm}$ de potência de entrada. A figura de ruído está entre 6,5 e 7,5 dB (para -30, -20 e -10 dBm de potência de entrada). Os valores de ganho em $1590 \mathrm{~nm}$ para $-20 \mathrm{dBm}$ estão muito próximos do valores obtidos na simulação mostrada na Figura 3.11 para 60 metros de fibra dopada com érbio.
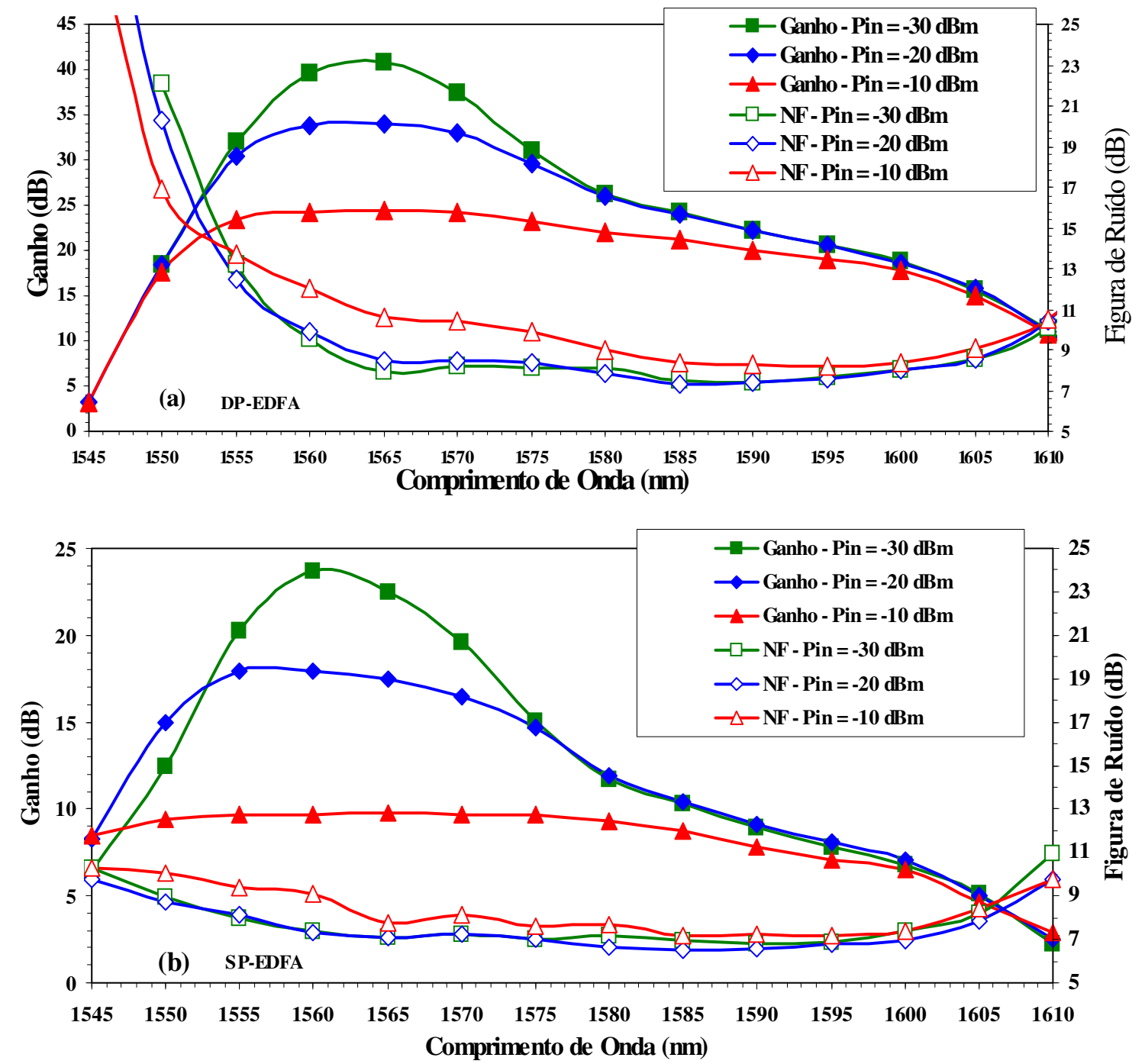

Fig. 3.12 - Ganho e figura de ruído para (a) DP-EDFA e (b) para SP-EDFA.

Os amplificadores foram configurados como amplificador de linha ou pré amplificador usando o arranjo experimental mostrado na Figura 3.10. A determinação da 
função do amplificador como amplificador de linha ou pré amplificador é feita através do ajuste da potência de entrada no receptor óptico, atuando-se no atenuador óptico $A_{1}$ mostrado na Figura 3.10. Um filtro óptico foi utilizado na recepção para filtragem da potência remanescente de ASE do amplificador. O sinal óptico foi modulado externamente (modulador de $\mathrm{LiNbO}_{3}$ ) em $10 \mathrm{Gbit} / \mathrm{s}$ por uma seqüência pseudo-aleatória de $2^{23}-1$. O comprimento de fibra convencional (STD-SMF) do enlace foi de $75 \mathrm{~km}$ com um coeficiente de dispersão cromática de 20 ps/nm.km em 1590 nm. O uso do módulo DCF de -1490ps/nm permite completo cancelamento do efeito da dispersão cromática da fibra de $75 \mathrm{~km}$ do enlace. A Figura 3.13(a) mostra a potência recebida na recepção versus taxa de erro de bit (BER), para avaliação do DP-EDFA. Podemos observar que a penalidade associada à dispersão cromática é de 4,3 dB para uma BER igual a $10^{-12}$ com o uso de $75 \mathrm{~km}$ de fibras ópticas convencionais sem amplificação. Para a configuração de amplificador de linha, as penalidades foram reduzidas para $1,4 \mathrm{~dB}$ e 2,5 respectivamente para as potências de entrada de -10 e $-20 \mathrm{dBm}$. A penalidade não foi completamente eliminada devido a presença da ASE no sinal de saída do amplificador, causando esta penalidade residual. O desempenho do pré-amplificador mostra uma melhoria na sensibilidade de $11 \mathrm{~dB}$. Nenhuma evidência de patamar de erros (floor) é observada, mostrando que o retroespalhamento Rayleigh foi adequadamente suprimido pela configuração de DP-EDFA que desenvolvemos.

Foi também avaliado o desempenho sistêmico da configuração SP-EDFA de forma análoga a já descrita para o DP-EDFA. Os resultados são mostrados na Figura 3.13(b). Podemos observar que, para a configuração de amplificador de linha usando potência de entrada de $-10 \mathrm{dBm}$, a penalidade foi reduzida por $2,1 \mathrm{~dB}$. O receptor óptico apresentou insuficiência de potência de entrada para $\mathrm{P}_{\text {in }}$ de $-20 \mathrm{dBm}$. A sensibilidade do pré-amplificador para o SP-EDFA foi de 5,9 dB. 

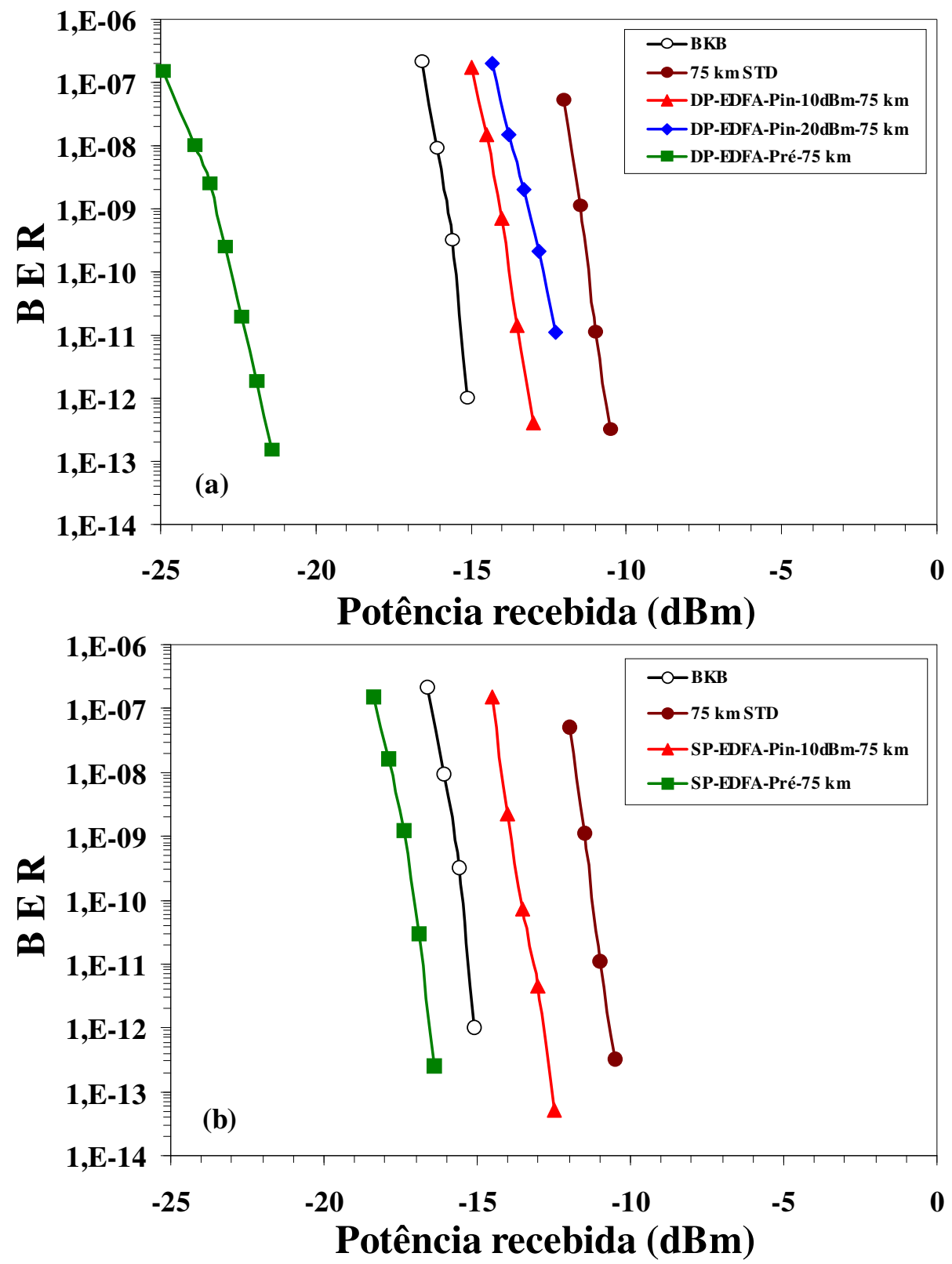

Fig.3.13 - Gráficos da potência recebida versus a taxa de erro de bit (BER) na recepção, para (a) DP-EDFA e (b) SP-EDFA.

Em resumo mostramos que o DP-EDFA incorporando uma fibra DCF apresentou bom desempenho para operação monocanal em sistemas ópticos em $10 \mathrm{~Gb} / \mathrm{s}$ na banda L. Em seguida, no Capítulo 4, detalharemos diversas aplicações do DP-EDFA por nós proposto, em sistemas multicanais e multibanda para operação nas bandas $\mathrm{S}, \mathrm{C}$ e L. 
CAPÍtULLO 4

CIRCUITOS DE DP-EDFAs COM DCF PARA APLICAÇÕES EM SISTEMAS MULTICANAIS E MULTIBANDAS 


\subsection{Introdução}

Na Seção 3.3, do capítulo anterior, descrevemos experimentos de avaliação sistêmica monocanal com o circuito de DP-EDFA com DCF embutida proposto nesta tese.

Neste capítulo estudaremos aplicações multicanal e multibanda para o amplificador proposto. Várias das aplicações demonstradas são originais não somente no que se refere ao amplificador de dupla-passagem com DCF, mas aos EDFAs de uma maneira geral, devido a ampla banda espectral coberta por alguns dos circuitos propostos.

Na seção 4.2 descreveremos a caracterização e os resultados de ganho e figura de ruído dos DP-EDFAs em sistemas WDM operando entre 1570 a 1610 nm. Resultados sistêmicos de taxa de erro de bit (BER) em 10Gb/s serão apresentados. Na Seção 4.3 descreveremos a caracterização e os resultados de ganho e figura de ruído dos DP-EDFAs e dos SP-EDFAs com DCF que operam simultaneamente nas bandas C e L (1530 a $1610 \mathrm{~nm})$, alargando desta forma a região espectral de funcionamento destes amplificadores. Nestes experimentos iremos comparar também o desempenho de configurações série e paralelo para amplificação em banda dupla. Na Seção 4.4 será apresentada a caracterização e os resultados de ganho e figura de ruído dos amplificadores de dupla passagem com DCF que funcionam simultaneamente nas bandas S, C e L (1450 a $1610 \mathrm{~nm})$, para aplicações em sistemas DWDM. Nestes experimentos utilizamos, para a banda S, um DP-TDFA, ou seja, um amplificador com fibra de fluoreto dopada com túlio. Na seção 4.5 descrevemos a caracterização e os resultados de ganho e figura de ruído dos DP-EDFAs associados aos DPTDFAs com DCF que também operem simultaneamente nas bandas S, C e L (1450 a 1610 nm), desta vez para aplicações em sistemas CWDM. Apresentaremos também um circuito de amplificador de dupla passagem composto unicamente por fibras dopadas com érbio para aplicações CWDM nas bandas S, C e L. Para a banda S é utilizada, pela primeira vez em aplicações de dupla passagem, uma nova e recente tecnologia para amplificação nesta banda, 
baseada em uma fibra "depressed-cladding" dopada com érbio. Os experimentos são complementados por uma caracterização sistêmica em 2,5 Gb/s com modulação direta, onde o DP-EDFA totalmente baseado em fibra dopada com érbio será testado em uma rede CWDM do tipo barramento. 


\subsection{Operação DWDM na banda $L$}

Para a caracterização do ganho e figura de ruído dos amplificadores DP-EDFA e SPEDFA sob operação DWDM, o laser sintonizável utilizado na caracterização monocanal da seção 3.3, foi substituído por um conjunto de 8 lasers operando na banda L, na faixa espectral entre 1587 e $1605 \mathrm{~nm}$.

Uma simulação computacional, apresentada nas Figuras 4.1(a) e 4.1(b), mostra o comportamento do ganho sob operação DWDM dos amplificadores SP-EDFA e DP-EDFA em função do comprimento da fibra dopada com érbio, para uma potência de $-20 \mathrm{dBm}$ por canal. O circuito óptico do SP-EDFA escolhido foi o da configuração de bombeio bidirecional (ver Figura 2.6) com laser de 980 nm na entrada e de 1480 nm na saída. Esta configuração é tradicionalmente escolhida em amplificadores com bombeio bidirecional, uma vez que o bombeio de $980 \mathrm{~nm}$ na entrada, proporciona melhor figura de ruído do que o bombeio de $1480 \mathrm{~nm}$, e na saída o bombeio de $1480 \mathrm{~nm}$ proporciona maior potência de saída do que o bombeio de $980 \mathrm{~nm}$. A potência de bombeio total foi de $300 \mathrm{~mW}$, dividida igualmente entre os dois lasers. A fibra DCF de $10 \mathrm{~dB}$ de perda de inserção é inserida entre dois estágios de fibra dopada, cujos comprimentos somados são indicados na Figura 4.1(a). Foi utilizado o mesmo modelo de fibra dopada do experimento monocanal. A configuração do DP-EDFA é a mesma mostrada na Figura 3.10, porém usando uma potência de bombeio em $1480 \mathrm{~nm}$ de 300 mW. Podemos observar que o DP-EDFA apresenta maior ganho para um comprimento de fibra de aproximadamente $100 \mathrm{~m}$, enquanto que para a configuração SP-EDFA o maior ganho ocorre para comprimentos de fibra dopada superiores a $170 \mathrm{~m}$. 

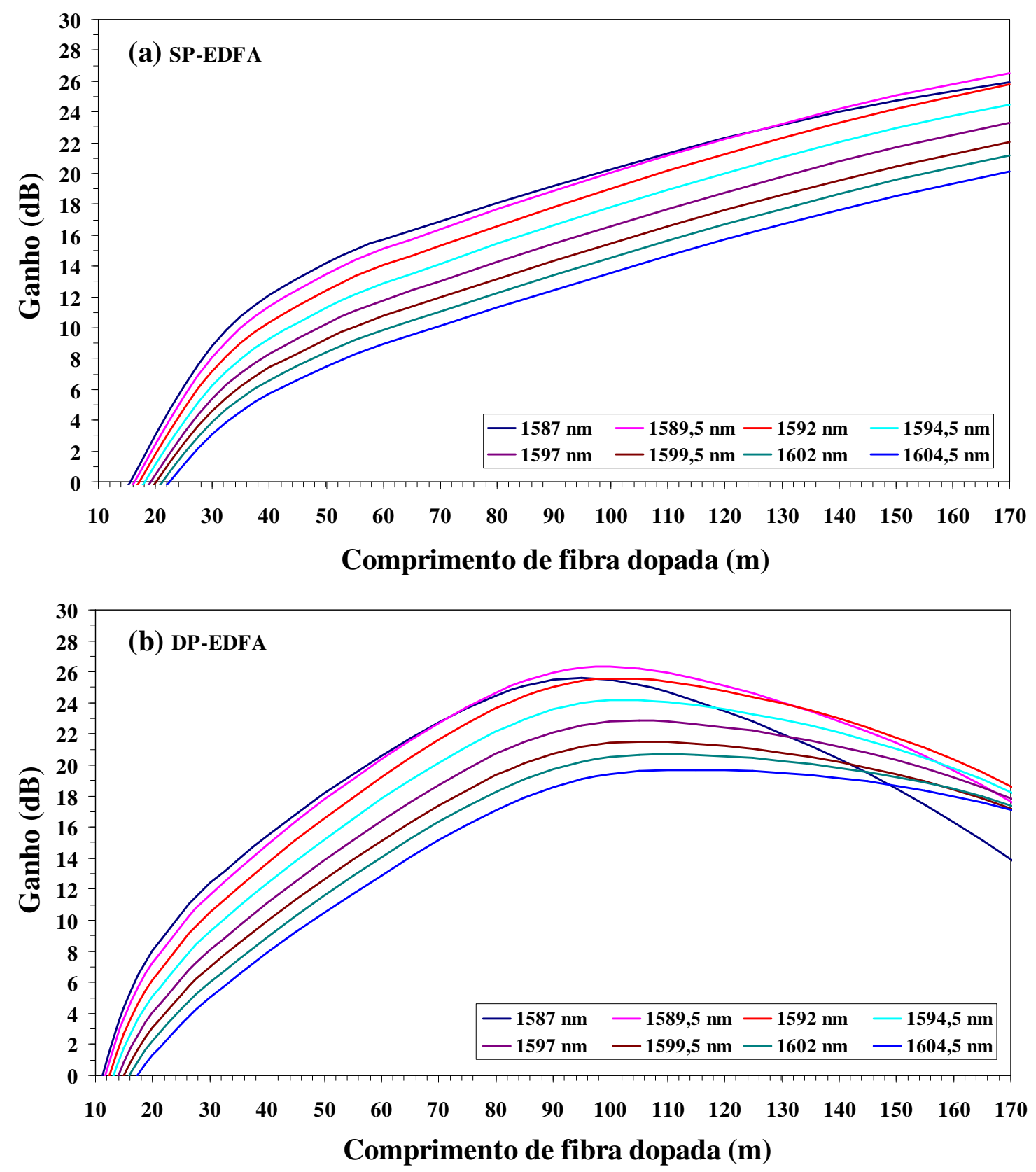

Fig. 4.1 - Resultados da simulação de ganho sob operação DWDM dos amplificadores (a) SP-EDFA e (b) DPEDFA.

Construímos um DP-EDFA com as mesmas características utilizadas na simulação computacional, com um comprimento de 100 metros de fibra dopada. A Figura 4.2 mostra o ganho e a figura de ruído do DP-EDFA para dois níveis de potência de entrada, -25 e -35 dBm. O DP-EDFA foi caracterizado usando duas diferentes DCFs, uma com compensação de $790 \mathrm{ps} / \mathrm{nm}$ e perda de $6 \mathrm{~dB}$ em $1590 \mathrm{~nm}$ e a outra de $-1490 \mathrm{ps} / \mathrm{nm}$ e perda de $10 \mathrm{~dB}$ em 1590 
nm. Podemos observar que, a despeito da alta atenuação da DCF, o ganho líquido obtido é alto. Especificamente, em 1587,34 nm, o valor do ganho é maior que $27 \mathrm{~dB}$ para $-25 \mathrm{dBm}$ de potência de entrada e maior que $29 \mathrm{~dB}$ para $-35 \mathrm{dBm}$ de potência de entrada. A figura de ruído é menor que 7,8 $\mathrm{dB}$ para $-25 \mathrm{dBm}$ de potência de entrada e menor que 7,2 $\mathrm{dB}$ para $-35 \mathrm{dBm}$ de potência de entrada em $1587,34 \mathrm{~nm}$.

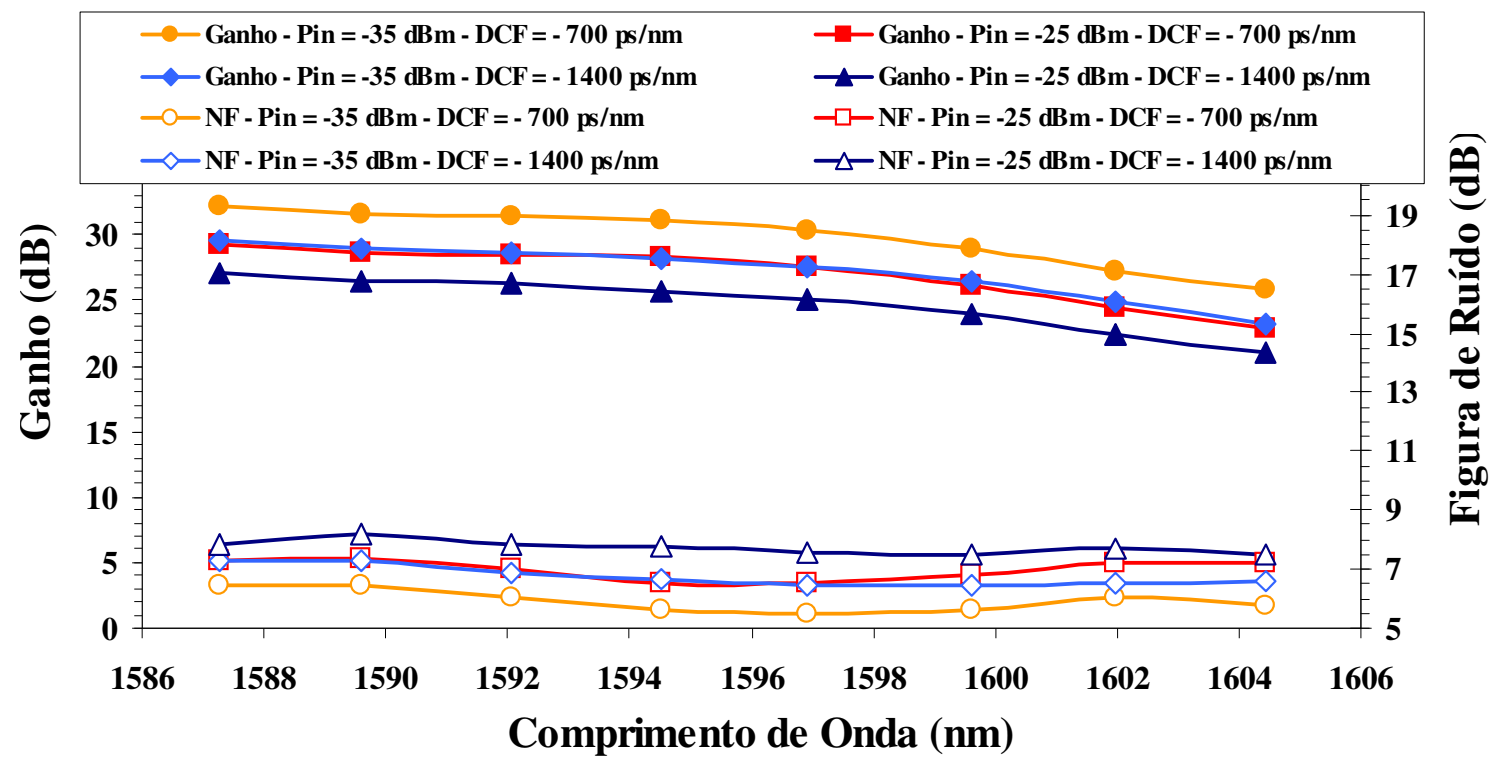

Fig. 4.2 - Ganho e figura de ruído do DP-EDFA para a banda L sob regime DWDM.

Em seguida, o DP-EDFA foi configurado para operação como pré-amplificador, de acordo com a Figura 3.10. O sinal óptico de entrada foi modulado externamente em $10 \mathrm{~Gb} / \mathrm{s}$ com uma seqüência binária pseudo-aleatória de $2^{23}-1$. Foram usados dois distintos comprimentos de enlace, usando fibra STD-SMF, respectivamente de 50 e $100 \mathrm{~km}$. O coeficiente de dispersão cromática desta fibras é de 19,1 ps/nm.km em $1590 \mathrm{~nm}$. Para demonstrar o efeito duplo e simultâneo da compensação da dispersão e amplificação óptica DWDM, utilizamos um DP-EDFA com uma fibra de $-790 \mathrm{ps} / \mathrm{nm}$ para $50 \mathrm{~km}$ de enlace e uma de $-1490 \mathrm{ps} / \mathrm{nm}$ para $100 \mathrm{~km}$ de enlace. 
A Figura 4.3 apresenta um gráfico de BER em função da potência óptica recebida para dois dos comprimentos de onda extremos da grade utilizada na banda L (\#1 em 1587,34 nm e \#8 em 1604,50 nm). Os resultados mostrados na Figura 4.3 indicam uma melhoria na sensibilidade para BER de $1 \times 10^{-12}$ entre 7 a $10 \mathrm{~dB}$, quando comparado com a condição "backto-back”. Para os outros canais não mostrados, o desempenho foi similar a estes dois canais. Nenhuma evidência de patamar de erros (floor) é observada, demonstrando que o retroespalhamento Rayleigh foi completamente eliminado.

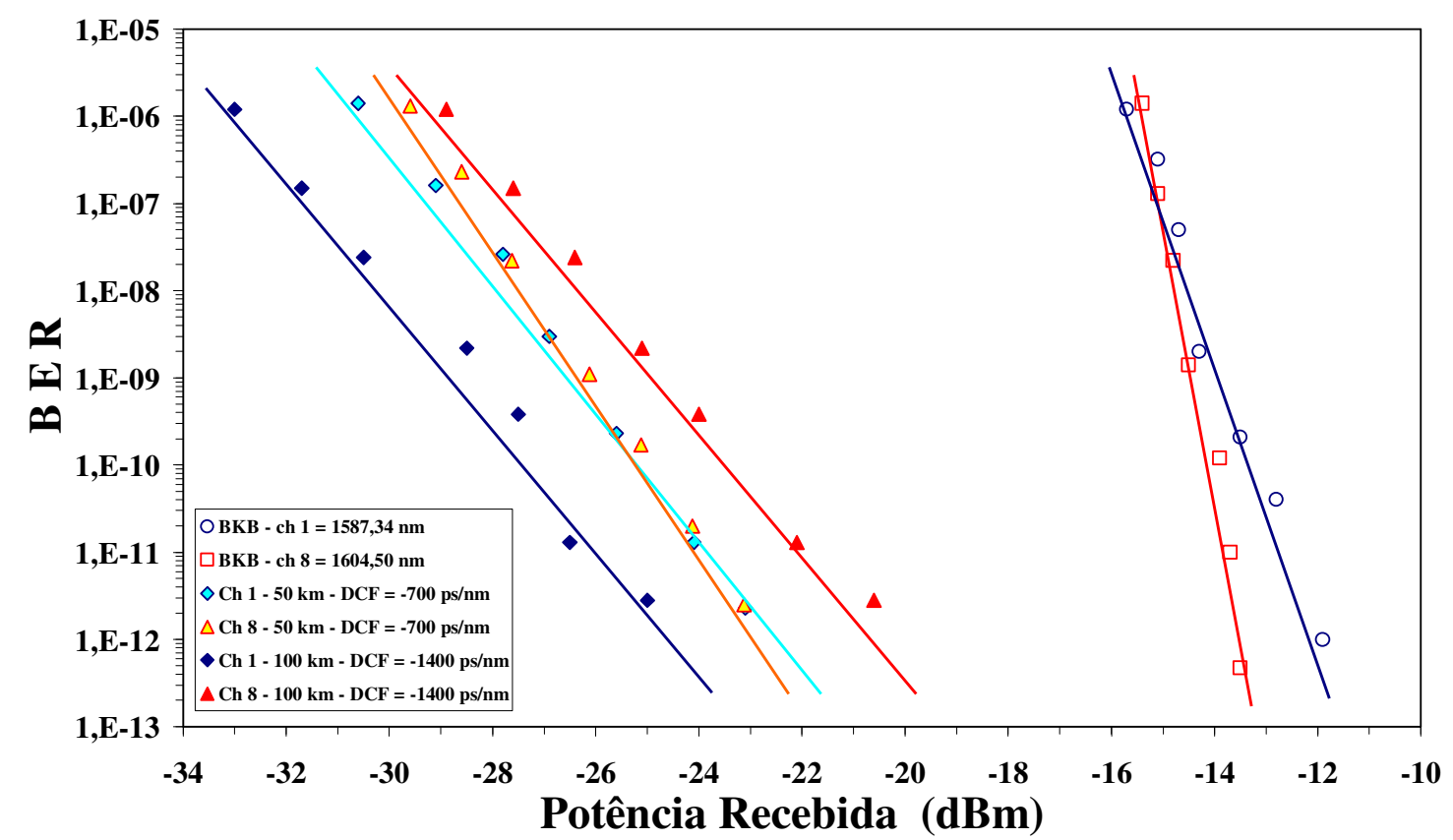

Fig. 4.3 - BER em função da potência óptica recebida no pré-amplificador DP-EDFA para os canais de 1587,34 nm e $1604,50 \mathrm{~nm}$ em $10 \mathrm{Gbit} / \mathrm{s}$.

Em resumo, mostra-se que o DP-EDFA incorporando uma fibra DCF apresentou bom desempenho para operação DWDM em $10 \mathrm{~Gb} / \mathrm{s}$ na banda L, melhorando a sensibilidade em mais que $7 \mathrm{~dB}$ e utilizando metade do número de dispositivos, incluindo menor comprimento de fibra, necessários para implementação de uma configuração de bombeio bidirecional que proporcionaria o mesmo ganho. 


\subsection{Operação nas Bandas C e L}

Devido à necessidade de comprimentos muito extensos de fibra dopada com érbio para amplificação óptica na região espectral da banda L, fibras de alta dopagem foram desenvolvidas para este propósito. As fibras de alta dopagem reduzem em uma ordem de grandeza o comprimento de fibra utilizada tanto para amplificadores na banda L como também para a banda C. Porém, não é possível a utilização de um único comprimento de fibra dopada que satisfaça os requisitos de ganho para as duas bandas. Para a implementação de amplificadores que atuem nas duas bandas é necessário o uso de circuitos de amplificação distintos, em paralelo ou em série. Descreveremos a seguir dois circuitos de DP-EDFAs contendo DCFs para operação simultânea nas bandas C e L.

Na Figura 4.4(a) mostramos o circuito de um DP-EDFA paralelo e na Figura 4.4(b) o circuito de um DP-EDFA série para operação nas bandas C e L. A idéia geral é implementar uma configuração de baixo custo usando lasers de bombeio de baixa potência e curtos comprimentos de fibra dopada com érbio. Como em configurações de DP-EDFAs já mostradas anteriormente, o circulador \# 1 é usado nas duas configurações para acoplar o sinal de entrada no amplificador e remover o sinal de saída já amplificado. O circulador \# 2 é usado em ambos os circuitos para permitir a conexão da fibra DCF de forma que o sinal passe apenas uma vez pela mesma, evitando o retorno de retroespalhamentos para o circuito de amplificação.

No circuito paralelo, dois multiplexadores de banda foram usados para separar os sinais da banda $\mathrm{C}$ e da banda $\mathrm{L}$, provendo dois caminhos ópticos distintos de amplificação. Tanto a fibra dopada da banda C como da banda L são bombeadas na configuração copropagante por lasers de $980 \mathrm{~nm}$. A configuração copropagante foi escolhida para proporcionar menor figura de ruído. A fibra de alta dopagem de érbio apresenta pico de 
absorção de 16 a $24 \mathrm{~dB} / \mathrm{m}$ em torno de $1530 \mathrm{~nm}$ e um filtro de alta isolação foi também utilizado no circuito da banda L para remover a maior parte da potência de ASE contrapropagante emitida na região da banda C pelo circuito da banda L. A não utilização deste filtro inviabiliza a operação na banda C. Na Figura 4.5 mostramos uma simulação feita no OASIX mostrando os altos níveis de ASE contrapropagante na saída do DP-EDFA sem a presença do filtro de ASE.

No circuito série o primeiro estágio de amplificação é comum às duas bandas. Apenas um laser de bombeio em $1480 \mathrm{~nm}$ é utilizado. Devido às características do multiplexador de bandas, o uso de bombeio em $1480 \mathrm{~nm}$ permite que parte do bombeio residual do primeiro estágio siga para um segundo estágio, destinado somente para a banda L, que é colocado em seguida ao primeiro estágio. Este multiplexador de bandas separa o sinal da banda $\mathrm{C}$ e da banda L e do bombeio residual em $1480 \mathrm{~nm}$. Em ambas as topologias um segundo multiplexador de bandas conecta os sinais no circulador \# 2. A configuração paralela tem a vantagem de propiciar amplificação independente das duas bandas, mas usa dois lasers de bombeio. A configuração série tem a vantagem de usar apenas um laser de bombeio, mas o processo de amplificação das bandas é dependente entre si.

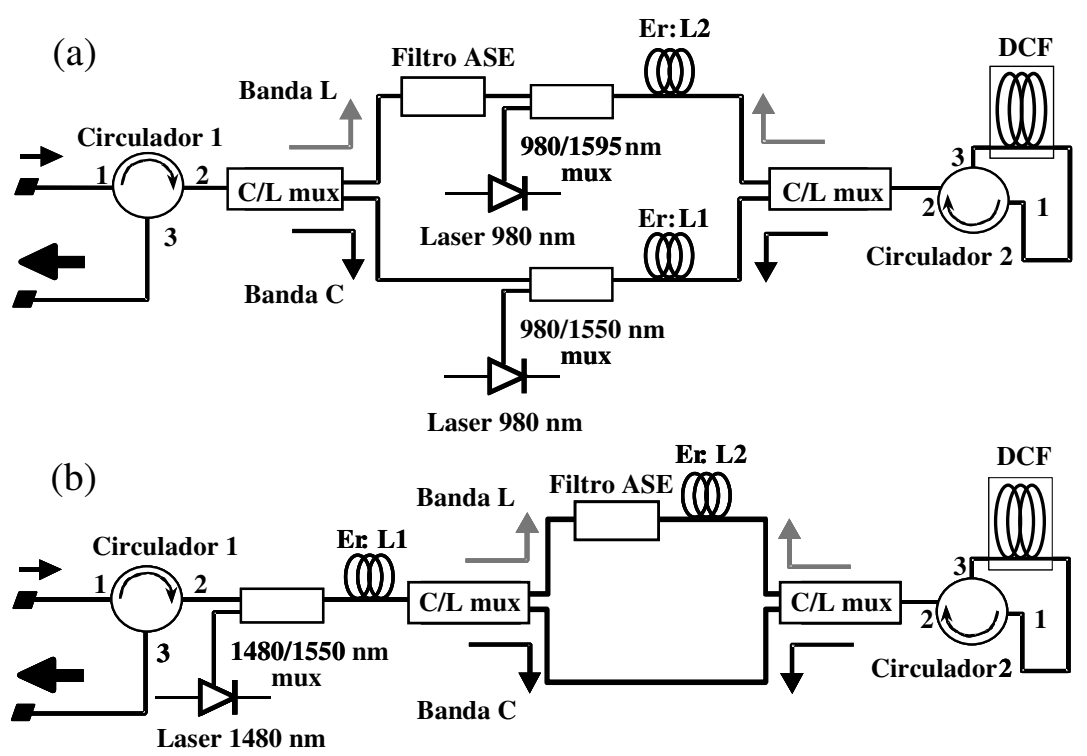

Fig. 4.4 - Circuitos do DP-EDFA para amplificação nas bandas C e L (a) circuito paralelo e (b) circuito série. 


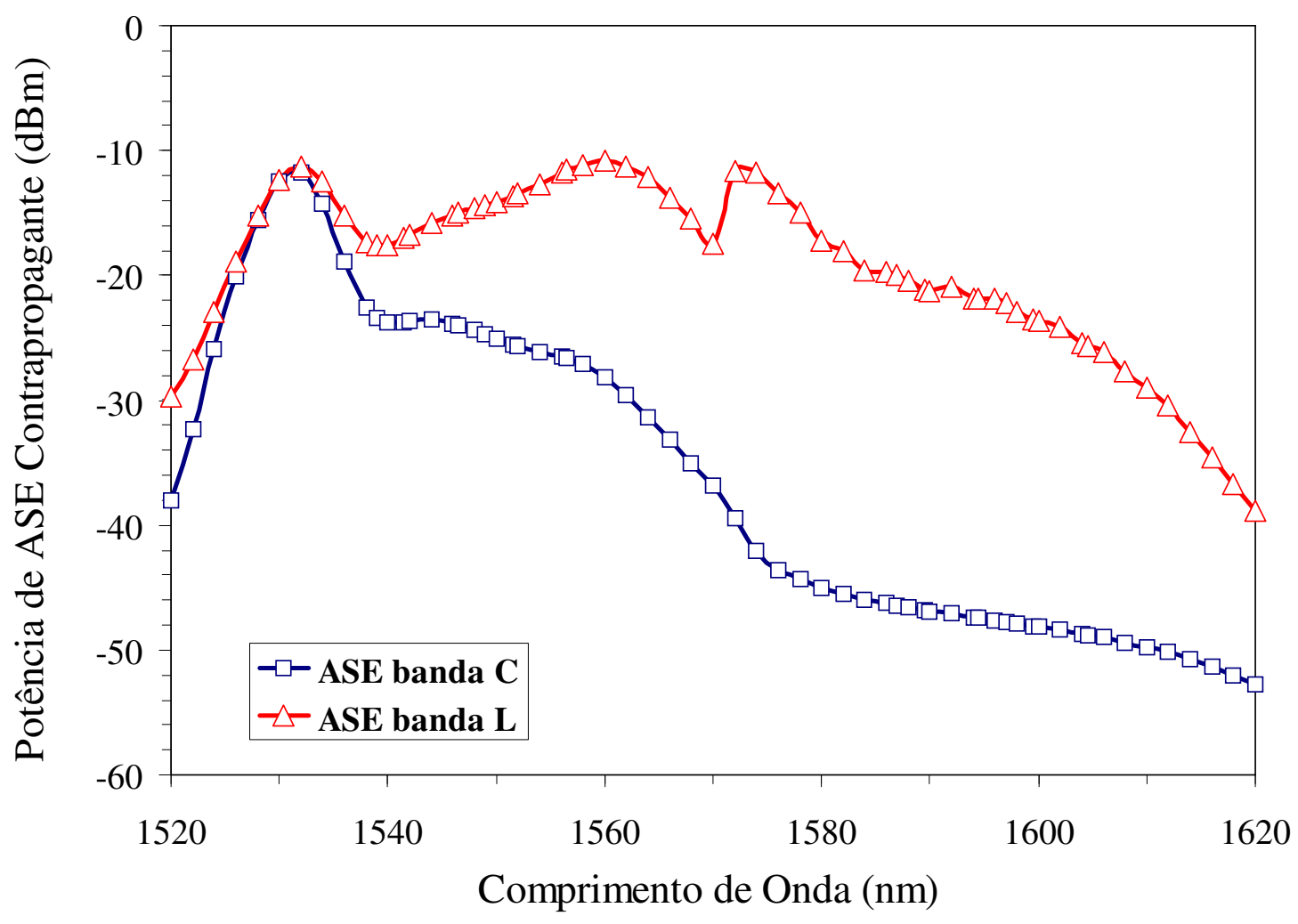

Fig. 4.5 - Simulação dos níveis de ASE contrapropagante na saída do DP-EDFA sem o uso do filtro de ASE.

Para obtenção dos comprimentos de fibra dopada para os circuitos da Figura 4.4 utilizamos o software OASIX v.3.1. Consideramos como objetivo um ganho de $20 \mathrm{~dB}+/-2$ $\mathrm{dB}$ na região da banda $\mathrm{C}$, compreendida entre 1539 to $1556 \mathrm{~nm}$, e $20 \mathrm{~dB}+/-5 \mathrm{~dB}$ para a banda L, compreendida entre 1587 a 1594,5 nm. A DCF foi simulada com perda de $6 \mathrm{~dB}$, e as perdas extras associadas ao multiplexador de bandas e circulador foram de $2 \mathrm{~dB}$. Às perdas de entrada do circulador \#1, do multiplexador de bombeio e do multiplexador de bandas foram atribuídas o valor de 2 dB. Os resultados da simulação são mostrados nas Figuras 4.6(a) e 4.6(b) para o circuito paralelo e nas Figuras 4.7(a) e 4.7(b) para o circuito série. 

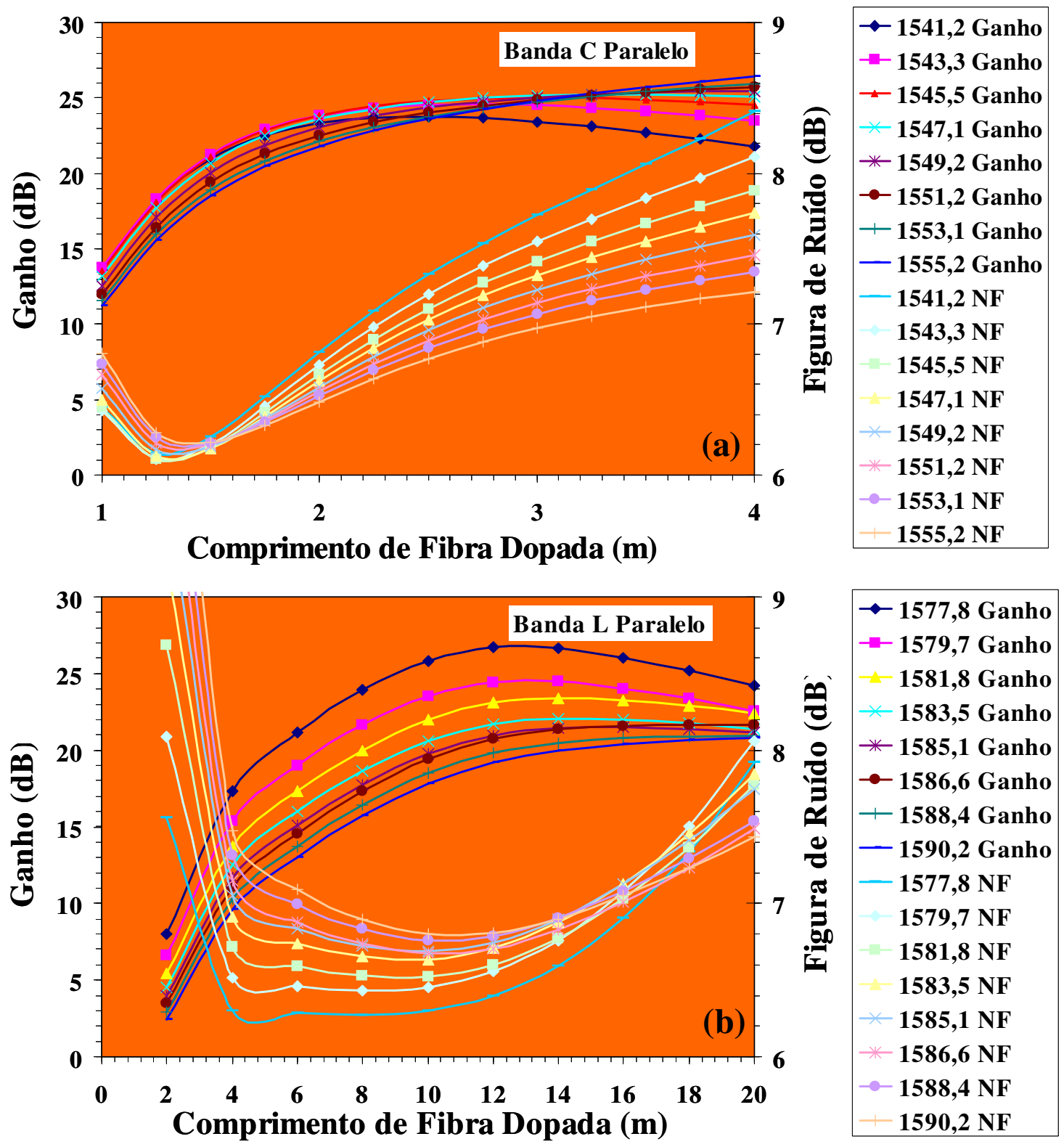

Fig. 4.6 - Simulações de ganho e figura de ruído em função do comprimento de fibra dopada para DP-EDFA circuito paralelo (a) banda $\mathrm{C}$ e (b) banda L. 

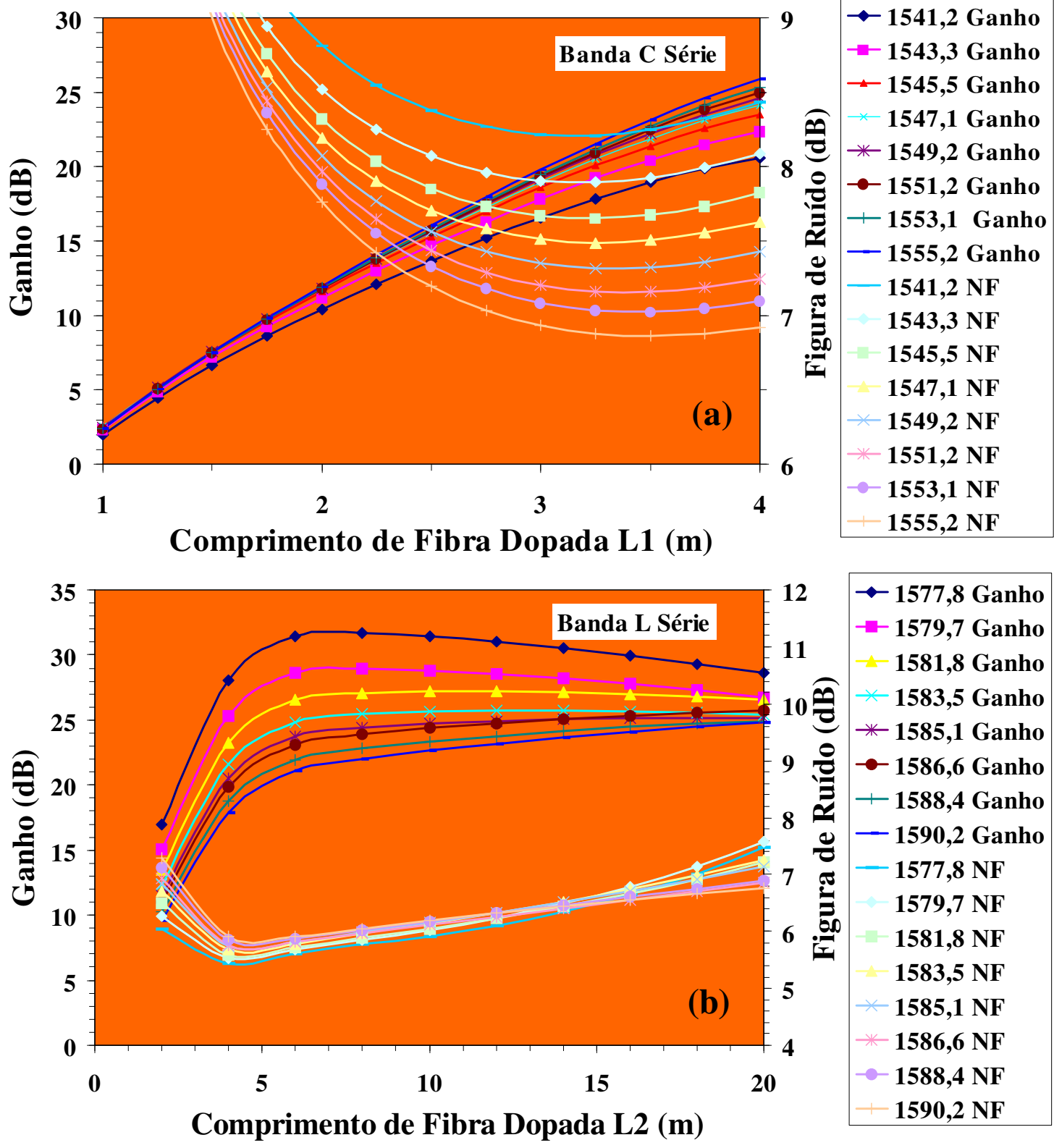

12

\begin{tabular}{|c|}
\hline$-1577,8$ Ganho \\
$-1579,7$ Ganho \\
$-1581,8$ Ganho \\
$-1583,5$ Ganho \\
$*-1585,1$ Ganho \\
$--1586,6$ Ganho \\
$+1588,4$ Ganho \\
$-1590,2$ Ganho \\
$-1577,8$ NF \\
$-1579,7$ NF \\
$-1581,8$ NF \\
$-1583,5$ NF \\
$-1585,1$ NF \\
$-1586,6$ NF \\
$-1588,4$ NF \\
$-1590,2$ NF \\
\hline
\end{tabular}

Fig. 4.7 - Simulações de ganho e figura de ruído em função do comprimento de fibra dopada para DP-EDFA circuito série (a) banda $\mathrm{C}$ para $\mathrm{L}_{2}=7 \mathrm{~m}$ e (b) DP-EDFA $\mathrm{L}$ para $\mathrm{L}_{1}=2,5 \mathrm{~m}$.

Enquanto a escolha do comprimento de fibra dopada para a configuração paralela pode ser feita de forma independente para as bandas C e L, para o circuito série, a escolha do comprimento do trecho $\mathrm{L}_{1}$ que é comum as duas bandas condiciona o projeto do trecho $\mathrm{L}_{2}$ para a banda L, e vice-versa. Os resultados apresentados nas Figuras 4.7(a) e 4.7(b) são os melhores resultados de uma série de variações nos trechos $\mathrm{L}_{1}$ e $\mathrm{L}_{2}$, que foram feitas alterando 
um trecho e mantendo o outro fixo. O comprimento de fibra dopada escolhido para os oito canais DWDM na banda C (1539 a $1556.5 \mathrm{~nm})$ foi de $1,6 \mathrm{~m}$ para a configuração paralela e em 3 m para a configuração série. O comprimento de fibra dopada escolhido para o trecho dedicado aos canais DWDM da banda L (1587 a $1594.5 \mathrm{~nm})$ foi de $16 \mathrm{~m}$ para configuração paralela e de 7 metros para a configuração série. A potência de bombeio utilizada foi de 100 mW e a potência de entrada considerada foi de $-20 \mathrm{dBm}$. Não foi possível otimizar simultaneamente ganho, figura de ruído e planicidade de ganho.

Os dois circuitos de amplificação mostrados na Figura 4.4 foram montados e testados usando os mesmos comprimentos de onda empregados na simulação computacional. Os amplificadores foram caracterizados para os níveis de potências de entrada de $-20,-25$ e -30 dBm. Os lasers utilizaram $120 \mathrm{~mW}$ de potência de bombeio para garantir os $100 \mathrm{~mW}$ de potência na entrada da fibra dopada com érbio. A isolação dos multiplexadores de banda foi de $16,3 \mathrm{~dB}$ na banda $\mathrm{C}$ e de $36,5 \mathrm{~dB}$ na banda $\mathrm{L}$. A perda de inserção dos multiplexadores de banda foi de $0,4 \mathrm{~dB}$ na banda $\mathrm{C}$ e de $0,2 \mathrm{~dB}$ na banda L. A isolação do filtro de ASE utilizado nos circuitos da banda $\mathrm{L}$ foi de 43,5 dB na banda $\mathrm{C}$ e sua perda de inserção foi de $1 \mathrm{~dB}$. Os circuladores usados apresentaram perda de inserção de 0,6 dB. A DCF utilizada de -900 ps/nm apresentou perda de $6 \mathrm{~dB}$. Nas Figuras 4.8(a) e 4.8(b) mostramos os resultados da caracterização experimental de ganho e figura de ruído para a configuração paralela e nas Figuras 4.9(a) e 4.9(b) os resultados da caracterização para a configuração série.

Podemos observar na Figura 4.8(a), ilustrando os resultados obtidos para a banda $\mathrm{C}$ do amplificador paralelo, que, para a potência de entrada de $-20 \mathrm{dBm}$, o ganho obtido nesta faixa espectral foi de 19,5 dB (+/- $1 \mathrm{~dB})$ com valores de figura de ruído em torno de 5,5 dB. O ganho aumenta para valores de potência de entrada acima de $-20 \mathrm{dBm}$, como esperado. A uniformidade do ganho é mantida para todos os valores abaixo de $-20 \mathrm{dBm}$. Por outro lado, a Figura 4.8(b) indica que o ganho não é uniforme na região da banda L. O valor obtido foi de 
$20 \mathrm{~dB}+/-2.5 \mathrm{~dB}$. Esta não uniformidade de ganho só pode ser corrigida através da inserção, no circuito de amplificação da banda L, de filtros aplainadores de ganho GFF (Gain Flattened Filter). A figura de ruído para a banda $\mathrm{L}$ variou entre 6,9 and 7,7 dB. Tanto os valores de ganho como de figura de ruído para as bandas $\mathrm{C}$ e L do circuito paralelo obtidos na caracterização experimental estão em boa concordância com os valores resultantes da simulação computacional.
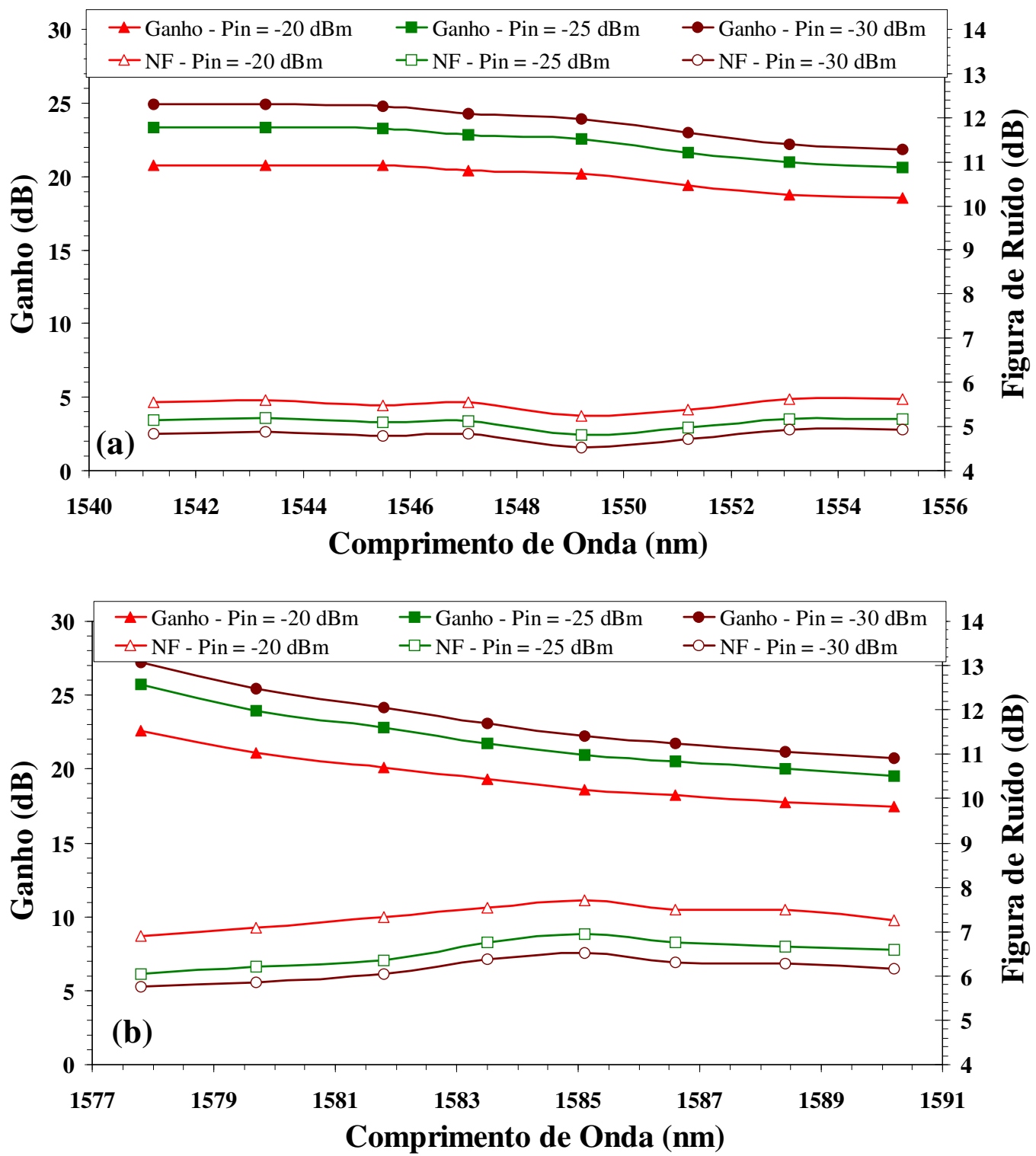

Fig. 4.8 - Caracterização de ganho e figura de ruído para o circuito DP-EDFA paralelo (a) banda C, (b) banda L. 

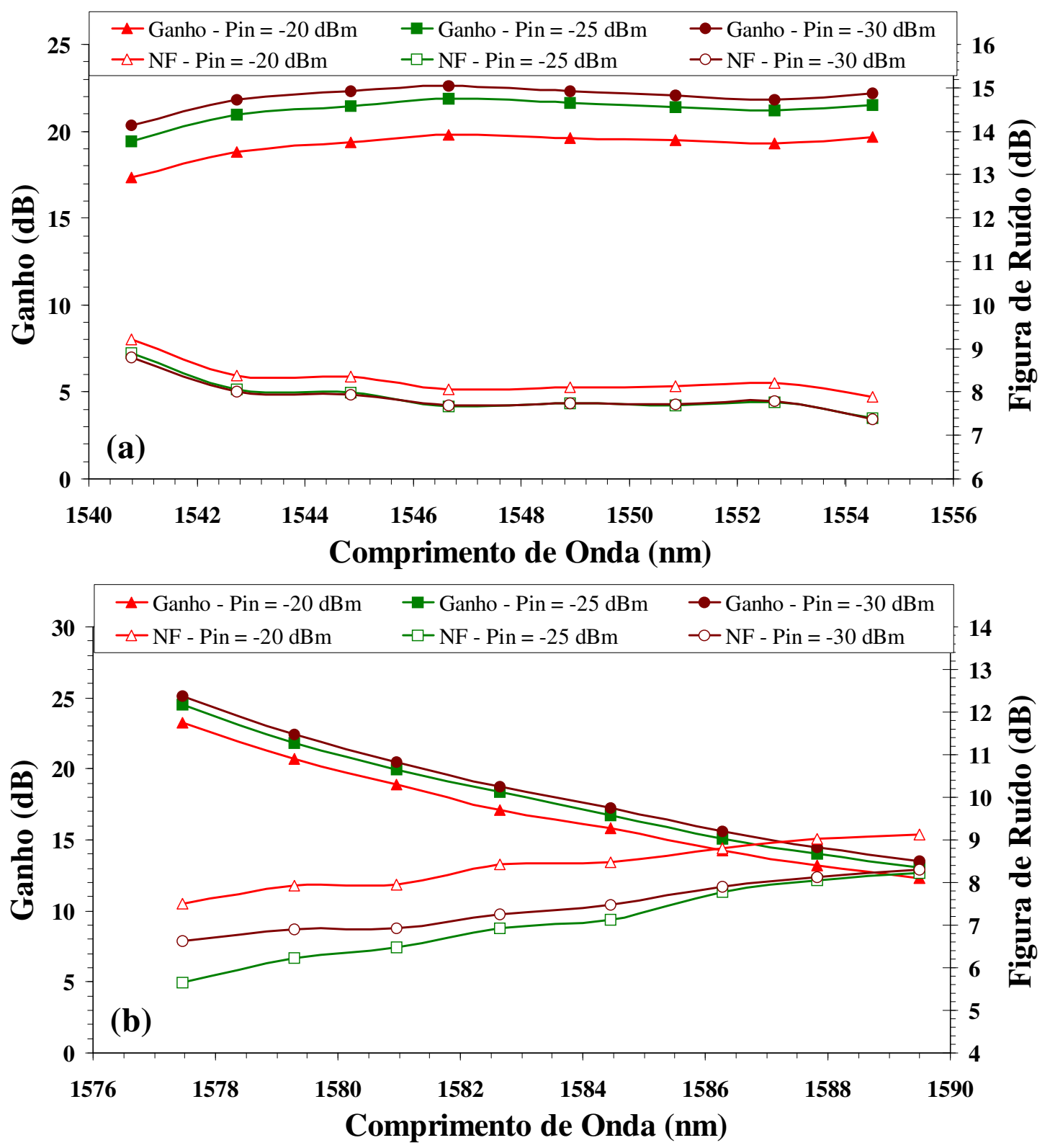

Fig. 4.9 - Caracterização de ganho e figura de ruído para o circuito DP-EDFA série (a) banda C e (b) banda L.

Para os resultados de caracterização do circuito série da banda L, mostrados na Figura 4.9(a), observa-se que, para potências de entrada de $-20 \mathrm{dBm}$, o ganho é da ordem de $18 \mathrm{~dB}$ +/- $1 \mathrm{~dB}$ com valores de figura de ruído variando de 8 a 9 dB. O ganho aumenta para potências de entrada inferiores a - $20 \mathrm{dBm}$, mantendo a planicidade. Por outro lado, a Figura 4.9(b) indica que o ganho não é uniforme na banda L. Os valores de ganho obtidos variam 
entre 10 e $20 \mathrm{~dB}$ para $\mathrm{P}_{\text {in }}$ de $-20 \mathrm{dBm}$, enquanto a figura de ruído varia entre 5 a $9 \mathrm{~dB}$, em toda a faixa espectral.

Comparando os resultados das duas configurações podemos concluir que a configuração paralela proporcionou melhor desempenho do que a configuração série. Os piores valores de ganho e figura de ruído, obtidos para a configuração série podem ser atribuídos a competição simultânea de ganho entre as duas bandas, realizada no primeiro estágio. Para melhor equalização de ganho na banda L torna-se necessário o uso de um filtro GFF. Outra providência necessária é o uso de um filtro de ASE no circuito da banda L para evitar a deterioração da figura de ruído na banda C.

Estes foram os primeiros resultados experimentais apresentados nesta tese para circuitos de amplificadores multibanda de dupla-passagem com DCF. Estes resultados podem ser comparados com os resultados do circuito proposto em [39], mostrados nas Figuras 2.11(a) e (b). Em relação aquele circuito, o DP-EDFA paralelo aqui proposto tem a vantagem do uso de menor potência de bombeio, menor comprimento de fibra, além de incorporar uma fibra DCF, cuja funcionalidade não é prevista naquele circuito, que, no entanto, apresenta a vantagem de menor figura de ruído, devido ao uso de um primeiro estágio de amplificação de passagem única. 


\subsection{Operação DWDM nas Bandas S, C e L (DP-EDFA/TDFA)}

Neste item descreveremos a montagem e teste de um amplificador de dupla passagem de três bandas contendo fibra DCF. As bandas C e L usam a mesma configuração em paralelo do DP-EDFA já descrito na seção anterior. A banda S (1450 a 1510 nm) utiliza um DPTDFA, ou seja, um amplificador a fibra de fluoreto dopada com túlio. O uso de dupla passagem em amplificadores TDFA garante, a semelhança de outras aplicações de DPEDFAs, uma maior eficiência de ganho, permitindo o uso de menores potências de bombeio ou menores comprimentos de fibra dopada [81].

A cobertura destas três bandas de operação abrange uma região espectral de amplificação superior a $150 \mathrm{~nm}$, sendo de grande utilidade para aplicações em sistemas DWDM ou em sistemas UDWDM (Ultra Dense Wavelength Division Multiplexing). Outra aplicação deste amplificador será mostrada na Seção 4.5, consistindo no seu uso para CWDM.

O circuito do DP-EDFA/TDFA de três bandas usando circuitos de amplificação paralela com DCF é mostrado na Figura 4.10. O circuito é muito semelhante ao já mostrado na Figura 4.4(a), para as bandas C e L. São acrescentados apenas dois novos multiplexadores de banda e o circuito copropagante para amplificação na banda S. Para esta banda, o laser de bombeio utilizado opera no comprimento de onda de $1050 \mathrm{~nm}$, uma vez que este é um dos comprimentos de absorção da fibra de fluoreto dopada com Túlio. A operação simultânea nas três bandas foi também possível graças à escolha adequada dos multiplexadores de banda. A Figura 4.11 mostra a perda de inserção e a isolação destes multiplexadores já associados. Também neste circuito é de fundamental importância a utilização de um multiplexador que tenha alta isolação da potência de ASE da banda L para a banda C.

Os comprimentos de fibra dopada utilizados para a banda C e L foram os mesmos utilizados na configuração da Figura 4.4(a), ou seja, 1,6 m para a banda C e 16 m para a banda 
L. Para a banda S utilizou-se um módulo comercial com $20 \mathrm{~m}$ de fibra de fluoreto dopada com túlio, com as seguintes características: comprimento de onda de corte $(\lambda \mathrm{c})$ de $1 \mu \mathrm{m}$, diferença de índice de refração $(\Delta \mathrm{n})$ de 2,5\% e concentração de Túlio de 2000 ppm.

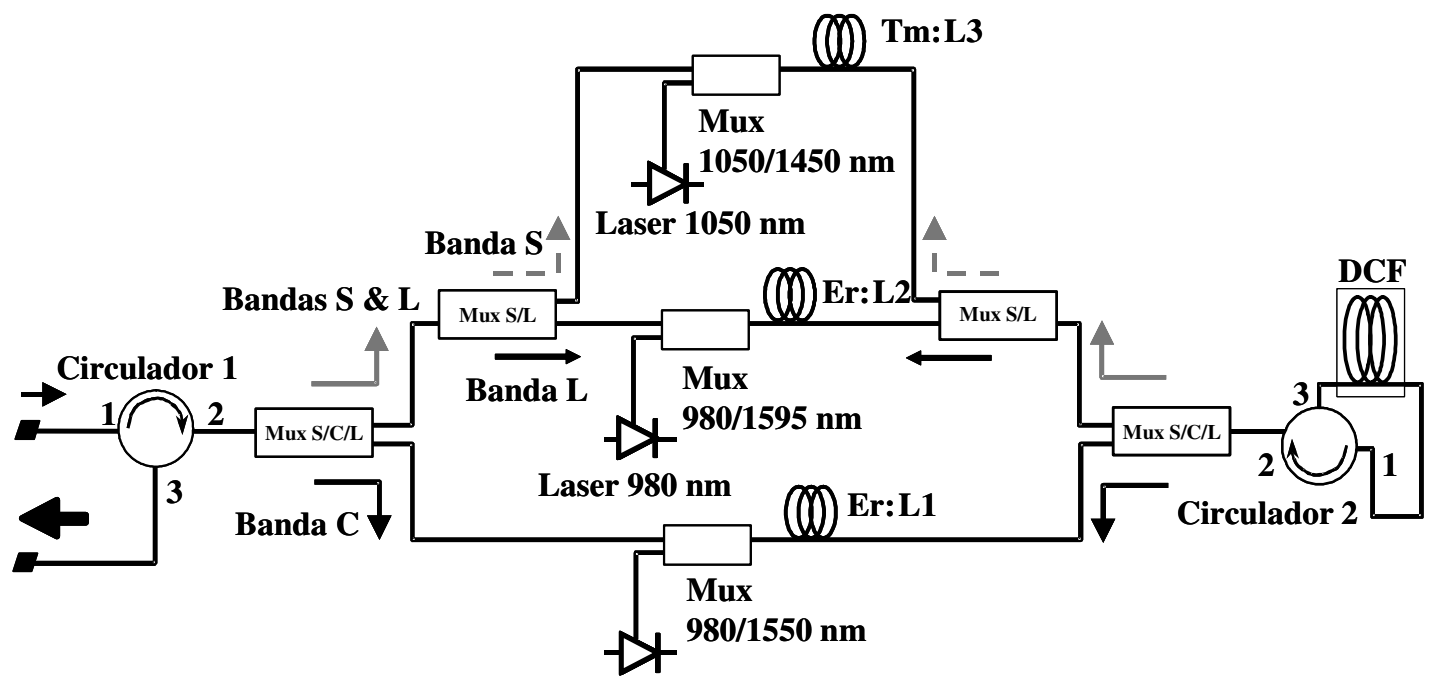

Laser $980 \mathrm{~nm}$

Fig. 4.10 - Configuração do DP-EDFA/TDFA para as bandas S, C e L.

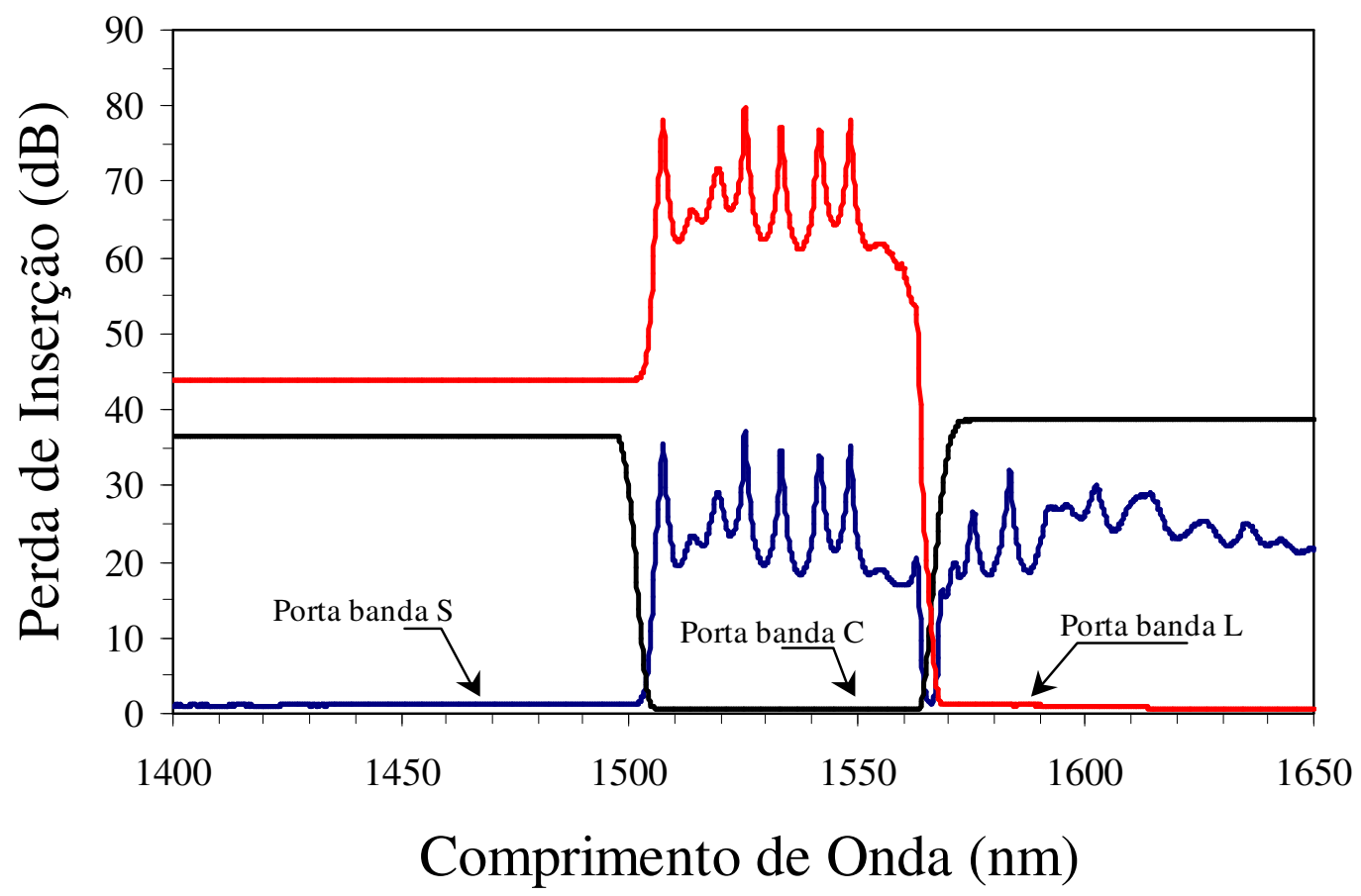

Fig. 4.11 - Perda e isolação dos multiplexadores usados no DP-EDFA/TDFA. 
O DP-EDFA de três bandas foi caracterizado em termos de ganho e figura de ruído, usando 8 comprimentos de onda em cada uma das seguintes faixas espectrais: 1460 à 1476 nm (banda S), 1541 à 1555 nm (banda C) e 1577 à 1590 nm (banda L). A Figura 4.12(a) mostra uma foto do sistema de 24 lasers cobrindo as três bandas e do analisador de espectro óptico, utilizado na caracterização do DP-EDFA/TDFA. A Figura 4.12(b) mostra uma foto do empacotamento do DP-EDFA/TDFA com a fibra DCF. O amplificador foi caracterizado para potências de entrada de $-15,-20$ e $-25 \mathrm{dBm}$, usando de um laser $120 \mathrm{~mW}$ para a banda $\mathrm{C}$ e um outro de $120 \mathrm{~mW}$ para a banda L. O laser de $1050 \mathrm{~nm}$ para a banda S operou com $200 \mathrm{~mW}$ de potência de bombeio. A DCF de -900 ps/nm utilizada apresentou uma perda de inserção de 6 dB em $1550 \mathrm{~nm}$. Os demais componentes apresentaram as características já descritas na seção anterior. A Figura 4.13 mostra o espectro do DP-EDFA/TDFA para uma potência de entrada de $-15 \mathrm{dBm}$.

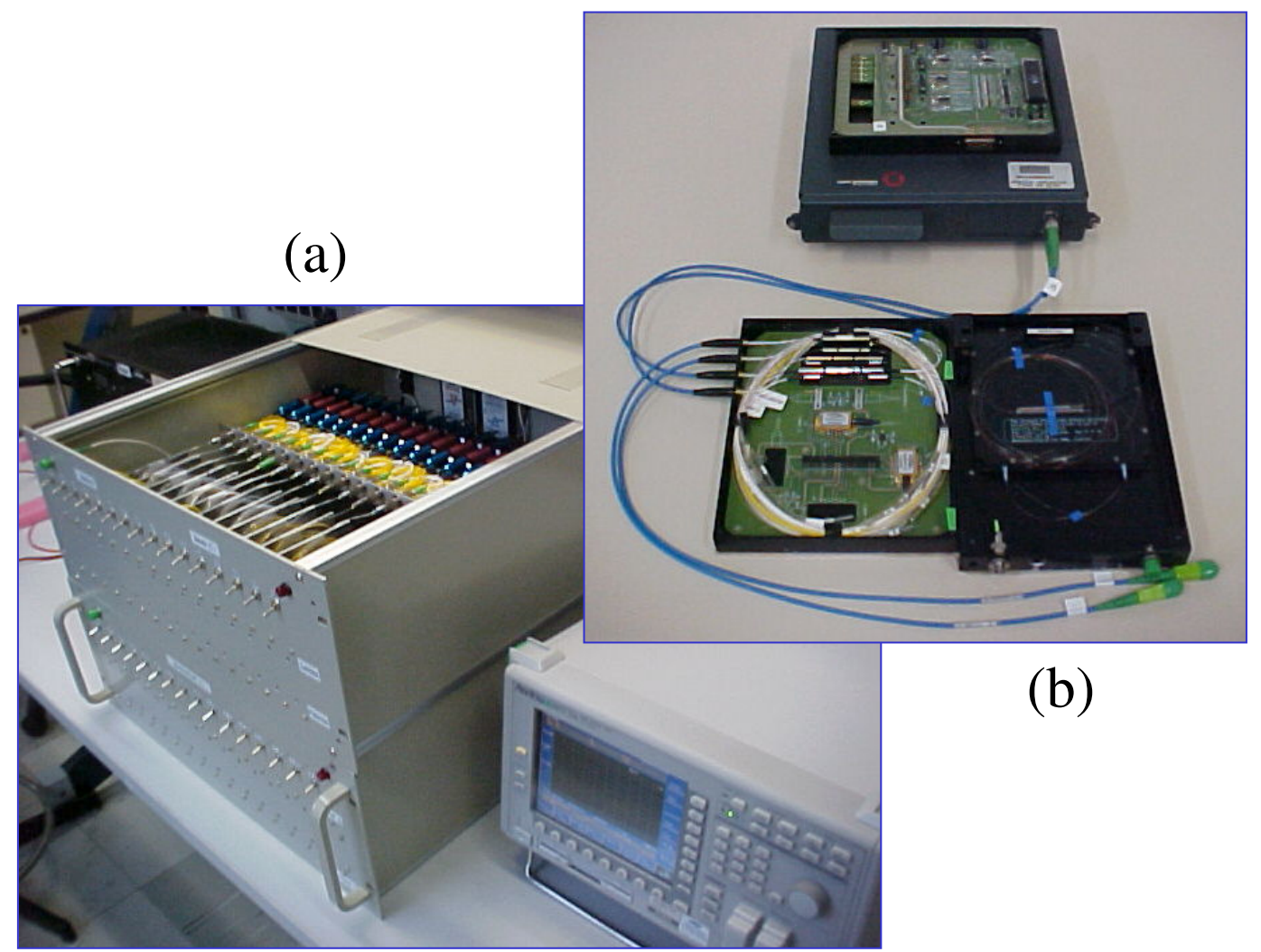

Fig. 4.12 - (a) Foto do sistema de 24 lasers cobrindo as três bandas e um analisador de espectro óptico, utilizado na caracterização do DP-EDFA/TDFA e (b) foto do empacotamento do DP-EDFA/TDFA com a fibra DCF. 


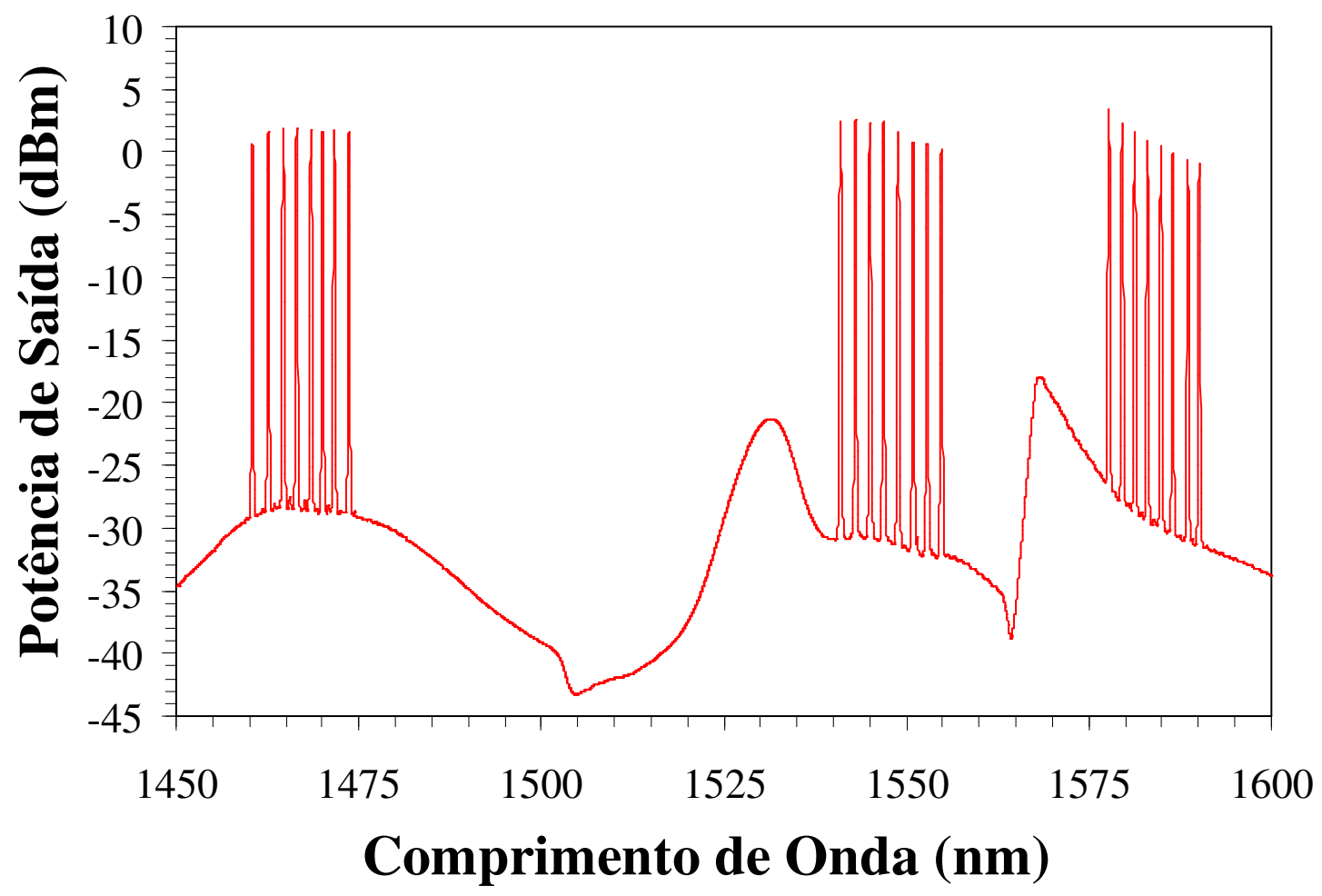

Fig. 4.13 - Espectro de saída DWDM do DP-EDFA/TDFA para uma potência de entrada de $-15 \mathrm{dBm}$.

Podemos observar que a região de amplificação não é continua. Este fato está ligado às características dos dopantes e dos comprimentos de fibra dopada utilizados. Uma região de baixo ganho ocorre entre aproximadamente 1490 e $1525 \mathrm{~nm}$, outra estreita região entre 1560 e $1570 \mathrm{~nm}$. Outro fato determinante para estas regiões espectrais desprovidas de ganho é o corte imposto pelos multiplexadores de banda.

Na Figura 4.14 mostramos os valores de ganho e figura de ruído para as três bandas em três níveis de potência de entrada. Os resultados para as bandas C e L são muito parecidos com os já mostrados na seção anterior para o amplificador paralelo das bandas C e L, uma vez que o circuito utilizado é basicamente o mesmo. Podemos notar que, para uma potência de entrada de $-20 \mathrm{dBm}$, o ganho é da ordem de 20,7+/- 0,5 dB para a banda $\mathrm{S}, 20,2+/-1,0 \mathrm{~dB}$ para a banda C e 20,6 +/- 2,5 dB para a banda L. Os valores de figura de ruído ficaram em torno de $8,0 \mathrm{~dB}$ para a banda $\mathrm{S}, 5,7 \mathrm{~dB}$ para a banda $\mathrm{C}$ e $8,1 \mathrm{~dB}$ para a banda $\mathrm{L}$. Os valores de 

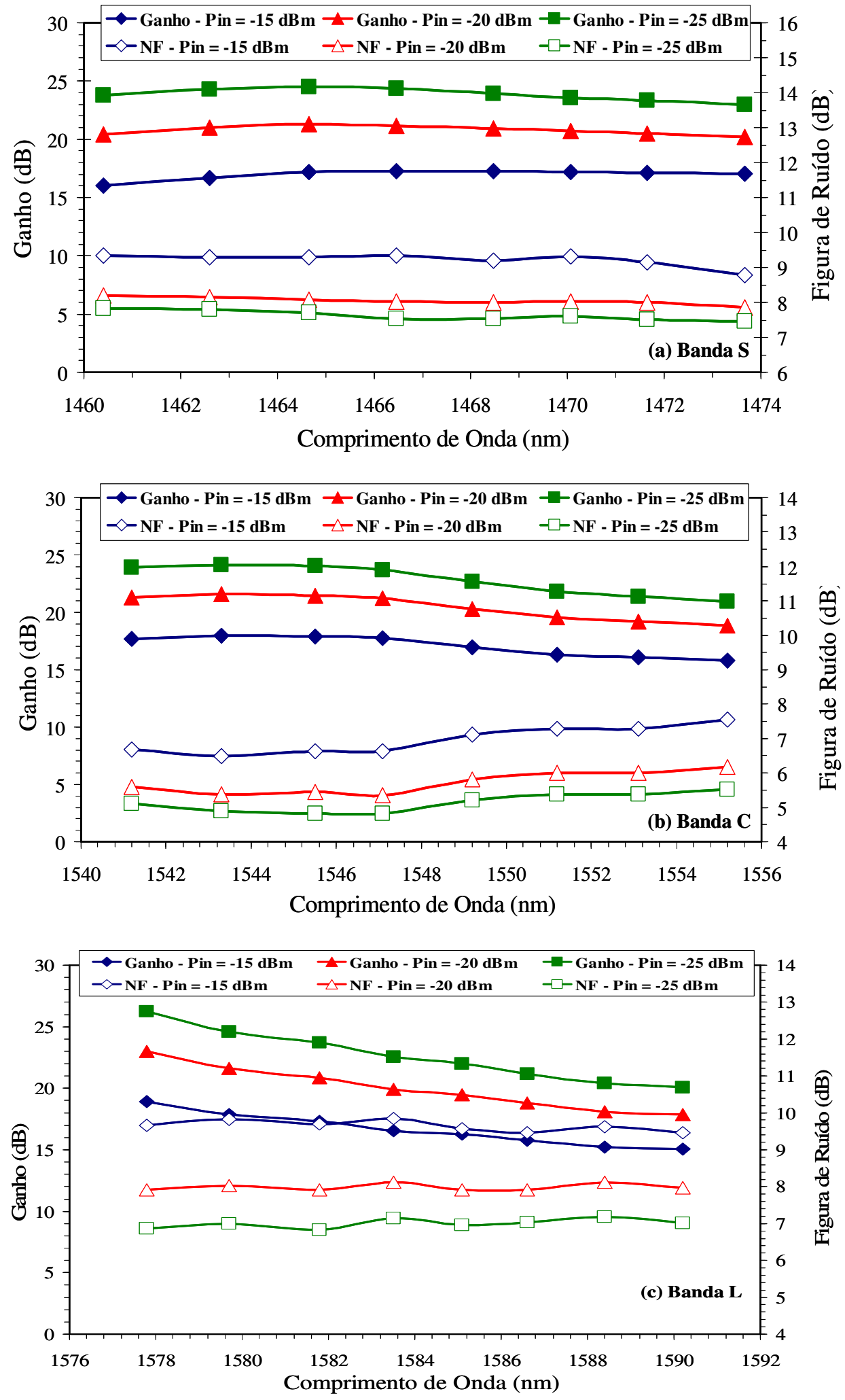

Fig. 4.14 - Ganho e figura de ruído para o DP-EDF/TDFA com fibra DCF de 900 ps/nm e $\mathrm{P}_{\text {in }}$ de $-15,-20$ e -30 dBm, (a) Banda S, (b) Banda C e (c) Banda L. 
ganho aumentam para $-25 \mathrm{dBm}$ de potência de entrada e se reduzem para $-15 \mathrm{dBm}$ de potência de entrada, mantendo a mesma planicidade. Por outro lado, a figura de ruído diminui para potência de entrada de $-25 \mathrm{dBm}$ e aumenta para potência de entrada de -15 dBm. Como já comentado anteriormente, a melhoria da planicidade de ganho na banda L só pode ser conseguida com a utilização de um filtro corretor de planicidade de ganho (GFF) no circuito da banda L.

Outra avaliação realizada no DP EDFA/TDFA investigou o efeito no ganho e na figura de ruído devido a presença ou não da fibra DCF com a utilização de DCFs com valores de perda de inserção distintos. Com este objetivo, caracterizamos o ganho e a figura de ruído do DP-EDFA/TDFA sem DCF, com a mesma DCF de -900 ps/nm já utilizada, que apresenta um perda de inserção de $6 \mathrm{~dB}$, e finalmente com uma DCF de -1600 ps/nm, cuja perda é de 10 dB. A Figura 4.15 mostra esta caracterização para as três bandas S, C e L. Podemos observar que a diminuição do ganho do DP-EDFA/TDFA usando a DCF de -900 ps/nm é da ordem de $3 \mathrm{~dB}$ quando comparado à configuração de DP-EDFA com DCF ausente. Quando a DCF de -1600 ps/nm é utilizada a diminuição de ganho é da ordem de 7 dB. Ou seja, o DPEDFA/TDFA compensa totalmente a perda das DCF com um ganho liquido da ordem de $3 \mathrm{~dB}$ para ambos os casos. O efeito do aumento da perda de inserção da DCF no ganho do DPEDFA, é similar ao efeito da diminuição da reflectividade de um espelho, tal como aquele, mostrado na Figura 2.7. O uso da DCF também afeta a figura de ruído. Isto ocorre com maior intensidade para as bandas S e L, pois apresentam baixa eficiência de ganho.

Finalmente, apresentamos na Figura 4.16 os resultados da comparação do desempenho da configuração de dupla passagem (DP-EDFA/TDFA) e da passagem única (SPEDFA/TDFA). A passagem única é obtida através da desconexão da porta 1 do circulador \#2. Mede-se a potência de saída após a passagem do sinal pela DCF. Podemos observar que o desempenho de ganho da estrutura de dupla passagem é na média $10 \mathrm{~dB}$ superior ao da 
estrutura de passagem única, em todas as faixas espectrais medidas, confirmando a vantagem desta topologia. Já a figura de ruído da estrutura de dupla passagem é superior em torno de 2,5 dB àquele da estrutura de passagem única.
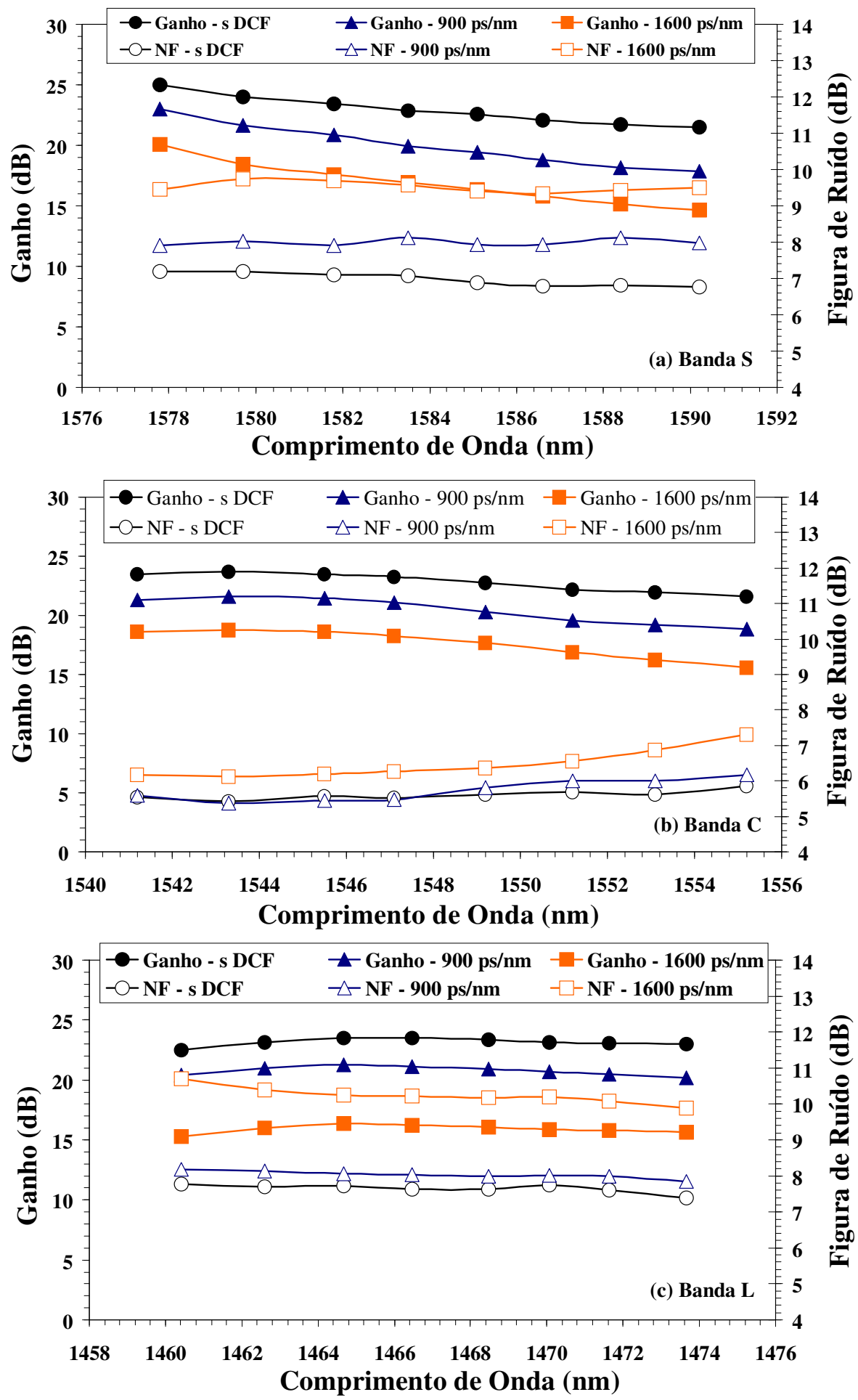

Fig. 4.15 - Ganho e figura de ruído para o DP-EDF/TDFA para $P_{\text {in }}$ de $-20 \mathrm{dBm}$, sem DCF e com fibra DCF de -900 e -1600 ps/nm (a) Banda S, (b) Banda C, (c) Banda L. 

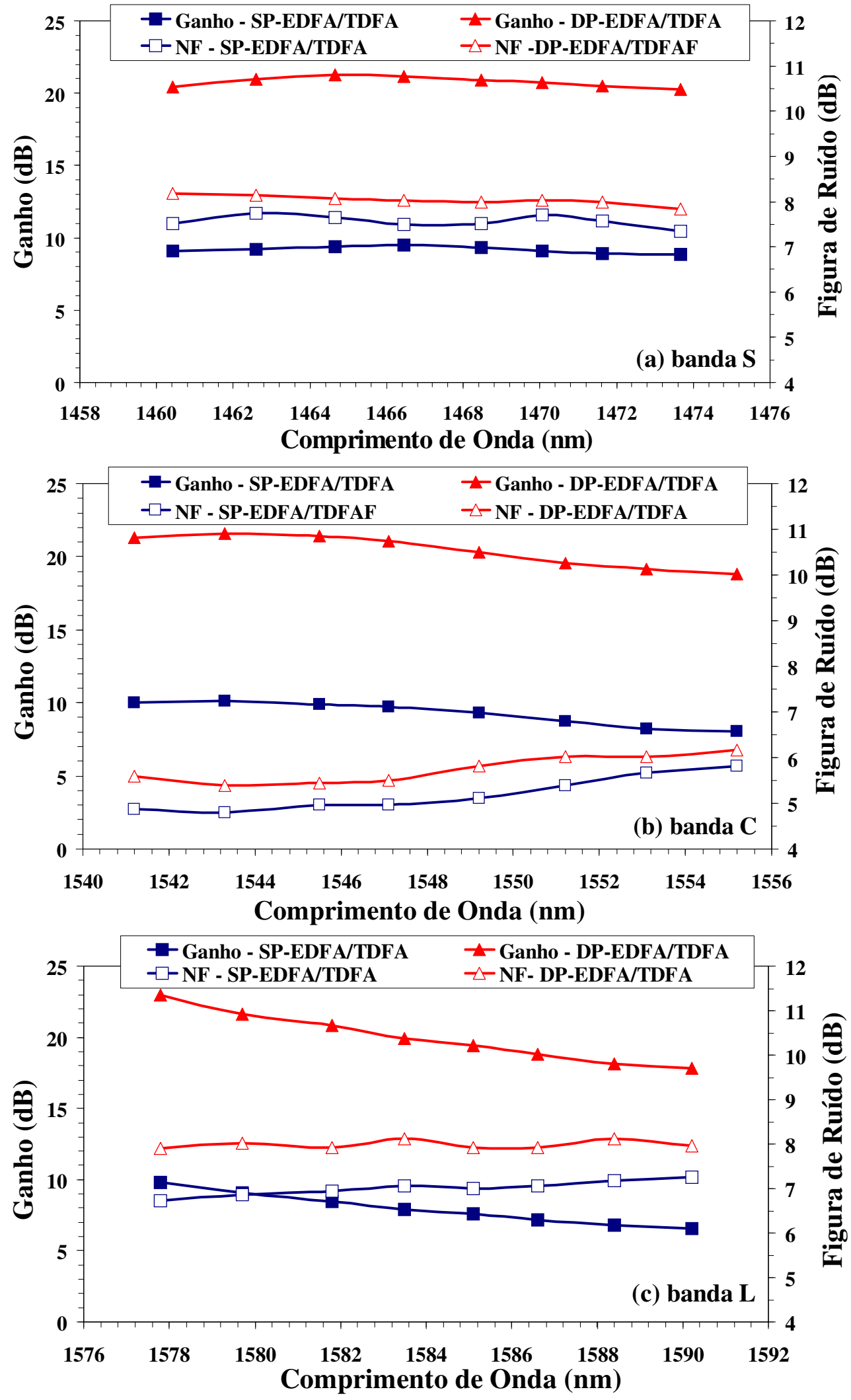

Fig. 4.16 - Ganho e figura de ruído para DP-EDF/TDFA e SP-EDFA, para $P_{\text {in }}$ de $-20 \mathrm{dBm}, \mathrm{DCF}=-900 \mathrm{ps} / \mathrm{nm}$ (a) Banda S, (b) Banda C, (c) Banda L. 


\subsection{Operação CWDM nas Bandas S, C e L}

Atualmente redes CWDM são utilizadas como opção de menor custo do que as redes DWDM em redes metropolitanas de borda, ou seja, redes que se conectam com usuários corporativos tais como bancos, shoppings, grandes empresas, etc...Estas redes operam com sistemas modulados diretamente em taxas até $2,5 \mathrm{~Gb} / \mathrm{s}$. Funções do tipo deriva/insere (Add/Drop) fixos são comuns em redes do tipo CWDM de barramento e anel. Porém, o uso da capacidade máxima de add/drops, que é padronizada em 16 pelas normas da ITU-T [19, 20], limita estas redes a poucas dezenas de quilômetros, devido às perdas introduzidas pelos add/drops, por conectores e emendas e pela atenuação da fibra. Amplificadores ópticos são, portanto, por sua vez, uma solução necessária para aumentar a extensão destas redes. O aumento da extensão coloca um outro limite, que é aquele devido a dispersão cromática da fibra e ao uso de modulação direta. Amplificadores de dupla passagem com DCFs são opções bem-vindas para aumentar a extensão destas redes, a partir da mitigação dos problemas de atenuação e dispersão cromática. Mais detalhes sobre o dimensionamento de enlaces envolvendo orçamento de potência e dispersão podem ser encontrados no Apêndice C. A seguir são detalhadas duas diferentes propostas para amplificadores de dupla passagem contendo fibras DCF para operação CWDM. A primeira proposta consiste do DPEDFA/TDFA de três bandas, já detalhado na Seção 4.4. A segunda proposta consiste na implementação de um amplificador de dupla passagem também de três bandas, porém usando como meio de ganho somente fibras dopadas com érbio.

\subsubsection{Amplificador DP-EDFA/TDFA com DCF}

O DP-EDFA/TDFA já detalhado na Seção 4.4 é agora caracterizado em termos de ganho e figura de ruído na grade CWDM. O amplificador foi avaliado para níveis de potência 
de entrada de -10 , -15 e $-20 \mathrm{dBm}$ com e sem a presença da DCF de $-900 \mathrm{ps} / \mathrm{nm}$. A Tabela 4.1 mostra os resultados destas medidas para oito comprimentos de onda da grade CWDM. É interessante observar que a grade CWDM, utilizada no experimento, não é contínua e tem uma posição vaga no comprimento de onda $1510 \mathrm{~nm}$. Isto ocorre porque o amplificador a fibra dopada com túlio não apresenta ganho significativo nesta região. A Figura 4.17 apresenta uma curva espectral da potência de saída para o DP-EDFA/TDFA para a condição de potência de entrada de $-15 \mathrm{dBm}$ com DCF.

Tab. 4.1 - Ganho e figura de ruído para o amplificador DP-EDFA/TDFA na grade CWDM.

\begin{tabular}{|l|c|c|c|c|c|c|c|c|c|}
\hline \multicolumn{1}{|c|}{ Lambda (nm) } & $\mathbf{1 4 5 0}$ & $\mathbf{1 4 7 0}$ & $\mathbf{1 4 9 0}$ & $\mathbf{1 5 1 0}$ & $\mathbf{1 5 3 0}$ & $\mathbf{1 5 5 0}$ & $\mathbf{1 5 7 0}$ & $\mathbf{1 5 9 0}$ & $\mathbf{1 6 0 7}$ \\
\hline Ganho sem DCF (dB) - Pin = -10 dBm & 11,5 & 20,4 & 13,5 & - & 21,5 & 17,6 & 22,4 & 17,1 & 13,3 \\
\hline Ganho sem DCF (dB) - Pin = -15 dBm & 15,5 & 24,2 & 15,2 & - & 26,3 & 20,5 & 27,5 & 19,6 & 15,1 \\
\hline Ganho sem DCF (dB) - Pin = -20 dBm & 18,2 & 27,4 & 16,7 & - & 30,7 & 22,9 & 32,0 & 21,6 & 16,5 \\
\hline \hline NF sem DCF (dB) - Pin = -10 dBm & 10,5 & 9,0 & 9,5 & - & 9,0 & 6,8 & 9,8 & 8,1 & 9,0 \\
\hline NF sem DCF (dB) - Pin = -15 dBm & 9,3 & 8,0 & 8,6 & - & 7,9 & 5,7 & 8,2 & 6,9 & 7,6 \\
\hline NF sem DCF (dB) - Pin = -20 dBm & 9,1 & 7,7 & 8,0 & - & 7,3 & 5,3 & 7,4 & 6,3 & 7,2 \\
\hline \hline Ganho com DCF (dB) - Pin = -10 dBm & 9,1 & 17,8 & 9,3 & - & 20,8 & 14,0 & 21,9 & 13,3 & 8,3 \\
\hline Ganho com DCF (dB) - Pin = -15 dBm & 12,6 & 20,9 & 10,8 & - & 25,5 & 16,5 & 26,7 & 15,5 & 9,9 \\
\hline Ganho com DCF (dB) - Pin = -20 dBm & 14,7 & 23,0 & 11,9 & - & 28,6 & 18,7 & 30,8 & 17,3 & 11,1 \\
\hline \hline NF com DCF (dB) - Pin = -10 dBm & 11,9 & 9,3 & 11,2 & - & 8,1 & 7,5 & 11,0 & 9,4 & 11,2 \\
\hline NF com DCF (dB) - Pin = -15 dBm & 10,4 & 8,4 & 10,2 & - & 7,0 & 6,5 & 9,3 & 8,4 & 10,0 \\
\hline NF com DCF (dB) - Pin = -20 dBm & 9,9 & 8,0 & 9,6 & - & 7,3 & 5,9 & 8,2 & 7,7 & 9,3 \\
\hline
\end{tabular}

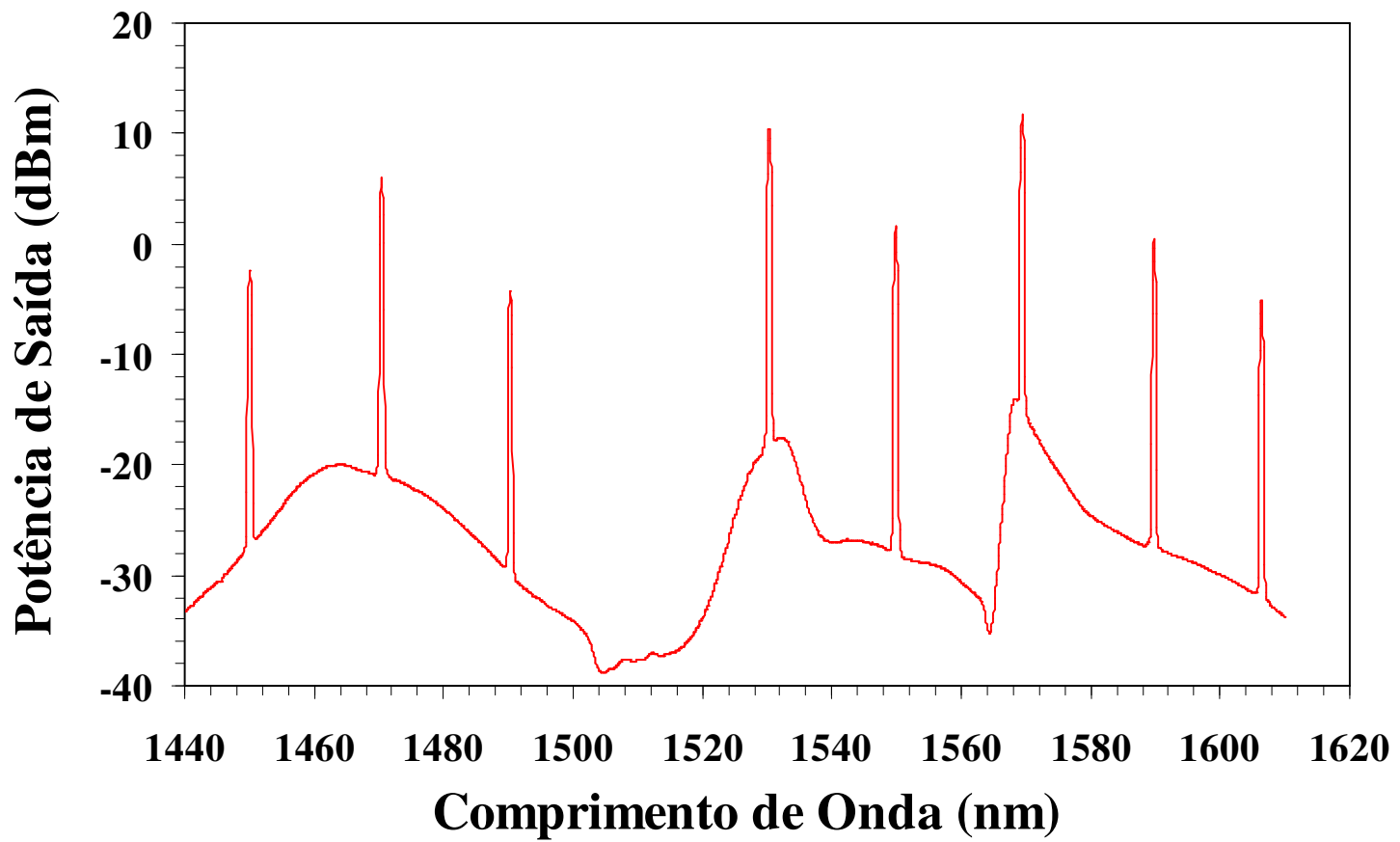

Fig. 4.17 - Espectro de saída CWDM do DP-EDFA/TDFA com DCF para uma potência de entrada de -15 dBm. 
Os valores de ganho mostrados na Tabela 4.1 apresentam grande variação no espectro. Esta característica ocorre porque os sinais amplificados ocupam até os extremos das bandas utilizadas, além do que os níveis do sinal de entrada utilizados não saturam adequadamente o amplificador. Porém, mesmo com este grande desnivelamento de ganho, o DP-EDFA/TDFA pode ser utilizado com amplificador de linha em sistemas CWDM do tipo barramento. Nestes sistemas as derivações de sinal ocorrem ao longo do enlace, de tal forma que derivações mais próximas do amplificador requerem menos ganho do que derivações situadas mais longe. Mais detalhes sobre esta aplicação serão vistos na Seção 4.3. Podemos observar, também na Tabela 4.1, que o ganho de um DP-EDFA/TDFA com DCF é menor do que o DPEDFA/TDFA sem DCF. A redução do ganho é maior em comprimentos de onda onde o DPEDFA/TDFA é menos eficiente, como, por exemplo, o comprimento de onda $1610 \mathrm{~nm}$. A figura de ruído, que já é maior em amplificadores de dupla passagem, tem valores elevados nos comprimentos de onda de menor eficiência. $\mathrm{O}$ aumento da potência de bombeio poderia aumentar o ganho e reduzir a figura de ruído nestes comprimentos de onda. Porém, para as aplicações de CWDM em barramento, supondo o uso de apenas um amplificador de dupla passagem e com relação sinal ruído na saída do DP-EDFA maior do que $20 \mathrm{~dB}$, estes valores de figura de ruído não comprometerão seriamente o desempenho do sistema.

\subsubsection{Amplificador DP-EDFA com DCF}

Recentemente um novo tipo de fibra de sílica dopada com érbio foi desenvolvido para amplificação na banda S [82 - 85], substituindo o uso de fibras de fluoreto dopadas com túlio. As fibras de fluoreto são mais caras, tem pouca disponibilidade de aquisição e apresentam dificuldades operacionais relativas à emenda com a fibra de sílica e fragilidade mecânica. 
Esta nova fibra de sílica dopada com érbio para a banda $S$ emprega uma configuração de perfil de índice de refração do tipo casca rebaixada (depressed cladding), formando um filtro de alta atenuação para comprimentos de onda acima de $1530 \mathrm{~nm}$. Por outro lado, o érbio apresenta emissão na região espectral entre 1480 e $1530 \mathrm{~nm}$, apesar dos altos níveis de absorção nesta região. Amplificação pode então ser obtida, desde que a ASE emitida acima de $1530 \mathrm{~nm}$ seja suprimida. Neste caso esta supressão é feita pelo próprio perfil de índice de refração da fibra dopada.

Investigações realizadas com este tipo de fibra mostram que há a necessidade de altos níveis de potência de bombeio para a obtenção de níveis de ganho satisfatórios [82-85]. O uso de amplificadores de dupla passagem permite o aumento da eficiência deste tipo de fibra, por otimizar o uso do bombeio, tal como já foi demonstrado nesta tese para EDFAs na banda L e para TDFAs na banda S, que apresentam, da mesma forma, pouca eficiência de amplificação nestas regiões do espectro.

Nesta seção detalhamos o uso deste novo tipo de fibra para amplificação na banda $S$, em associação a fibra de érbio convencional mostrada nas Seções 4 e 5 para amplificação na banda $\mathrm{C}$ e $\mathrm{L}$.

No entanto, para o correto funcionamento da fibra dopada com érbio de perfil de índice rebaixado torna-se necessário curvar a fibra para que a estrutura de filtragem passe a funcionar adequadamente [84]. Isto é tradicionalmente feito enrolando a fibra em um carretel com diâmetro adequado. Uma outra sistemática desenvolvida nesta tese, consiste em enrolar a fibra numa forma elíptica conhecida como "figura oito", conforme veremos adiante.

Para testar um arranjo de curvatura adequado para o uso da fibra dopada com érbio para a banda $\mathrm{S}$ utilizamos uma configuração de bombeio copropagante de dupla passagem, sem DCF, semelhante àquela mostrada na Figura 2.7. O comprimento de fibra dopada utilizada foi de $14 \mathrm{~m}$, conforme sugestão do fabricante da fibra. Os outros parâmetros para 
esta fibra dopada com érbio, fornecidos pelo fabricante, são: dopagem do núcleo com $\mathrm{Er} / \mathrm{La} / \mathrm{Al}$, comprimento de onda de corte do modo fundamental próximo de $1530 \mathrm{~nm}$, perdas na banda $\mathrm{C}$ devido a curvaturas superior a $10 \mathrm{~dB} / \mathrm{m}$ para uma bobina de $60 \mathrm{~mm}$ de diâmetro. A absorção do bombeio é de 7,6 dB/m. A forma geométrica mostrada na parte interna da Figura 4.18 é a figura oito utilizada para enrolar a fibra dopada. Nesta figura é mostrada a dimensão D, que representa o eixo menor da elipse. Através do ajuste da dimensão D é possível sintonizar a região de ganho do DP-EDFA na banda S de 1480 até $1525 \mathrm{~nm}$. Escolhendo o comprimento de onda de 1500,8 $\mathrm{nm}$ medimos o ganho e o espectro de saída do DP-EDFA para a banda S com bombeio em $980 \mathrm{~nm}$ de $100 \mathrm{~mW}$. Podemos observar que o valor ótimo de ganho para o comprimento de onda de 1500,8 nm é de $23 \mathrm{~dB}$ para a dimensão D de $65 \mathrm{~mm}$. Os valores de ganho diminuem sensivelmente para comprimentos de onda mais curtos, devido à redução da seção de choque de emissão do érbio nesta região espectral. Para comprimentos de onda acima de $1500 \mathrm{~nm}$ o ganho diminui devido ao efeito de filtragem pela fibra dopada.

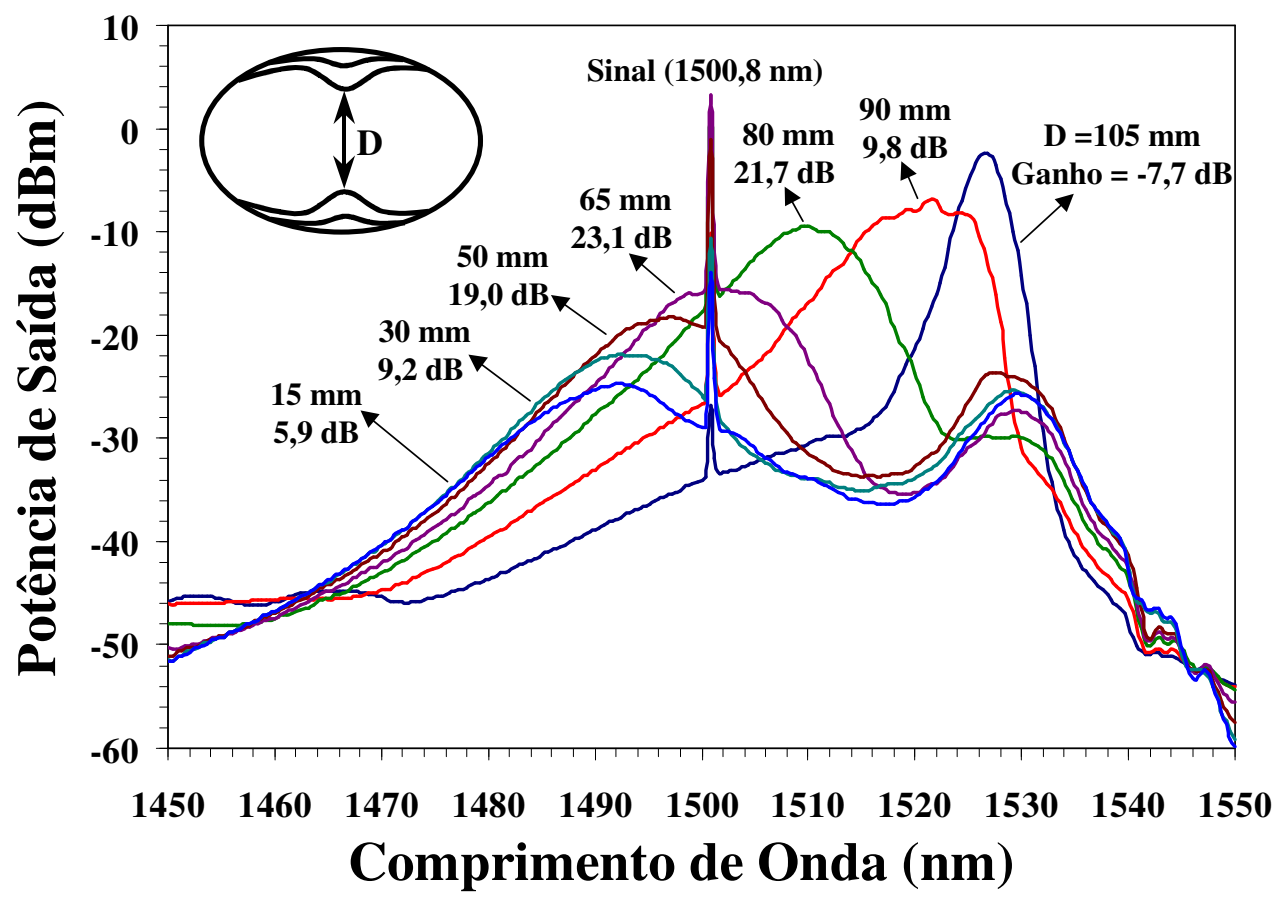

Fig. 4.18 - Potência de saída e ganho em 1500,8 nm em função do comprimento de onda para vários valores da dimensão D mostrada na mesma figura. O valor do eixo maior da elipse é constante e vale $180 \mathrm{~mm}$. 
Ainda com a configuração descrita anteriormente e com o parâmetro D de $65 \mathrm{~mm}$ realizamos a caracterização do DP-EDFA (idem para a configuração SP-EDFA), ainda sem DCF, para vários níveis de potência de bombeio. Os resultados mostrados na Figura 4.19 comprovam a superioridade do amplificador de dupla passagem no ganho também para este tipo de fibra. Como já esperado a figura de ruído também é maior para a configuração de dupla passagem.

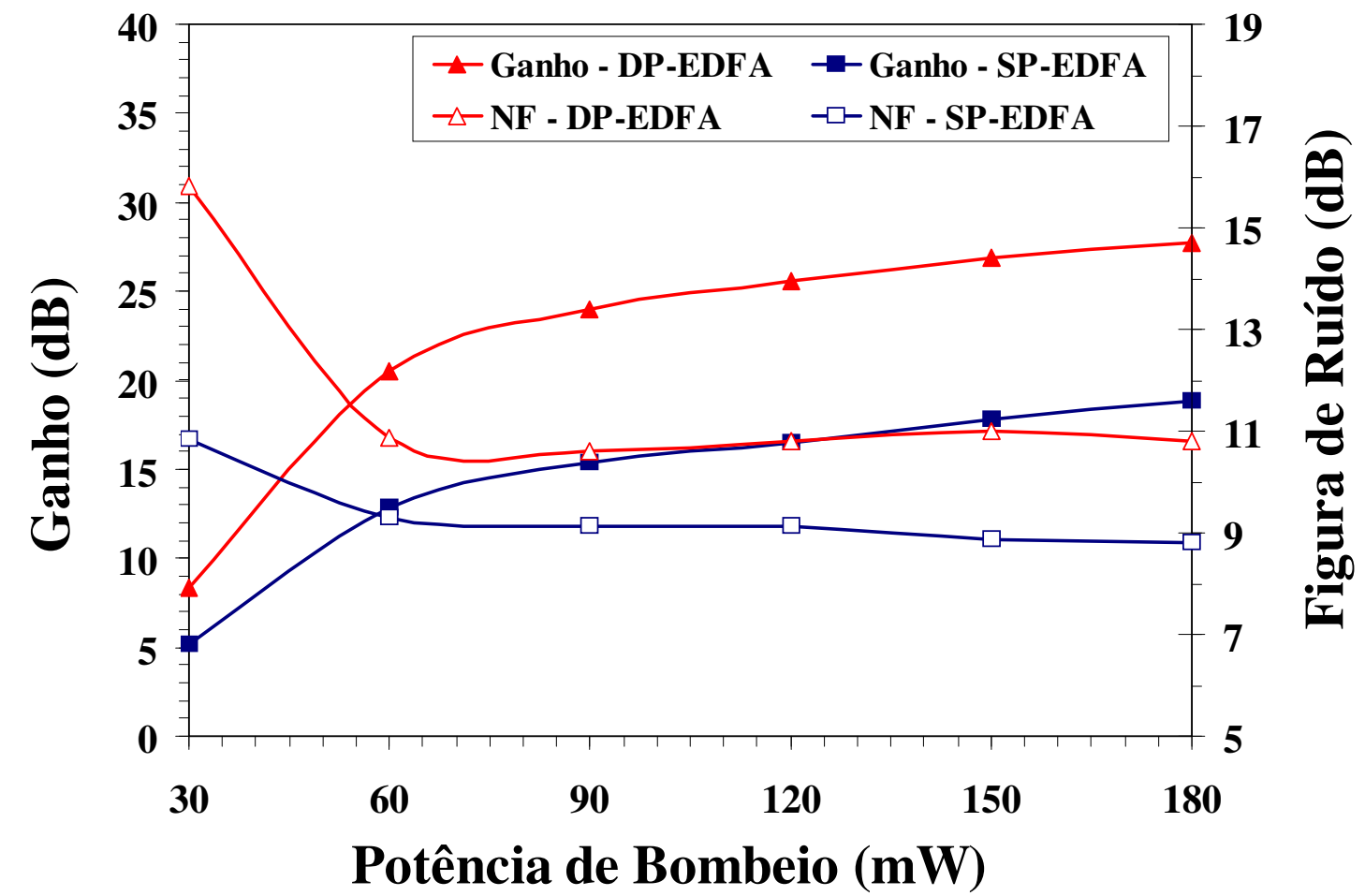

Fig. 4.19 - Ganho e figura de ruído em função da potência de bombeio, para DP-EDFA e SP-EDFA com fibra dopada com érbio na banda $\mathrm{S}$.

Esta fibra foi então utilizada na montagem de um amplificador de dupla passagem de três bandas substituindo a fibra de túlio utilizada na seção anterior. Para a escolha da topologia adotada para o DP-EDFA de três bandas para aplicações em redes CWDM, consideramos como premissa fundamental o menor custo possível. Isto é conseguido com algumas medidas básicas: em primeiro lugar adotando somente fibras dopadas com érbio. Em segundo lugar, reduzindo o número de dispositivos ativos. Adotou-se o uso de somente dois lasers de bombeio no comprimento de onda de $980 \mathrm{~nm}$. A adoção de dois lasers de bombeio 
para todas as bandas requer o uso de uma configuração série/paralela, ou seja, circuito série para as bandas S e C e paralelo para a banda L. Uma configuração parecida com esta já foi detalhada para o DP-EDFA de duas bandas (C e L) mostrado na Seção 4.2. Apesar dos resultados obtidos naquele amplificador não terem sido animadores, neste presente caso as circunstâncias são diferentes, como veremos adiante. O circuito adotado é mostrado na Figura 4.20.

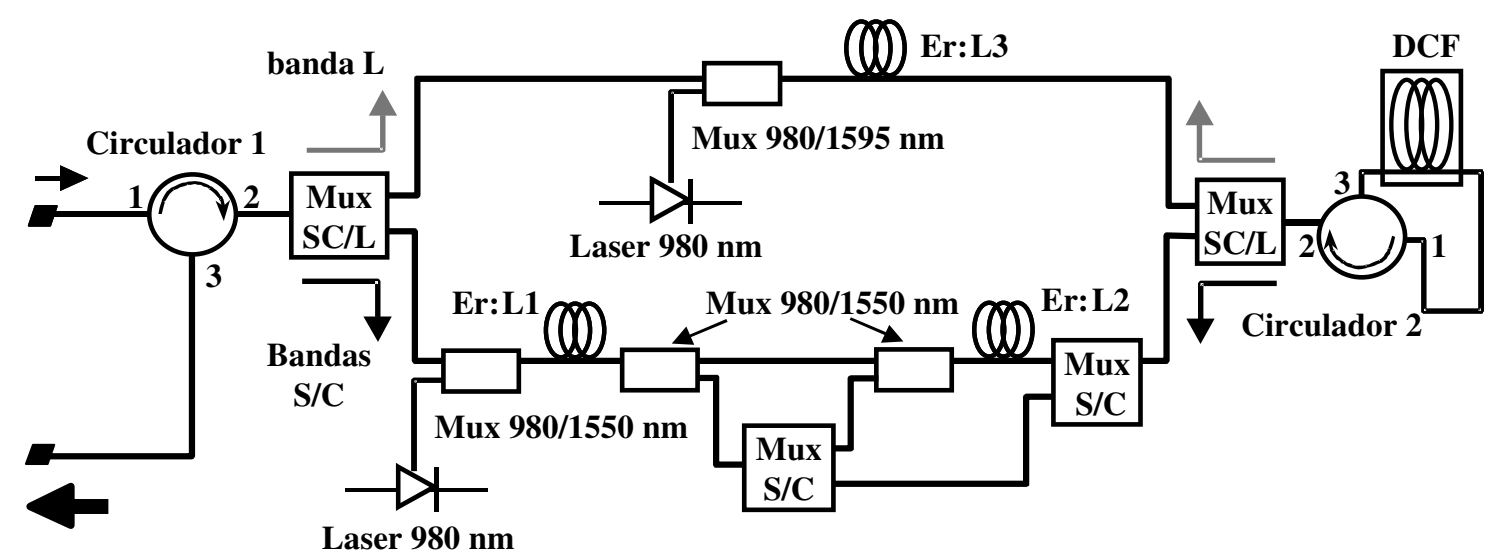

Fig. 4.20 - Circuito do DP-EDFA de três bandas para aplicações em sistemas CWDM.

O circuito mostrado na Figura 4.20 tem muitas semelhanças com outros circuitos já descritos anteriormente. Alguns detalhes particulares são: as fibras dopadas $\mathrm{L}_{1}$ e $\mathrm{L}_{3}$ são do mesmo tipo daquela fibra usada e já descrita na Seção 4.4, ou seja, fibra de alta dopagem. O comprimento de $L_{1}$ é igual a 1,7 metros e o comprimento de $L_{3}$ é de 16 metros. A fibra $L_{2}$ é a fibra de perfil de índice rebaixado para aplicações na banda S. O comprimento utilizado para $\mathrm{L}_{2}$ foi de 14 metros. No primeiro trecho do circuito série os comprimentos de onda da grade CWDM amplificados são $1490 \mathrm{~nm}, 1510 \mathrm{~nm}, 1530 \mathrm{~nm}$ e $1550 \mathrm{~nm}$. Os dois primeiros comprimentos de onda obtêm ligeiro ganho neste primeiro estágio, sendo o restante do ganho fornecido pelo trecho de fibra $\mathrm{L}_{2}$. Os comprimentos de onda de $1530 \mathrm{~nm}$ e $1550 \mathrm{~nm}$ são totalmente amplificados no primeiro trecho $\mathrm{L}_{1}$. Este mesmo trecho é projetado para, além de fornecer ganho para todos os quatro comprimentos de onda citados, permitir uma sobra de 
bombeio, que é levada para o trecho de fibra dopada $\mathrm{L}_{2}$. Esta utilização de bombeio residual somente é possível para amplificadores de linha (ou pré-amplificadores), onde ocorre baixa supressão de bombeio. Uma simulação aproximada do processo de ganho que ocorre com estes comprimentos de onda no primeiro estágio é mostrado na Figura 4.21. A simulação é aproximada porque não é possível simular no software OASIX o ganho da fibra de perfil de índice de refração rebaixado. Assim, o que vemos no primeiro trecho de amplificação $\mathrm{L}_{1}$ não inclui totalmente os efeitos de depleção de bombeio que os comprimentos de onda de 1490 e $1510 \mathrm{~nm}$ amplificados em $\mathrm{L}_{2}$, poderiam causar em $\mathrm{L}_{1}$. De toda forma, podemos observar na Fig.4.21 que, para 1,7 m de comprimento de fibra dopada do trecho $\mathrm{L}_{1}$, o ganho em $1500 \mathrm{~nm}$ é de $4 \mathrm{~dB}$, para $1510 \mathrm{~nm}$ é de $8 \mathrm{~dB}$, para $1530 \mathrm{~nm}$ é de $34 \mathrm{~dB}$ e para $1550 \mathrm{~nm}$ é de $22 \mathrm{~dB}$. O valor de potência de bombeio residual em $980 \mathrm{~nm}$ na saída de $\mathrm{L}_{1}$ é de $65 \mathrm{~mW}$.

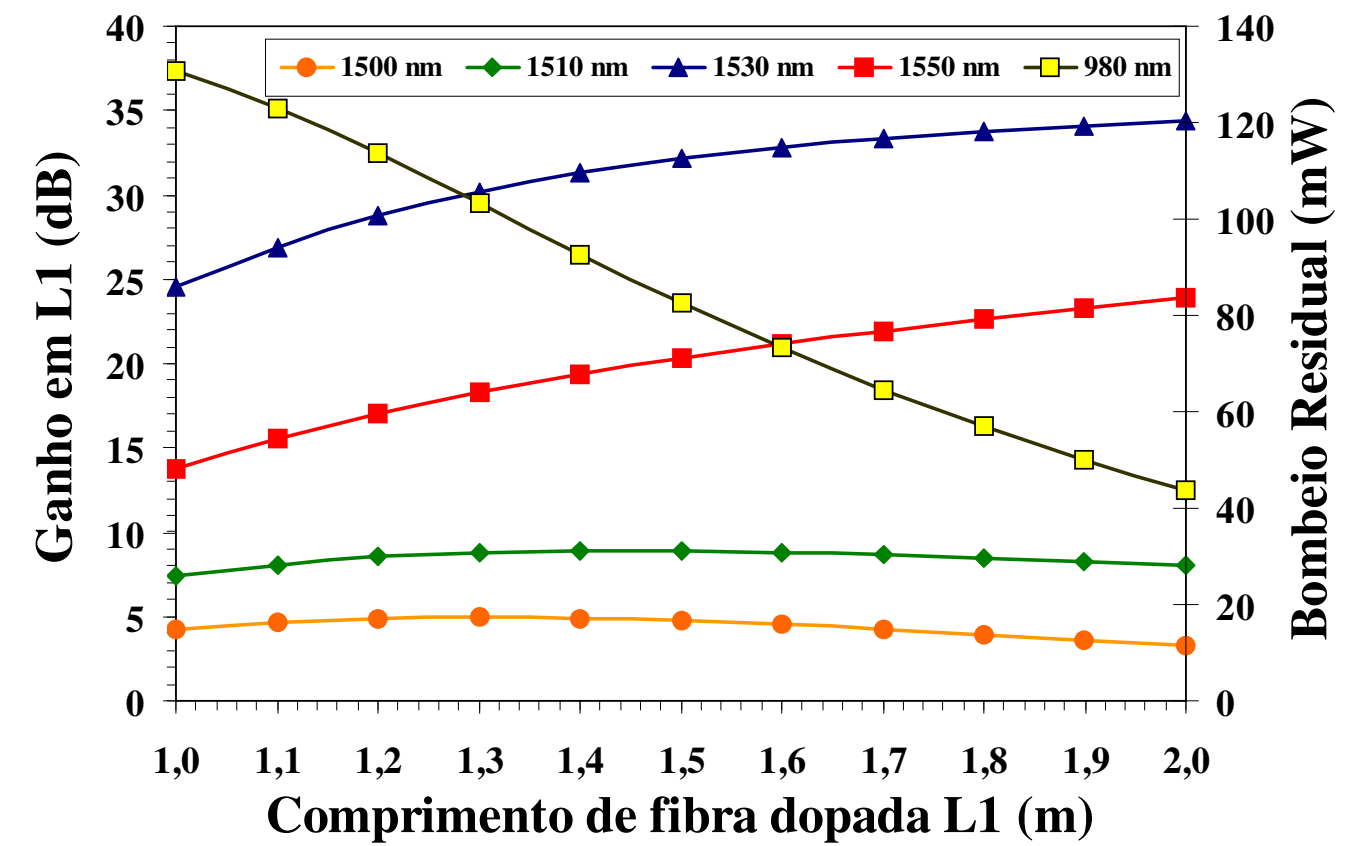

Fig.4.21 - Simulação do comportamento do ganho e da potência de bombeio residual do primeiro trecho de fibra $\mathrm{L}_{1}$ em função do comprimento de fibra dopada $\mathrm{L}_{1}$.

Multiplexadores de banda semelhantes aqueles já descritos nas seções 4.3 e 4.4 são usados em pontos estratégicos do circuito para a separação ou junção das bandas utilizadas. O circuito foi então montado e caracterizado em termos de ganho e figura e ruído com e sem a presença de fibra DCF para potências de entrada de $-10,-15$ e $-20 \mathrm{dBm}$. A fibra DCF 
utilizada foi a de - 900 ps/nm com 6 dB de perda de inserção. Os resultados são mostrados na Tabela 4.2. A potência para o laser de bombeio da banda $\mathrm{L}$ foi de $120 \mathrm{~mW}$ e para o laser das bandas S e C foi de $150 \mathrm{~mW}$. A Figura 4.22 apresenta uma curva espectral da potência de saída para o DP-EDFA para a condição de potência de entrada de -15 dBm com DCF.

Tab. 4.2 - Ganho e figura de ruído para o amplificador DP-EDFA na grade CWDM.

\begin{tabular}{|l|c|r|r|r|r|r|r|r|r|}
\hline \multicolumn{1}{|c|}{ Lambda (nm) } & $\mathbf{1 4 5 0}$ & $\mathbf{1 4 7 0}$ & $\mathbf{1 4 9 0}$ & $\mathbf{1 5 1 0}$ & $\mathbf{1 5 3 0}$ & $\mathbf{1 5 5 0}$ & $\mathbf{1 5 7 0}$ & $\mathbf{1 5 9 0}$ & $\mathbf{1 6 1 0}$ \\
\hline Ganho sem DCF (dB) - Pin = -10 dBm & - & - & 9,01 & 10,45 & 19,97 & 14,09 & 20,94 & 13,76 & 6,87 \\
\hline Ganho sem DCF (dB) - Pin = -15 dBm & - & - & 15,10 & 18,13 & 23,98 & 16,33 & 24,35 & 16,18 & 8,48 \\
\hline Ganho sem DCF (dB) - Pin = -20 dBm & - & - & 19,48 & 23,87 & 27,19 & 18,03 & 29,88 & 17,91 & 9,63 \\
\hline \hline NF sem DCF (dB) - Pin = -10 dBm & - & - & 12,48 & 13,61 & 7,05 & 6,51 & 8,24 & 8,36 & 10,58 \\
\hline NF sem DCF (dB) - Pin = -15 dBm & - & - & 10,45 & 10,63 & 6,12 & 5,85 & 8,49 & 7,61 & 9,57 \\
\hline NF sem DCF (dB) - Pin = -20 dBm & - & - & 9,60 & 9,27 & 5,74 & 5,53 & 6,47 & 7,53 & 9,15 \\
\hline \hline Ganho com DCF (dB) - Pin = -10 dBm & - & - & 6,72 & 9,24 & 18,24 & 10,15 & 20,16 & 9,77 & 1,20 \\
\hline Ganho com DCF (dB) - Pin = -15 dBm & - & - & 13,90 & 18,32 & 21,73 & 11,91 & 24,57 & 11,86 & 2,44 \\
\hline Ganho com DCF (dB) - Pin = -20 dBm & - & - & 18,49 & 24,46 & 24,35 & 13,26 & 28,30 & 13,31 & 3,47 \\
\hline \hline NF com DCF (dB) - Pin = -10 dBm & - & - & 14,55 & 15,25 & 8,31 & 8,01 & 9,53 & 10,33 & 18,70 \\
\hline NF com DCF (dB) - Pin = -15 dBm & - & - & 10,75 & 10,69 & 7,56 & 7,32 & 8,35 & 9,50 & 15,60 \\
\hline NF com DCF (dB) - Pin = -20 dBm & - & - & 9,43 & 8,79 & 6,94 & 6,76 & 7,31 & 9,14 & 14,01 \\
\hline
\end{tabular}

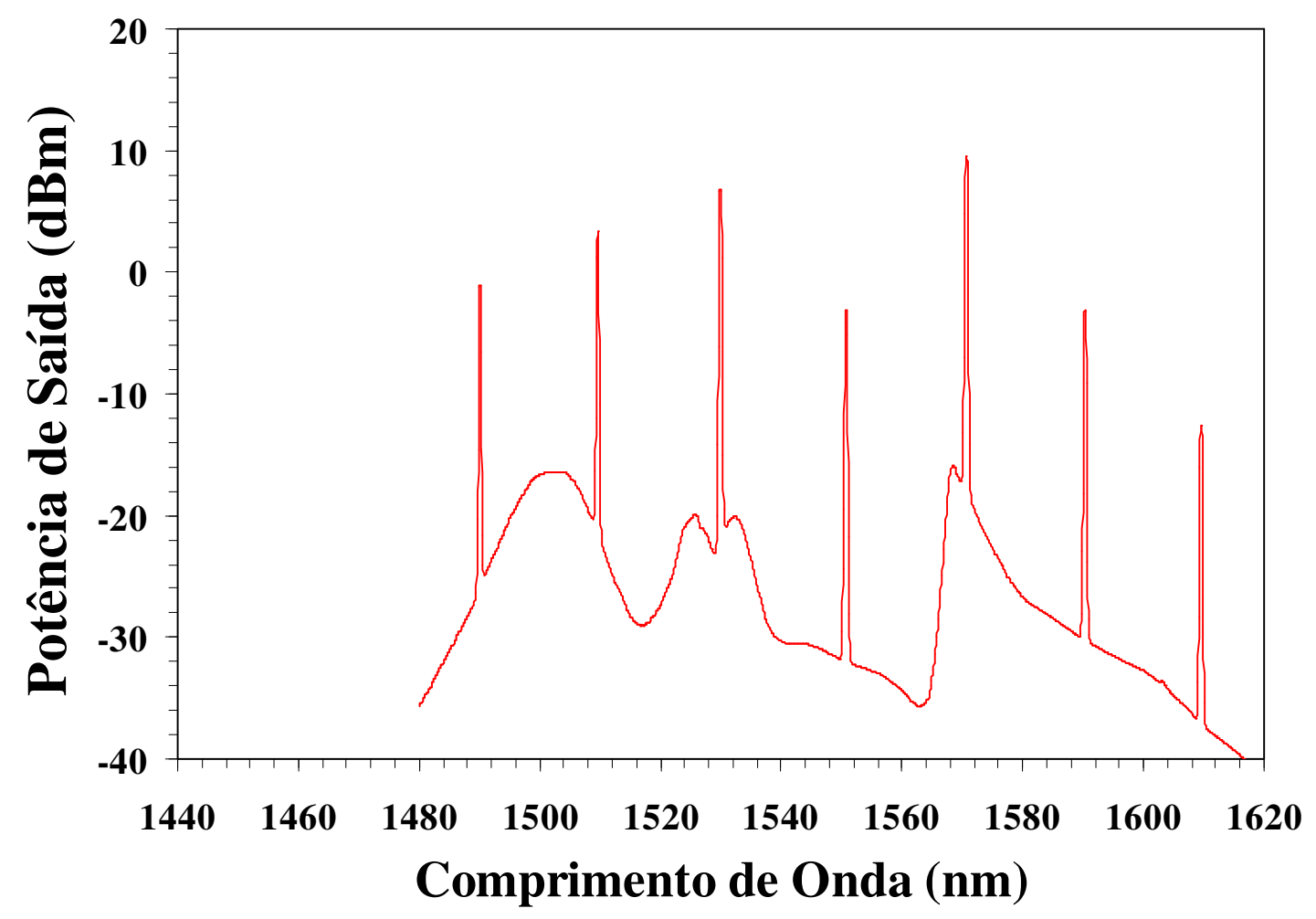

Fig. 4.22 - Espectro de saída CWDM do DP-EDFA com DCF para uma potência de entrada de $-15 \mathrm{dBm}$. 
Torna-se necessária uma comparação dos parâmetros de ganho e figura de ruído, entre o amplificador DP-EDFA apresentado na Seção 4.5.1 e o DP-EDFA/TDFA apresentado nesta seção. Desta forma mostramos na Figura 4.23(a) os resultados das diferenças de ganho e na Figura 4.23(b) os resultados das diferenças de figura de ruído, para as duas configurações, ou seja, os parâmetros do DP-EDFA/TDFA mostrados na Tabela 4.1 subtraídos dos parâmetros do DP-EDFA mostrados na Tabela 4.2. A Figura 4.23 aponta também em que região espectral os dois amplificadores funcionam mais eficientemente.
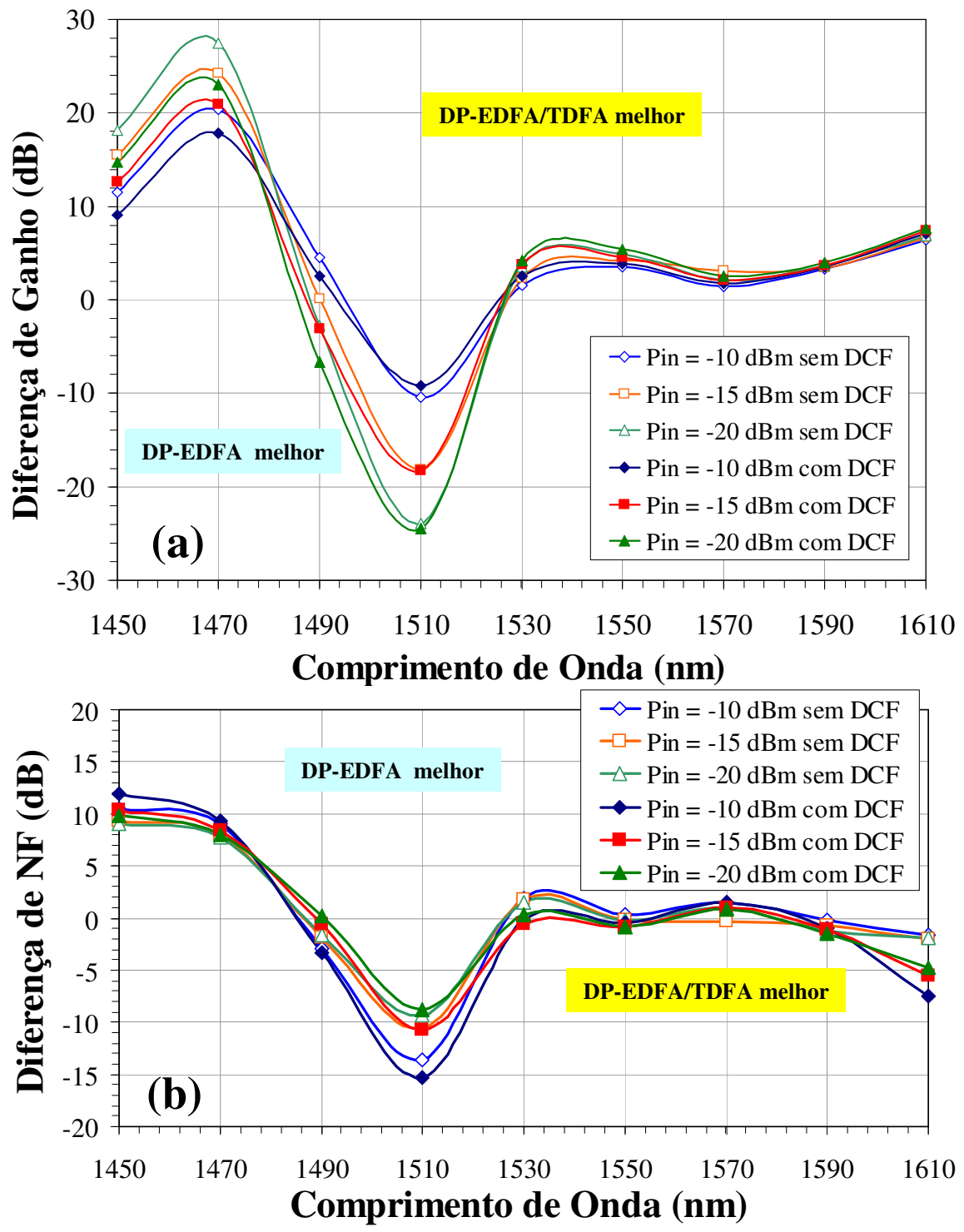

Fig. 4.23 - Resultados da diferenças entre os parâmetros (a) ganho e (b) figura de ruído para os amplificadores DP-EDFA/TDFA e DP-EDFA. 
Devemos considerar, inicialmente, que os comprimentos de onda de $1450 \mathrm{~nm}$ e 1470 não apresentam ganho no DP-EDFA/TDFA e o comprimento de onda de $1510 \mathrm{~nm}$ só apresenta ganho no DP-EDFA. Todos os outros comprimentos de onda são amplificados nos dois tipos de amplificadores. A análise de ganho mostra que o DP-EDFA/TDFA tem um ganho maior do que o DP-EDFA entre 1530 até $1610 \mathrm{~nm}$, com valores variando entre 2 a 8 dB. O circuito de amplificação na banda L é praticamente idêntico nos dois tipos de amplificadores, excetuando o fato de que no DP-EDFA/TDFA são usados dois multiplexadores de banda adicionais. A diferença de ganho na região na banda L entre os dois circuitos é atribuída à acomodação dos componentes, curvaturas acentuadas e eventuais emendas com perda elevada. A amplificação na banda L para comprimentos mais longos (acima de $1570 \mathrm{~nm}$ ) é um processo que apresenta baixa eficiência. Assim uma eventual redução da potência de bombeio ao longo da fibra dopada, devido às curvaturas e emendas de alta perda, podem reduzir significativamente o ganho nesta região do espectro. Em 1490 nm, para valores de potência de entrada abaixo de $-15 \mathrm{dBm}$, o DP-EDFA é melhor do que o DPEDFA/TDFA. A análise de figura de ruído mostra que o DP-EDFA têm valores inferiores ao DP-EDFA/TDFA entre 1530 até $1570 \mathrm{~nm}$, variando entre 0,5 a $2 \mathrm{~dB}$. De $1590 \mathrm{~nm}$ até 1610 nm o DP-EDFA/TDFA tem melhor figura de ruído do que o DP-EDFA, com valores variando entre 0,5 a 7,5 dB. Esta faixa de valores é explicada pelos motivos já expostos para a redução de ganho na banda L do DP-EDFA. Em 1490 nm o DP-EDFA/TDFA é melhor do que o DPEDFA com valores variando entre 0,5 a $3,5 \mathrm{~dB}$.

Os resultados do DP-EDFA podem ser comparados com os resultados do circuito proposto em [84]. Apesar da caracterização realizada no circuito proposto naquela referência ser monocanal e o circuito não ser de dupla passagem, o circuito por nós proposto tem uma alguma similaridade com o da Figura 4.20, dado que foram utilizadas fibras de mesmas características e circuitos em paralelo e série. Em relação àquele circuito, o DP-EDFA aqui 
proposto tem a vantagem de usar menor potência de bombeio, possuir maior ganho, usar menor comprimento de fibra, menor número de componentes, além de incorporar uma fibra DCF, cuja funcionalidade não é prevista naquele circuito. Em ambas as propostas a largura de banda total disponível é de $120 \mathrm{~nm}$.

A comparação dos resultados do DP-EDFA/TDFA pode ser feita com o amplificador de passagem simples tipo EDFA/TDFA da referência [86]. O amplificador proposto nesta tese opera como amplificador de linha, usando circuitos ópticos de amplificação em paralelo. O amplificador da referência [86] também faz uso de circuitos ópticos de amplificação em paralelo, mas é feito para operar como amplificador de potência. O amplificador de [86] tem a vantagem de possuir amplificação na região de $1510 \mathrm{~nm}$, fato este não propiciado pelo amplificador que propomos.

\subsubsection{Caracterização sistêmica do DP-EDFA com DCF em redes CWDM de barramento}

A aplicação alvo do DP-EDFA descrito na Seção 4.5.2 são as redes CWDM, em particular redes CWDM em barramento, como mostrado no esquema da Figura 4.24 para o sentido estação/cliente.

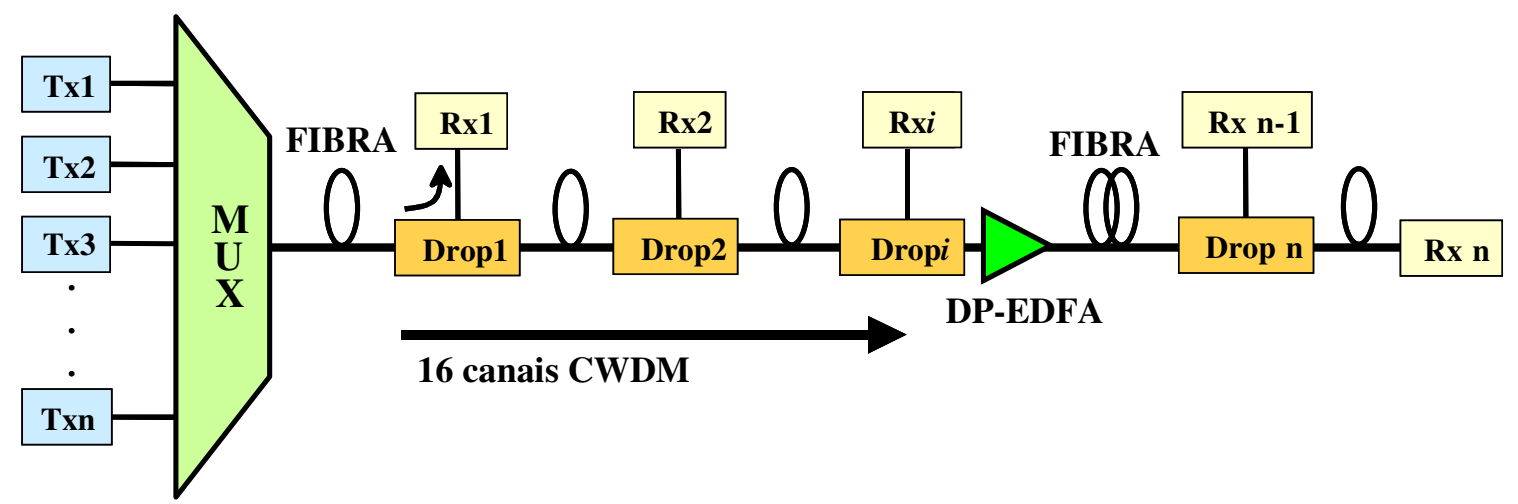

Fig. 4.24 - Rede CWDM em barramento, mostrando apenas para o sentido estação/cliente.

Redes em barramento ou anel são limitadas em distância devido ao acúmulo de perda dos elementos passivos de remoção e inserção de sinal (add/drops), de conectores ópticos, da própria fibra óptica e suas emendas. O uso do amplificador pode aumentar consideravelmente 
os limites desta topologia, até que um novo limite seja imposto, neste caso devido a dispersão cromática de fibras convencionais.

Utilizando as expressões de cálculo desenvolvidas no Apêndice C, simulamos os limites desta topologia para diversas situações, ilustradas na Figura 4.25, para 2,5 Gb/s. Para realizar estes cálculos utilizamos os valores de atenuação e dispersão de fibras convencionais do tipo A, B, C e D especificadas na referência [20]. Os tipos A e B são fibras convencionais com atenuação suplementar na região de 1400 nm devida à absorção do íon $\mathrm{OH}^{-}$. Os tipos $\mathrm{C}$ e D são fibras convencionais sem atenuação devido a esta impureza. Outros dados tais como perda dos insere/remove, conectores e emendas são típicos de componentes comerciais e respectivamente valem $0,7,0,3$ e $0,05 \mathrm{~dB}$. Os valores de potência de transmissão e sensibilidade são obtidos da referência [20]. Para compensação de dispersão foi considerada uma DCF de -700 ps/nm em $1550 \mathrm{~nm}$.

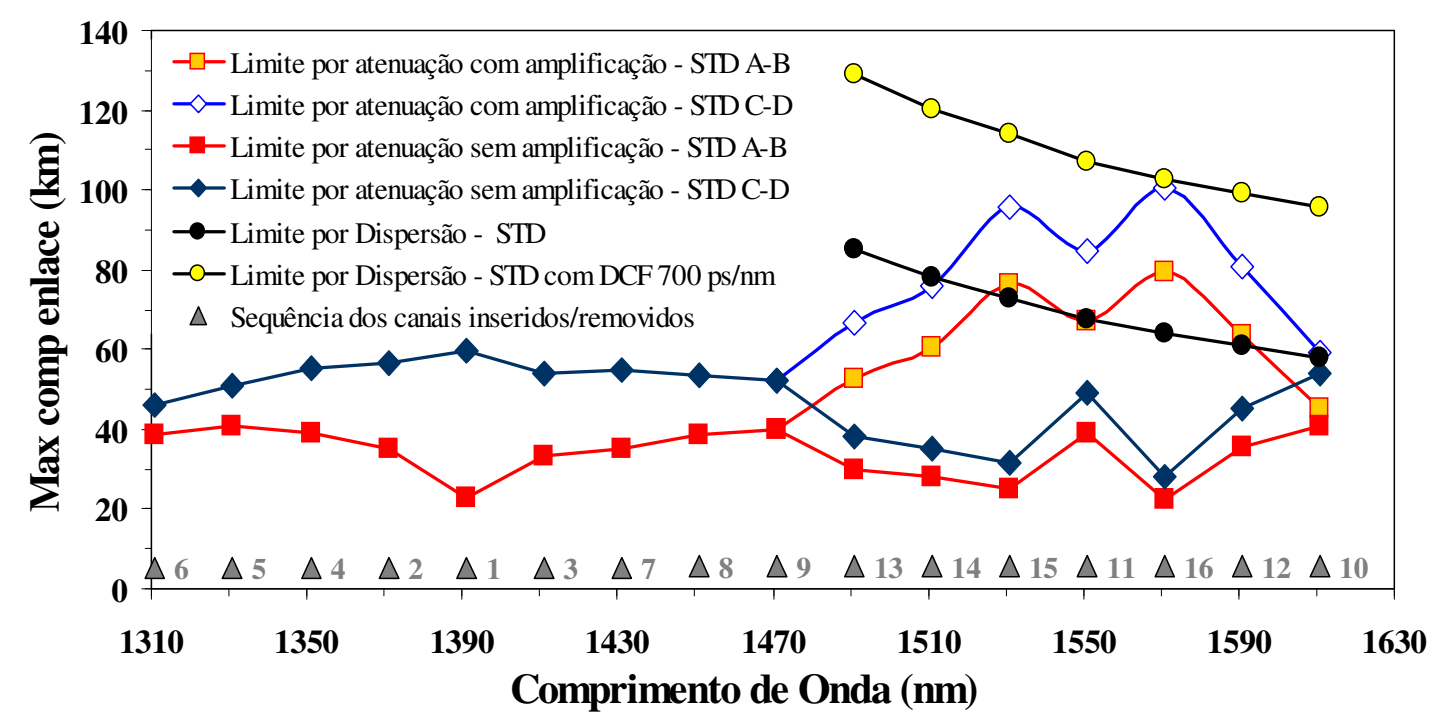

Fig. 4.25 - Simulações de comprimento máximo de redes CWDM em barramento para diversas situações.

A estratégia adotada para otimizar a rede CWDM simulada foi escolher a posição de cada insere/remove na rede de acordo com a atenuação causada pela fibra em cada comprimento de onda. Desta forma, os canais em comprimentos de onda de maior atenuação 
são primeiramente removidos/inseridos, e os de menor atenuação são alocados mais próximos ao fim da rede.

Como pode ser visto na Figura 4.25 o comprimento máximo da rede CWDM sem amplificação, que é representado pela posição do canal removido/inserido número 16 (1570 $\mathrm{nm}$ ) é de $28 \mathrm{~km}$ para fibras tipo C e D, e de $22 \mathrm{~km}$ para fibras A e B. Nesta simulação foi adotado o fotodetector APD, que apresenta melhor sensibilidade na recepção. Na simulação com amplificação os valores de ganho para a potência de $-15 \mathrm{dBm}$ mostrados na Tabela 4.2 foram utilizados agora com fotodetector tipo PIN (para melhor custo benefício). Como pode ser visto na Figura 4.25 o comprimento máximo da rede CWDM com amplificação, que é também representada pela posição do canal removido/inserido número 16 (1570 nm), é de $102 \mathrm{~km}$ para fibras tipo C e D, e de $80 \mathrm{~km}$ para fibras A e B. A Figura 4.25 mostra também os limites de dispersão, com ênfase na região espectral entre 1590 e 1610 nm. Pode-se observar que a maioria dos canais amplificados necessita de compensação de dispersão para operarem adequadamente nos novos limites de distância da rede.

Para testar na prática o amplificador DP-EDFA, descrito na seção 4.5.2 utilizamos uma rede CWDM laboratorial em barramento constituída por 16 canais espaçados de $20 \mathrm{~nm}$ de $1310 \mathrm{~nm}$ até $1610 \mathrm{~nm}$. Cada canal é transmitido em modulação direta em 2,5 Gb/s por um laser DFB sem refrigeração (cooler). Após multiplexados em uma única fibra, os 16 canais são levados a rede de barramento, contendo também 16 deriva/inseres, construídos usando a tecnologia de filme dielétrico. A Figura 4.26(a) mostra o sistema de transmissão e multiplexação de comprimento de onda contendo os 16 lasers CWDM. A Figura 4.26(b) mostra o empacotamento para os 16 deriva/insere junto com trechos de fibra convencional do tipo A e B, que compõe a rede de CWDM de barramento. A Figura 4.26(c) mostra o empacotamento do amplificador DP-EDFA para as bandas S, C e L. Na Figura 4.27 mostramos a perda de inserção/remoção de canais e também a perda média de passagem do 
sinal pelo deriva/insere no espectro de transmissão CWDM. No mesmo gráfico mostramos a atenuação da fibra convencional dos tipos $A \& B$ e $C \& D$ obtida da referência [20]. Os conectores ópticos impõem perdas da ordem de $0,3 \mathrm{~dB}$ por inserção e as emendas impõem perdas inferiores a $0,1 \mathrm{~dB}$ cada.
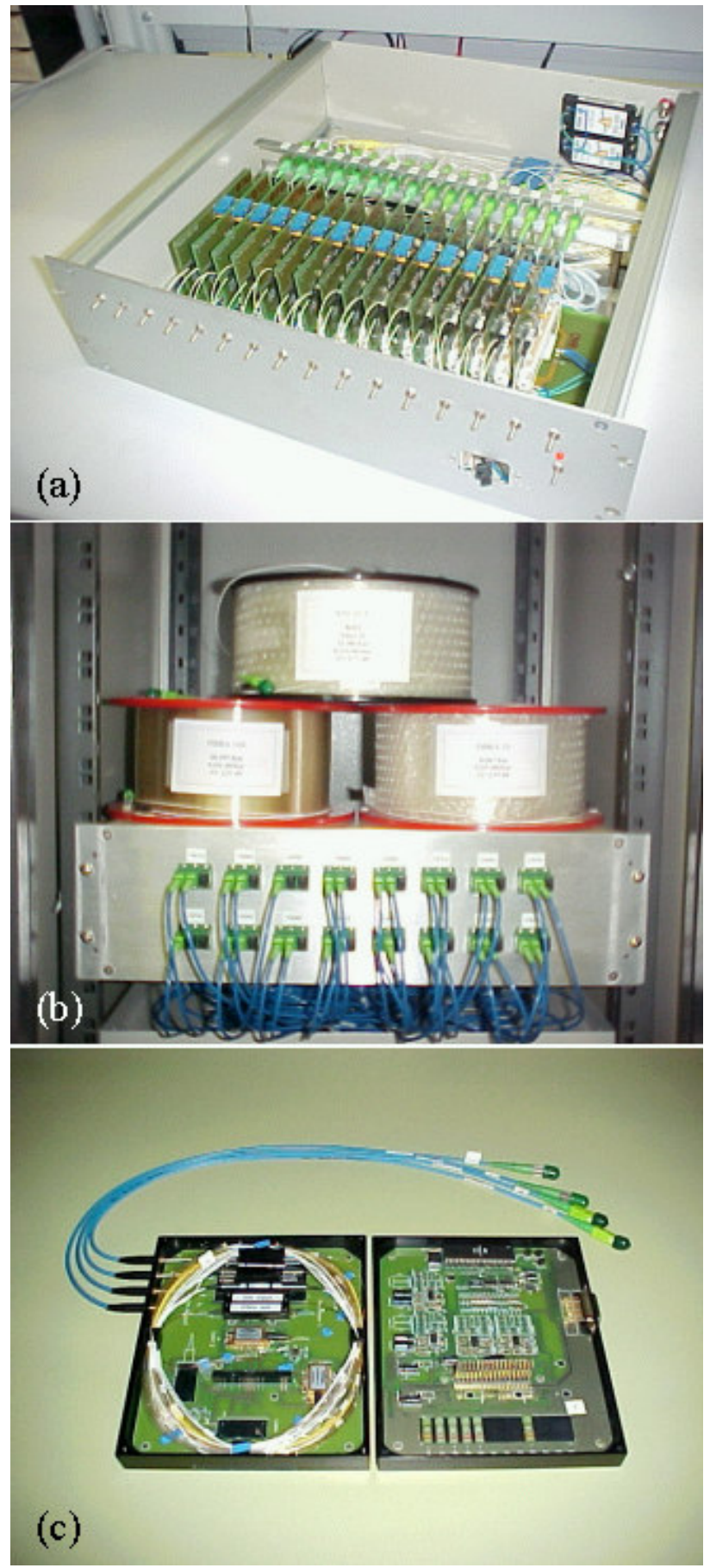

Fig. 4.26 - (a) Sistema de transmissão e multiplexação dos conversores de comprimento de onda, (b) empacotamento para os 16 deriva/insere junto com trechos de fibra convencional que compõe a rede de CWDM de barramento e (c) DP-EDFA para as bandas S, C e L. 


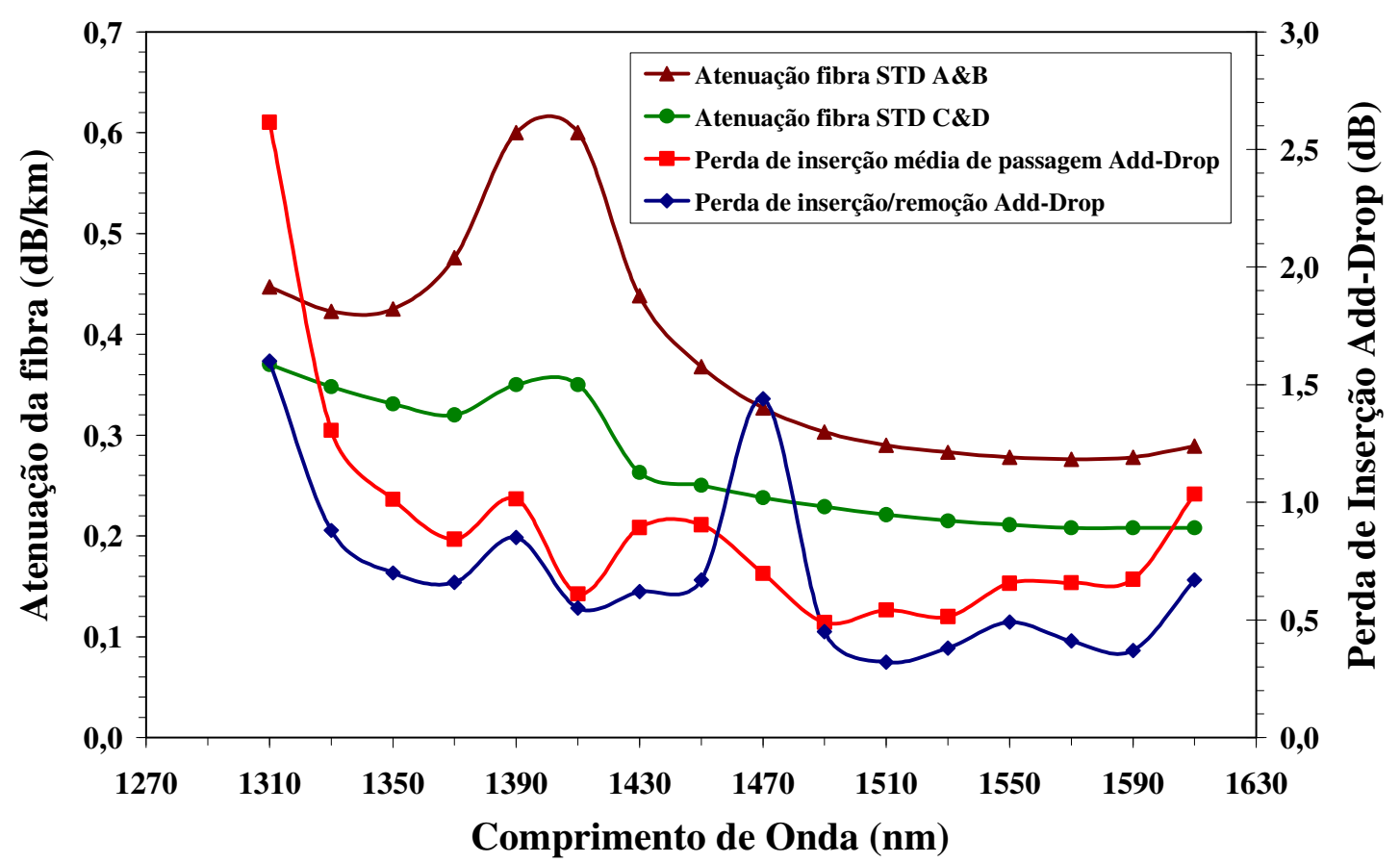

Fig. 4.27 - Perda de inserção/remoção e perda média de passagem do sinal pelo deriva/insere e atenuação da fibra convencional dos tipos A\&B e C\&D obtida da referência [20].

O amplificador DP-EDFA com uma DCF de -700 ps/nm foi posicionado na rede após o décimo primeiro add-drop $(1470 \mathrm{~nm})$. Nesta posição, a potência de entrada média para os canais entre $1490 \mathrm{~nm}$ e $1590 \mathrm{~nm}$ foi de $-13 \mathrm{dBm}$. A potência do último canal da grade, 1610 $\mathrm{nm}$, foi de $-19 \mathrm{dBm}$. No trecho anterior ao DP-EDFA foi inserido uma fibra convencional tipo A ou B de $32 \mathrm{~km}$, além dos 9 elementos insere/remove. Após o DP-EDFA foram posicionados comprimentos de onda compatíveis com o ganho do amplificador em cada comprimento de onda, além dos elementos insere/remove para os comprimentos de onda amplificados. Os canais foram caracterizados sistemicamente em termos de taxa de erro de bit em função da potência recebida, para duas situações: com e sem DCF. A Figura 4.28 mostra esta caracterização para um canal escolhido em cada banda, ou seja, em $1490 \mathrm{~nm}, 1530 \mathrm{~nm}$ e $1590 \mathrm{~nm}$. Todas as fibras utilizadas apresentaram atenuação de $0,20 \mathrm{~dB} / \mathrm{km}$ em $1550 \mathrm{~nm}$ e coeficiente de dispersão cromática de 17 ps/nm.km. A atenuação das fibras usadas no experimento é menos severa do que aquelas utilizadas na simulação mostrada na Figura 4.25. Deve ser observado também que a 
inclinação natural das curvas de dispersão da DCF e da fibra convencional (ver Figura 2.5(a)) possibilita a equalização da compensação de dispersão nas bandas S, C e L.

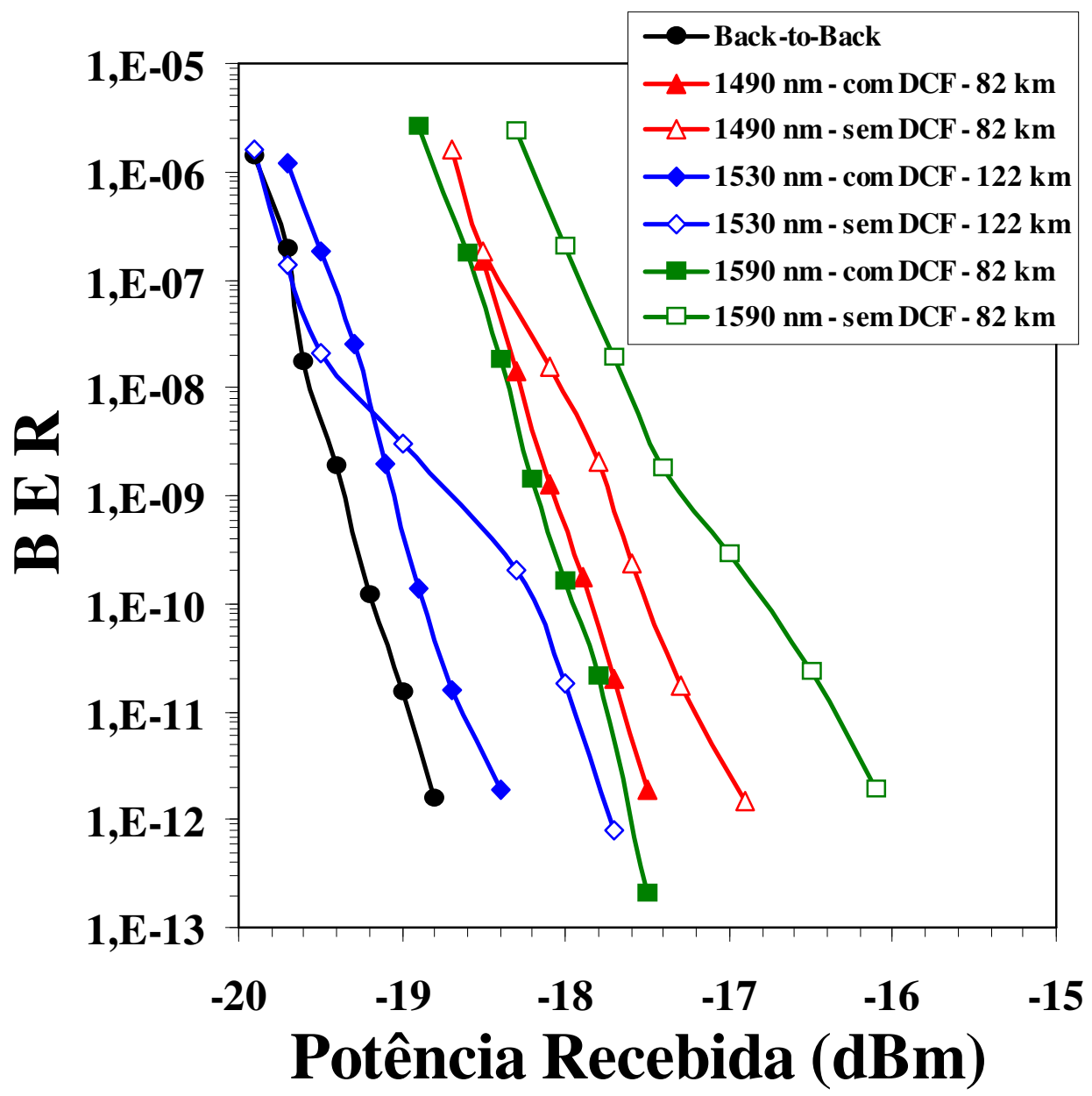

Fig. 4.28 - Taxa de erro de bit em função da potência recebida para três canais da grade CWDM amplificados pelo DP-EDFA com DCF.

Uma análise do gráfico da Figura 4.28 mostra que todos os canais medidos foram penalizados tanto pela dispersão cromática (curvas sem DCF) como pela ASE do DP-EDFAs (ambas as curvas), que eleva a figura de ruído. Nenhum patamar de erros é observado nas curvas dos DP-EDFAs. Na Figura 4.29 apresentamos um gráfico que resume as penalidades de todos os canais medidos (exceto para o DP-EDFA com DCF em $1610 \mathrm{~nm}$ ), numa taxa de erros de bit de $10^{-12}$, para DP-EDFA com e sem DCF, em $82 \mathrm{~km}$. Não foi possível realizar medidas com o canal $1610 \mathrm{~nm}$ para DP-EDFA com DCF, devido ao reduzido ganho neste comprimento de onda, e ao comprimento excessivo de enlace para este canal. As medidas para $122 \mathrm{~km} \mathrm{de}$ 
fibra se tornam possíveis para os comprimentos de onda de 1530 e $1570 \mathrm{~nm}$, devido ao elevado ganho destes canais.

Tanto a penalidade por dispersão como a penalidade por ASE tem dependência com o comprimento de onda. Comprimentos de onda mais longos são mais penalizados pela dispersão cromática. A ASE penaliza com intensidade decrescente na sequiência, os comprimentos de onda da banda C, banda L e, finalmente banda S. Pode ser observado que o uso da DCF conjugada ao amplificador de dupla passagem reduziu a penalidade dos canais medidos. A alta penalidade observada no comprimento de onda de 1510 nm é atribuída a um provável deslocamento da curva de ganho do amplificador e conseqüentemente da figura de ruído, devido a mudanças nas curvaturas da fibra dopada com érbio usada na banda $\mathrm{S}$, dentro do empacotamento do amplificador.

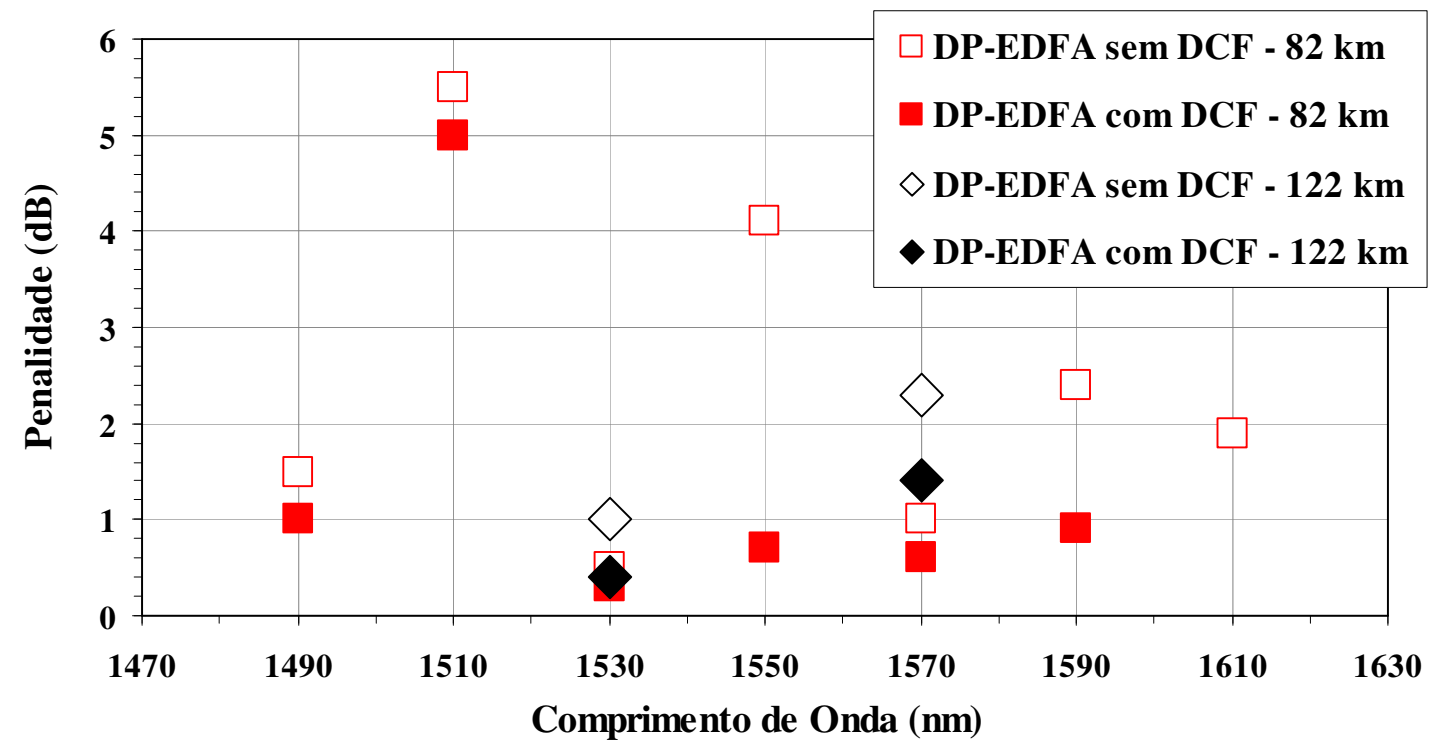

Fig. 4.29 - Resumo das penalidades de todos os canais medidos em $82 \mathrm{~km} \mathrm{e} 122 \mathrm{~km}$.

Demonstrou-se, portanto que o DP-EDFA com DCF de dupla passagem analisado permite a extensão de redes CWDM em barramento, corrigindo, não somente a atenuação dos elementos de inserção e remoção de sinal e própria fibra óptica entre 1490 e 1610 nm, como também os efeitos de penalidade na recepção devido à dispersão cromática. 


\section{CAPÍtULO 5}

\section{CONCLUSÕES}

Esta tese investigou amplificadores ópticos a fibra dopada de dupla passagem (DPEDFA) com fibras compensadoras de dispersão (DCF) embutidas. Estes amplificadores são uma promissora opção para aplicações em redes metropolitanas e de acesso onde baixo custo é um parâmetro prioritário na aceitação da tecnologia. DP-EDFAs apresentam um estrutura de amplificação mais enxuta, que o torna recomendável para estas aplicações. O uso integrado da DCF potencializa sua aplicação em redes de alta taxa de transmissão empregando fontes ópticas com modulação direta, como é o caso de redes CWDM, onde a dispersão é também uma limitação. No trabalho desenvolvido mostrou-se inicialmente, através de experimentos laboratoriais, que algumas configurações de DP-EDFAs com DCFs embutidas apresentam problemas de operação em sistemas ópticos reais, devido à variação da polarização do sinal e ao retroespalhamento Rayleigh, que deteriora a qualidade do sinal. Para eliminar estes problemas em DP-EDFAs com DCF, apresentamos uma nova proposta que foi extensivamente testada, apresentando bons resultados. Esta nova configuração proposta foi adaptada para uma série de aplicações em sistemas de comunicações ópticas multicanal e multibanda. Os DP-EDFAs analisados nestas aplicações apresentaram ganho de sinal superior aos amplificadores convencionais de passagem única e de único estágio. A figura de ruído também analisada mostrou-se pior do que amplificadores convencionais de passagem única e de único estágio devido ao efeito da potência de ASE, que é mais intensa em DP-EDFAs. Ainda assim mostrou-se, através de experimentos sistêmicos em 2,5 e $10 \mathrm{~Gb} / \mathrm{s}$, que o desempenho do DP-EDFA com DCF embutida é bastante satisfatório para aplicações em redes metropolitanas e de acesso, a um custo inferior aos amplificadores de passagem única. 


\subsection{Contribuições originais desta Tese}

As primeiras contribuições originais desta Tese são relativas às avaliações experimentais do desempenho de ganho e figura de ruído de duas configurações de DPEDFAs com DCF frente a variação da polarização do sinal de entrada. Outra contribuição original, consiste na caracterização de desempenho, em termos de taxa de erro de bit, para três configurações de DP-EDFAs com DCF. Uma destas configurações, que é proposta nesta tese, é utilizada para demonstração sistêmica em $10 \mathrm{~Gb} / \mathrm{s}$, pela primeira vez, de um amplificador DP-EDFA com DCF.

Outro conjunto de contribuições originais se deve a demonstrações experimentais de vários circuitos ópticos de DP-EDFAs com DCF para operações em sistemas multicanal e multibanda. As seguintes contribuições foram dadas, relativas a estas aplicações:

- Avaliação experimental em sistema DWDM na banda L, de ganho, figura de ruído e taxa de erro de bit do DP-EDFA com DCF.

- Avaliação experimental em sistema DWDM nas bandas C e L, de ganho e figura de ruído do DP-EDFA com DCF na configuração de circuito paralelo.

- Avaliação experimental em sistema DWDM nas bandas C e L, de ganho e figura de ruído do DP-EDFA com DCF na configuração de circuito série.

- Avaliação experimental em sistema DWDM nas bandas S, C e L, de ganho e figura de ruído de uma configuração mista DP-EDFA/TDFA com DCF na configuração de circuito paralela.

- Avaliação experimental em sistema CWDM nas bandas S, C e L, de ganho e figura de ruído de uma configuração mista DP-EDFA/TDFA com DCF na configuração de circuito paralela.

Outras contribuições desta Tese consistem na análise experimental do desempenho sistêmico do DP-EDFAs com DCF em redes CWDM de barramento, nas bandas S, C e L. 
Finalmente obtivemos resultados experimentais originais relativos à técnica de sintonia de banda de ganho em fibras dopadas com érbio do tipo depressed cladding para a utilização na banda $\mathrm{S}$.

As publicações relativas a estas contribuições encontram-se listadas no Apêndice D.

\subsection{Propostas para continuação deste trabalho}

Alguns dos tópicos de investigação que podem dar continuidade a esta Tese são:

- Estudo de técnicas para a melhoria da figura de ruído de DP-EDFAs com e sem DCF.

- Estudo de controle de ganho automático em DP-EDFAs com DCF.

- Estudo de DP-EDFAs com reflexão por grade para aplicações em CWDM. 


\section{REFERÊNCIAS BIBLIOGRÁFICAS}

[1] Connelly, M. J., (2002), "Semiconductor Optical Amplifiers", Dordrecht: Kluwer Academic Publishers.

[2] Islam, M. N., (2003), "Raman Amplifiers for Telecommunications 1: Physical Principles", Berlin: Springer-Verlag.

[3] Agrawal, G. P., Agrawal, Govind. P., (2001), "Nonlinear Fiber Optics", Londres: Academic Press.

[4] Becker, P. C., Olsson, N.A., Simpson, J.R., (1999), "Erbium-Doped Fiber Amplifiers", Londres: Academic Press.

[5] Mears, R. J., Reekie, L., Jauncey, I. M., Payne, D. N. (1987), "High-Gain Rare-Earth Doped Fiber Amplifier Operating at 1.54 um, Optical Fiber Conference - OFC, p167.

[6] Desurvire, E., Simpson, J. R., Becker P. C. (1987), "High-Gain Erbium-Doped TravelingWave Fiber Amplifier", Optics Letters, Vol.12, no 11, p888.

[7] Giles, C. R., Desurvire, E., (1991), "Modeling Erbium-Doped Fiber Amplifiers", IEE Journal of Lightwave Technology, Vol.9, no 2, p271-283, Fevereiro.

[8] Souza, E. A. (1991), “Aplicações de Fibras Dopadas com Er3+”, 80p. Tese (Doutorado) Universidade de Campinas, Campinas.

[9] Rosolem, J. B., Chiarotino, P., (1994), “Amplificador a Fibra Dopada com Érbio: Teste de Campo CPqD/Telebrás e Telesp”, Revista Telebrás Tecnologia, Vol.18, no.61, p79-82, Setembro.

[10] Mazzali, C. (1997), "Geração e Amplificação de Sinais Ópticos para Sistemas de Comunicação de Alta Capacidade", 234p. Tese (Doutorado) - Universidade de Campinas, Campinas.

[11] Milo, S. (2003), "Análise de Desempenho de Topologias de Amplificadores Ópticos a Fibra Dopada com Érbio", 234p. Tese (Mestrado) - Universidade de Campinas, Campinas. 
[12] ITU-T, (1998), “G.661 - Definition and test methods for the relevant generic parameters of optical amplifier devices and subsystems", outubro.

[13] ITU-T, (1998), "G.662 - Generic characteristics of optical amplifier devices and subsystems", outubro.

[14] ITU-T, (2000), "G.663 - Application related aspects of optical amplifier devices and subsystems", abril.

[15] ITU-T, (2003), “G.664 - Optical safety procedures and requirements for optical transport systems”, março.

[16] ITU-T, (2003), "G.691 - Optical interfaces for single channel STM-64 and other SDH systems with optical amplifiers", dezembro.

[17] ITU-T, (1998), “G.692 - Optical interfaces for multichannel systems with optical amplifiers", outubro.

[18] ITU-T, (2002), "G.694.1 Spectral grids for WDM applications: DWDM frequency grid”, junho.

[19] ITU-T, (2003), “G.694.2 - Spectral grids for WDM applications: CWDM wavelength grid", dezembro.

[20] ITU-T, (2004), "G.695 - Optical interfaces for coarse wavelength division multiplexing applications", fevereiro.

[21] Gaarde, P. B., (2003), "Raman Amplification and Dispersion Compensation", Disponível em: http://cnls.lanl.gov/Conferences/Raman2003/Gaarde.pdf, acessado em 25/06/2005.

[22] Telcordia, (1997), “GR-2854-CORE - Generic Requirements for Fiber Optic Dispersion Compensators", Issue 2, dezembro.

[23] Agrawal G. P., (2002), "Fiber Optic Communication Systems", New York: John Wiley \& Sons, Inc.

[24] Nielsen, L. G. (2003), "Dispersion Compensating, Techniques and Systems Requirements", European Congress on Optical Communication - ECOC, 2003, Rimini Italy, short course SC6. 
[25] Rosolem, J. B. (1990), “Técnicas de Multiplexação Óptica para Enlaces Telefônicos Digitais”, 133p. Dissertação (Mestrado) - Escola de Engenharia de São Carlos, Universidade de São Paulo, São Carlos.

[26] Olsson, N. A. (1989), "Polarization Independent Configuration Optical Amplifier", IEE Electronics Letters, Vol.24, p1075-1076.

[27] Nishi, S., Aida, K., Nakagawa, K., (1990), "Highly Efficient Configuration of Erbium Doped Fiber Amplifier", European Congress in Optical Communication - ECOC, Amsterdam, Vol.1, p99-102.

[28] Lauridsen, V., Tadayoni, R., Bjarklev, A., Povlsen, H., Pedersen, B., (1991), "Gain and Noise Perfomance of Fibre Amplifiers Operating in New Pump Configurations", IEE Electronics Letters, Vol.27, no 4, P327-329, Fevereiro.

[29] Duling III, I. N., Esman, R. D., (1992), “Single Polarization Fibre Amplifier”, IEE Electronics Letters, Vol. 28, n.12, p1126-1128, Junho.

[30] Giles, C. R., (1994), "Suppression of polarization hole burning-induced gain anisotropy in reflective EDFAs”, IEE Electronics Letters, Vol. 30, n.12, p p976-977, Junho.

[31] Yamashita, S., Hotate, K., Ito, M., (1996), "Polarization Properties of a Reflective Fiber Amplifier Employing a Circulator and Faraday Rotator Mirror", Journal of Lightwave Technology, Vol.14, no 13, p385-390, Março.

[32] Zeng, J. Y., Guo, W. Y., Chen, Y. K., (1994), "Lossless Wide-Band Reflective Star Coupler Using Erbium-Doped Fiber Amplifiers", IEEE Photonics Technology Letters, Vol.6, no 12, p1485-1487, Dezembro.

[33] Delavaux, J. M. P., Chausse, E., Nagel, J. A., Di Giovanni, D., (1995), "Multistage EDFA-circulator-based designs", Optical Fiber Conference - OFC, 1995, paper TuJ6, p47-49.

[34] Hakimini, F., Kintzer E. S., Bondurant, R. S., (1998), "High-power Single Polarization EDFA with Wavelength Multiplexed Pumps”, CLEO’98, p287-288, paper CWK1.

[35] Heens, B., Wang, X., Meuleman L., Ravet, R., Blondel M., (1998), "Improvement of the EDFA Design for Both Preamplifier and Booster Applications", Mediterranean Electrotechnical Conference (MELECON'98), p1404-1408. 
[36] Chang, K. F., Poopalan, P., Teyo, T. C., Subramaniam, T., Ahmad H., (2002), "Gain Enhancement in Double Pass Erbium Doped Fiber Amplifier", International Conference on Optical Communication and Networks - ICOCN, Singapore, paper 12D3, p77-79.

[37] Ahn, J. T., Jeon, M. Y., Kim, K. H., (2001), “Two Stage Reflective Type Erbium Doped Fiber Amplifier with Enhanced Noise Characteristics”, Optics Communications, Vol.197, p121-125, Setembro.

[38] Hwang, S.T., Song, K. W., Kim, S. T., Joo, Y. H., Lee, G. W., Cho, K., (2001), "The Novel Structure of C Plus L Band Erbium Doped Fiber Amplifier", European Congress in Optical Communication - ECOC 2001, Amsterdam, paper WeP11, p400-4001.

[39] Hwang, S.T., Song, K. W., Kwon, H. J., Koh, J., Oh, Y. J., Cho, K., (2001), "Broad Band Erbium Doped Fiber Amplifier With Double-Pass Configuration”, IEEE Photonics Technology Letters, Vol.13, no 12, p1289-1291, Dezembro.

[40] Mao, Q., Lit, J. W. Y., (2002), “Amplification enhancement of L band erbium doped fiber amplifiers by reflection scheme", Optics Communications, Vol.201, p61-69, Janeiro.

[41] Harun, S. W., Poopalan, P., Ahmad, H., (2002), "Gain and Noise Figure Improvements in Double Pass L Band EDFA Using a Band Pass Filter", Journal of Optical Communications, Vol.23, no.6, p223-225.

[42] Harun, S. W., Poopalan, P., Ahmad, H., (2002), "Highy Efficient L Band Erbium Doped Fiber Amplifier With Unpumped Erbium Doped Fiber in Double Pass Configuration", Japanese Journal Applied Physics, Vol.41, p-1833-1835, Julho.

[43] Harun, S. W., Tamchek, N., Poopalan, P., Ahmad, H., (2002), "Double Pass L Band EDFA With Unpumped EDF", International Conference on Optical Communication and Networks - ICOCN, Singapore, paper 12D5, p82-84.

[44] Harun, S. W., Poopalan, P., Ahmad, H., (2002), "Gain Enhancement in L Band EDFA Through a Double Pass Technique", IEEE Photonics Technology Letters, Vol.14, no.3, Março.

[45] Harun, S. W., Tamchek, N., Poopalan, P., Ahmad, H., (2003), "Double Pass L Band EDFA with Enhanced Noise Figure Characteristics", IEEE Photonics Technology Letters, Vol.15, no.8, Agôsto. 
[46] Ahn, J. T., Kim, K. H., (2002), "Long Wavelength Band Erbium Doped Fiber Amplifier With a Reflective Type First Stage Amplifier", Optics Communications, Vol.212, p275278, Novembro.

[47] Meng, H., Gao, W., Liu, Y., Zhang, H., Zhao, C., Yuan, S., Dong, X., Liu, S., (2003), "The Gain and Noise Figure Improvement of Refection L Band Erbium Doped Fiber Amplifier", Optics Communications, Vol.228, p85-89.

[48] Yi, L. L., Zhan, L., Ji, J.H., Ye, Q. H., Xia, Y. X., (2004), "Improvement of Gain and Noise Figure in Double Pass L Band EDFA by Incorporating a Fiber Bragg Grating", IEEE Photonics Technology Letters, Vol.16, no.4, Abril.

[49] Aozasa, S., Masuda, H., Ono, H., Sakamoto, T., Knamori, T., (2001), "1480-1510 nm Band Tm Doped Fibre Amplifier with High Power Conversion Efficiency de 42\%", IEE Electronics Letters, Vol.37, no.19, Setembro.

[50] Aozasa, S., Masuda, H., Ono, H., Sakamoto, Shikano, T., Shimizu, M., (2002), “Gain Shifted TDFA Employing High Concentration Doping Technique with High Internal Power Conversion Efficiency de 70\%”, IEE Electronics Letters, Vol.38, no.8, Abril.

[51] Bastos Filho, C. J. A., Martins Filho, J. F., Gomes, A. S. L., (2003), "38 dB Gain from a Double Pass Single Pump Thulium Doped Fiber Amplifier”, International Symposium in Microwave and Optics - IMOC 2003, Foz do Iguaçu.

[52] Nilsson, J., Kim, J. M., Lee, Y. W., Hwang, S. T., Yoon, S. Y., Kim, S. J., (1999), "Multi Channel Power Equalizing Reflective Erbium Doped Fiber Amplifier", Conference on Lasers and Electro-Optics - CLEO Pacific Rim 1999, paper ThH5, p652-653.

[53] Nilsson, J., (2000), "Intrinsic Multichannel Power Control in Cascaded Power Equalizing Erbium Doped Amplifiers", IEEE Photonics Technology Letters, Vol.12, no.8, 2000.

[54] Inoue, K., (1999), "Gain Clamped Fiber Amplifier with a Loop Mirror Configuration", IEEE Photonics Technology Letters, Vol.5, no.8, Maio.

[55] Xia, B., Pudo, D., Chen, L. R., (2003), "Comparation of the Static and Dynamic Properties of Single and Double Pass Partially Gain Clamped Two Stage L Band EDFAs”, IEEE Photonics Technology Letters, Vol.15, no.4, Abril, 2003.

[56] Mao, Q., Wang, J., Sun, X., Zhang M., (1999), “A Theoretical Analysis of Amplification Characteristics of Bidirectional Erbium Doped Fiber Amplifiers With Single Erbium Doped Fiber", Optics Communications, Vol.159, p149-157, Janeiro. 
[57] Mahdi, M.A., Khairi, K. A., Bouzid, B., Abdullah, M. K., (2004), "Optimum Pumping Scheme of Dual Stage Triple Pass Erbium Doped Fiber Amplifier", IEEE Photonics Technology Letters, Vol.16, no.2, Fevereiro.

[58] Bouzid, B., Ali, B. M., Abdullah, M. K., (2004), “A High Gain EDFA Design Using Double Pass Amplification With a Double Pass Filter", IEEE Photonics Technology Letters, Vol.15, no.9, Setembro.

[59] Delavaux, J. M., Nagel, J. A., Ogawa,, K., DiGiovanni, D., (1995), “Compensating Optical Balanced Reflective Amplifier”, Optical Fiber Technology, Vol.1, p.162-166.

[60] Onaka, H., Sekiya, M., (1997), "Dispersion Compensator and Optical Amplifier", US Patent no. 5.596.448, USA, Janeiro.

[61] Moeller, L. B. E. J., (2001), "Optical Dispersion Compensation”, US Patent no. 6.236.495, USA, Maio.

[62] Itu, T., (2001), "Dispersion Compensator Apparatus", US Patent no. 6.332.054, USA, Dezembro.

[63] Imai, T., Matsumoto, T, (1988), "Polarization Fluctuations in a Single Mode Optical Fiber", Journal of Lightwave Technology, Vol. 6, no. 9, p1366-1375, Setembro.

[64] Namihira Y., Huriuchi, Y., Ryu, S., Mochizuki, K., Wakabayashi, H., (1988), “Dynamic Polarization Fluctuation Characteristics of Optical Fiber Submarine Cables Under Various Environmental Conditions", Journal of Lightwave Technology, Vol. 6, no. 5, p728-738, Maio.

[65] Namihira Y., K., Wakabayashi, H., (1989), "Real Time Measurements of Polarization Fluctuations in a Optical Fiber Submarine Cable in a Deep Sea Trial Using Electrooptic LiNbOs Device”, Journal of Lightwave Technology, Vol. 7, no. 8, p1201-1206, Agôsto.

[66] Nicholson G., Temple, D. J., (1989), "Polarization Fluctuation Measurements on Installed Single Mode Optical Fiber Cables", Journal of Lightwave Technology, Vol. 7, no. 8, p1197-1200, Agôsto.

[67] Namihira Y., Kawazawa, T., Wakabayashi, H., (1991), "Field Demonstration of Endless Polarization Control in $195 \mathrm{~km}$ Installed Optical Fiber Submarine Cable at a Sea Depth of 2900 m”, Journal of Lightwave Technology, Vol. 3, no. 4, p384-386, Abril. 
[68] Karlsson, M., Brentel, J., Andrekson, P. A., (2000), “Long Term Measurement of PMD and Polarization Drift in Installed Fibers", Journal of Lightwave Technology, Vol. 18, no. 7, p941-951, Julho.

[69] Peterson Jr., D., Ward, B. C., Rochford, K. B., Leo, P. J., Simer, G., (2002), "Polarization Mode Dispersion Compensator Field Trial and Field Fiber Characterization", Optics Express, Vol. 10, no. 14, p614-621, Julho.

[70] Wuttke, J., Krummrich, P. M., Rosch, J., (2003), "Polarization Oscillations in Aerial Fiber Caused by Wind and Power Line Current", IEEE Photonics Technology Letters, Vol. 15, no. 6, p882-883, Junho.

[71] Yadlowsky, M. J., Silva, V. L., (1998), "Experimental Comparison of the Effect of Discrete and Distributed Path In band Crosstalk on System Performance: Application to Predicting System Performance Penalties", Journal of Lightwave Technology, Vol.16, no.10, p1813-1821, Outubro.

[72] Bromage, J., Kim, C. H., Winzer, P. J., Nelson, L. E., Essiambre, R. J., Jopson, R. M., (2002), "Relative Impact of Multiple Path Interference and Amplified Spontaneous Emission Noise on Optical Receiver Perfomance", Optical Fiber Conference OFC/2002, paper TuRe.

[73] Winzer, Peter J., Essiambre R. J., Bromage, J., (2002), "Combined Impact of DoubleRayleigh Backscatter and Amplified Spontaneous Emission on Receiver Noise", Optical Fiber Conference - OFC/2002, paper ThGG87.

[74] Sumida, M., Kubo, T., Imai, T., (2003) "Limitations Imposed by Rayleigh Backscattering in Closely Interleaved Bidirectional WDM Transmission Systems", IEEE Photonics Technology Letters, Vol.15, no.1, Janeiro.

[75] Ko, J., Kim, S., Lee, J., Won, S., Kim, Y. S., Jeong, J., (2003) "Estimation of Performance Degradation of Bidirectional WDM Transmission Systems Due to Rayleigh Backscattering and ASE Noises Using Numerical and Analytical Models", IEEE Photonics Technology Letters, Vol.21, no.4, Abril.

[76] Sugizaki, R., Akasaka, Y., Emori, Y., Namiki, S., Susuki, Y., (1999), "Polarization Insensitive Broadband Transparent DCF Module With Faraday Rotator Mirror, Raman Amplified by Single Polarization Diode Laser Pumping", Optical Fiber Conference OFC/1999, paper TuS5-1, pp. 279-281. 
[77] Tang, M., Shum, P., Gong, Y. D., (2003), "Design of Double Pass Discrete Raman Amplifier and the Impairments Induced by Rayleigh Backscattering", Optics Express, Vol. 11, no. 16, p1887-1893, Agôsto.

[78] Tang, M., Gong, Y. D., Shum, P, (2003), "Design of Double Pass Dispersion Compensated Raman Amplifier for Improved Efficiency: Guidelines and Optimizations", Journal of Light wave Technology, Vol. 22, no. 8, p1899-1907, Agôsto.

[79] Rosolem, J.B., Barros, M. R. X. ; Rossi, S. M., Juriollo, A. A. ; Rocha, M. L.,Benayon, F. R. B., Pereira, F., (2002) "Limites de Potência Transmitida em Sistemas Ópticos sem Repetição", X Simpósio da SBMO, Recife, Setembro.

[80] Masuda, H., Kawakami, H., Kuwahara S., Hirano, A., Sato, K., Miyamoto, Y., (2003), "First Field Trial Using Novel Two Stage Remotely Pumped EDF Distributed Raman Hybrid In Line Amplifiers With 1,28 Tbit/s (32,43 Gbit/s) Capacity Over 528 km (6X88 km) DSF in the L Band", Optical Amplifiers and Their Applications Topical Meeting OAA-2003, Post Deadline Paper PD2-1, Otaru.

[81] Fernandes, Julio Cesar Rodrigues; Rosolem, João Batista; Juriollo, Antonio Amauri, (2003), "Thulium Doped Fiber Amplifier Performance in S Band using Two Different Complementary Pumping Wavelengths", International Microwave and Optoelectronics Conference, Foz do Iguaçu.

[82] M.A. Arbore, Y. Zhou, G. Keaton and T. Kane, (2002), "36dB gain in S-band EDFA with distributed ASE suppression", Optical Amplifiers and Their Applications OAA, paper PD-4-1.

[83] M.A. Arbore, Y. Zhou, H. Thiele, J. Bromage and L.E. Nelson, (2003), "S-band ErbiumDoped Fiber Amplifiers for WDM transmission between 1488 and 1508 nm", Optical Fiber Conference OFC, paper WK2.

[84] C.H. Yeh, C.C. Lee and S. Chi, (2004), “120-nm Bandwidth Erbium-Doped Fiber Amplifier in Parallel Configuration", IEEE Photonics Technology Letters, Vol.16, no. 7, pp. 1055-1057, julho.

[85] K. Thyagarajan and C. Kakkar, (2004), "S Band Single Stage EDFA with 25 dB Gain Using Distributed ASE Suppression”, IEEE Photonics Technology Letters, Vol.16, n. 11, pp. 2448-2450, novembro.

[86] FiberLabs Inc, (2005), "SCL-band Optical Amplifier for CWDM signal transmission", Disponível em: http://www.fiberlabs-inc.com/amp-1u-cwdm.htm, acessado em 25/06/2005. 
[87] GR-253-CORE, (1995), "Synchronous Optical Network (SONET) Transport Systems: Commom Generic Criteria", Telcordia, Issue 2, dezembro. 


\section{APÊNDICE A}

\section{PARÂMETROS DE MÉRITO DE EDFAs}

Alguns dos parâmetros básicos que caracterizam os amplificadores a fibra dopada com érbio são aqui definidos: ganho, coeficiente de ganho, planicidade de ganho, potência de saturação, potência de ASE e figura de ruído [4].

\section{A.1 Ganho}

O ganho, em dB, é definido como o logaritmo da razão entre a potência do sinal na saída e potência do sinal na entrada, dadas em $\mathrm{mW}$, isto é [4]:

$\mathrm{G}(\mathrm{dB})=10 \log \left(\mathrm{P}_{\text {saída }} / \mathrm{P}_{\text {entrada }}\right)=10 \log \left[\left(\mathrm{P}_{\text {total }}-\mathrm{P}_{\text {ase }}\right) / \mathrm{P}_{\text {entrada }}\right]$

A potência do sinal na entrada é medida através de um medidor de potência ou de um analisador de espectro óptico. A medida da potência do sinal na saída do amplificador requer o uso de um analisador de espectro óptico, pois na saída está presente também a ASE, ou emissão espontânea amplificada. Para se obter a potência do sinal na saída, é necessário subtrair o nível de ASE no comprimento de onda do sinal da potência total de saída conforme ilustra a Figura A.1.

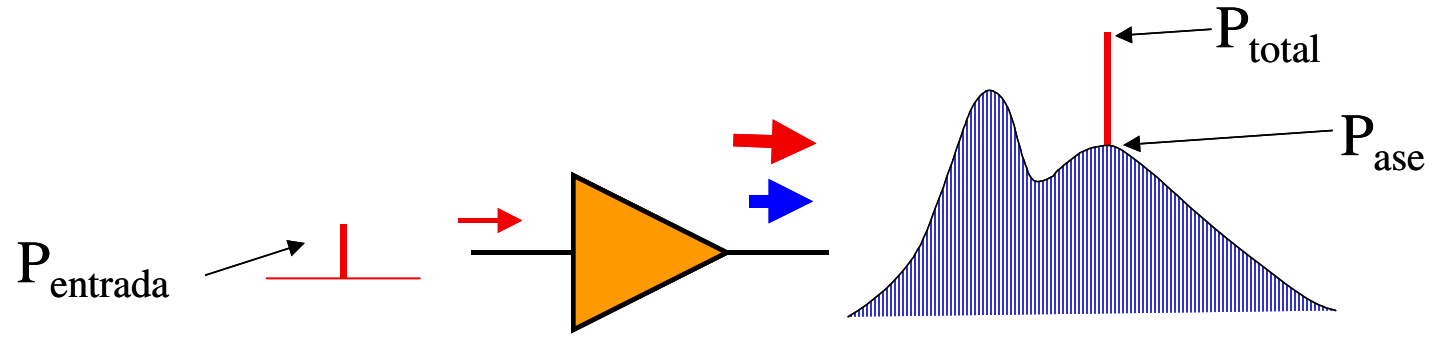

Fig. A.1 - Espectro de saída do amplificador mostrando a potência de saída somada a potência de ASE. 
O ganho depende do nível de sinal na entrada no amplificador. Para potências de entrada abaixo de um certo valor, o ganho é constante. Esta é a chamada região de operação linear. Com o aumento da potência de sinal na entrada, o ganho passa a diminuir, isto é, a potência de saída começa a apresentar saturação. O ganho de pequeno sinal é o valor de ganho obtido para um sinal injetado de baixa potência, ou seja, para a região de operação linear do amplificador. É importante observar também que, no amplificador a fibra dopada com érbio, o ganho depende do comprimento de onda. Portanto, o valor do ganho é medido para um dado comprimento de onda específico.

\section{A.2 Eficiência de Ganho}

A eficiência de ganho $\left(\eta_{\mathrm{G}}\right)$ é definido como a tangente à curva de ganho em função da potência óptica de bombeio, partindo do ponto de ganho zero, como ilustra a Figura A.2. Este parâmetro está associado à eficiência do amplificador empregando fibra dopada com érbio e foi bastante utilizado no início da década de 90 para comparar o desempenho de fibras dopadas. Atualmente, a avaliação da eficiência de ganho é feita através da medida da potência de ASE contrapropagante.

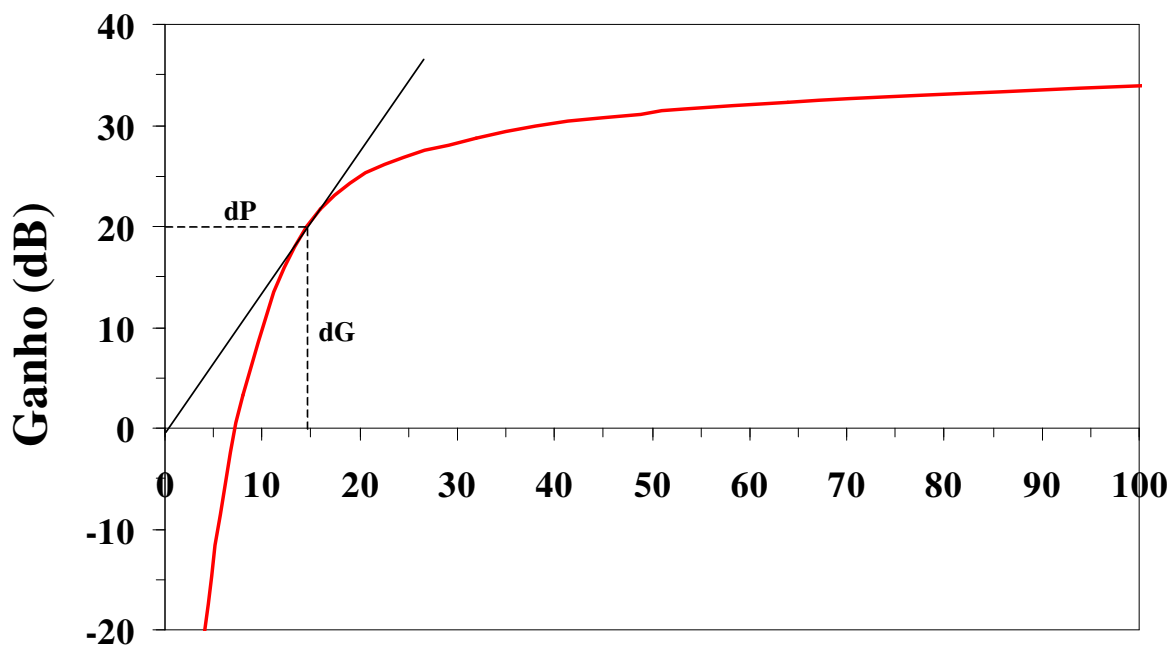

\section{Potência de Bombeio (mW)}

Fig. A.2 - Eficiência de ganho do amplificador, definida através da curva de ganho em função da potência de bombeio. 


\section{A.3 Planicidade de Ganho}

Corresponde à variação do ganho numa dada região espectral de interesse. Em um sistema WDM a planicidade mostra a homogeneidade da potência de saída dos canais amplificados, conforme indica a Figura A.3.

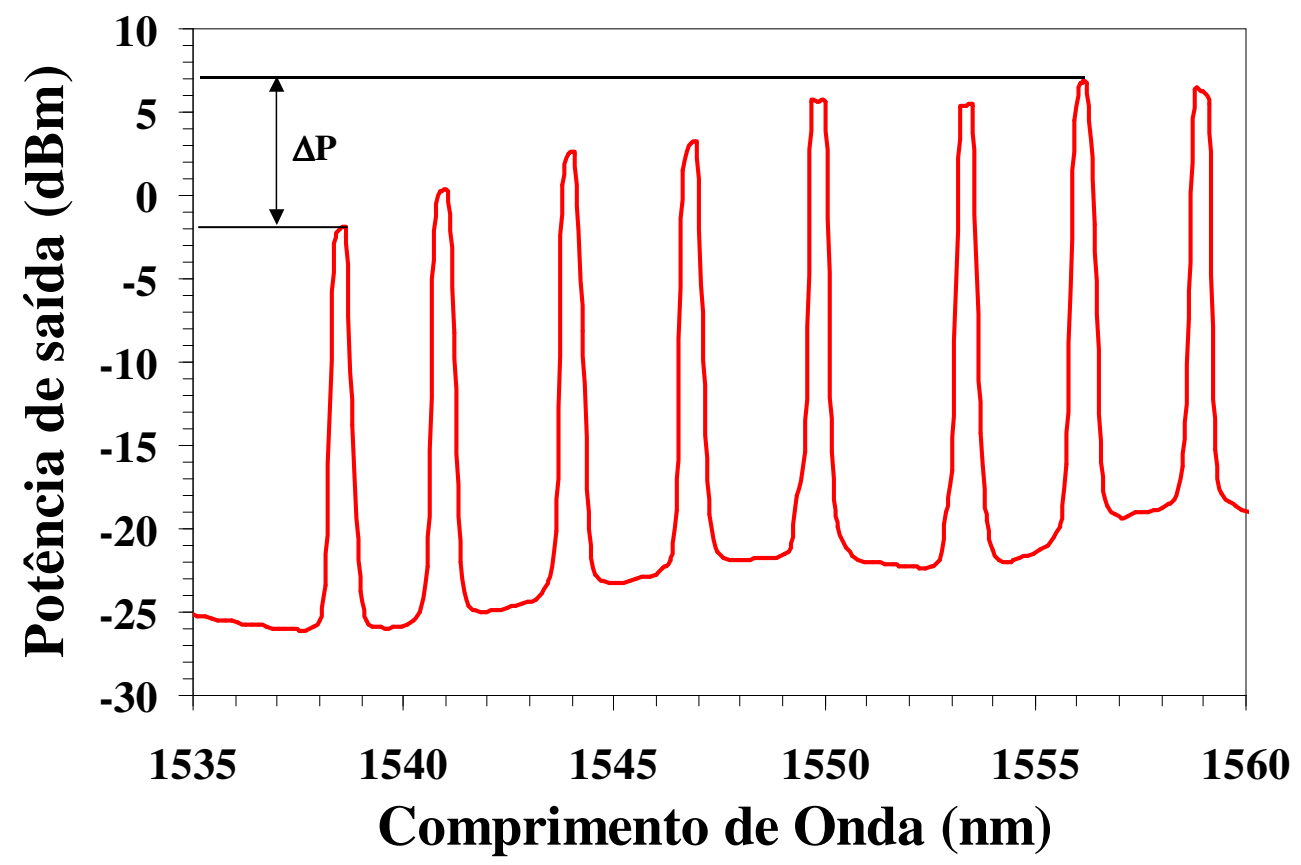

Fig. A.3 - Potência de saída de vários canais WDM amplificados, ilustrando a variação de potência causada pela não planicidade de ganho do amplificador.

\section{A.4 Potência de Saturação}

A potência de saída de um amplificador óptico é a potência amplificada, para uma dada potência na entrada do amplificador. A potência de saída saturada é definida como sendo a potência medida na saída, na condição de $3 \mathrm{~dB}$ de compressão do ganho (Figura A.4), isto é, quando o ganho sofre uma redução de $3 \mathrm{~dB}$ em relação ao ganho de pequenos sinais. Acima deste valor o amplificador entra no regime de saturação. 


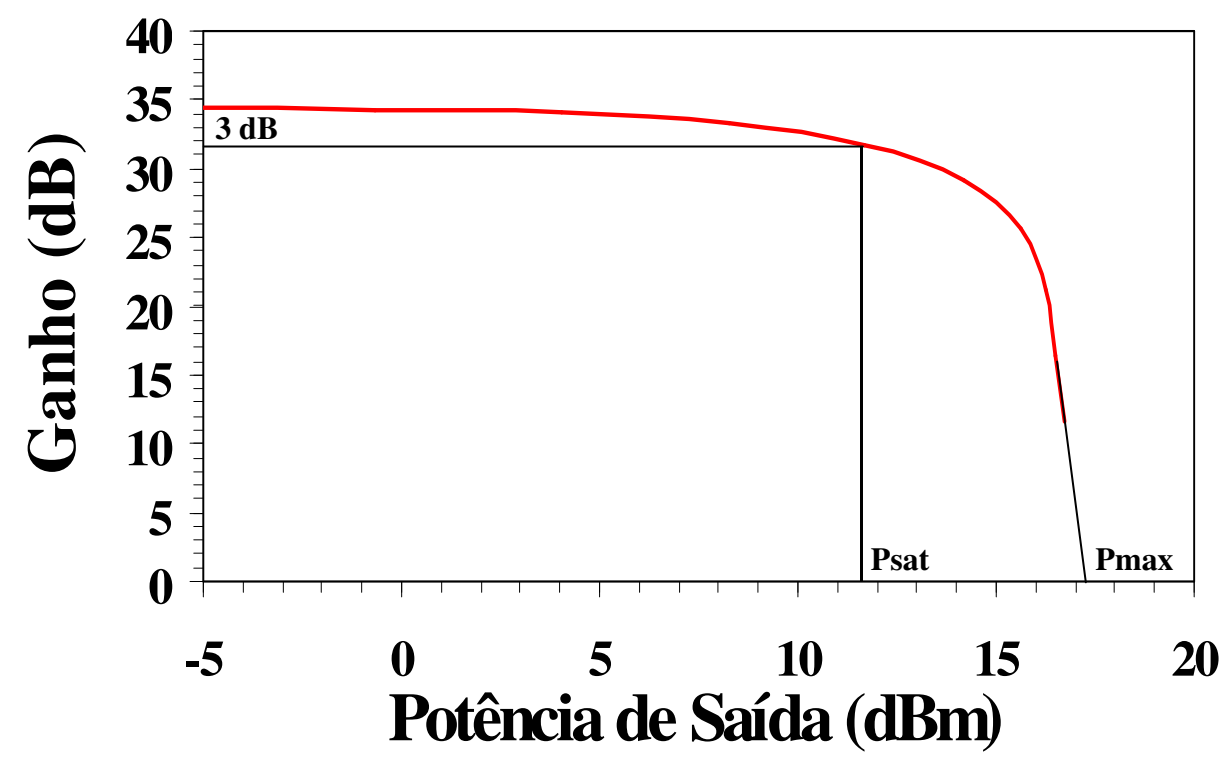

Fig. A.4 - Curva de ganho em função da potência do sinal, na saída mostrando o ponto da potência de saturação.

\section{A.5 Potência de ASE}

A passagem de sinal óptico pelo meio dopado com érbio estimula a transição dos elétrons para níveis de energia menor, levando à emissão de luz coerente no mesmo comprimento de onda e com mesma polarização do sinal. Esta é a chamada emissão estimulada, que contribui para aumentar o nível de potência de sinal. Entretanto, parte dos elétrons decaem espontaneamente para níveis de energia menor, gerando luz com comprimento de onda e polarização diferentes daqueles do sinal original. Esta é a chamada emissão espontânea, que contribui para o aumento do ruído no amplificador. O tempo de decaimento espontâneo dos elétrons do érbio na matriz de sílica é de 10 ms.

A emissão espontânea gerada no amplificador se propaga ao longo da fibra e é amplificada, gerando ruído na saída do amplificador. Este ruído é chamado de emissão espontânea amplificada ou ASE (Amplified Spontaneous Emission). A potência de ASE apresenta uma variação com o comprimento de onda, conforme ilustrado na figura A.5. O nível de potência de ASE copropagante é menor que a potência de ASE contrapropagante. 


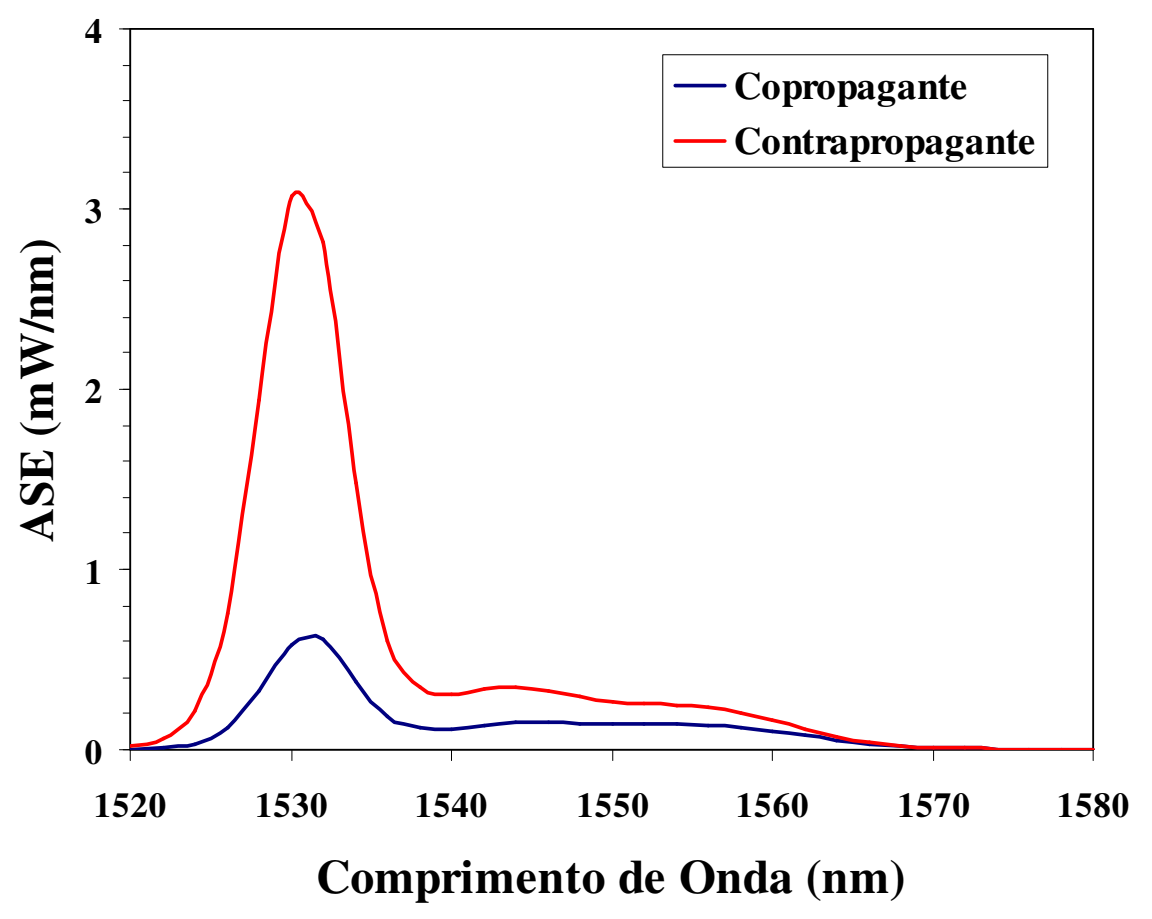

Fig. A5 - Variação da potência de ASE com o comprimento de onda.

\section{A.6 Figura de Ruído}

A figura de ruído indica a potência de ruído adicionada ao sinal pelo amplificador. A principal fonte de ruído introduzido pelo amplificador é a ASE emitida pela fibra dopada com érbio.

A figura de ruído pode ser medida de várias formas diferentes. A técnica mais usada consiste em medir o nível da ASE no comprimento de onda do sinal. Para isto, faz-se uma interpolação do nível medido de ASE, no comprimento de onda do sinal. A figura de ruído é dada pela expressão [4]:

$\mathrm{NF}=\mathrm{P}_{\mathrm{ase}} /((\mathrm{G}-1) \mathrm{h} v \Delta v)$

onde $\mathrm{P}_{\mathrm{ase}}$ é a potência da ASE no comprimento de onda do sinal em W, G é o ganho linear do amplificador, h é a constante de Planck, $v$ é a freqüência óptica do sinal em $\mathrm{Hz}$, e $\Delta v$ é a largura de banda óptica, em Hz, do filtro usado para a filtrar a potência de ASE. 


\section{APÊNDICE B}

\section{AMBIENTE DE SIMULAÇÃO OASIX V 3.1}

O software OASIX (Optical Amplifier Simulation System) [4] é destinado à modelagem de fibras dopadas com érbio fabricadas pela OFS, uma empresa originada da Lucent. Todo o modelamento implementado no software foi desenvolvido a partir de formulações teóricas desenvolvidas por Giles et al [7] em 1991. A precisão do modelo segundo o fabricante do software é tipicamente da ordem de 0,5 $\mathrm{dB}$ para ganho e figura de ruído.

Segundo este modelo, as equações de taxa para o sinal, bombeio e ASE, propagando nas duas direções da fibra, são dadas por:

$$
\begin{aligned}
& \frac{d P_{s k}^{ \pm}(z)}{d z}= \pm \Gamma_{s}\left[\left(\sigma_{e}\left(\lambda_{s k}\right)+\sigma_{a}\left(\lambda_{s k}\right)\right) N_{2}(z)-\sigma_{a}\left(\lambda_{s k}\right) N_{o}\right] P_{s k}^{ \pm}(z) \mp \alpha_{s} P_{s k}^{ \pm}(z) \\
& \frac{d P_{p}^{ \pm}(z)}{d z}= \pm \Gamma_{p}\left[\left(\sigma_{e}\left(\lambda_{p}\right)+\sigma_{a}\left(\lambda_{p}\right)\right) N_{2}(z)-\sigma_{a}\left(\lambda_{p}\right) N_{o}\right] P_{p}^{ \pm}(z) \mp \alpha_{p} P_{p}^{ \pm}(z) \\
& \frac{d P_{a s e}^{ \pm}(z)}{d z}= \pm \Gamma_{s}\left[\left(\sigma_{e}\left(\lambda_{a s e, j}\right)+\sigma_{a}\left(\lambda_{a s e, j}\right)\right) N_{2}(z)-\sigma_{a}\left(\lambda_{a s e, j}\right) N_{o}\right] P_{a s e, j}^{ \pm}(z) \mp \\
& 2 \Gamma_{s} \sigma_{e}\left(\lambda_{a s e, j}\right) N_{2}(z) h v_{a s e, j} \Delta v_{j} \mp \alpha_{s} P_{a s e, j}^{ \pm}(z)
\end{aligned}
$$

onde o símbolo \pm significa $(+)$ copropagante e (-) contrapropagante, $\mathrm{P}_{\mathrm{p}}(\mathrm{z})$ é a potência de bombeio no comprimento de onda $\lambda_{\mathrm{p}}, \mathrm{P}_{\mathrm{sk}}(\mathrm{z})$ é a potência de sinal no comprimento de onda $\lambda_{\text {sk }}$ e $\mathrm{P}_{\text {asej }}(\mathrm{z})$ é a potência de ASE de banda $\Delta v_{\mathrm{j}}$ e frequência central $\nu_{\text {asej. }} \sigma_{\mathrm{a}}\left(\lambda_{\mathrm{i}}\right)$ e $\sigma_{\mathrm{e}}\left(\lambda_{\mathrm{i}}\right)$ são as seções de choque de absorção e emissão estimulada, respectivamente, no comprimento de 
onda $\lambda_{\mathrm{i}}$, h é a constante de Planck, $\Gamma_{\mathrm{s}}$ e $\Gamma_{\mathrm{p}}$ representam os fatores de sobreposição entre a distribuição da dopagem de érbio e os campos modais do sinal e do bombeio. $\alpha_{s}$ e $\alpha_{p}$ representam os coeficientes de perda intrínseca no comprimento de onda do sinal e do bombeio, $\mathrm{N}_{\mathrm{o}}$ é a densidade da dopagem de érbio e $\mathrm{N}_{2}$ é a população no nível metaestável no estado de equilíbrio, que pode ser escrita como:

$$
\begin{aligned}
& N_{2}(z)=\left(\sum_{j} \frac{\Gamma_{s} \sigma_{a}\left(\lambda_{a s e, j}\right)\left(P_{a s e, j}^{+}(z)+P_{a s e, j}^{-}(z)\right.}{A h v_{a s e, j}}\right. \\
& \left.+\sum_{i} \frac{\Gamma_{s} \sigma_{a}\left(\lambda_{s k}\right)\left(P_{s k}^{+}(z)+P_{s k}^{-}(z)\right)}{A h v_{s k}}+\frac{\Gamma_{p} \sigma_{a}\left(\lambda_{p}\right)\left(P_{p}^{+}(z)+P_{p}^{-}(z)\right)}{A h v_{p}}\right) \\
& \times\left(A_{21}+\sum_{j} \frac{\Gamma_{s}\left(\sigma_{a}\left(\lambda_{a s e, j}\right)+\sigma_{e}\left(\lambda_{a s e, j}\right)\right)\left(P_{a s e, j}^{+}(z)+P_{a s e, j}^{-}(z)\right.}{A h v_{a s e, j}}\right. \\
& \left.+\sum_{i} \frac{\Gamma_{s}\left(\sigma_{a}\left(\lambda_{s k}\right)+\sigma_{e}\left(\lambda_{s k}\right)\right)\left(P_{s k}^{+}(z)+P_{s k}^{-}(z)\right)}{A h v_{s k}}+\frac{\Gamma_{p}\left(\sigma_{a}\left(\lambda_{p}\right)+\sigma_{e}\left(\lambda_{p}\right)\right)\left(P_{p}^{+}(z)+P_{p}^{-}(z)\right)}{A h v_{p}}\right)^{-1}
\end{aligned}
$$

onde $\mathrm{A}_{21}$ é a taxa de emissão espontânea e A representa a área efetiva da fibra dopada com érbio.

No desenvolvimento desta tese utilizamos as fibras da OFS cujos dados técnicos são apresentados na Tabela B.1.

Tab. B.1 - Dados de fibras dopadas com érbio fornecidas pela OFS e utilizadas nesta Tese.

\begin{tabular}{|l|c|c|}
\hline Propriedades ópticas, de materiais e geométricas & Fibra MP 980 & Fibra R37103 \\
\hline Pico de absorção perto de $\mathbf{1 5 3 0} \mathbf{~ n m}(\mathbf{d B} / \mathbf{m})$ & $5,0-7,0$ & $16,0-24,0$ \\
\hline Abertura numérica & $0,23+/-0,02$ & $0,25+/-0,02$ \\
\hline Diâmetro do campo modal $(\boldsymbol{\mu m})$ & $4,9-6,3$ & $4,9-5,9$ \\
\hline Max. dispersão do modo de polarização $(\mathbf{p s} / \mathbf{m})$ & 0,02 & 0,02 \\
\hline Perda em 1200 $\mathbf{~ n m ~}(\mathbf{d B} / \mathbf{k m})$ & $<5,0$ & $<10,0$ \\
\hline Comprimento de onda de corte $(\mathbf{n m})$ & $800-950$ & $800-980$ \\
\hline Co-dopantes & $\mathrm{Ge} / \mathrm{Al}$ & $\mathrm{La} / \mathrm{Al}$ \\
\hline Conteúdo típico de alumínio $(\mathbf{M \%})$ & 12,0 & - \\
\hline Diâmetro da casca $(\boldsymbol{\mu m})$ & $125+/-2$ & $125+/-1$ \\
\hline Diâmetro do recobrimento $(\boldsymbol{\mu m})$ & $250+/-2$ & $245+/-2$ \\
\hline Erro de concentricidade casca/núcleo $(\boldsymbol{\mu m})$ & $\leq 15,0$ & $\leq 16,0$ \\
\hline Erro de concentricidade núcleo $(\boldsymbol{\mu m})$ & $\leq 0,3$ & $\leq 0,5$ \\
\hline Intensidade de proof-test & $2 \%(200 \mathrm{kpsi})$ & $2 \%(200 \mathrm{kpsi})$ \\
\hline
\end{tabular}


O software OASIX permite a simulação de uma grande variedade de circuitos ópticos de amplificadores, incluindo os DP-EDFAs. Na figura B.1 mostramos uma das telas do OASIX programada para simulação do DP-EDFA estudado no Seção 3.3. O software não apresenta interface gráfica para visualização dos dados. Os gráficos apresentados nesta tese foram construídos em EXCEL a partir dos dados de saída do software OASIX. Na Figura B.2 mostramos uma outra tela com os resultados de saída para o ganho do amplificador da seção 3.3. Neste caso, no OASIX o ganho é calculado como perda de retorno. O tempo de simulação foi de aproximadamente 6 minutos. Na Figura B.1 as perdas da DCF e do circulador entram no programa através do coeficiente de reflexão no final do amplificador.

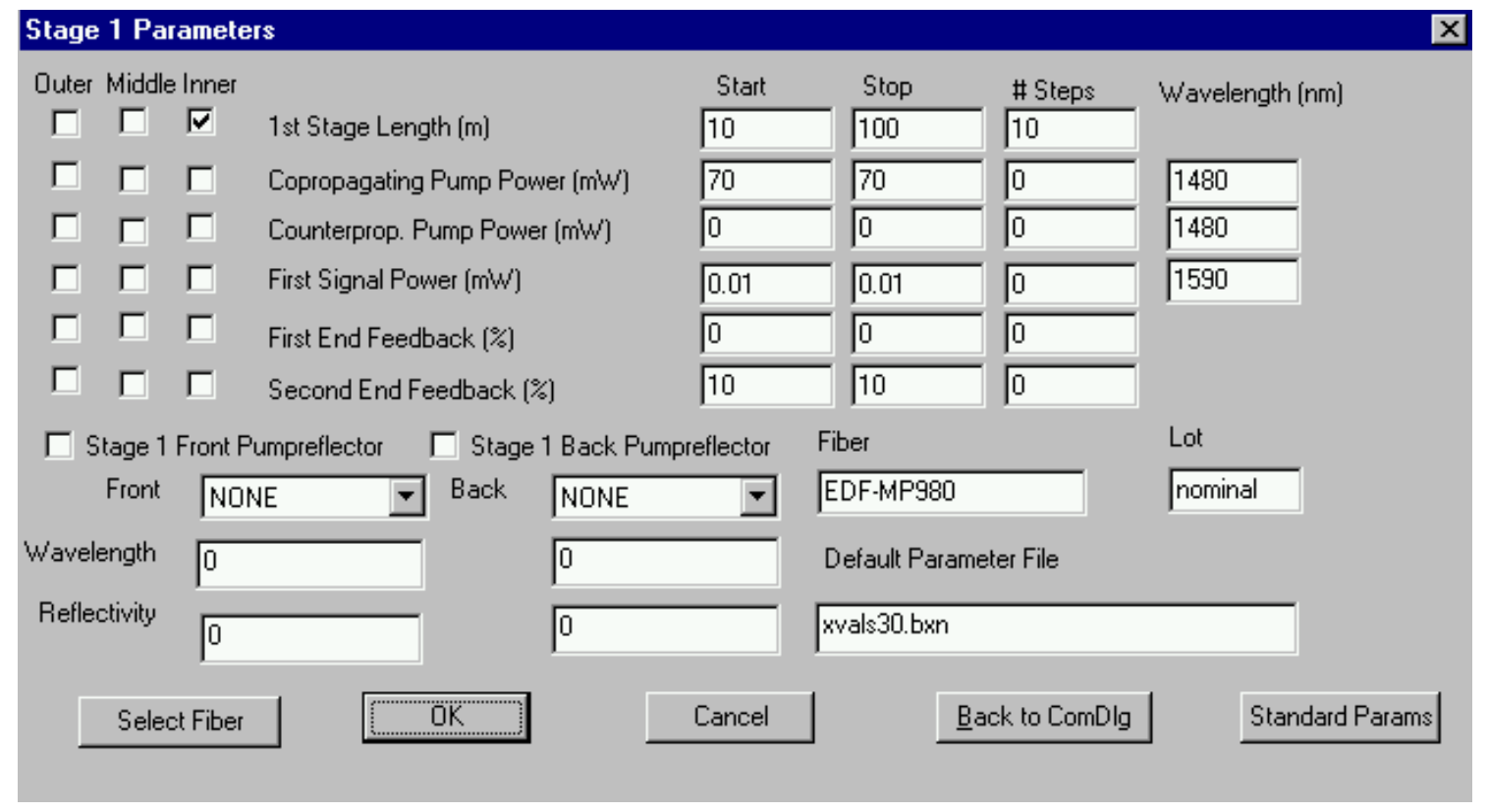

Fig. B.1 - Tela do OASIX programado para simulação do DP-EDFA. 


\section{Untitled - DASIX Simulation Software}

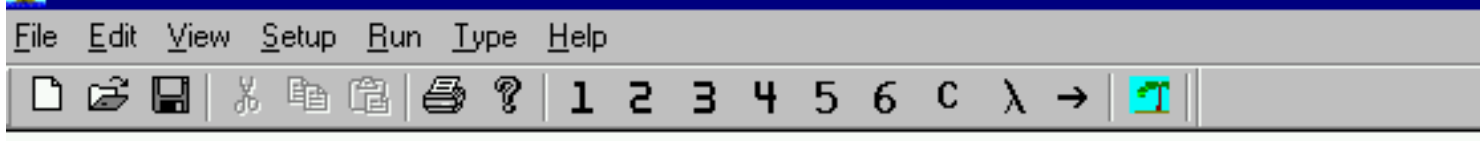

Lucent Technologies ass simulation program v.3.1

Simulation date: Tue Mar $2 \hat{2} 28: 03: 13$ 2005

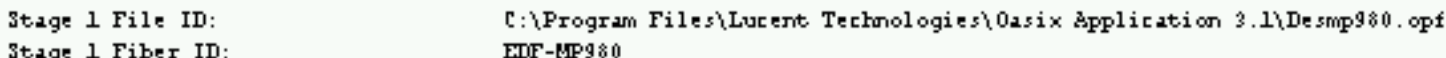

St.ge 1 Fiber ID:

3t.2ge 1 Fiber Lot:

תominal

One-stage simulation

3tg 1 Co-Pump wavelength $(\mathrm{mm}) \quad 1480$

Stg 1 Crt-Pump wavelength $(\mathrm{rm}) \quad 1480$

Sig 1 wavelength ( $\mathrm{sm}) \quad 1590$

ASE wavelengths $(\mathrm{sm}): \quad 1520$

1530153

154001542

15501558

$1560 \quad 1568$

$1570 \quad 1572$

$1580 \quad 1588$

15901598

$1600 \quad 1608$

161001618

$15 \hat{2} \hat{2}$

1534

1544

1554

1564

1574

1584

1594

1604

1614
1584

1536

1546

1556

1566

1576

1586

1596

1606

1616
1526

1538

1548

1558

1568

1578

1588

1598

1608

including input and output losses in calculations

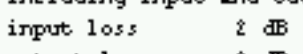

70

0.01

0

10

$\begin{array}{lll}\text { Stgl Len }(m) & 1590 \text { Ref } 3 i g & 1590 \text { Ret Loss } \\ 10 & 0.0187783 & -1.06473 \\ 80 & 0.0706913 & -8.49365 \\ 30 & 0.180077 & -18.5546 \\ 40 & 0.378755 & -15.7148 \\ 50 & 0.698903 & -18.4448 \\ 60 & 1.19629 & -20.7783 \\ 70 & 1.81914 & -22.5986 \\ 80 & 2.28856 & -23.4685 \\ 90 & 1.65731 & -22.194 \\ 100 & 0.593907 & -17.7378\end{array}$

Fig. B.2 - Resultados de saída para o ganho do DP-EDFA usado da seção 3.3. O ganho é a perda de retorno com o sinal invertido. 


\section{APÊNDICE C}

\section{DIMENSIONAMENTO DE ENLACES ÓPTICOS}

\section{CONSIDERANDO A DISPERSÃO}

Este Apêndice descreve procedimentos de dimensionamento de enlaces ópticos considerando não somente o orçamento de potência como também a dispersão cromática da fibra. As considerações aqui desenvolvidas tem por base as normas propostas pela Telcordia, antigo Bellcore [22,87].

\section{C1 - Limitações no Orçamento de Potência}

A Figura C.1 mostra o modelo de sistema de transmissão adotado em [87], que inclui potência de transmissão, sensibilidade do receptor e várias fontes de perdas. Para o projeto do enlace, o mesmo é divido nas seções de equipamento terminal e de cabo.

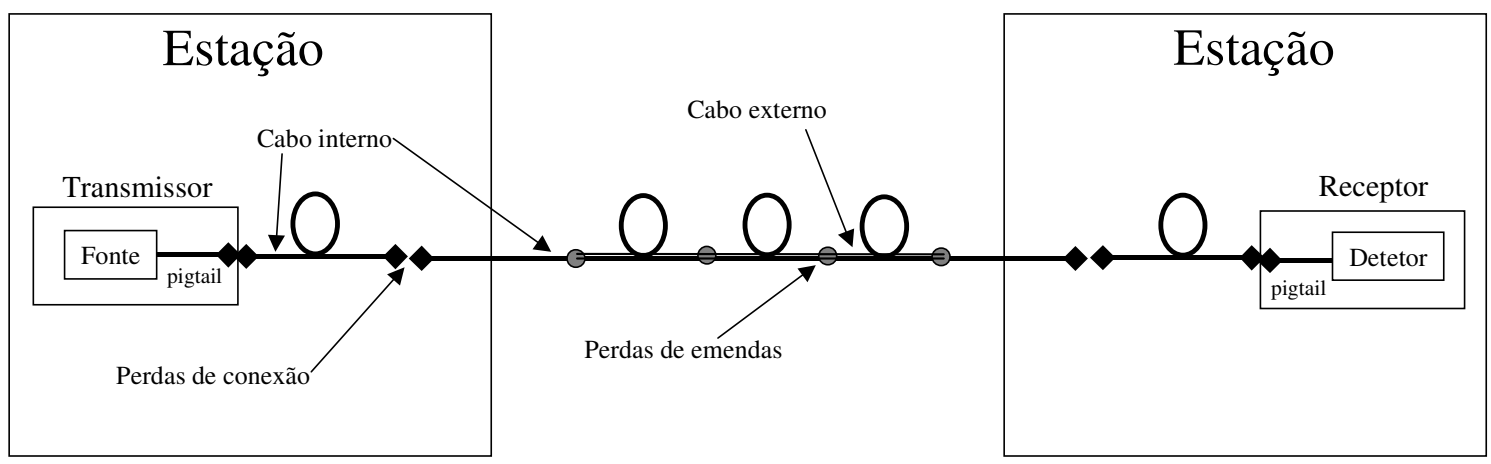

Fig. C.1 - Modelo de sistema de transmissão para modelo de orçamento de potência.

A Faixa da Dinâmica do sistema (FD) referida à seção do terminal é dada por:

$$
F D=P_{T}-P_{R}-P_{D}-M-U_{W D M}-l_{S M} \cdot U_{S M}-N_{c o n} . U_{c o n}
$$

As perdas da seção do cabo são dadas por: 
$L=l_{t}\left(U_{c}-U_{c T}-U_{\lambda}\right)+N_{S}\left(U_{S}+U_{S T}\right)$

onde:

$\mathrm{P}_{\mathrm{T}}$ : Potência óptica de saída do transmissor.

$\mathrm{P}_{\mathrm{R}}$ : Sensibilidade do transmissor, medida em uma dada taxa de erros (normalmente $10^{-10}$ ).

$P_{D}$ : Penalidade por dispersão, medida em uma dada taxa de erros (normalmente $10^{-10}$ ).

M : Margem de segurança, em dB.

$\mathrm{U}_{\mathrm{WDM}}$ : Perdas em dB, no pior caso, de todos elementos passivos associados com o equipamento WDM, incluindo efeitos de variação com a temperatura.

$1_{\mathrm{SM}}$ : Comprimento total em km do cabo interno os terminais de transmissão/recepção.

$\mathrm{U}_{\mathrm{SM}}$ : Perda do cabo óptico interno da seção do terminal de transmissão, no final de vida útil, $\mathrm{em} \mathrm{dB} / \mathrm{km}$.

$\mathrm{N}_{\text {con }}$ : Número de conexões ópticas.

$\mathrm{U}_{\text {con }}$ : Pior caso de perda do conector óptico, em dB.

$1_{t}:$ Comprimento total do cabo em $\mathrm{km}$.

$\mathrm{U}_{\mathrm{c}}$ : Perda do cabo no fim da vida útil, em $\mathrm{dB} / \mathrm{km}$, a $23^{\circ} \mathrm{C}$, no comprimento de onda central do transmissor.

$\mathrm{U}_{\mathrm{cT}}$ : Efeito da temperatura no fim de vida útil, do cabo em $\mathrm{dB} / \mathrm{km}$, no pior caso, na faixa de temperatura de operação do cabo.

$\mathrm{U}_{\lambda}$ : Maior aumento da perda do cabo em $\mathrm{dB} / \mathrm{km}$ em a $23^{\circ} \mathrm{C}$, acima de $\mathrm{U}_{\mathrm{c}}$, que ocorre na faixa de variação do comprimento de onda do transmissor.

$\mathrm{N}_{\mathrm{S}}$ : Número de emendas no cabo no comprimento $1_{\mathrm{t}}$.

$\mathrm{U}_{\mathrm{S}}$ : Máxima perda de emenda admissível (dB/emenda) a $23^{\circ} \mathrm{C}$.

$\mathrm{U}_{\mathrm{ST}}$ : Efeito da temperatura na perda da emenda, no pior caso, em dB/emenda. 


\section{C2 - Comprimento do enlace limitado por Dispersão Cromática}

Em geral, para sistemas baseados em fibras monomodo operando em taxas inferiores a $622 \mathrm{Mb} / \mathrm{s}$, o comprimento dos enlaces será limitado por atenuação. Porém, em altas taxas de transmissão, o comprimento máximo passará a ser dominado por dispersão. A dispersão ocorrerá devido aos efeitos de dispersão cromática, e/ou ruído de partição modal e devido ao gorgeio (chirp) do laser.

O sistema não será limitado por dispersão quando:

$D\left(\lambda_{t}\right) x l \leq D_{\text {SRmax }}$

onde:

$\mathrm{D}\left(\lambda_{\mathrm{t}}\right)$ : Coeficiente de dispersão cromática no comprimento de onda $\lambda_{\mathrm{t}}$ em ps/(nm.km).

1 : comprimento da fibra em $\mathrm{km}$.

$\mathrm{D}_{\text {SRmax }}$ : Dispersão máxima em ps/nm devido ao comprimento da fibra entre os pontos $\mathrm{S}$ e $\mathrm{R}$ que pode ser acomodada pelo receptor para uma taxa de $10^{-10}$.

Considerando a variação do coeficiente de dispersão cromática na faixa de operação do comprimento de onda transmitido, o comprimento de enlace limitado por dispersão será:

$l_{D} \leq D_{S R \max } / D_{\max }$

onde:

$\mathrm{D}_{\max }$ : pior caso do módulo do valor do coeficiente de dispersão cromática em ps/(nm.km) na faixa espectral de operação do transmissor.

$1_{\mathrm{D}}:$ comprimento limitado por dispersão em $\mathrm{km}$.

A expressão C.4 é válida quando o fornecedor do sistema de transmissão fornece o valor de $\mathrm{D}_{\mathrm{SRmax}}$. A expressão que avalia $l_{D}$ é dada por [22]:

$l_{D}=10^{3} . \varepsilon / D_{\max } \cdot B \cdot W$

onde:

$W=\sqrt{(\Delta \lambda)^{2}+\left(0,00092 \cdot B \cdot \lambda_{t}^{2}\right)^{2}}$ 
B : taxa de transmissão em $\mathrm{Gb} / \mathrm{s}$.

$\Delta \lambda$ : largura espectral da fonte em nm medida a $20 \mathrm{~dB}$ abaixo do pico.

$\lambda_{\mathrm{t}}$ : comprimento de onda central $\lambda_{\mathrm{t}}$ em $\mu \mathrm{m}$.

$\varepsilon$ : 0,306 para uma penalidade por dispersão de $1 \mathrm{~dB}$ em $10^{-10}$.

\section{C3 - Compensação de dispersão usando fibras DCF}

O mais importante parâmetro da DCF é sua dispersão, um valor negativo dado em ps/nm. Este valor é especificado dentro de uma banda espectral de operação, ou, são indicados os valores máximos e mínimos dentro da banda.

O projetista deverá conhecer o valor de dispersão do enlace óptico de fibra convencional a ser compensado no comprimento de onda de interesse. Desde que a dispersão em fibras ópticas convencionais em $1550 \mathrm{~nm}$ varia muito pouco de fibra para fibra, uma estimativa do valor da dispersão do enlace de fibra é em geral suficiente para a escolha da DCF. Altos níveis de precisão não são em geral necessários na maioria das aplicações.

Se L é o comprimento de fibra do enlace e a fibra tem um coeficiente de dispersão D, então o produto DxL é o valor de dispersão aproximado que terá de ser compensado pela DCF.

As DCFs são oferecidas com valores discretos de dispersão que podem não casar exatamente com o requerido em uma particular aplicação. Portanto, se uma DCF é projetada para compensar um específico comprimento $L_{c}$ ou específica dispersão $D . L_{c}$ de uma fibra convencional instalada, a dispersão total (positiva ou negativa) é $\mathrm{D}\left(\mathrm{L}-\mathrm{L}_{\mathrm{C}}\right)$. Se $\mathrm{L}=\mathrm{L}_{\mathrm{C}}$, a dispersão cromática é totalmente balanceada pela dispersão negativa da DCF, a dispersão total é exatamente zero. Pela equação C.5 a dispersão negativa requerida para um sistema com taxa de transmissão B, e largura espectral W é D.L $L_{D}$. Portanto o comprimento de fibra convencional L é limitado ao máximo comprimento dado por:

$L_{\max }=L_{C}+L_{D}$ 
para a dispersão positiva total e para o comprimento mínimo dado por:

$L_{\min }=L_{C}-L_{D}$

para dispersão total negativa. O comprimento de fibra L pode estar em qualquer valor entre estes dois extremos e o sistema não será limitado por dispersão. A Tabela C.1 exemplifica o uso de DCFs e as faixas de comprimentos de fibra $\mathrm{L}_{\max }$ e $\mathrm{L}_{\min }$ para algumas taxas de transmissão [22].

Tab. C.1 - Faixas de comprimentos de fibra com DCFs projetados para compensar comprimentos típicos de fibra convencional [22].

\begin{tabular}{|c|c|c|c|c|c|c|}
\hline \multirow{3}{*}{ Taxa (Gb/s) } & $\begin{array}{c}\text { Comprimento } \\
\text { Compensação } \\
\mathbf{L}_{\mathbf{C}}(\mathbf{k m})\end{array}$ & \multicolumn{2}{|c|}{$\begin{array}{c}\text { Dispersão da } \\
\text { DCF (ps/nm) }\end{array}$} & \multicolumn{2}{|c|}{ Lmin - Lmax (km) para várias larguras de linha (nm) } \\
& 20 & & $\mathbf{1}$ & $\mathbf{0 . 1}$ & \multicolumn{2}{|c|}{$\mathbf{0 1}$} \\
\hline \multirow{3}{*}{$\mathbf{2 , 5}$} & 40 & 340 & $0-64$ & $0-435$ & $0-1270$ & $0-1320$ \\
\cline { 2 - 7 } & 80 & 680 & $0-84$ & $0-455$ & $0-1290$ & $0-1340$ \\
\cline { 2 - 7 } & 20 & 1360 & $36-124$ & $0-495$ & $0-1330$ & $0-1380$ \\
\hline \multirow{3}{*}{$\mathbf{1 0}$} & 40 & 340 & $9-33$ & $0-85$ & $0-100$ & $0-100$ \\
\cline { 2 - 7 } & 80 & 680 & $29-51$ & $0-105$ & $0-120$ & $0-120$ \\
\cline { 2 - 7 } & 20 & 1360 & $69-91$ & $15-145$ & $0-160$ & $0-160$ \\
\cline { 2 - 7 } & 40 & 640 & $18-22$ & $15-25$ & $15-25$ & $15-25$ \\
\cline { 2 - 7 } & 80 & 1360 & $78-82$ & $75-85$ & $75-85$ & $75-85$ \\
\hline
\end{tabular}

Outros dois parâmetros que devem ser considerados no dimensionamento do enlace são:

a perda da DCF e a inclinação da curva de compensação (slope). Uma figura de mérito freqüentemente usada para a perdas de inserção das DCFs é a FoM dada em ps/nm.dB, que relaciona a capacidade de compensação da dispersão pela perda introduzida. Já a inclinação da compensação que é dada em $\left(\mathrm{ps} / \mathrm{nm}^{2}\right)$ é importante para o cálculo da compensação em uma ampla faixa espectral em sistemas WDM. 


\section{APÊNDICE D}

\section{PUBLICAÇÕES DO AUTOR}

[1] J. B. Rosolem, A. A. Juriollo, R. Arradi, A. D. Coral, J.C.R. F. Oliveira, M. A. Romero, (2005), "All Silica Triple Band Double Pass EDFA for CWDM Applications", LEOS 2005 Annual Meeting, Sydney, Outubro.

[2] J. B. Rosolem, A. A. Juriollo, R. Arradi and M. A. Romero, (2005), "Series and Parallel Configurations for Broadband Double Pass EDFA with an Embedded DCF", XXII Simpósio Brasileiro de Telecomunicações SBrT, Campinas, Setembro.

[3] J. B. Rosolem, A. A. Juriollo, R. Arradi, A. D. Coral, J.C.R. F. Oliveira, M. A. Romero, (2005), "Triple Band Silica Based Double Pass EDFA with an Embedded DCF Module for CWDM Applications", Optical Amplifiers and Their Applications OAA 2005, Budapest, Agosto.

[4] J. B. Rosolem, A. A. Juriollo, R. Arradi and M. A. Romero, (2005), "Triple Band Double Pass EDFA/TDFA with an Embedded DCF for DWDM and CWDM applications", International Microwave and Optoelectronics Conference IMOC 2005, Brasília, Julho.

[5] J. B. Rosolem, A. A. Juriollo, R. Arradi, A. D. Coral, J. C. R. F. Oliveira, M. A. Romero, (2005), "All Silica Double Pass Erbium Doped Fiber Amplifier", IEEE Photonics Technology Letters, v.17, n.7, Julho.

[6] J. B. Rosolem, A. A. Juriollo, R. Arradi, Romero M. A., (2004), "Double Pass Broadband EDFA: Design and Characterization", $11^{\text {th }}$ International Conference on Telecommunications - ICT 2004, Fortaleza, p.1382-1382, Julho.

[7] J. B. Rosolem, A. A. Juriollo, M. R. X. de Barros, M. R. Horiuchi, J. C. R. F. Oliveira, M. A. Romero, (2004), "Análise dos efeitos da polarização óptica em EDFAs de dupla passagem com módulo de compensação de dispersão embutido", MOMAG 2004, São Paulo.

[8] J. B. Rosolem, A. A. Juriollo, M. A. Romero, (2004), "Polarization Analysis in DoublePass Erbium-Doped Fiber Amplifiers with an Embedded-DCF Module", IEEE Photonics Technology Letters, New York - USA, v. 16, p. 1828-1830, Agosto.

[9] J. B. Rosolem; M. R. X. de Barros, A. A. Juriollo, J. C. R. F. Oliveira, M. R. Horiuchi, M. A. Romero, (2003), "Double Pass Erbium Doped Fiber Amplifier with an Embedded DCF Module for L band DWDM Applications", Topical Meeting: Optical Amplifiers and 
Their Applications (OSA), 2003, Otaru. Trends in Optics and Photonics 2003, Technical Digest Postconference Edition, V. 92. p.17-22, Dezembro.

[10] J. B. Rosolem; Barros, M. R. X. de Barros, A. A. Juriollo, J. C. R. F. Oliveira, M. R. Horiuchi, (2003), "Double Pass Erbium Doped Fiber Amplifier with an Embedded DCF Module for L Band DWDM Applications", Optical Amplifiers and Their Applications OAA 2003, Otaru., p.64-66, Julho.

[11] J. B. Rosolem; M. R. X. de Barros, A. A. Juriollo, M. R. Horiuchi, (2003), "Double Pass L Band Erbium Doped Fiber Amplifier with an Embedded DCF", International Microwave and Optoelectronics Conference 2003, Foz do Iguaçu, Setembro. 